\author{
Marcelo Suetake
}

\title{
Implementação de Sistemas Inteligentes em Processadores Digitais para Controle de Máquinas Elétricas Rotativas
}

Dissertação Mestrado apresentada à Escola de Engenharia de São Carlos da Universidade de São Paulo, sendo parte dos requisitos para obtenção do título de Mestre em Engenharia Elétrica.

Orientador: Prof. Dr. Ivan Nunes da Silva

São Carlos 

Candidato: Engenheiro MARCELO SUETAKE

Dissertação defendida e julgada em 08/05/2008 perante a Comissão Julgadora:

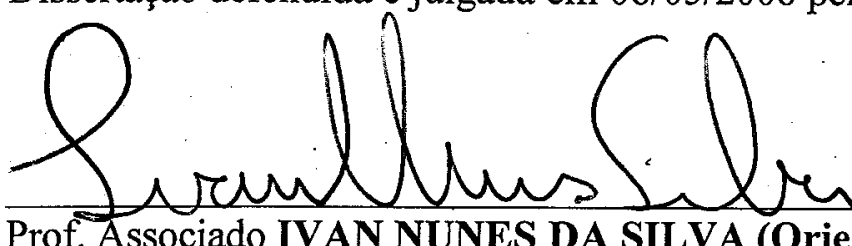

Prof. Associado IVAN NUNES DA SILVA (Orientador)

APROVADO

(Escola de Engenharia de São Carlos/USP)

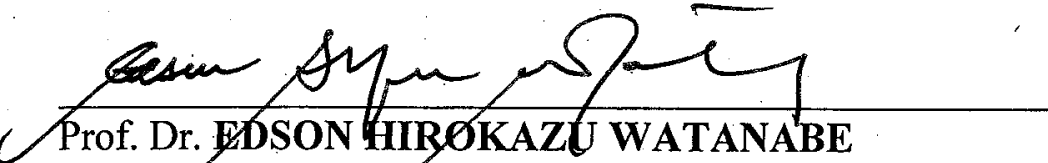

APROVADO

(Univeysidade Federal do Rio de Janeiro/UFRJ)
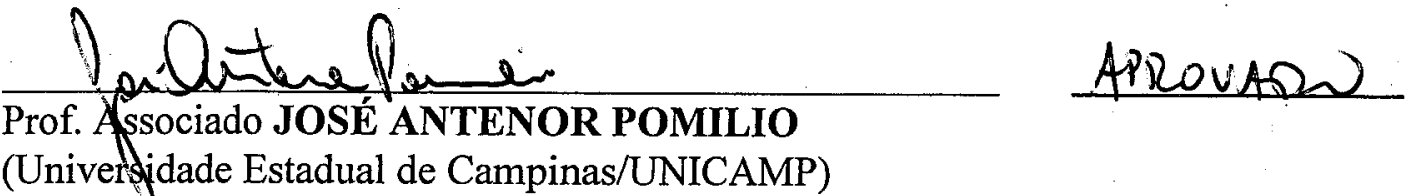

(Univer jidade Estadual de Campinas/UNICAMP)

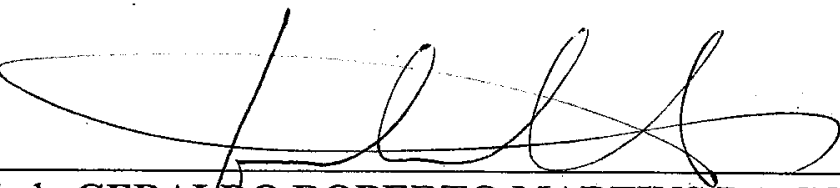

Prof. Associado GERAIDO ROBERTO MARTINS DA COSTA

Coordenador do Programade Pós-Graduação em Engenharia Elétrica e

Presidente da Comissão de Pós-Graduação 

"Porque dele e por meio dele, e para ele, são todas as coisas. Glória, pois a ele eternamente. Amém."

Romanos 11, 36 



\section{Agradecimentos}

A conclusão desta dissertação de mestrado é fruto da dedicação e principalmente da colaboração de diversas pessoas que se envolveram de forma direta e/ou indireta.

Gostaria de agradecer, em primeira instância, a toda minha família pelo especial apoio e incentivo aos estudos que sempre me concederam, em especial, à minha mãe, Massae Susaki Suetake e ao meu irmão Carlos Suetake.

Ao Prof. Dr. Ivan Nunes da Silva que, mediante sua expressiva tutoria desde o período de Iniciação Científica, contribuiu de forma efetiva, não somente pela conclusão do trabalho, como também para formação ética e profissional. Agradeço pela orientação técnica e acadêmica, pelos ensinamentos na elaboração de projetos, pelo incentivo e motivação à pesquisa e pela revisão dos artigos publicados em eventos científicos.

Ao Prof. Dr. Alessandro Goedtel, por possibilitar a produção de diversos trabalhos vinculados à bancada de ensaios experimentais desenvolvido durante a sua tese, pelas sugestões e correções de artigos científicos, pelo auxílio nos conceitos relativos às Máquinas Elétricas e pela orientação sobre os inúmeros problemas encontrados durante a confecção desta dissertação.

Aos colegas Eng. Dr. Rogério Andrade Flauzino, Eng. Dr. Antônio Vanderlei Ortega, MSc. Rodrigo Antonio Faccioli, Eng. MSc. Sérgio Ferreira da Silva, Eng. Cristiano Minotti, Eng. MSc. Fernando Ranieri, Eng. MSc. Danilo Hernane Spatti, Eng. MSc. Wesley Fernando Usida, Eng. MSc. Aline D. P. Juliani, Prof. MSc. Matheus Giovanni Pires, Prof. Dra. Fabiana Cristina Bertoni, Eng. Ricardo 
Fernandes, Diego Salvaia e aos demais colegas pelas inúmeras contribuições ao trabalho.

Aos professores e companheiros de graduação da UNESP/Bauru, Curso de Engenharia Elétrica - 2001, instituição na qual tive o privilégio em adquirir toda base de conhecimento acadêmico.

Aos professores da Universidade de São Paulo (USP/EESC/SEL), em especial, ao Prof. Dr. Diógenes P. Gonzaga, ao Prof. Dr. Manoel L. de Aguiar e ao Prof. Evandro L. L. Rodrigues.

Aos funcionários da Universidade de São Paulo (USP/EESC/SEL), em especial, ao técnico de laboratório, Rui Bertho; ao suporte técnico de informática, Roseli Ribeiro e à secretária de Pós-Graduação, Marisa Fortulan.

À FAPESP (Fundação de Amparo à Pesquisa do Estado de São Paulo), pelo auxílio financeiro concedido no período da realização deste trabalho na forma de bolsa de estudos (06/56093-3) sem a qual o mesmo não seria possível.

À CAPES (Coordenação de Aperfeiçoamento de Pessoal de Nível Superior), por possibilitar o acesso a inúmeras revistas e periódicos renomados gratuitamente, permitindo o desenvolvimento de um projeto de pesquisa de qualidade superior.

À Escola de Engenharia de São Carlos (EESC/USP) que acolheu este trabalho de mestrado, por meio da destinação de espaço físico e apoio administrativo, traduzindo assim a grandiosidade da instituição e visão de futuro. 


\section{SUMÁRIO}

Resumo

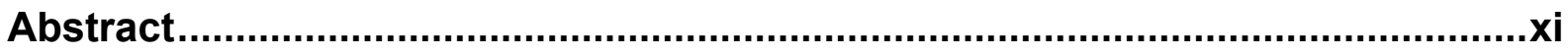

Lista de Siglas e Abreviaturas ...................................................................... xiii

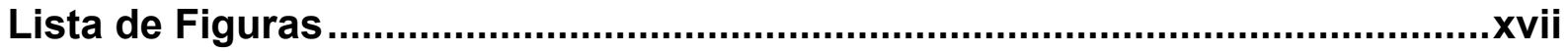

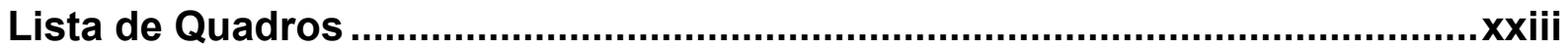

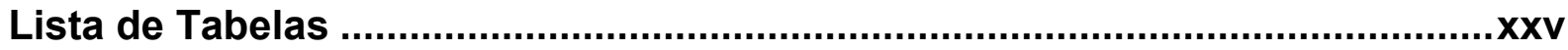

1 Introdução

1.1 Motivação e Relevância do Trabalho ………………………………....

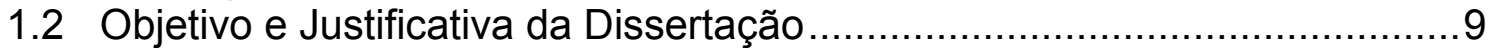

1.3 Organização da Dissertação ..............................................................10

1.4 Trabalhos Publicados em Eventos Científicos ........................................11

2 Fundamentos de Máquinas Elétricas ........................................................13

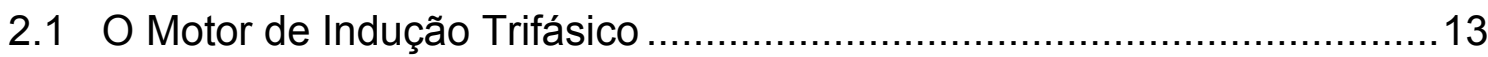

2.2 Aspectos de Modelagem Matemática do MIT ....................................15

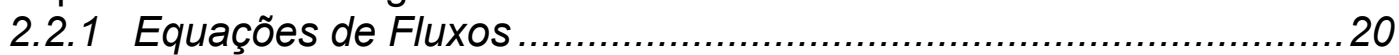

2.2.2 Equações das Tensões ..............................................................21

2.2.3 Equação do Torque Eletromagnético ………….........................23

2.2.4 Equações Mecânicas da Máquina ............................................25

2.2.5 Transformações Lineares ......................................................25

2.2.6 A Máquina de Corrente Contínua ...............................................30

2.2.7 Modelagem Matemática da MCC .............................................32

2.3 Aspectos de Controle de Velocidade de MIT .........................................34

2.3.1 Controle Volts/Hertz Constante ...............................................36

2.3.2 Velocidade de Escorregamento Controlado .................................. 38

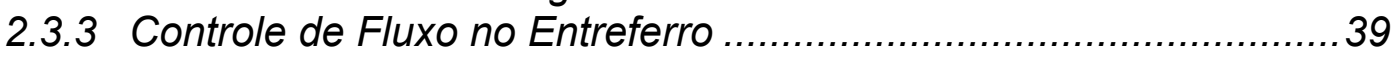

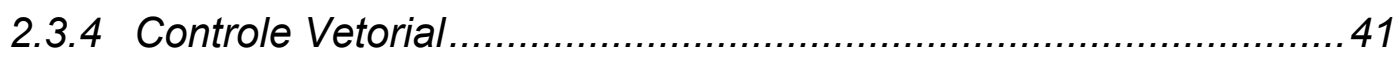

2.3.5 Controle Direto de Torque ....................................................46

2.4 Principais Tipos de Cargas Acopladas ao Motor de Indução .....................47

2.4.1 Carga Quadrática ................................................................ 48

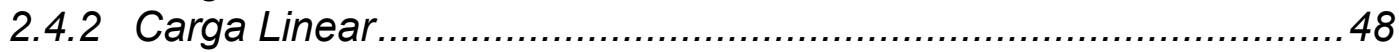

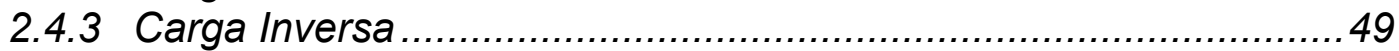

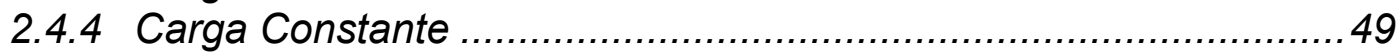

3 Aspectos da Bancada de Ensaios Experimentais .....................................51

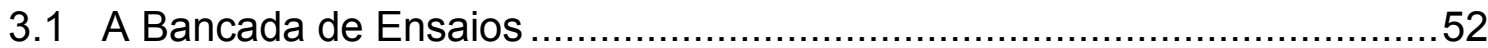

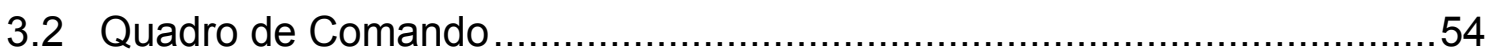

3.3 Excitação do Enrolamento de Campo do GCC .......................................55

3.4 Circuito de Carga na Armadura do GCC .............................................57

3.5 Sensores Hall de Corrente e Tensão ………........................................57 


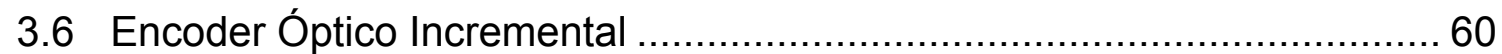

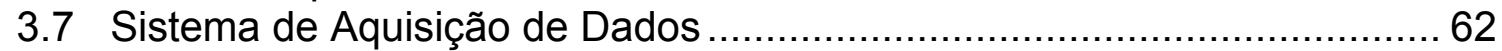

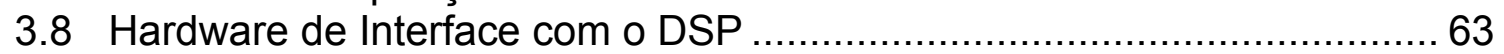

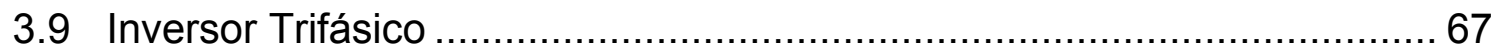

4 Abordagem Desenvolvida para Controle de Velocidade do MIT ................. 71

4.1 Aspectos Fundamentais do Sistema Fuzzy ......................................... 71

4.1.1 Sistemas de Inferência Fuzzy ................................................ 73

4.1.2 Método de Implicação de Mamdani .......................................... 76

4.2 Controle Escalar V/f Fuzzy de Velocidade ........................................... 80

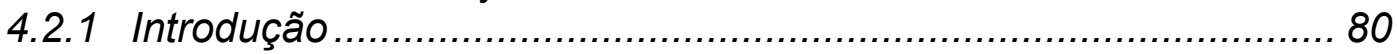

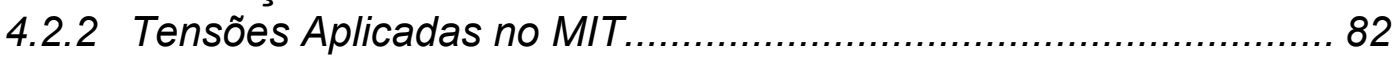

4.2.3 Parâmetros da Máquina....................................................... 83

4.2.4 Projeto do Controlador Fuzzy ................................................ 83

4.3 Resultados de Simulações Computacionais.......................................... 89

4.3.1 Resposta à Carga Quadrática................................................. 91

4.3.2 Resposta à Carga Linear ...................................................... 93

4.3.3 Resposta à Carga Inversa ..................................................... 96

4.3.4 Resposta à Carga Constante ................................................... 99

4.3.5 Resposta aos Degraus de Torque de Carga............................. 101

5 Projeto do Sistema de Controle Fuzzy Embarcado em DSP...................... 103

5.1 Aspectos Gerais do Sistema de Controle .......................................... 103

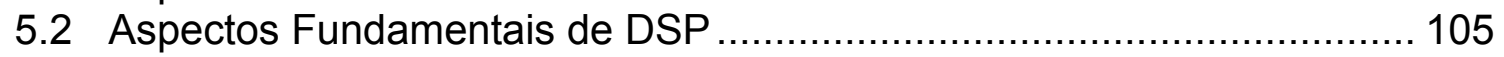

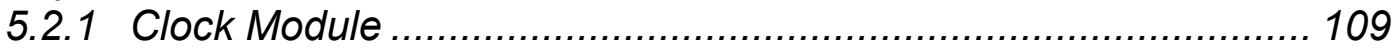

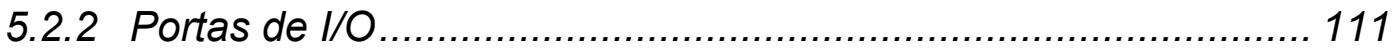

5.2.3 Sistema de Interrup̧̧ões ....................................................... 112

5.2.4 Event Manager............................................................. 116

5.3 Projeto do Sistema de Controle em DSP ......................................... 126

5.3.1 Inicialização do Sistema.................................................... 127

5.3.2 Configuração das Portas de I/O Digitais ................................... 128

5.3.3 Configuração dos Registradores Event Manager ........................ 129

5.3.4 Inicialização dos Vetores de Interrupções.................................. 133

5.3.5 Geração de Sinais PWM com Modulação Senoidal..................... 135

5.3.6 Cálculo da Velocidade Angular ............................................... 143

5.3.7 Projeto do Controlador Fuzzy Embarcado ................................. 144

5.4 Resultados Experimentais ......................................................... 148

5.4.1 Resposta ao Degrau de Referência........................................ 150

5.4.2 Resposta à Rampa de Referência ............................................ 154

5.4.3 Resposta ao Degrau de Torque de Carga ................................ 157

5.4.4 Aprimoramento dos Resultados Experimentais ......................... 161

5.4.5 Resposta ao Degrau de Referência (Aprimorado) ....................... 162

5.4.6 Resposta à Rampa de Referência (Aprimorado) .......................... 166

5.4.7 Resposta ao Degrau de Torque (Aprimorado) ................................ 168

5.4.8 Análise Comparativa com o Controlador PI .................................. 170

6 Conclusões Gerais e Trabalhos Futuros ................................................ 175

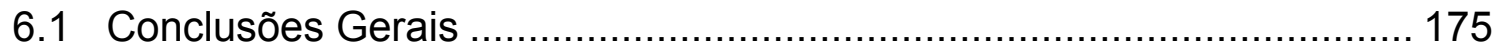

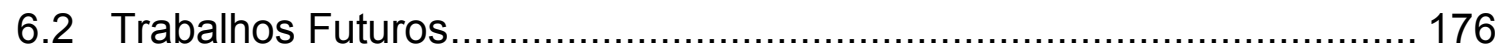

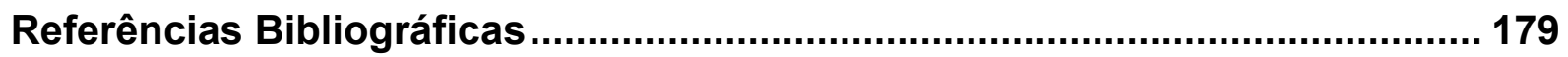




\section{Resumo}

SUETAKE, M. (2008). Implementação de Sistemas Inteligentes em Processadores Digitais Para Controle de Máquinas Elétricas Rotativas. Dissertação (Mestrado) Escola de Engenharia de São Carlos, Universidade de São Paulo, 2008.

O objetivo deste trabalho consiste na implementação de arquiteturas de Sistema Inteligentes em Processadores Digitais de Sinais (DSP) visando, sobretudo, o controle em tempo real de motores de indução trifásicos. Para tanto, propõe-se uma abordagem fuzzy para o controle de velocidade de motores de indução trifásicos baseado na metodologia de ajuste de tensão e freqüência (Volts/Hertz) proveniente de um inversor PWM, de modo que o fluxo no entreferro seja mantido constante. O enfoque principal consiste no desenvolvimento do sistema de controle em hardware considerando o estudo dinâmico do controlador frente às variações de conjugado de carga, cujo desempenho da metodologia proposta será avaliado mediante simulações computacionais e ensaios experimentais realizados em laboratório.

Palavras Chave: Motor de Indução Trifásico, Controle de Velocidade, DSP, Sistemas Fuzzy. 



\section{Abstract}

SUETAKE, M. (2008). Implementation of Intelligent System in Digital Processor for Rotative Electric Machine Control. Dissertation (Master's Degree) - Escola de Engenharia de São Carlos, Universidade de São Paulo, 2008.

The objective of this work consists of the implementation of Intelligent System Architecture in Digital Signal Processor (DSP) aiming at the real-time threephase induction motor control. Therefore, a fuzzy logic speed control drive system for three-phase induction motor is proposed, whereas the control methodology is based on voltage and frequency (Volts/Hertz) adjustment of a PWM inverter so that the airgap flux maintains constant. The main focus concerns about hardware development of the control system considering the controller dynamic response study in relation to load torque variations, from which the proposed methodology performance is evaluated by means of computational simulation and experimental results obtained in laboratory.

Keywords: Three-phase Induction Motor, Speed Control, DSP, Fuzzy System. 



\section{Lista de Siglas e Abreviaturas}

AC

Alternate Current

COMCONA Compare Control Register A

ACKTRA Compare Action Control Register A

CENABLE Compare Enable

CMPRx Compare Register " $x$ "

DBTCONA Dead-Band Control Register A

DBTPS Dead-Band Timer Prescaler

DC Direct Current

DSC Digital Signal Controller

DSP Digital Signal Processor

DTC Direct Torque Control

EV Event Manager

EVA Event Manager A

EVB Event Manager B

EVATimerx Event Manager A Timer " $x$ "

eCAN Enhanced Controller Area Network

FCOMPOE Full Compare Output Enable

FOC Field Oriented Control

GCC Gerador de Corrente Contínua

GPTCONA General Purpose Timer Control Register A

GPTimer General Purpose Time

GPxDAT General Purpose " $x$ " Data Register

GPxDIR General Purpose " $x$ " Direction Control Register 
GPXQUAL General Purpose "x" Qualification Control Register

GPxMUX General Purpose " $x$ " Mux Control Register

HISPCLK High Speed Clock

HISPCP High Speed Prescaler Clock Register

IER Interrupt Enable Register

IFR Interrupt Flag Register

IQ Interger-Quotient

INTM Interrupt Mask

LOSPCLK Low Speed Clock

LOSPCP Low Speed Clock Prescaler Clock Register

OTP One-Time Programmable

MAC Multiplica e Acumula

McBSP Multi-channel Buffered Serial Port

MCC Máquina/Motor de Corrente Contínua

MIRB Motor de Indução com Rotor Bobinado

MIRGE Motor de Indução com Rotor em Gaiola de Esquilo

MIPS Mega-Instructions per Seconds

MIT Motor de Indução Trifásico

PD Proporcional e Derivativo

PI Proporcional e Integral

PID Proporcional, Integral e Derivativo

PIE Peripheral Interrupt Extension

PIEIFR PIE Interrupt Flag Register

PIEIER PIE Interrupt Enable Register

PLCKCR Peripheral Clock Control Register 
PLLCR Phase-Locked Loop Control Register

PWM Pulse Width Modulation

QEP Quadrature Encoder Pulse Unit

RNA Redes Neurais Artificiais

SARAM Single-Access Memory

$\mathrm{SCl} \quad$ Serial Communication Interface

SPI Serial Peripheral Interface

TCLKIN Timer Clock In

TINTO Timer Interrupt 0

TPS Timer Pre-Scaler

TxCON Timer " $x$ " Control Register

TxCNT Timer " $x$ " Counter Register

TxPR Timer " $x$ " Period Register

WDCR Watchdog Control Register 



\section{Lista de Figuras}

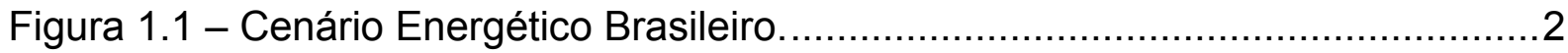

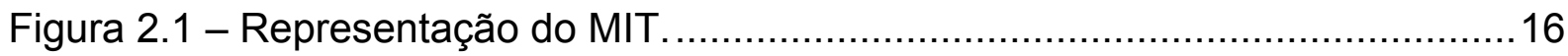

Figura 2.2 - Representação da indutância mútua entre as bobinas do estator e

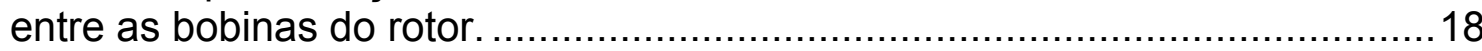

Figura 2.3 - Representação da indutância mútua entre as bobinas de estator e rotor.

Figura 2.4 - Circuito equivalente de uma das fases do estator............................22

Figura 2.5 - Efeitos da Transformação $0 \alpha \beta \ldots \ldots \ldots \ldots \ldots \ldots \ldots \ldots \ldots \ldots \ldots \ldots \ldots \ldots \ldots \ldots \ldots \ldots \ldots \ldots . . .26$

Figura 2.6 - Efeitos da Transformação dq. .....................................................27

Figura 2.7 - Sistema de referência de eixos genérico. ......................................29

Figura 2.8 - Representação esquemática de uma MCC.........................................31

Figura 2.9 - Circuito equivalente de armadura de uma MCC.................................32

Figura 2.10 - Diagrama de blocos do controlador escalar Volts/Hertz.......................37

Figura 2.11 - Controle de velocidade com escorregamento controlado. ..................39

Figura 2.12 - Diagrama fasorial do controle vetorial. .........................................44

Figura 2.13 - Vetores de fluxo de estator e de rotor no plano $\alpha \beta \ldots \ldots \ldots \ldots \ldots \ldots \ldots \ldots \ldots . .47$

Figura 2.14 - Tipos de cargas empregadas na simulação. ....................................50

Figura 3.1 - Esquema geral do laboratório de ensaios de máquinas elétricas. ........52

Figura 3.2 - Visão geral da estrutura da bancada de ensaios. ................................53

Figura 3.3 - Descrição do quadro de comando...................................................54

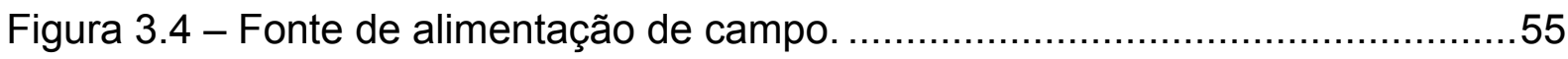

Figura 3.5 - Variador de tensão monofásico.......................................................56

Figura 3.6 - Carga resistiva para o enrolamento de armadura. ..............................57

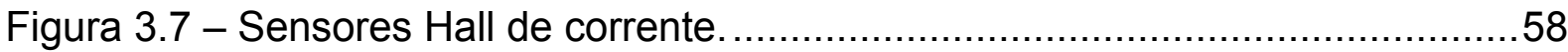

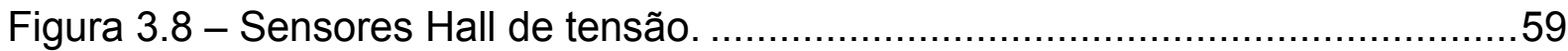


Figura 3.9 - Funcionamento do encoder óptico incremental. ................................ 61

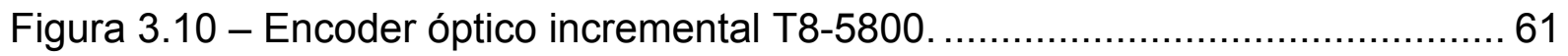

Figura 3.11 - Placa de aquisição de dados NIDAQmx PCle-6259.......................... 62

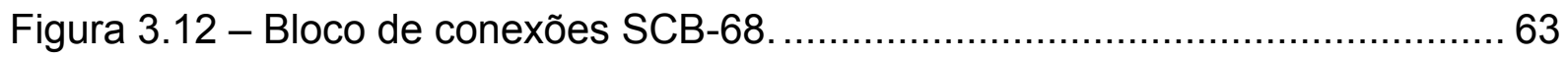

Figura 3.13 - Interface de entrada digital opto-acoplada..................................... 64

Figura 3.14 - Placa de interface de entrada digital opto-acoplada.......................... 65

Figura 3.15 - Interface de saída digital opto-acoplada....................................... 66

Figura 3.16 - Placa de Interface opto-acoplada de saída digital. ........................... 66

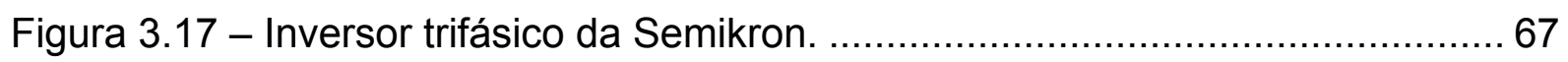

Figura 3.18 - Diagrama esquemático do inversor trifásico.................................... 68

Figura 4.1 - Função característica da teoria clássica dos conjuntos........................ 72

Figura 4.2 - Funções de pertinência dos conjuntos fuzzy...................................... 73

Figura 4.3 - Modelo genérico de um sistema de inferência fuzzy. ......................... 74

Figura 4.4 - Fuzzificação das Entradas.......................................................... 77

Figura 4.5 - Implementação completa de uma regra fuzzy. ................................... 78

Figura 4.6 - Método de Implicação de Mamdani. ……......................................... 80

Figura 4.7 - Diagrama de blocos do controlador fuzzy ....................................... 81

Figura 4.8 - Diagrama de blocos do sistema de controle V/f fuzzy. ....................... 84

Figura 4.9 - Funções de pertinências do sistema fuzzy........................................ 85

Figura 4.10 - Normalização das variáveis lingüísticas. ......................................... 86

Figura 4.11 - Método de implicação de Mamdani para o controlador fuzzy............. 88

Figura 4.12 - Agregação e defuzzificação.......................................................... 89

Figura 4.13 - Diagrama de blocos do controlador fuzzy no simulink...................... 90

Figura 4.14 - Desempenho do controlador fuzzy frente aos degraus e rampas

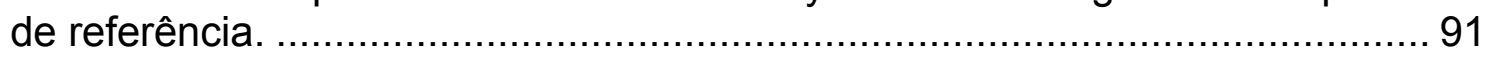

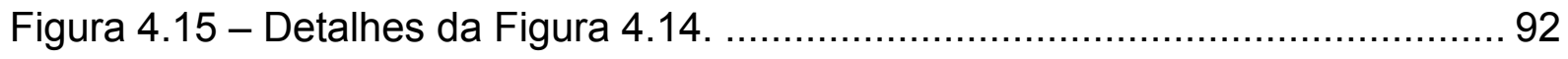

Figura 4.16 - Desempenho do controlador fuzzy frente às variações de tensão. .... 93

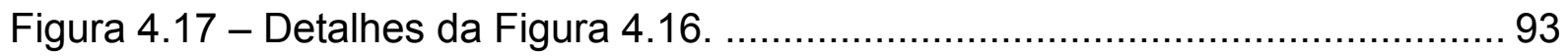


Figura 4.18 - Desempenho do controlador fuzzy frente aos degraus e rampas de referência.

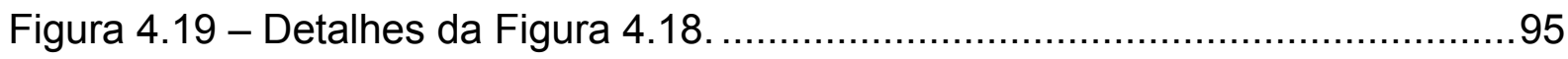

Figura 4.20 - Desempenho do controlador fuzzy frente às variações de tensão.....95

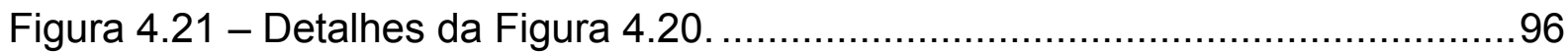

Figura 4.22 - Desempenho do controlador fuzzy frente aos degraus e rampas de referência.

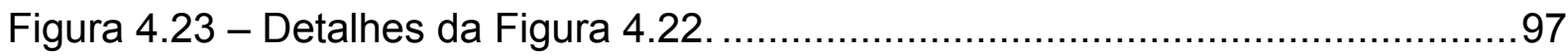

Figura 4.24 - Desempenho do controlador fuzzy frente às variações de tensão. .....98

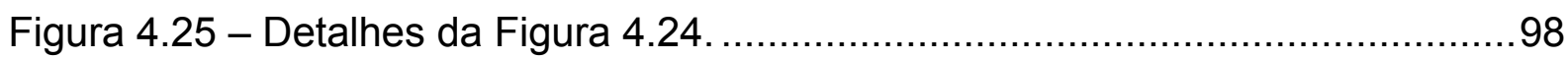

Figura 4.26 - Desempenho do controlador fuzzy frente aos degraus e rampas de referência.

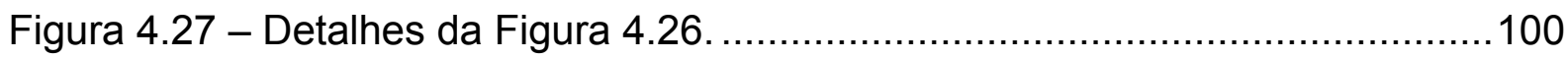

Figura 4.28 - Desempenho do controlador fuzzy frente às variações de tensão....100

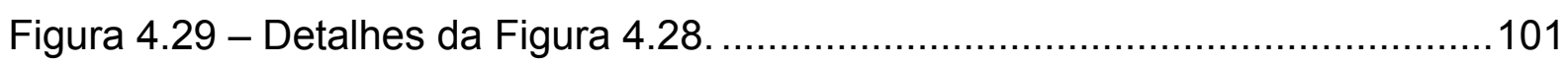

Figura 4.30 - Desempenho do controlador em resposta aos degraus de torque

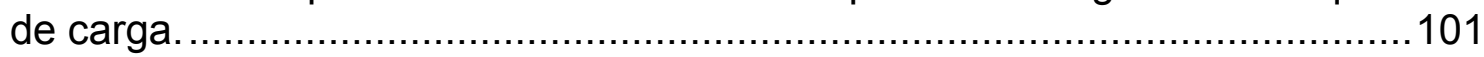

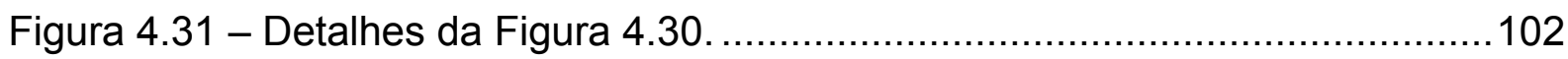

Figura 5.1 - Diagrama de blocos do sistema de controle de velocidade do MIT em hardware.

Figura 5.2 - Diagrama de blocos do esquema de geração de perfis de carga imposta ao MIT.

Figura 5.3 - Kit de desenvolvimento eZDSP-TMS320F1812 .......................... 107

Figura 5.4 - Representação interna do conjunto: oscilador e PLL clock module. ...109

Figura 5.5 - Linhas do sistema de interrupções do DSP.

Figura 5.6 - Processo de máscara de interrupções.

Figura 5.7 - Diagrama de esquemático do PIE.

Figura 5.8 - Diagrama de blocos da unidade Event Manager A.

Figura 5.9 - Diagrama de blocos do GP-Timer (EVA). ............................... 118

Figura 5.10 - Modos de operações dos Timers do EV. 
Figura 5.11 - Princípio de geração de ondas PWM. ........................................ 119

Figura 5.12 - Diagrama de blocos do Compare Units (EVA)................................ 122

Figura 5.13 - Acionamento simultâneo do IGBTs TOP/BOT................................. 123

Figura 5.14 - Forma do sinal PWM após a configuração do dead-time. ................ 124

Figura 5.15 - Modulação PWM senoidal. ......................................................... 135

Figura 5.16 - Controle de amplitude da componente fundamental de saída......... 136

Figura 5.17 - Geração de PWM com modulação senoidal pelos registradores

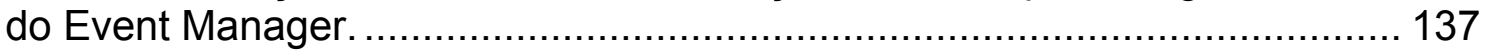

Figura 5.18 - Determinação da reta paralela ao vetor de discretização.................. 145

Figura 5.19 - Determinação da reta antiparalela ao vetor de discretização. ........... 146

Figura 5.20 - Determinação das retas ativas dos conjuntos fuzzy....................... 147

Figura 5.21 - Resposta do controlador fuzzy ao degrau de referência. ................. 151

Figura 5.22 - Torque de carga aplicado ao eixo do MIT. ...................................... 151

Figura 5.23 - Erro de velocidade do controlador fuzzy ........................................ 152

Figura 5.24 - Freqüência de acionamento. ……………………………….... 153

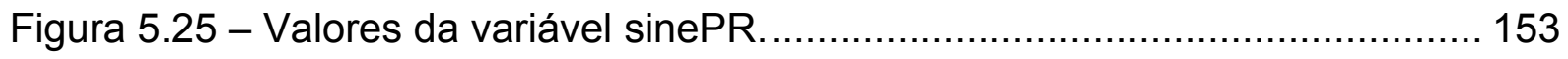

Figura 5.26 - Resposta do controlador fuzzy à rampa de referência. ………........ 154

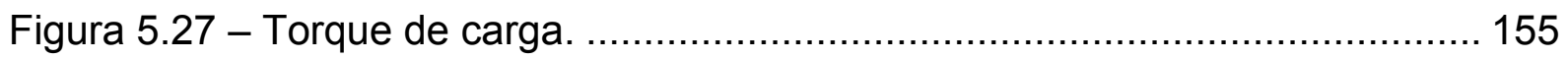

Figura 5.28 - Erro de velocidade do controlador fuzzy ..................................... 156

Figura 5.29 - Freqüência de acionamento do MIT. ………................................ 156

Figura 5.30 - Valores da variável sinePR ………….................................... 157

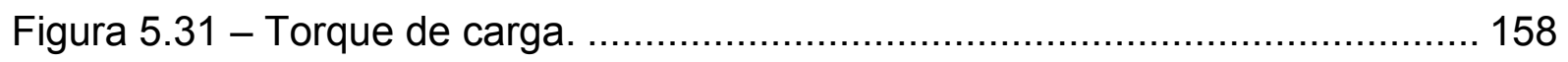

Figura 5.32 - Resposta do controlador fuzzy frente à variação de carga............... 158

Figura 5.33 - Erro de velocidade do controlador fuzzy ..................................... 159

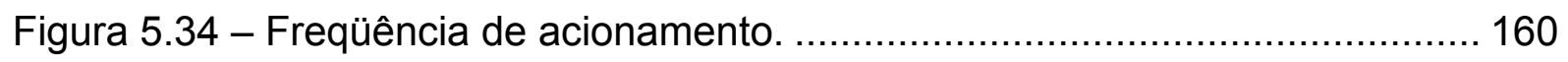

Figura 5.35 - Valores da variável sinePR....................................................... 160

Figura 5.36 - Resposta do controlador fuzzy ao degrau de referência. .................. 163

Figura 5.37 - Erro de Velocidade do controlador fuzzy...................................... 164 
Figura 5.38 - Freqüência de acionamento do MIT..........................................164

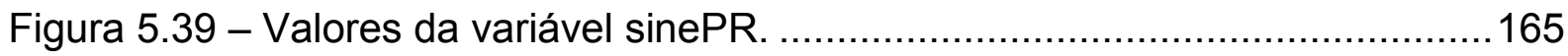

Figura 5.40 - Valores da variável sinePR (Detalhes).........................................166

Figura 5.41 - Resposta do controlador fuzzy à rampa de referência.....................167

Figura 5.42 - Erro de velocidade do controlador fuzzy. ......................................167

Figura 5.43 - Resposta do controlador fuzzy frente à variação de carga. ..............168

Figura 5.44 - Erro de velocidade do controlador fuzzy. .....................................169

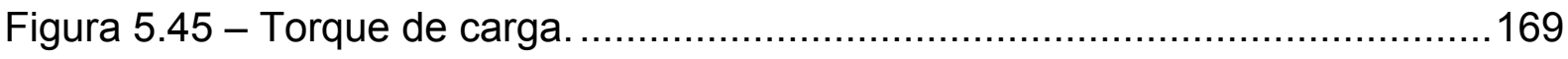

Figura 5.46 - Análise comparativa com o controlador PI (ensaio: degrau de

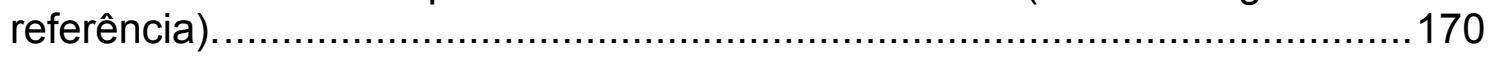

Figura 5.47 - Detalhes do primeiro degrau da Figura 5.46 ............................... 171

Figura 5.48 - Análise comparativa com o controlador PI (ensaio: rampa de

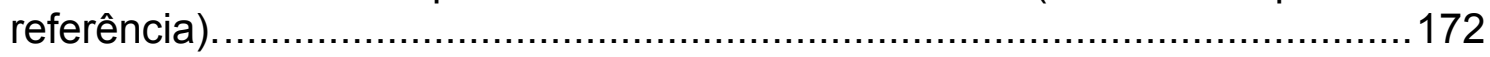

Figura 5.49 - Análise comparativa com o controlador PI (ensaio: variação de carga). 



\section{Lista de Quadros}

Quadro 5.1 - Código para inicialização do sistema. ..........................................128

Quadro 5.2 - Código para configuração das portas de I/O digitais.........................129

Quadro 5.3 - Configuração do Registrador T1CON...........................................130

Quadro 5.4 - Código para a geração PWM com ciclo de trabalho constante.........131

Quadro 5.5 - Configuração do registrador ACTRA...........................................131

Quadro 5.6 - Configuração do registrador COMCONA. ......................................132

Quadro 5.7 - Configuração do registrador DBTCONA .........................................133

Quadro 5.8 - Código para configuração do sistema de interrupção. .......................134

Quadro 5.9 - Rotina de Interrupção do CPUTimer0. ..........................................139

Quadro 5.10 - Rotina para desenvolver o incremento do índice da tabela de seno.

Quadro 5.11 - Rotina de Interrupção de atualização de CMPR1 para a geração PWM senoidal.

Quadro 5.12 - Rotina de interrupção de atualização de CMPR2 para a geração PWM senoidal adiantada em 120 graus.

Quadro 5.13 - Rotina de Interrupção de atualização de CMPR2 para a geração PWM senoidal atrasada em 120 graus.

Quadro 5.14 - Código para o cálculo da velocidade angular 



\section{Lista de Tabelas}

Tabela 4.1 - Parâmetros do MIT 83

Tabela 4.2 - Base de regras do sistema de controle fuzzy. 87

Tabela 5.1 - Definição do registrador PLLCR para o fator de multiplicação de freqüência.

Tabela 5.2 - Resolução da freqüência de acionamento do MIT. 162 



\section{Introdução}

\subsection{Motivação e Relevância do Trabalho}

Os motores elétricos são elementos de conversão de energia elétrica em mecânica, indispensáveis para realização de diversos processos envolvidos nos setores produtivos. Em virtude de suas inúmeras características atraentes sobre os demais tipos de motores, tais como, baixo custo, facilidade de transporte, limpeza, facilidade de comando, construção simples, grande versatilidade de adaptação às cargas, facilidade de controle, e alto rendimento (Krause et al., 1995; Krishnan, 2001; Trzynadlowski, 2001; Fitzgerald et al., 2006; Goedtel, 2007), os motores elétricos são largamente empregados nos mais diversos tipos de aplicações industriais.

No cenário energético, estima-se que $47 \%$ da energia elétrica produzida no Brasil é destinada à classe industrial, o que equivale a aproximadamente 346 bilhões de MWh (MegaWatts horas) em 2005, conforme os estudos realizados pela Empresa de Pesquisa Energética (Eletrobrás, 2007). A partir desse montante, 50\% da energia consumida são atribuídas aos motores elétricos, conforme pode ser observado na Figura 1.1. Entretanto, em virtude da relevante atuação dos motores elétricos também em setores não industriais, acredita-se que sua participação energética é superior aos $23,5 \%$ da energia elétrica total produzida.

Devido à sua cada vez mais crescente aplicação nas indústrias e à sua relevância no panorama energético, os estudos relativos aos motores elétricos têm 
se garantido um papel de suma importância no que diz respeito à melhoria de eficiência energética, dimensionamento adequado, técnicas de controle preciso, manutenção preventiva e qualidade de energia.

\section{Cenário Energético Brasileiro}

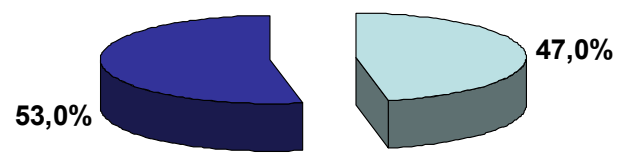

$\square$ Indústriais $\square$ Não-Industriais
Energia destinada aos Motores Elétricos

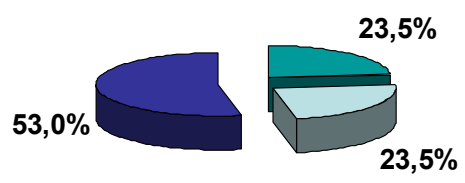

$\square$ Motores Elétricos $\square$ Outras Cargas Industriais $\square$ Não Industriais

Figura 1.1 - Cenário Energético Brasileiro.

Na documentação técnica da Siemens (2006), revela-se que estudo de mercados indicam que o custo gerado pelo consumo de energia elétrica é correspondente à cerca de $97 \%$ dos custos totais durante o ciclo de vida de um motor elétrico, na qual o restante de apenas 3\% está relacionado ao custo de aquisição, instalação e manutenção. Além disso, em Trzynadlowski (2001) é descrito que, dentre a grande quantidade de tipos de motores elétricos empregados em setores industriais, cerca de 90\% constitui-se de Motores de Indução Trifásicos (MIT). Conseqüentemente, deduz-se que os MITs, em especial o Motor de indução com Rotor em Gaiola de Esquilo (MIRGE), cuja característica mais atraente reside no seu baixo custo de aquisição e manutenção, contribuem significativamente para os resultados contidos em Siemens (2006). Por outro lado, pesquisas relativas à eficiência energética se tornam também relevantes e motivadoras.

Com os avanços das tecnologias no campo da eletrônica de potência, os dispositivos controladores de velocidades para motores de indução trifásicos tornaram-se precisos e eficientes, substituindo principalmente as máquinas de 
corrente contínua que dominavam as aplicações industriais de velocidades variáveis até as últimas décadas.

Diversas metodologias convencionais de controle de velocidade de MITs podem ser encontradas na literatura, as quais, de forma genérica, podem ser enquadradas em duas grandes categorias: comando escalar e comando vetorial (Krishnan, 2001; Trzynadlowski, 2001; Fitzgerald et al., 2006). Neste contexto, os controles baseados em PI, PD e PID são os mais usualmente aplicados nas indústrias com grandes aceitações práticas.

Entretanto, as maiores dificuldades do controle eficiente do MIT consistem no fornecimento de uma tensão com freqüência ajustável, no tratamento das não linearidades e complexidade analítica do motor, além das incertezas de seus parâmetros (Trzynadlowski, 2001). Na prática, tais fatores se agravam devido ao efeito da curva de magnetização do fluxo eletromagnético, ao efeito pelicular, à alimentação desequilibrada, ao efeito das harmônicas, às variações paramétricas do motor em função do aumento de temperatura e à assimetria do motor, tornando o sistema altamente não linear e, conseqüentemente, de difícil solução matemática.

Na tentativa de contornar tais problemas, as técnicas baseadas em sistemas inteligentes para o controle de velocidade de MITs se tornam atraentes em virtude da sua habilidade de lidar com sistemas não lineares e variantes no tempo e de não necessitar de um modelo matemático preciso que represente a planta a ser controlada, além de apresentar uma grande facilidade de integração computacional com as técnicas convencionais. Dentre as diversas técnicas de sistemas inteligentes, as principais e mais populares consistem nas Redes Neurais Artificiais (RNA), nos Sistemas Fuzzy e nos Algoritmos Genéticos. 
As RNAs consistem de um conjunto de unidades de processamento denominados de neurônios, os quais são inter-conectados por meio de pesos sinápticos que representam o conhecimento armazenado em forma distribuída. Suas principais características atrativas residem na capacidade de mapear sistemas não lineares mediante a processo de aprendizado, na adaptação de seus parâmetros livres aos sistemas variantes no tempo, na capacidade de generalização das soluções e na habilidade de classificar e de agrupar padrões semelhantes (Haykin, 1999). Tais virtudes torna as RNAs uma ferramenta alternativa poderosa para solução de processos envolvidos na identificação e controle de máquinas elétricas.

Enquanto as RNAs trabalham com um conjunto de dados com intuito de ajustar os seus pesos sinápticos por meio de algoritmos de aprendizagem, os Sistemas Fuzzy são capazes de lidar com as incertezas e imprecisões das variáveis envolvidas no processo mediante a sua base de conhecimento expressa na forma de regras do tipo "Se-Então" aplicadas em variáveis lingüísticas. Desta forma, os Sistemas Fuzzy possuem a habilidade de explorar os aspectos qualitativos do processo para mapear a solução do problema (Tsoukalas e Uhrig, 1997). Neste sentido, os Sistemas Fuzzy apresentam uma ampla aplicabilidade em processos envolvidos com máquinas elétricas a fim de contornar as não linearidades e incertezas paramétricas.

Já os algoritmos genéticos ou computação evolutiva consistem de técnicas de otimização e busca inspiradas no mecanismo de seleção natural e genética. Esta técnica não garante uma solução ótima, porém, geralmente encontra uma solução quase ou suficientemente ótima para um problema em um tempo aceitável. Os algoritmos genéticos aplicam uma técnica estocástica de busca, que embora aleatória, não definem caminhos desordenados em direção a uma solução ótima, 
uma vez que se utilizam de informações históricas para definir os novos pontos de busca. Estes são realizados, durante cada geração, por meio de operadores baseados em princípios de seleção, reprodução e mutação aplicados a uma população de candidatos (Braga et al., 2000). Em virtude da grande capacidade de otimização e busca eficiente, a sua aplicação em controle de máquinas elétricas mostrou-se promissoras em determinados problemas.

Os sistemas inteligentes podem ser combinados entre si com o intuito de explorar suas potencialidades e desenvolver um sistema com melhores desempenhos. Técnicas como estas, denominadas de sistemas inteligentes híbridos (Tsoukalas e Uhrig, 1997), também vêm apresentando ótimos resultados em diversas áreas de atuação. Dentre as combinações, algumas podem ser citadas: Sistemas Neuro-Fuzzy, Neuro-Genético, Fuzzy-Genético e Neuro-Fuzzy-Genético.

No contexto do controle de MIT, os sistemas inteligentes têm sido aplicados com sucesso, conforme registrado na literatura, obtendo resultados que se destacam pela robustez, baixo custo e de altas eficiências (Cruz e Paredes, 2003a; Dazhi et al., 2004; Sakarung e Chatratana, 2004; Islam et al., 2005; Lin et al., 2005; Oh et al., 2006; Trentin et al., 2006; Zidani et al., 2006).

Em Oh et al. (2006), propõe-se um método de controle de velocidade de motor de indução baseado em redes neurais artificiais recorrentes. Neste esquema, fornecem-se as informações da variação da carga, ruído do sistema e as variações dos parâmetros da máquina de indução ao controlador, por meio de pesos sinápticos das RNA, estimados em tempo real (online) a partir da aplicação do filtro de Kalman estendido. Com o intuito de se projetar o filtro de Kalman com as constantes ótimas, desenvolveu-se um algoritmo genético simples. Em tal trabalho, o 
desempenho do controlador foi avaliado apenas mediante simulações computacionais utilizando o pacote MatLab ${ }^{\mathrm{TM}} /$ Simulink $^{\mathrm{TM}}$.

O algoritmo de Filtro de Kalman Estendido apresentou característica atraente, incrementando a eficiência do treinamento das redes neurais artificiais, a qual exigiu significativamente menos dados de treinamento comparando-se com as que utilizam o gradiente descendente puro. Entretanto, o algoritmo consome tempo de processamento para determinar os parâmetros ótimos do Filtro de Kalman (Oh et al., 2006).

O trabalho realizado em Dazhi et al. (2004) revela um controlador PID adaptativo baseado em redes neurais artificiais. A estratégia de controle consistiu no controle por orientação de campo. Aplicam-se duas RNA: uma para identificar o fluxo e a velocidade do rotor por meio das variáveis de tensão e corrente, e outra para efetuar o controle de velocidade do motor de indução. Dado que a primeira RNA é responsável pela estimação das variáveis de controle mediante as variáveis elétricas, denota-se a mesma por uma tecnologia conhecida como sensorless ${ }^{1}$ na literatura. A identificação é realizada online. Os resultados desta pesquisa consistiram em simulações computacionais e análises comparativas com modelos de controle PID convencionais.

A proposta do trabalho descrito em Cruz e Paredes (2003a; 2003b) consistiu no desenvolvimento de um Controle Direto de Torque (DTC) que permitiu aprimorar o desempenho do controle do motor de indução de forma que se minimize a distorção da corrente e do fluxo de estator, mantendo-se a freqüência de chaveamento do inversor. Além disso, um controlador PI neuro-fuzzy de velocidade é também proposto. Desta forma, o esquema consistiu basicamente na aplicação de

\footnotetext{
${ }^{1}$ Não se utiliza sensor de posição e velocidade angular.
} 
duas técnicas: estimação da resistência do estator por meio de RNA com treinamento online, a partir do sinal de erro do fluxo de entrada; e um controlador PI neuro-fuzzy adaptativo construído dentro de um estimador do tipo Sugeno. Em tal trabalho, resultados experimentais e simulados na região de torque constante e de campo enfraquecido são apresentados.

Em Sakarung e Chatratana (2004), apresentou-se a aplicação híbrida de duas estratégias de controle de máquinas de indução: controle por orientação de campo (Field Oriented Control - FOC) e controle direto de torque. Para tanto, propõe-se duas RNAs, cada uma responsável por realizar uma estratégia de controle. O treinamento é feito separadamente com dados entrada/saída obtidos da simulação baseada em modelos estruturais.

Na literatura, muitos artigos de FOC e DTC relatam a superioridade de uma estratégia de controle sobre a outra e vice-versa. Na prática, é difícil de afirmar claramente a superioridade de uma técnica sobre a outra, devido aos méritos balanceados entre ambas as técnicas (Sakarung e Chatratana, 2004).

Por um lado, o DTC é preferido devido a uma resposta rápida no regime transiente. Entretanto, apresenta-se um maior ripple de torque em regime permanente. A estratégia híbrida lida com as vantagens das duas técnicas em ambas as condições de funcionamento para aprimorar a performance tanto no regime transiente quanto no regime permanente. Desta forma, comuta-se a estratégia de controle com o critério baseado na forma de operação do motor. A análise de resultados apresentado em Sakarung e Chatratana (2004) se baseia também apenas em simulações computacionais.

Em Deng e Tu (2006), propôs-se uma metodologia para reduzir o ripple de torque ocasionado pelo motor de indução em baixas velocidades mediante sistema 
de controle fuzzy aplicado na estratégia de controle DTC. Com base nos reguladores PI convencionais, o regulador de velocidade PI fuzzy foi projetado de forma que os coeficientes de ganho proporcional e integral fossem ajustados dinamicamente com a variação de velocidade. Para tanto, utilizou-se do erro de velocidade e sua taxa de variação como parâmetro. Desenvolveu-se então um controlador vetorial fuzzy de tensão com o objetivo de diminuir o ripple de torque, onde o ângulo de fluxo do estator, o erro de fluxo do estator, e o erro de torque são fuzzificados em diversos subconjuntos fuzzy para otimizar a seleção do vetor de tensão aplicado. Os resultados experimentais são promissores em relação a uma das desvantagens da aplicação do controle DTC quando em baixas velocidades, como conforme citado em Deng e Tu (2006):

"The experimental results show that the proposed fuzzy control system can ensure swift speed response, small overshooting, and high steady speed precision, and can effectively decrease torque ripple in low speed, and enhances the robustness of the whole system."

Os controladores DTC convencionais não requerem sensores mecânicos, reguladores de corrente, transformações de coordenadas, e depende somente da resistência do estator (Buja e Kazmierkowski, 2004). Um dos problemas principais desta estratégia de controle reside no seu comportamento a baixas velocidades, onde a estimação do fluxo do estator se torna extremamente dependente da resistência do estator. Desta forma, em Zidani et al. (2006), propôs-se um identificador fuzzy de resistência de estator sem a necessidade de medições adicionais como temperatura ou qualquer outro método de controle, tais como observadores e estimadores, os quais consomem tempo computacional e ajuste delicado. 


\subsection{Objetivo e Justificativa da Dissertação}

Os objetivos gerais desse projeto de pesquisa consistem na investigação, desenvolvimento, projeto, implementação e validação de arquiteturas de sistemas inteligentes utilizando $D S P$, os quais podem ser utilizados nos processos envolvidos com a identificação e controle de parâmetros de máquinas elétricas rotativas, principalmente aqueles envolvidos com os motores de indução. Assim, por meio das ferramentas desenvolvidas é possível a construção de modelos capazes de realizar predições confiáveis sobre o comportamento do motor, bem como executar ações que visam o controle adequado do mesmo em tempo real. Dentro desse contexto, os objetivos gerais deste projeto de pesquisa são pautados em cinco itens principais apresentados a seguir.

- Implementar em DSP as estratégias de controle baseadas nos sistemas inteligentes desenvolvidos.

- Contribuir para otimização dos processos de especificação e controle de motores de indução.

- Permitir que novas técnicas, desenvolvidas mediante a aplicação de sistemas inteligentes e de métodos convencionais, possam ser testadas e validadas experimentalmente.

- Disponibilizar um banco de informações com dados experimentais que poderão ser utilizados em diversas outras pesquisas afins.

- Comparar as estratégias de controle e acionamento desenvolvidas com as abordagens convencionais já existentes.

Os resultados obtidos nessa pesquisa poderão ser diretamente aplicados na indústria, visando principalmente um melhor dimensionamento dos motores, 
acionamentos e controles e, como conseqüência, a utilização mais racional da energia elétrica.

\subsection{Organização da Dissertação}

A dissertação está organizada em cinco capítulos principais. O Capítulo 1 apresenta a motivação e relevância, o estado da arte referente ao controle de motores de indução trifásicos, bem como os principais objetivos deste trabalho.

No Capítulo 2 são tratados os conceitos e fundamentos relativos às máquinas elétricas empregadas na bancada experimental. Uma breve descrição das principais metodologias de controle de motores de indução trifásicos e dos tipos de cargas comumente acopladas ao seu eixo em ambientes industriais também serão apresentados.

No Capítulo 3, descrevem-se os principais componentes da bancada de pesquisa responsável pela extração de dados e pela validação experimental de modelos implementados.

No Capítulo 4, os conceitos fundamentais do sistema de inferência fuzzy e a proposição de um controlador escalar (Volts/Hertz) fuzzy, bem como resultados de simulações computacionais serão delineados.

No Capítulo 5 são discutidos os aspectos fundamentais do DSP empregado neste trabalho, as principais metodologias de acionamento e controle da máquina de indução trifásica, bem como os resultados experimentais.

No Capítulo 6, fornecem-se as conclusões gerais e as diretivas dos passos a serem desenvolvidos em trabalhos futuros. Por fim, as referências bibliográficas deste trabalho são apresentadas. 


\subsection{Trabalhos Publicados em Eventos Científicos}

No decorrer do período de mestrado, os seguintes trabalhos foram publicados em anais de congressos científicos:

- SUETAKE, Marcelo ; SILVA, Ivan Nunes ; GOEDTEL, Alessandro . Controlador Escalar Fuzzy V/F de Velocidade de Motores de Indução Trifásicos. In: VIII Simpósio Brasileiro de Automação Inteligente, 2007, Florianópolis. Anais do VIII Simpósio Brasileiro de Automação Inteligente (CD-ROM // Paper No. 30887 // 06 Páginas), 2007.

- SUETAKE, Marcelo ; GOEDTEL, Alessandro ; SILVA, Ivan Nunes . Arquitetura de Sistema Fuzzy Para Controle de Motores de Indução Trifásicos Frente à Variação de Tensão e Carga. In: 6th Brazilian Conference on Dymanics, Control and Their Applications, 2007, São José do Rio Preto. Proceedings of the 6th Brazilian Conference on Dymanics, Control and Their Applications, 2007. p. 924-934. 



\section{Fundamentos de Máquinas Elétricas}

\subsection{O Motor de Indução Trifásico}

O enfoque principal desta dissertação consiste no controle da Máquina de Indução Trifásica mediante a implementação de algoritmos de sistemas inteligentes em processadores digitais. Em decorrência deste fato, a descrição dos conceitos fundamentais do MIT, os principais equacionamentos que representam a sua operação e o sistema de aquisição de dados experimentais fornecem bases essenciais para o desdobramento dos próximos passos da dissertação e, portanto, serão tópicos abordados nesta seção.

Os MITs consistem de máquinas assíncronas, cujo princípio de funcionamento se baseia no seguinte: as bobinas do enrolamento trifásico do estator são alimentadas por correntes alternadas trifásicas, as quais criam um campo girante que atua na estrutura que contém as bobinas do rotor e, por indução, proporciona nesta uma corrente circulante, cujo campo resultante procura se alinhar ao campo girante (Fitzgerald et al., 2006; Junior, 2006). Como conseqüência, desenvolve-se o movimento rotativo.

Os motores de indução podem ser enquadrados em duas categorias: Motor de Indução com Rotor em Gaiola de Esquilo (MIRGE) e Motor de Indução com Rotor Bobinado (MIRB).

O MIRB caracteriza-se pela existência de bobinas no rotor que permite o seu acesso elétrico por meio de escovas de carvão, as quais deslizam sobre anéis 
condutores. Desta forma, um reostato ajustável pode ser conectado em série com as bobinas com a finalidade de reduzir a corrente e aumentar o torque de partida, bem como efetuar um controle de velocidade restrito (Trzynadlowski, 2001). Geralmente, os terminais das bobinas são curto-circuitados quando o motor atinge a velocidade de operação. Entretanto, as possibilidades extras oferecidas pelo rotor bobinado tornam os custos mais elevados, além de ser menos robusto que os motores do tipo de gaiola de esquilo (Trzynadlowski, 2001). Por esta razão, a aplicação dos MIRBs nas indústrias vem se tornando cada vez mais rara, sendo substituídos pelos MIRGEs controlados, apesar do aumento de custos associados aos sistemas de acionamento destes. Atualmente, grande parte das aplicações de geradores eólicos constituem de MIRBs.

O MIRGE, por outro lado, caracteriza-se por apresentar um rotor constituído por barras de metais condutores com suas extremidades em curto-circuito por anéis, cujo formato se assemelha a uma "Gaiola de Esquilo", motivo pelo qual este tipo de motor recebe tal nomenclatura. Este aspecto dispõe-se de uma robustez e extrema simplicidade construtiva que traz como conseqüência diversas características vantajosas, tais como baixo custo de produção e aquisição (Trzynadlowski, 2001; Fitzgerald et al., 2006). Além disso, a ausência de escovas e anéis de contato evita a ocorrência de centelhas e fagulhas. Com isto, reduz-se o custo de manutenção, bem como proporciona uma ampla abrangência nos campos de aplicações, visto que o MIRGE pode ser empregado em ambientes hostis com riscos de explosões (Trzynadlowski, 2001). Embora apresente a desvantagem da impossibilidade de acesso elétrico ao rotor, tais virtudes, sem dúvidas, fazem com que o MIRGE seja o tipo de motor de indução mais utilizado e mais popular em aplicações industriais. 
Devido à sua relevância prática, nesta dissertação serão abordados com mais detalhes os conceitos relativos ao MIRGE.

Além das características supracitadas, o MIT se destaca pela capacidade de operar em altas velocidades, suportar cargas mecânicas pesadas e até mesmo sobrecarga elétrica. Desta forma, sua aplicação é indicada a uma ampla faixa de exigências de cargas. Em dispositivos de controle de velocidade, a baixa constante de tempo elétrica aumenta a resposta dinâmica ao comando de controle do MIT (Trzynadlowski, 2001).

Entretanto, as desvantagens dos MIT com relação aos outros motores elétricos residem principalmente na dificuldade de efetuar o seu controle, visto que há a necessidade de desenvolver freqüência e tensão variável e de se lidar com as não linearidades do sistema (Fitzgerald et al., 2006).

\subsection{Aspectos de Modelagem Matemática do MIT}

O desenvolvimento da modelagem matemática do MIT será realizado levando em consideração algumas hipóteses iniciais (Barbi, 1985), cujo intuito é de reduzir a complexidade dos aspectos não lineares e assimétricos encontrados na prática, mantendo o modelo aproximado do funcionamento de uma máquina real.

- Os enrolamentos tanto do estator quanto do rotor são idênticos e possuem ângulos elétricos iguais entre si;

- As resistências das bobinas, as indutâncias próprias dos enrolamentos e o entreferro são considerados constantes;

- O circuito magnético é considerado ideal (linear), na qual a saturação magnética não existe; 
- Considera-se que a distribuição de densidade de fluxo magnético no entreferro é radial e senoidal;

- Para efeito de estudo, a máquina será considerada bipolar, no entanto, o modelo pode ser generalizado para $p$ pólos;

- Não serão consideradas as perdas magnéticas, os efeitos de temperatura e pelicular.

O esquema ilustrativo do MIT é representado pela Figura 2.1.

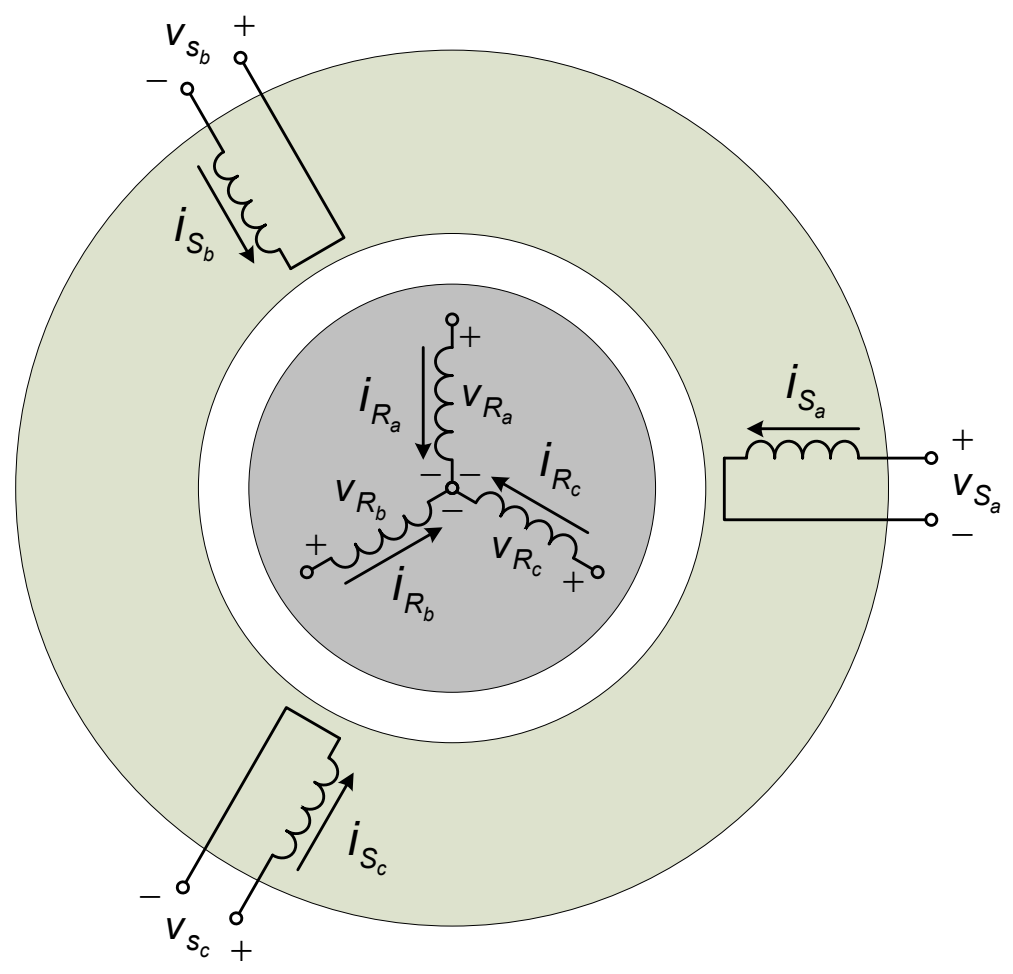

Figura 2.1 - Representação do MIT.

onde $v_{S_{a}}, v_{S_{b}}, v_{S_{c}}$ são as tensões aplicadas nas fases $a, b$ e $c$ do estator; $i_{S_{a}}, i_{S_{b}}, i_{S_{c}}$ são as correntes das fases $a, b$ e $c$ do estator; $v_{R_{a}}, v_{R_{b}}, v_{R_{c}}$ são as tensões induzidas das fases $a, b$ e $c$ do rotor; $i_{R_{a}}, i_{R_{b}}, i_{R_{c}}$ são as correntes induzidas das fases $a, b$ e $c$ do rotor.

Tais grandezas podem ser representadas na forma vetorial conforme segue: 


$$
\begin{gathered}
\mathbf{v}_{\mathbf{S}}=\left[\begin{array}{lll}
v_{S_{a}} & v_{S_{b}} & v_{S_{c}}
\end{array}\right]^{t} \\
\mathbf{i}_{\mathbf{S}}=\left[\begin{array}{lll}
i_{S_{a}} & i_{S_{b}} & i_{S_{c}}
\end{array}\right]^{t} \\
\mathbf{v}_{\mathbf{R}}=\left[\begin{array}{lll}
v_{R_{a}} & v_{R_{b}} & v_{R_{c}}
\end{array}\right]^{t} \\
\mathbf{i}_{\mathbf{R}}=\left[\begin{array}{lll}
i_{R_{a}} & i_{R_{b}} & i_{R_{c}}
\end{array}\right]^{t}
\end{gathered}
$$

em que $\mathbf{v}_{\mathbf{S}}, \mathbf{i}_{\mathbf{S}}, \mathbf{v}_{\mathbf{R}}$ e $\mathbf{i}_{\mathbf{R}}$ são vetores de tensões e correntes relativos ao estator e rotor, respectivamente, e o símbolo super-escrito $t$ representa a transposição do vetor.

Em decorrência das hipóteses acima consideradas, o fato dos enrolamentos de estator e rotor serem idênticos, as seguintes simplificações podem ser realizadas:

$$
\begin{gathered}
L_{S_{a}}=L_{S_{b}}=L_{S_{c}}=L_{S} \\
L_{R_{a}}=L_{R_{b}}=L_{R_{c}}=L_{R} \\
R_{S_{a}}=R_{S_{b}}=R_{S_{c}}=R_{S} \\
R_{R_{a}}=R_{R_{b}}=R_{R_{c}}=L_{R}
\end{gathered}
$$

onde $L_{S_{a}}, L_{S_{b}}, L_{S_{c}}, R_{S_{a}}, R_{S_{b}}$ e $R_{S_{c}}$ são indutâncias próprias e resistências das bobinas de cada fase de estator, os quais são representados por $L_{S}$ e $R_{S}$, respectivamente; e $L_{R_{a}}, L_{R_{b}}, L_{R_{c}}, R_{R_{a}}, R_{R_{b}}$ e $R_{R_{c}}$ são indutâncias próprias e resistências das bobinas de cada fase do rotor, sendo representados por $L_{R}$ e $R_{R}$, respectivamente;

Em virtude das defasagens angulares entre as bobinas de estator e rotor serem idênticas, conforme ilustrado pela Figura 2.2, as indutâncias mútuas entre as bobinas das fases do estator e entre as bobinas das fases do rotor são equivalentes. Assim,

$$
M_{S_{a b}}=M_{S_{b c}}=M_{S_{a c}}=M_{S}
$$




$$
M_{R_{\mathrm{ab}}}=M_{R_{\mathrm{bc}}}=M_{R_{\mathrm{ac}}}=M_{R}
$$

onde $M_{S_{a b}}$ representa a indutância mútua entre as bobinas da fase a e $b$ do estator e $M_{R_{a b}}$ descreve a indutância mútua entre os enrolamentos a e $b$ do rotor, cuja interpretação pode ser generalizada para os termos $M_{S_{b c}}, M_{S_{a c}}, M_{R_{b c}}$ e $M_{R_{a c}}$. Por serem equivalentes, estas são representadas por $M_{S}$ e $M_{R}$, respectivamente.

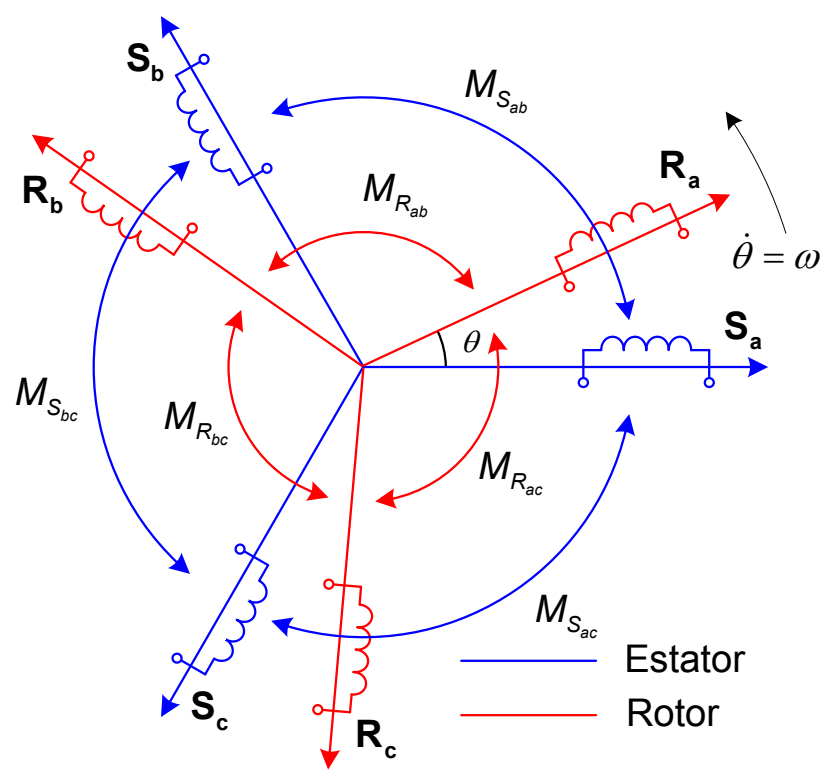

Figura 2.2 - Representação da indutância mútua entre as bobinas do estator e entre as bobinas do rotor.

Na ilustração da Figura 2.2, $\mathbf{S}_{a}, \mathbf{S}_{b}, \mathbf{S}_{c}, \mathbf{R}_{a}, \mathbf{R}_{b}$ e $\mathbf{R}_{c}$ denotam os fasores que representam o posicionamento angular entre as bobinas de estator e rotor, respectivamente. $\mathrm{O}$ ângulo entre as bobinas $\mathbf{S}_{\mathrm{a}}$ e $\mathbf{S}_{\mathrm{b}}$ consiste de 120 graus elétricos, o que pode ser generalizado para as bobinas $\mathbf{S}_{b}$ e $\mathbf{S}_{c}, \mathbf{S}_{c}$ e $\mathbf{S}_{a}, \mathbf{R}_{a}$ e $\mathbf{R}_{b}, \mathbf{R}_{b}$ e $\mathbf{R}_{c}$, e, finalmente, $\mathbf{R}_{\mathrm{c}}$ e $\mathbf{R}_{\mathrm{a}}$. Por outro lado, $\theta$ descreve o ângulo entre a bobina da fase $a$ do estator $\left(\mathbf{S}_{\mathrm{a}}\right)$ e a fase a do rotor $\left(\mathbf{R}_{\mathrm{a}}\right)$, e a sua derivada em relação ao tempo $\dot{\theta}=\omega$ representa a velocidade angular do rotor em ângulos elétricos. 
Cabe salientar que o presente modelo trata de uma máquina bipolar e, portanto, o ângulo elétrico é idêntico ao ângulo mecânico. A relação entre essas duas grandezas pode ser obtida por:

$$
\theta_{e}=\frac{p}{2} \theta_{m}
$$

onde $\theta_{e}$ e $\theta_{m}$ são os ângulos elétrico e mecânico, respectivamente, e $p$ é o número de pólos.

A determinação da indutância mútua entre as bobinas do estator e as bobinas do rotor pode ser realizada com o auxílio da Figura 2.3.

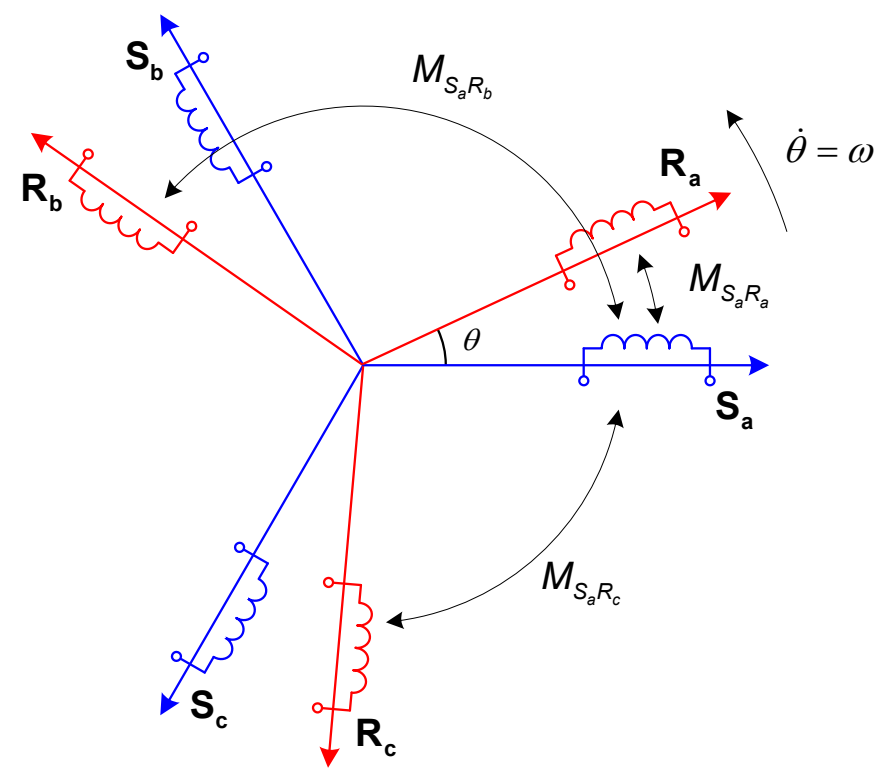

Figura 2.3 - Representação da indutância mútua entre as bobinas de estator e rotor.

A indutância mútua entre a bobina da fase a do estator e as demais bobinas do rotor são determinadas da seguinte forma:

$$
\begin{aligned}
& M_{S_{a} R_{a}}=M_{S R} \cos (\theta) \\
& M_{S_{a} R_{b}}=M_{S R} \cos (\theta+2 \pi / 3) \\
& M_{S_{a} R_{c}}=M_{S R} \cos (\theta-2 \pi / 3)
\end{aligned}
$$

Generalizando-se para as demais bobinas, têm-se 


$$
\begin{aligned}
& M_{S_{b} R_{a}}=M_{S R} \cos (\theta-2 \pi / 3) \\
& M_{S_{b} R_{b}}=M_{S R} \cos (\theta) \\
& M_{S_{c} R_{c}}=M_{S R} \cos (\theta+2 \pi / 3) \\
& M_{S_{b} R_{a}}=M_{S R} \cos (\theta+2 \pi / 3) \\
& M_{S_{b} R_{b}}=M_{S R} \cos (\theta-2 \pi / 3) \\
& M_{S_{c} R_{c}}=M_{S R} \cos (\theta)
\end{aligned}
$$

Na forma matricial, as matrizes das indutâncias mútuas entres as bobinas de estator e rotor pode ser obtido da seguinte maneira:

$$
\mathbf{L}_{\mathbf{S R}}(\theta)=\left[\begin{array}{lll}
M_{S_{a} R_{a}} & M_{S_{a} R_{b}} & M_{S_{a} R_{c}} \\
M_{S_{b} R_{a}} & M_{S_{b} R_{b}} & M_{S_{b} R_{c}} \\
M_{S_{c} R_{a}} & M_{S_{c} R_{b}} & M_{S_{c} R_{c}}
\end{array}\right]
$$

\subsubsection{Equações de Fluxos}

Os fluxos eletromagnéticos que atravessam os enrolamentos são superpostos e podem ser determinados mediante o somatório da contribuição de cada enrolamento (Barbi, 1985). Desta forma, os fluxos dos enrolamentos do estator são descritos conforme as seguintes expressões:

$$
\begin{aligned}
& \lambda_{S_{a}}=L_{S} i_{S_{a}}+M_{S} i_{S_{b}}+M_{S} i_{S_{c}}+M_{S_{a} R_{a}} i_{R_{a}}+M_{S_{a} R_{b}} i_{R_{b}}+M_{S_{a} R_{c}} i_{R_{c}} \\
& \lambda_{S_{b}}=L_{S} i_{S_{b}}+M_{S} i_{S_{a}}+M_{S} i_{S_{c}}+M_{S_{b} R_{a}} i_{R_{a}}+M_{S_{b} R_{b}} i_{R_{b}}+M_{S_{b} R_{c}} i_{R_{c}} \\
& \lambda_{S_{c}}=L_{S} i_{S_{c}}+M_{S} i_{S_{a}}+M_{S} i_{S_{b}}+M_{S_{c} R_{a}} i_{R_{a}}+M_{S_{c} R_{b}} i_{R_{b}}+M_{S_{c} R_{c}} i_{R_{c}}
\end{aligned}
$$

onde $\lambda_{S_{a}}, \lambda_{S_{b}}$ e $\lambda_{S_{c}}$ são os fluxos concatenados totais que atravessam as bobinas da fase $a, b$ e c, respectivamente, cuja representação matricial é denotada por:

$$
\left[\begin{array}{l}
\lambda_{S_{a}} \\
\lambda_{S_{b}} \\
\lambda_{S_{c}}
\end{array}\right]=\left[\begin{array}{ccc}
L_{s} & M_{s} & M_{s} \\
M_{s} & L_{s} & M_{s} \\
M_{s} & M_{s} & L_{s}
\end{array}\right]\left[\begin{array}{l}
i_{S_{a}} \\
i_{S_{b}} \\
i_{S_{c}}
\end{array}\right]+\left[\begin{array}{ccc}
M_{S_{a} R_{a}} & M_{S_{a} R_{b}} & M_{S_{a} R_{c}} \\
M_{S_{b} R_{a}} & M_{S_{b} R_{b}} & M_{S_{b} R_{c}} \\
M_{S_{c} R_{a}} & M_{S_{c} R_{b}} & M_{S_{c} R_{c}}
\end{array}\right]\left[\begin{array}{l}
i_{R_{a}} \\
i_{R_{b}} \\
i_{R_{c}}
\end{array}\right]
$$


Mediante a simplificação da Equação (2.19), e efetuando-se o mesmo procedimento para os enrolamentos de rotor, têm-se:

$$
\begin{aligned}
& \lambda_{S}=\mathbf{L}_{s s} \mathbf{i}_{S}+\mathbf{L}_{S R}(\theta) \mathbf{i}_{R} \\
& \lambda_{R}=\mathbf{L}_{R S}(\theta) \mathbf{i}_{S}+\mathbf{L}_{R R} \mathbf{i}_{R}
\end{aligned}
$$

em que:

$$
\begin{gathered}
\mathbf{L}_{\mathrm{ss}}=\left[\begin{array}{ccc}
L_{s} & M_{s} & M_{s} \\
M_{s} & L_{s} & M_{s} \\
M_{s} & M_{s} & L_{s}
\end{array}\right] \\
\mathbf{L}_{\mathrm{RR}}=\left[\begin{array}{ccc}
L_{R} & M_{R} & M_{R} \\
M_{R} & L_{R} & M_{R} \\
M_{R} & M_{R} & L_{R}
\end{array}\right] \\
\mathbf{L}_{\mathrm{SR}}(\theta)=M_{\mathrm{SR}}\left[\begin{array}{ccc}
\cos \theta & \cos (\theta+2 \pi / 3) & \cos (\theta-2 \pi / 3) \\
\cos (\theta-2 \pi / 3) & \cos (\theta) & \cos (\theta-2 \pi / 3) \\
\cos (\theta+2 \pi / 3) & \cos (\theta-2 \pi / 3) & \cos (\theta)
\end{array}\right] \\
\mathbf{L}_{\mathrm{RS}}(\theta)=\mathbf{L}_{\mathrm{SR}}(\theta)^{t}
\end{gathered}
$$

\subsubsection{Equações das Tensões}

As equações das tensões de um MIT conectado em estrela podem ser obtidas com base no circuito equivalente representado pela Figura 2.4, o qual, embora seja referente ao equacionamento da tensão da fase a do estator, pode ser generalizado para as demais fases. Desta forma, a equação da fase a pode ser escrita como:

$$
v_{S_{a}}=R_{S_{a}} i_{S_{a}}+\frac{d \lambda_{S_{a}}}{d t}
$$




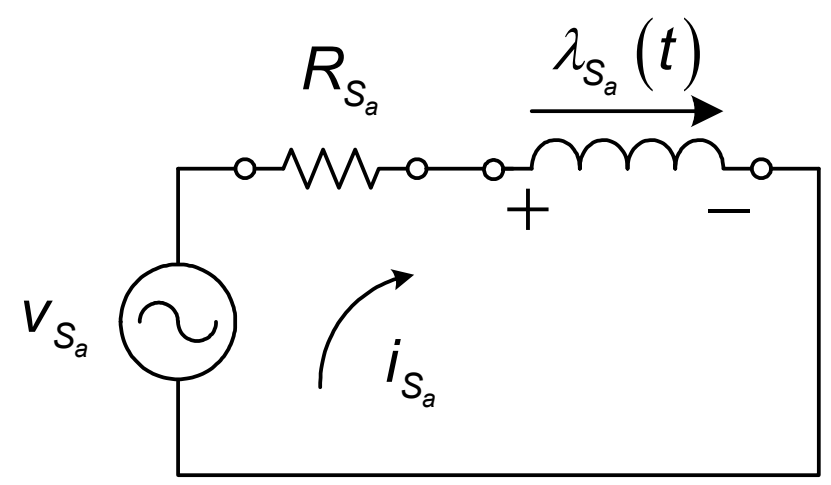

Figura 2.4-Circuito equivalente de uma das fases do estator.

De forma análoga à determinação da Equação (2.26), as demais expressões são encontradas e representadas na forma matricial conforme a Equação (2.27) e (2.28)

$$
\begin{aligned}
& \mathbf{v}_{\mathbf{S}}=\mathbf{R}_{\mathbf{S}} \mathbf{i}_{\mathbf{s}}+\frac{d \boldsymbol{\lambda}_{\mathbf{S}}}{d t} \\
& \mathbf{v}_{\mathbf{R}}=\mathbf{R}_{\mathbf{R}} \mathbf{i}_{\mathbf{R}}+\frac{d \boldsymbol{\lambda}_{\mathbf{R}}}{d t}
\end{aligned}
$$

onde:

$$
\begin{aligned}
& \mathbf{R}_{\mathbf{S}}=\left[\begin{array}{ccc}
R_{S} & 0 & 0 \\
0 & R_{S} & 0 \\
0 & 0 & R_{S}
\end{array}\right] \\
& \mathbf{R}_{\mathbf{R}}=\left[\begin{array}{ccc}
R_{R} & 0 & 0 \\
0 & R_{R} & 0 \\
0 & 0 & R_{R}
\end{array}\right]
\end{aligned}
$$

Substituindo a Equação (2.20) na Equação (2.27) e a Equação (2.21) na Equação (2.28), e solucionando a derivada da matriz de fluxo em relação ao tempo, obtêm-se as equações das tensões:

$$
\begin{aligned}
& \mathbf{v}_{\mathbf{S}}=\mathbf{R}_{\mathrm{s}} \mathbf{i}_{\mathbf{s}}+\mathbf{L}_{\mathrm{ss}} \frac{d \mathbf{i}_{\mathbf{S}}}{d t}+\mathbf{L}_{\mathrm{SR}}(\theta) \frac{d \mathbf{i}_{\mathrm{R}}}{d t}+\frac{\partial \mathbf{L}_{\mathrm{SR}}(\theta)}{\partial \theta} \mathbf{i}_{\mathbf{R}} \frac{d \theta}{d t} \\
& \mathbf{v}_{\mathbf{R}}=\mathbf{R}_{\mathrm{R}} \mathbf{i}_{\mathbf{R}}+\mathbf{L}_{\mathrm{RR}} \frac{d \mathbf{i}_{\mathbf{R}}}{d t}+\mathbf{L}_{\mathrm{RS}}(\theta) \frac{d \mathbf{i}_{\mathbf{S}}}{d t}+\frac{\partial \mathbf{L}_{\mathrm{RS}}(\theta)}{\partial \theta} \mathbf{i}_{\mathbf{S}} \frac{d \theta}{d t}
\end{aligned}
$$


As Equações (2.31) e (2.32) podem ser reescritas e compactadas segundo a Equação (2.33):

$$
\mathbf{v}=\mathbf{R} \mathbf{i}+\mathbf{L}(\theta) \frac{d \mathbf{i}}{d t}+\frac{\partial \mathbf{L}(\theta)}{\partial \theta} \mathbf{i} \frac{d \theta}{d t}
$$

em que:

$$
\begin{gathered}
\mathbf{v}=\left[\begin{array}{l}
\mathbf{v}_{\mathbf{s}} \\
\mathbf{v}_{\mathbf{R}}
\end{array}\right] \\
\mathbf{R}=\left[\begin{array}{cc}
\mathbf{R}_{\mathbf{S}} & \mathbf{0} \\
\mathbf{0} & \mathbf{R}_{\mathbf{R}}
\end{array}\right] \\
\mathbf{L}(\theta)=\left[\begin{array}{cc}
\mathbf{L}_{\mathbf{S S}} & \mathbf{L}_{\mathrm{SR}}(\theta) \\
\mathbf{L}_{\mathbf{R S}}(\theta) & \mathbf{L}_{\mathrm{RR}}
\end{array}\right] \\
\mathbf{i}=\left[\begin{array}{l}
\mathbf{i}_{\mathbf{S}} \\
\mathbf{i}_{\mathbf{R}}
\end{array}\right]
\end{gathered}
$$

\subsubsection{Equação do Torque Eletromagnético}

A expressão que determina o toque eletromagnético (Barbi, 1985) pode ser obtida por meio do cálculo da potência mecânica da máquina, visto que a relação entre estas duas grandezas é descrita por:

$$
P_{\text {mec }}=T \omega
$$

onde $P_{\text {mec }}$ e $T$ são a potência mecânica e o torque eletromagnético desenvolvido pela máquina, respectivamente.

Desta forma, pré-multiplicando a Equação (2.33) pelo vetor corrente transposto, obtém-se a Equação (2.39):

$$
\mathbf{i}^{t} \mathbf{v}=\mathbf{i}^{t} \mathbf{R} \mathbf{i}+\mathbf{i}^{t} \mathbf{L}(\theta) \frac{d \mathbf{i}}{d t}+\mathbf{i}^{t} \frac{\partial \mathbf{L}(\theta)}{\partial \theta} \mathbf{i} \dot{\theta}
$$


Por outro lado, a potência elétrica armazenada nos enrolamentos pode ser expressa conforme a Equação (2.40).

$$
\frac{d}{d t}\left(\frac{1}{2} \mathbf{i}^{\mathrm{t}} \mathbf{L}(\theta) \mathbf{i}\right)=\frac{1}{2} \mathbf{i}^{t} \mathbf{L}(\theta) \frac{d \mathbf{i}}{d t}+\frac{1}{2} \mathbf{i}^{\frac{\partial \mathbf{L}(\theta)}{\partial \theta}} \mathbf{i} \dot{\theta}+\frac{1}{2} \frac{d \mathbf{i}^{t}}{d t} \mathbf{L}(\theta) \mathbf{i}
$$

A partir das propriedades de operações de matrizes, o primeiro termo é idêntico ao terceiro, ambos referentes ao lado direito da igualdade da Equação (2.40) , ou seja:

$$
\frac{1}{2} \mathbf{i}^{\mathrm{t}} \mathbf{L}(\theta) \frac{d \mathbf{i}}{d t}=\frac{1}{2} \frac{d \mathbf{i}^{t}}{d t} \mathbf{L}(\theta) \mathbf{i}
$$

Desta forma,

$$
\mathbf{i}^{\mathrm{t}} \mathbf{L}(\theta) \frac{d \mathbf{i}}{d t}=-\frac{1}{2} \mathbf{i}^{t} \frac{\partial \mathbf{L}(\theta)}{\partial \theta} \mathbf{i} \dot{\theta}+\frac{d}{d t}\left(\frac{1}{2} \mathbf{i}^{\mathrm{t}} \mathbf{L}(\theta) \mathbf{i}\right)
$$

Substituindo a Equação (2.42) na Equação (2.39), tem-se:

$$
\mathbf{i}^{t} \mathbf{v}=\mathbf{i}^{t} \mathbf{R} \mathbf{i}+\frac{d}{d t}\left(\frac{1}{2} \mathbf{i}^{t} \mathbf{L}(\theta) \mathbf{i}\right)+\frac{1}{2} \mathbf{i}^{t} \frac{\partial \mathbf{L}(\theta)}{\partial \theta} \mathbf{i} \dot{\theta}
$$

onde a parcela $\mathbf{i}^{t} \mathbf{v}$ representa a potência elétrica fornecida ao MIT, i $\mathbf{i}^{t} \mathbf{R} \mathbf{i}$ corresponde às perdas nos enrolamentos, $\frac{d}{d t}\left(\frac{1}{2} i^{t} \mathbf{L}(\theta) \mathbf{i}\right)$ se refere à energia armazenada no campo magnético, e finalmente, $\frac{1}{2} \mathbf{i}^{t} \frac{\partial \mathbf{L}(\theta)}{\partial \theta} \mathbf{i} \dot{\theta}$ denota a potência mecânica entregue ao eixo do MIT. Assim sendo, a potência mecânica é dada por:

$$
P_{\text {mec }}=\frac{1}{2} \mathbf{i}^{t} \frac{\partial \mathbf{L}(\theta)}{\partial \theta} \mathbf{i} \dot{\theta}
$$

Substituindo a Equação (2.44) na Equação (2.38), pode-se determinar o torque eletromagnético desenvolvido pelo MIT, ou seja:

$$
T=\frac{1}{2} \mathbf{i}^{t} \frac{\partial \mathbf{L}(\theta)}{\partial \theta} \mathbf{i}
$$




\subsubsection{Equações Mecânicas da Máquina}

A expressão denotada pela Equação (2.46) representa os aspectos mecânicos da máquina, os quais envolvem as variáveis relacionadas com a característica construtiva, bem como os efeitos da carga imposta ao eixo do MIT, tais como momento de inércia e constante de atrito viscoso.

$$
T_{e l}=\left(J_{m}+J_{c}\right) \cdot \frac{d \omega_{m}}{d t}+\left(B_{m}+B_{c}\right) \cdot \omega_{m}+T_{c}
$$

em que $J_{m}, J_{c}, B_{m}, B_{c}$ e $T_{c}$ são, respectivamente, o momento de inércia da máquina, o momento de inércia da carga, a constante de atrito viscoso da máquina, a constante de atrito viscoso da carga e o torque mecânico imposto pela carga.

\subsubsection{Transformações Lineares}

O sistema de equações diferenciais denotado pelas Equações (2.33) e (2.45) são lineares com coeficientes variantes no tempo e de difícil solução. Desta forma, técnicas de transformações lineares foram desenvolvidas com o intuito de se alcançar um modelo mais simples, no qual seja possível viabilizar o estudo do comportamento da máquina por meio de simulações computacionais (Barbi, 1985; Krause et al., 1995; Krishnan, 2001). Cabe salientar que, nesta dissertação, todos estes passos foram desencadeados para se analisar o desempenho do sistema de controle fuzzy de velocidade do MIT. Dentre as transformações lineares, destacamse a transformação $0 \alpha \beta$ e a transformação Park.

\section{- Transformação $0 \alpha \beta$}

A transformação $0 \alpha \beta$ apresenta o efeito de diagonalizar as matrizes simétricas presentes no modelo da máquina de indução trifásica simétrica formulada 
na subseção anterior. Fisicamente, esta pode ser interpretada com a transformação de uma máquina trifásica em um modelo bifásico equivalente (Barbi, 1985), com mesma potência mecânica, torque, velocidade e número de pólos, conforme pode ser analisada pela Figura 2.5 .
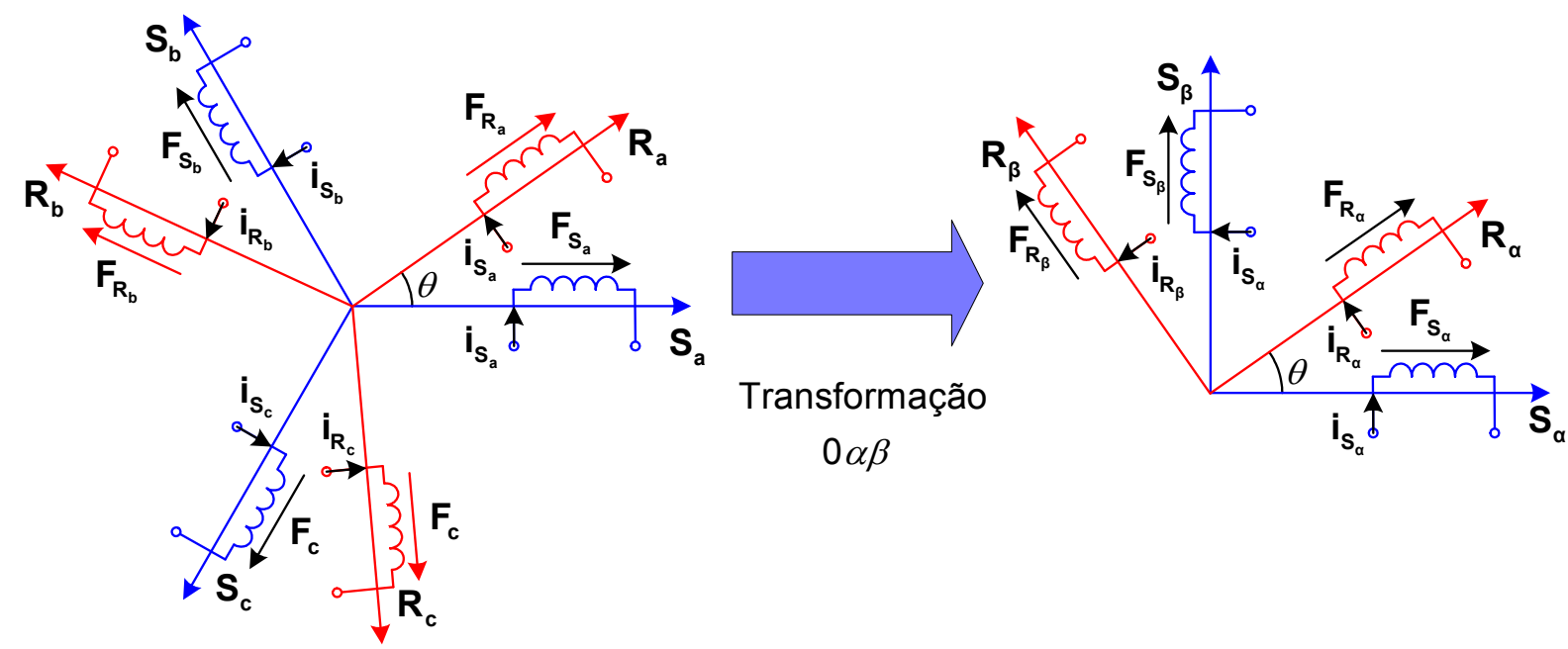

Figura 2.5 - Efeitos da Transformação $0 \alpha \beta$.

A transformação linear de coordenadas abc para $0 \alpha \beta$ é realizada mediante a Equação (2.47).

$$
F_{0 \alpha \beta}=A^{-1} F_{a b c}
$$

onde

$$
\begin{gathered}
\mathbf{F}_{0 \alpha \beta}=\left[\begin{array}{lll}
F_{0} & F_{\alpha} & F_{\beta}
\end{array}\right]^{t} \\
\mathbf{A}^{-1}=\sqrt{\frac{2}{3}}\left[\begin{array}{ccc}
1 / \sqrt{2} & 1 / \sqrt{2} & 1 / \sqrt{2} \\
1 & -1 / 2 & -1 / 2 \\
0 & \sqrt{3} / 2 & -\sqrt{3} / 2
\end{array}\right]
\end{gathered}
$$

em que $\mathbf{F}_{\text {oa }}$ e $\mathbf{A}^{-1}$ representam o vetor força magnetomotriz resultante semelhante àquelas produzidas pelo modelo trifásico e a matriz de transformação de coordenadas, respectivamente. 
Por outro lado, a transformação linear inversa de coordenadas $\alpha \beta 0$ para $a b c$ pode ser efetuada por meio da Equação (2.50).

$$
F_{\mathrm{abc}}=\mathbf{A F _ { 0 a \beta }}
$$

Embora as transformações denotadas pelas Equações (2.47) e (2.50) estejam em função da força magnetomotriz, estas podem ser generalizadas e serem aplicadas nas tensões e correntes da máquina.

\section{- Transformação de Park}

A transformação de Park consiste na transformação dos eixos rotóricos girantes em eixos pseudo-estacionários (Barbi, 1985) mediante a projeção de seus fasores no eixo de coordenadas $d q$, conforme ilustrado pela Figura 2.6. Esta transformação proporcionou relevantes avanços nas análises dinâmicas das máquinas de indução trifásicas em virtude da simplificação dos sistemas de equações do modelo da máquina.

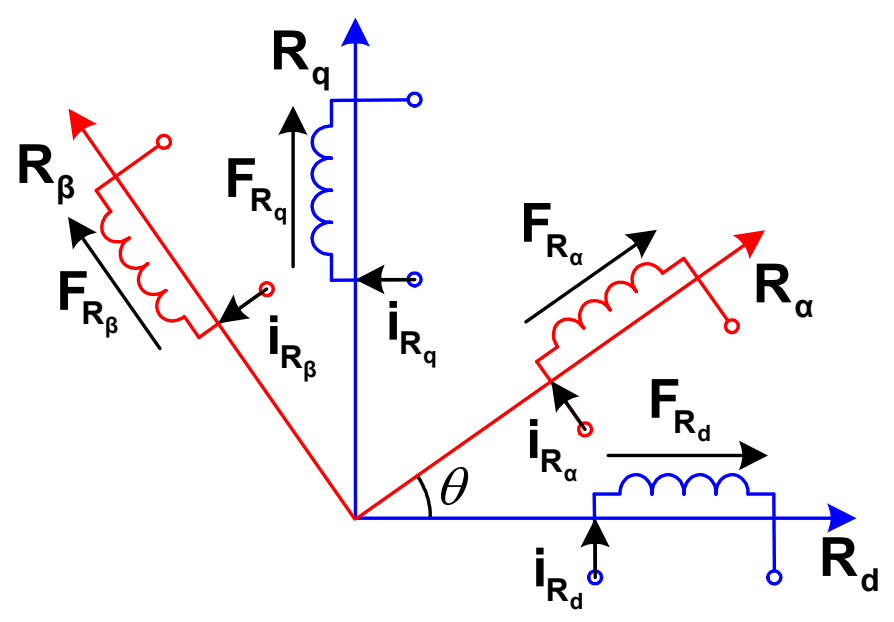

Figura 2.6 - Efeitos da Transformação dq.

A transformação $\alpha \beta 0$ para o eixo de coordenadas $d q$ pode ser efetuada por meio da Equação (2.51). 


$$
\mathrm{F}_{\text {odq }}=\mathbf{B}^{-1} \mathrm{~F}_{\text {oaß }}
$$

onde

$$
\mathbf{B}^{-1}=\left[\begin{array}{ccc}
1 & 0 & 0 \\
0 & \cos (\theta) & -\sin (\theta) \\
0 & \sin (\theta) & \cos (\theta)
\end{array}\right]
$$

em que $\mathbf{B}^{-1}$ representa a matriz de transformação de coordenadas $\alpha \beta 0$ para $d q$.

Substituindo a Equação (2.47) em (2.51), obtém-se a transformação direta do eixo de coordenadas abc para dq conforme a Equação (2.53) a seguir:

$$
F_{0 d q}=B^{-1} A^{-1} F_{a b c}
$$

Aplicando a transformação de Park denotada pela Equação (2.53) nas variáveis de tensão e corrente das equações das tensões (2.33) e de torque eletromagnético (2.45), e ainda, generalizando-se para $p$ pólos mediante a relação descrita pela Equação (2.11), obtêm-se as Equações (2.54) e (2.55) no eixo de coordenadas $d q$.

$$
\begin{gathered}
{\left[\begin{array}{l}
V_{S_{d}} \\
V_{S_{q}} \\
V_{R_{d}} \\
V_{R_{q}}
\end{array}\right]=\left[\begin{array}{cccc}
R_{S}+\rho \mathrm{L}_{S} & 0 & \rho m_{S R} & 0 \\
0 & R_{S}+\rho \mathrm{L}_{S} & 0 & \rho m_{S R} \\
\rho m_{S R} & \frac{p}{2} \dot{\theta} m_{S R} & R_{R}+\rho \mathrm{L}_{R} & \frac{p}{2} \dot{\theta} \mathrm{L}_{R} \\
-\frac{p}{2} \dot{\theta} m_{S R} & \rho m_{S R} & -\frac{p}{2} \dot{\theta} \mathrm{L}_{R} & R_{R}+\rho \mathrm{L}_{R}
\end{array}\right]\left[\begin{array}{l}
i_{S_{d}} \\
i_{S_{q}} \\
i_{R_{d}} \\
i_{R_{q}}
\end{array}\right]} \\
T=\frac{p}{2} m_{S R}\left(i_{S_{d}} i_{S_{q}}-i_{R_{d}} i_{R_{q}}\right)
\end{gathered}
$$

onde $\rho$ representa o operador de derivada com relação ao tempo $\frac{d}{d t}$ e os termos $\mathrm{L}_{S}, \mathrm{~L}_{R}$ e $m_{S R}$ são utilizados apenas para se alcançar uma representação simplificada da Equação (2.54) e podem ser determinados como segue:

$$
\mathrm{L}_{s}=L_{s}-M_{s}
$$




$$
\begin{gathered}
\mathrm{L}_{R}=L_{R}-M_{R} \\
m_{S R}=\frac{3}{2} M_{S R}
\end{gathered}
$$

As equações desenvolvidas até o momento representam um caso especial, no qual o eixo de coordenadas $d q$ está referenciado no estator. Como conseqüência, os fasores estatóricos das coordenadas $0 \alpha \beta$ são idênticos ao das coordenadas $d q$. Este referencial foi adotado para se efetuar a análise de simulação computacional do controlador de velocidade desenvolvido neste trabalho. No entanto, com o auxílio da Figura 2.7, é possível generalizar o sistema de eixo de referência.

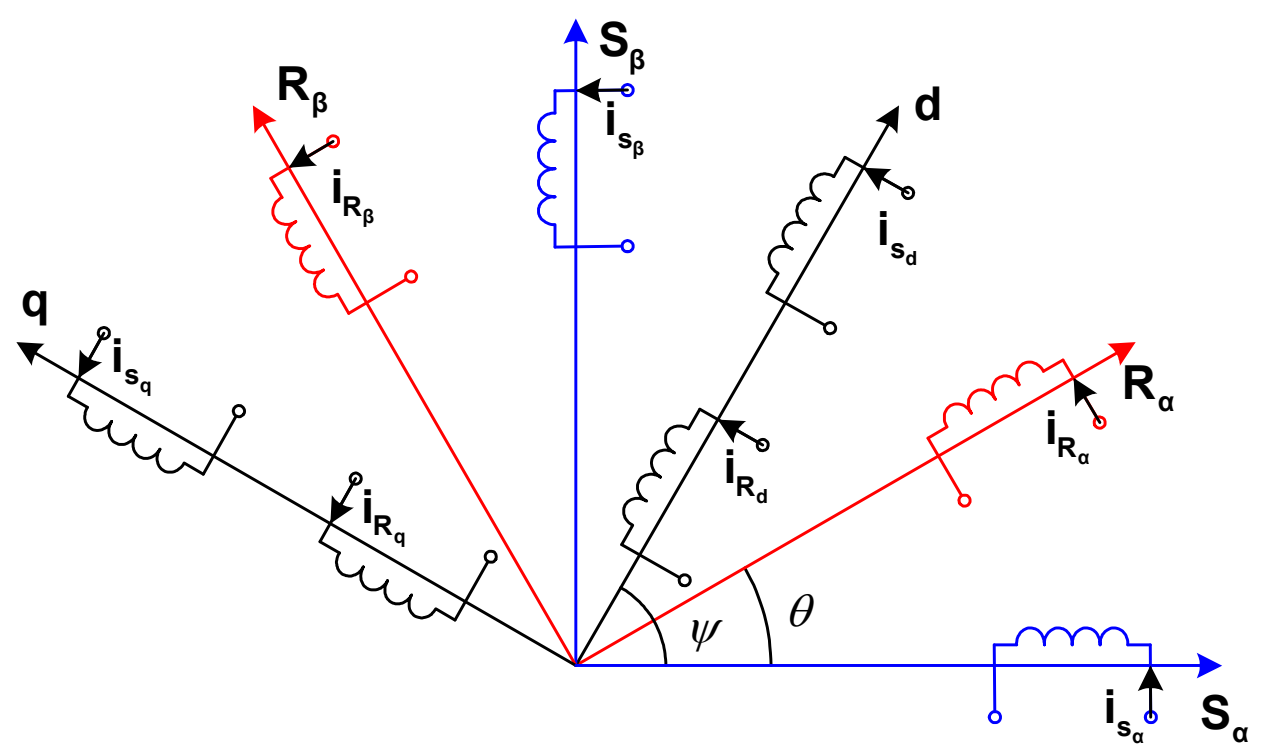

Figura 2.7 - Sistema de referência de eixos genérico.

Na literatura, é comum adotar o referencial $d q$ no eixo de coordenadas do estator $(\Psi=0)$, do rotor $(\Psi=\theta)$ ou do campo girante $\left(\Psi=\omega_{s} t\right.$ e $\left.\theta=\omega_{m} t\right)$, sendo esta também denominada de referência síncrona. Desta forma, o sistema de equações diferenciais que define o modelo dinâmico do MIT é representado pela Equação (2.59). 


$$
\left[\begin{array}{l}
v_{S_{d}} \\
v_{S_{q}} \\
v_{R_{d}} \\
v_{R_{q}}
\end{array}\right]=\left[\begin{array}{cccc}
R_{S}+\rho \mathrm{L}_{S} & -\mathrm{L}_{S} \dot{\Psi} \frac{p}{2} & \rho m_{S R} & -m_{S R} \dot{\Psi} \frac{p}{2} \\
\mathrm{~L}_{S} \dot{\Psi} \frac{p}{2} & R_{S}+\rho \mathrm{L}_{S} & m_{S R} \dot{\Psi} \frac{p}{2} & \rho m_{S R} \\
\rho m_{S R} & -m_{S R}(\dot{\Psi}-\dot{\theta}) \frac{p}{2} & R_{R}+\rho \mathrm{L}_{R} & -\mathrm{L}_{R}(\dot{\Psi}-\dot{\theta}) \frac{p}{2} \\
m_{S R}(\dot{\Psi}-\dot{\theta}) \frac{p}{2} & \rho m_{S R} & -m_{S R} \mathrm{~L}_{R}(\dot{\Psi}-\dot{\theta}) & R_{R}+\rho \mathrm{L}_{R}
\end{array}\right]\left[\begin{array}{l}
i_{S_{d}} \\
i_{S_{q}} \\
i_{R_{d}} \\
i_{R_{q}}
\end{array}\right]
$$

\subsubsection{A Máquina de Corrente Contínua}

As Máquinas de Corrente Contínua (MCC) fora muito populares em diversas aplicações industriais ao longo do passado por apresentarem uma grande versatilidade. Tipicamente, as MCC são caracterizadas pelo desenvolvimento de um torque nominal em todas as velocidades, desde o rotor bloqueado até a velocidade nominal (Hubert, 1991). Em virtude de sua facilidade de controle, as mesmas são freqüentemente utilizadas em aplicações que exigem uma ampla faixa de velocidade ou controle preciso (Fitzgerald et al., 2006).

Embora o avanço da eletrônica de potência aplicada em dispositivos de acionamento de máquinas de corrente alternada venha substituindo as máquinas de corrente contínua, a sua versatilidade combinada com a relativa simplicidade dos seus sistemas de acionamento assegura o seu uso continuado em uma ampla variedade de aplicações (Fitzgerald et al., 2006).

Tipicamente, uma máquina de corrente contínua é composta por dois tipos de enrolamento: o enrolamento de campo e o enrolamento de armadura. $\mathrm{O}$ enrolamento de campo é alimentado por fontes de tensão contínua, sendo responsável pela geração de fluxo eletromagnético que atravessa o enrolamento de armadura acoplado no rotor. No caso em que a máquina opera como motor, o enrolamento de armadura também é alimentado por tensão contínua gerando um 
fluxo eletromagnético. Este procura se alinhar com o fluxo produzido pelo enrolamento de campo, desenvolvendo-se então o torque eletromagnético e o giro do rotor. Por outro lado, quando a máquina opera como gerador, o movimento do rotor devido a uma fonte de energia mecânica fará com que circule uma corrente no sentido de anular o fluxo produzido pelo enrolamento de campo, desenvolvendo-se assim uma força contra-eletromotriz no enrolamento de armadura.

O diagrama esquemático denotado pela Figura 2.8 descreve a representação de uma máquina de corrente contínua. O estator apresenta pólos salientes excitados por bobinas de campo gerando uma distribuição simétrica no entreferro com relação ao eixo direto. A tensão alternada gerada no enrolamento de armadura é retificada e convertida em tensão contínua por meio de comutadores mecânicos e de escovas situadas em sua extremidade, na qual se conecta a carga.

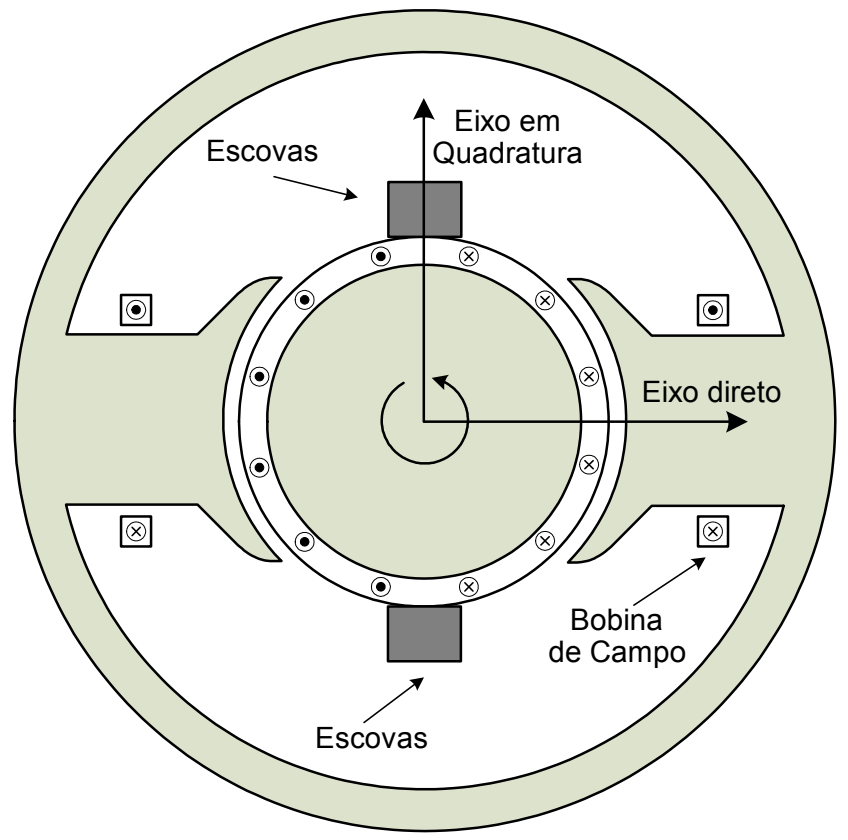

Figura 2.8 - Representação esquemática de uma MCC.

O posicionamento das escovas é realizado de tal forma para que a comutação ocorra no momento em que os lados da bobina em comutação estejam na zona neutra, ou seja, a meio caminho entre os pólos de campo. 
Conseqüentemente, o eixo da onda de FMM de armadura estará em quadratura com o eixo dos pólos de campo (na direção das escovas), conforme ilustrado na Figura 2.8 (Fitzgerald et al., 2006).

As MCCs podem ser projetadas mediante diversas combinações de enrolamentos (série, derivação e excitação independente) de forma que haja uma ampla variedade de característica tensão-corrente ou velocidade-conjugado para uma operação dinâmica e em regime permanente (Fitzgerald et al., 2006).

\subsubsection{Modelagem Matemática da MCC}

O circuito equivalente de um motor de corrente contínua constitui-se de uma fonte de tensão $v_{A}$, um enrolamento de armadura de resistência $R_{A}$ e indutância $L_{A}$, e uma tensão induzida e, conforme ilustrado pelo circuito da Figura 2.9.

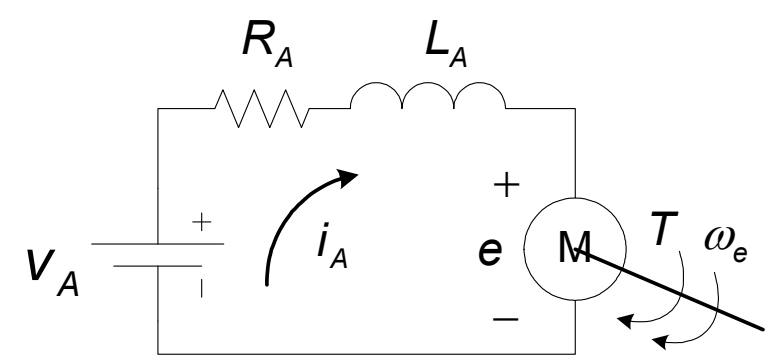

Figura 2.9 - Circuito equivalente de armadura de uma MCC.

Embora os desdobramentos das equações sejam baseados na máquina de corrente contínua funcionando como motor, cuja energia de entrada é a elétrica e a de saída é a mecânica, as mesmas podem ser generalizadas para o gerador. Assim sendo, a relação terminal pode ser escrita por:

$$
v_{A}=e+R_{A} i_{A}+L_{A} \frac{d i_{A}}{d t}
$$


Em regime permanente, a corrente de armadura é constante e, conseqüentemente, o termo com derivada se torna zero. Desta forma, a equação de tensão de armadura se reduz à seguinte expressão:

$$
v_{A}=e+R_{A} i_{A}
$$

A tensão induzida devido ao fluxo gerado pelo enrolamento de campo, somado ao deslocamento angular das bobinas de armadura, pode ser determinada por:

$$
e=K \phi_{f} \omega_{m}
$$

onde $K$ é uma constante que representa as características construtivas da máquina e $\omega_{m}$ é a velocidade angular mecânica.

Se o fluxo produzido pelo enrolamento de campo é constante, então a força contra-eletromotriz induzida no enrolamento de estator é proporcional à velocidade do rotor mediante uma constante de indução eletromagnética $K_{b}$.

$$
e=K_{b} \omega_{m}
$$

em que,

$$
K_{b}=K \phi_{f}
$$

A tensão induzida também pode ser expressa em função da indutância mútua, $M_{A f}$,entre os enrolamentos de armadura e de campo conforme a seguinte expressão:

$$
e=M_{A f} i_{f} \omega_{m}
$$

A equação que descreve o balanço de potência é obtida pela multiplicação de (2.61) pela corrente de armadura $i_{A}$, resultando em:

$$
v_{A} i_{A}=e i_{A}+R_{A} i_{A}^{2}
$$


O termo $R_{A} i_{A}^{2}$ denota as perdas no enrolamento de armadura - também chamado de perdas no cobre - e o termo $V_{A} i_{A}$ é a potência total de entrada. $O$ termo remanescente, $e i_{A}$, representa a potência elétrica efetivamente transformada em energia mecânica. Esta potência é também conhecida de gap e simbolizada por $P_{A}$, a qual é expressa em termos de torque e velocidade angular, ou seja:

$$
P_{A}=\omega_{m} T=e i_{a}
$$

Desta forma, o torque eletromagnético $T$ é representado pela seguinte expressão:

$$
T=\frac{e i_{A}}{\omega_{m}}=K \phi_{f} i_{A}=K_{b} i_{A}
$$

Deve ser notado que o torque é igual ao produto da corrente de armadura pela constante de indução eletromagnética $K_{b}$, considerando que esta é expressa em Volt-segundo/rad para uma máquina com fluxo constante. O fluxo constante pode ser obtido por imãs permanentes inseridos na estrutura da máquina ou através da excitação independente.

\subsection{Aspectos de Controle de Velocidade de MIT}

Os MITs convencionais alimentados por fontes de tensões senoidais de freqüência constante atendem satisfatoriamente às exigências de acionamento de velocidade constantes. No entanto, em uma diversidade de aplicações industriais é exigida uma faixa de velocidade ajustáveis (Fitzgerald et al., 2006). Estima-se que mais de 50 milhões de dólares podem ser economizados anualmente mediante a substituição dos MITs convencionais por aqueles controlados (Trzynadlowski, 2001).

A velocidade do MIT pode ser controlada de diversas maneiras. Para tanto, geralmente, adotam-se metodologias que se baseiam na variação da velocidade 
síncrona ou no controle de escorregamento do MIT. A velocidade síncrona pode ser alterada por meio da variação do número de pólos ou da freqüência da linha. Já o escorregamento pode ser controlado mediante a variação da tensão de linha, alterando-se a resistência do rotor ou aplicando tensões de freqüência adequadas ao circuito do rotor (Fitzgerald et al., 2006).

O controle de velocidade do MIT alimentado por um inversor é, em geral, realizado por meio da variação da freqüência. Inúmeras estratégias de controle têm sido formuladas, dependendo de como a razão tensão-freqüência é implementada. As principais técnicas aplicadas na prática são: controle de Volt/Hertz constante, controle de escorregamento constante, controle de fluxo no entreferro constante e controle vetorial (Krishnan, 2001).

A técnica de controle escalar pode ser empregada em aplicações a torque constante ou variável. Em geral, o controle escalar pode controlar a velocidade de rotação do motor com uma precisão de até $0,5 \%$ da rotação nominal para sistemas sem variação de carga, e de $3 \%$ a $5 \%$ com variação de carga de 0 a $100 \%$ do torque nominal (Brito, 2006).

Já a estratégia de controle vetorial é empregada, em geral, quando se deseja obter alta performance dinâmica, respostas rápidas e alta precisão de regulação de torque e velocidade para uma faixa abrangente de condições de operação. Entretanto, esta estratégia exige o conhecimento ou a obtenção de alguns parâmetros do motor de indução, tais como resistência de estator, resistência de rotor, indutância do estator, indutância do rotor, indutância de magnetização, entre outros (Brito, 2006). 


\subsubsection{Controle Volts/Hertz Constante}

A idéia central deste tipo de controle é variar a velocidade do campo girante do motor, mantendo sua amplitude nominal, conservando-se o fluxo magnético constante ao especificado pelo fabricante. Desta forma, este método considera que mantendo a relação entre a tensão e freqüência constante, seja possível manter também o fluxo constante. Conforme descrito em Krishnan (2001), a tensão induzida no entreferro de uma máquina de corrente alternada é dada por:

$$
E_{1}=4,44 K_{\omega_{1}} \phi_{m} f_{s} N_{s}
$$

onde $K_{\omega_{1}}$ é o fator de acoplamento da bobina do estator, $\phi_{m}$ é valor de pico do fluxo do entreferro, $f_{s}$ é a freqüência de alimentação do estator e $N_{s}$ é o número de espiras do estator. Desprezando-se a impedância do estator, a tensão induzida se torna aproximadamente igual à tensão de fase de alimentação. Portanto,

$$
V_{p h}=E_{1}
$$

Desta forma, o fluxo pode ser escrito como:

$$
\phi_{m}=\frac{V_{p h}}{K_{b} f_{s}}
$$

onde:

$$
K_{b}=4,44 K_{\omega_{1}} N_{s}
$$

Se $K_{b}$ é constante, o fluxo é aproximadamente proporcional à razão entre a tensão de alimentação e a freqüência, conforme descrito a seguir:

$$
\phi_{m} \propto \frac{V_{p h}}{f_{s}}
$$

A partir da Equação (2.73), nota-se que para manter o fluxo constante, a razão entre a tensão e a freqüência de alimentação deve ser preservada constante. 
Portanto, sempre que a freqüência de estator é alterada para realizar o controle de velocidade, a tensão de alimentação também deverá ser ajustada de forma que o fluxo no entreferro seja mantido constante.

A implementação do controlador Volts/Hertz pode ser realizada em malha aberta, entretanto, as aplicações se restringem aos problemas de baixa performance. A velocidade do motor não pode ser controlada com precisão em virtude da velocidade do rotor ser sempre menor que a velocidade síncrona, uma vez que somente a freqüência do estator é controlada neste esquema. Além disso, o escorregamento não pode ser mantido constante, já que a velocidade do rotor não é mensurada. Isto pode levar a máquina a uma região de operação instável da característica torque-velocidade.

O controle de malha fechada é esquematizado para superar tais problemas, conforme ilustrado na Figura 2.10.

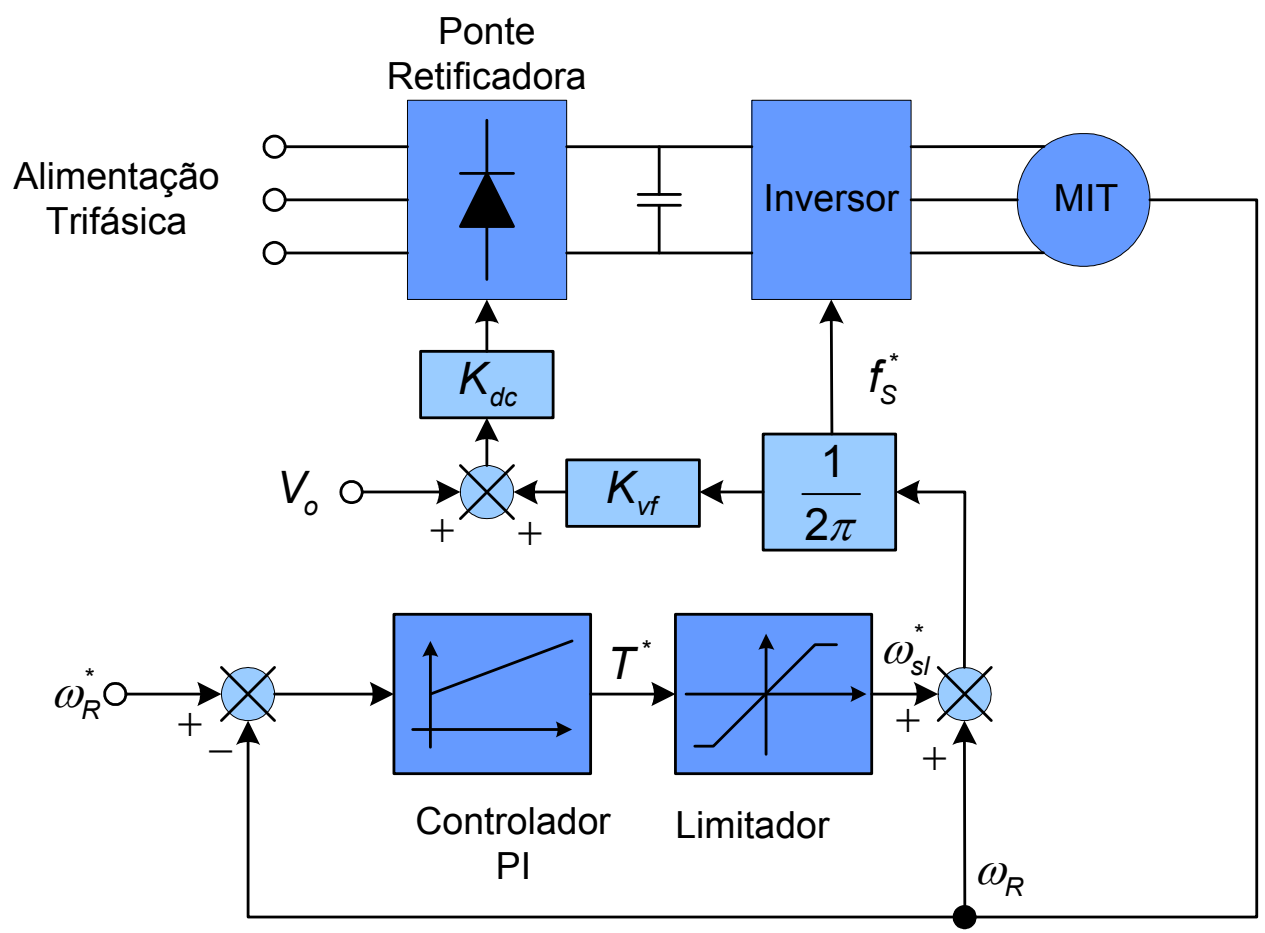

Figura 2.10 - Diagrama de blocos do controlador escalar Volts/Hertz. 
A velocidade do atual rotor é comparada com a velocidade de referência e o erro gerado é processado pelo controlador, usualmente PI. A sua ação de controle é limitada a fim de se manter o escorregamento dentro de um intervalo admissível. Após isto, a ação de controle é enviada ao retificador controlado e ao inversor de forma a produzir a tensão e freqüência adequada.

\subsubsection{Velocidade de Escorregamento Controlado}

Neste método de controle, deseja-se manter o escorregamento do motor de indução constante. Portanto, para diversas velocidades do rotor, o escorregamento irá variar conforme descrito como segue (Krishnan, 2001):

$$
\begin{gathered}
\omega_{s}=\omega_{r}+\omega_{s l} \\
\omega_{s l}=s \omega_{s}=\text { constante }
\end{gathered}
$$

O escorregamento é obtido pela seguinte relação:

$$
s=\frac{\omega_{s l}}{\omega_{s}}=\frac{\omega_{s l}}{\omega_{r}+\omega_{s l}}
$$

em que $\omega_{s l}$ é a velocidade de escorregamento que deve ser mantida constante.

O controle de velocidade de escorregamento trabalha com o objetivo de preservar a característica torque-velocidade estática. Para tanto, é necessário que a velocidade do rotor seja medida ou estimada e, em seguida, realimentada à malha de controle. A freqüência de alimentação do estator é então obtida pela soma da freqüência de escorregamento com a freqüência elétrica do rotor. A tensão de alimentação do MIT é determinada em função do sinal de erro de velocidade, conforme ilustrado na Figura 2.11. 


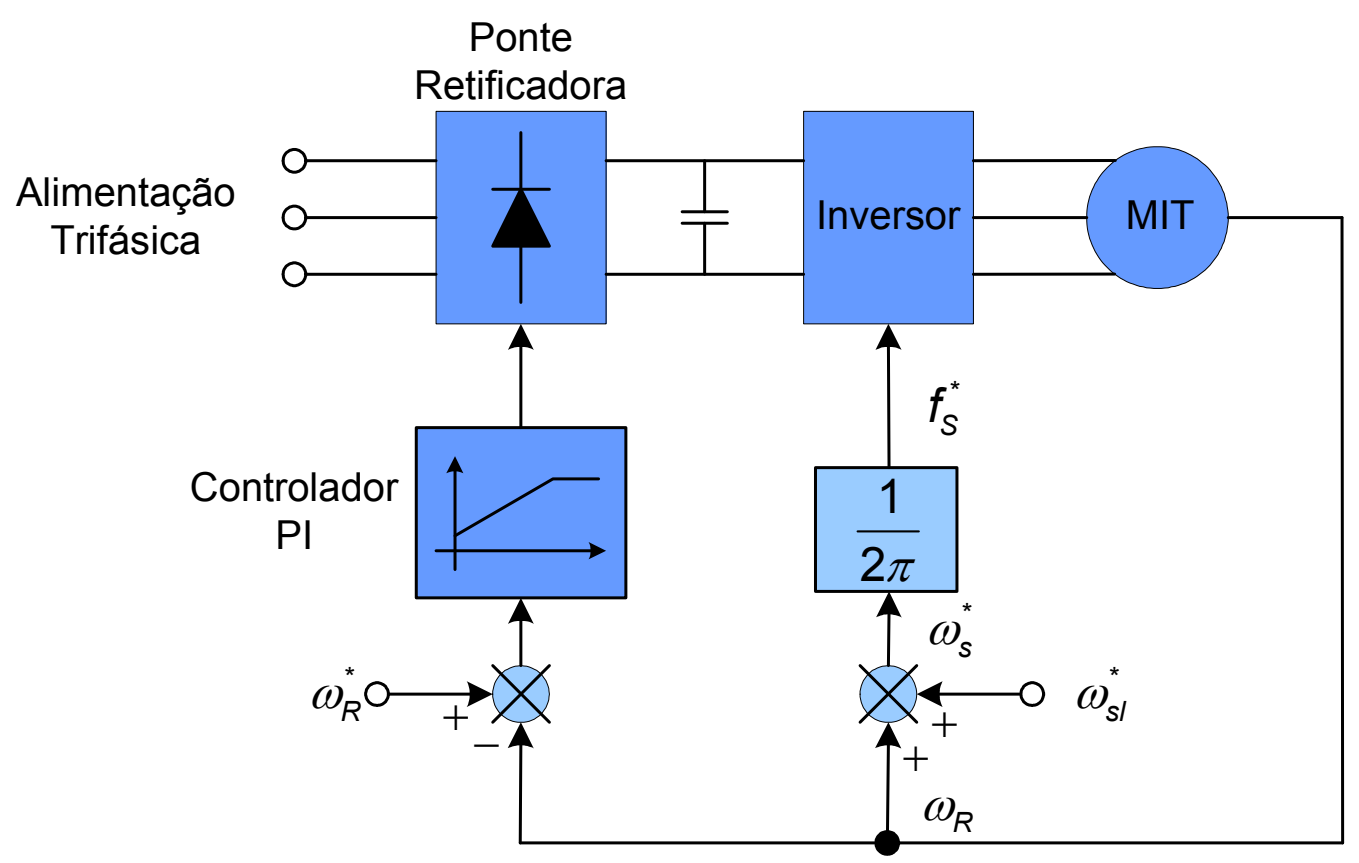

Figura 2.11 - Controle de velocidade com escorregamento controlado.

\subsubsection{Controle de Fluxo no Entreferro}

O controle de fluxo constante no entreferro transforma o motor de indução em um equivalente motor de corrente contínua com excitação independente em termos de sua velocidade de resposta, mas não em termos de acoplamento de fluxo e torque (Krishnan, 2001). Ter um fluxo constante no entreferro resulta em:

$$
\lambda_{m}=L_{m} i_{m}=\frac{V}{\omega_{s}}
$$

Assumindo que o fluxo no entreferro seja mantido constante, a expressão do torque é dada por:

$$
T=K_{t m} \frac{\left(\frac{R_{R}^{\prime}}{\omega_{s l}}\right)}{\left(\frac{R_{R}^{\prime}}{\omega_{s l}}\right)^{2}+\left(L_{R}^{\prime}\right)^{2}}
$$


onde $R_{R}^{\prime}$ e $L_{R}^{\prime}$ são resistência e indutância de dispersão referidas ao primário e $K_{t m}$ é uma constante definida por:

$$
K_{t m}=3 \frac{p}{2} \lambda_{m}^{2}
$$

Desta forma, o torque eletromagnético é dependente somente da freqüência de escorregamento, como pode ser observado na Equação (2.78). Tal característica significa um importante fenômeno pelo fato de que a freqüência de escorregamento pode ser variada instantaneamente, fazendo com que a resposta do torque também seja instantânea. Uma resposta rápida de torque abre o caminho para um controlador de alta performance, adequado para diversas aplicações, substituindo os MCCs com excitação independente.

Entretanto, este controle depende fortemente da sensibilidade da resistência do rotor e da indutância de dispersão. Na prática, a resistência do rotor varia em uma ampla faixa de valores compreendida entre 0,8 a 2 vezes do seu valor nominal à temperatura ambiente, o que torna muito complicado de se efetuar o controle (Krishnan, 2001).

O fato do fluxo constante no entreferro exigir o controle da corrente de magnetização requer um controle na corrente do estator separado da sua freqüência. $\mathrm{O}$ inversor de tensão com malha interna de corrente seria transformado em uma fonte de corrente variável com freqüência também variável.

O erro de velocidade é atribuído à entrada do controlador PI com limitador, gerando-se então a ação de controle de escorregamento. Esta, por sua vez, é adicionada ao sinal de velocidade do rotor para fornecer o sinal de controle de freqüência. 


\subsubsection{Controle Vetorial}

Diversas estratégias de controle de motor de indução alimentado por inversor têm fornecido bons desempenhos em regime estacionário. Entretanto, a sua resposta dinâmica deixa a desejar. Um dos motivos da pobre resposta dinâmica se deve ao fato de que o fluxo no entreferro se desvia do seu valor previamente ajustado, tanto na sua amplitude como na sua fase. Desta forma, a variação do fluxo deve ser controlada pela magnitude, freqüência da corrente de fase do estator e do rotor e pela sua fase instantânea. As estratégias de controle explanadas nos itens anteriores utilizam a magnitude da corrente de fase do estator e a sua freqüência, mas não leva em consideração a sua fase. Isto proporciona, como conseqüência, um desvio na fase e magnitude do fluxo magnético (Krishnan, 2001).

As oscilações no fluxo também resultam em oscilações no torque e, conseqüentemente, na velocidade do motor de indução. Este fato é indesejável para muitas aplicações de alto desempenho e precisão. Além disso, a variação no fluxo magnético pode exigir do conjunto, conversor e inversor, um maior pico de corrente para alimentar as bobinas do estator, o que acarretaria em maior custo.

Os motores de corrente contínua com excitação independente são mais simples de serem controlados, já que estes possuem um controle de fluxo magnético independente e, quando mantido constante, contribuem para o controle independente de torque. Além disso, o controle de uma máquina de corrente contínua requer somente o controle de campo e da magnitude da corrente de armadura.

Em contrapartida, os motores de indução requerem o controle das coordenadas da corrente de estator, freqüência e sua fase, pois a interação entre o campo do estator e rotor, cuja orientação não é mantida ortogonal e varia conforme 
a operação, torna o sistema mais complexo de se controlar. Desta forma, o controle vetorial consiste em aplicar um vetor de corrente de forma que tais condições de fluxo sejam atingidas mediante o controle adequado do inversor de freqüência. Este tipo de controle é também chamado de controle por campo orientado.

O controle vetorial pode ser classificado em função de como o ângulo de campo é adquirido. Se o ângulo de campo for calculado utilizando as informações de tensão e corrente, ou medido por sensores Hall ou pelo sensoriamento do fluxo nas bobinas, o controle é classificado como controle vetorial direto. Por outro lado, o ângulo do campo pode também ser obtido por meio de medição da posição do rotor ou pela estimação parcial usando somente os parâmetros das máquinas sem utilizar quaisquer outras variáveis. Neste caso, o controle é classificado como controle vetorial indireto.

Para se entender o princípio do controle vetorial, assume-se que a posição do vetor de fluxo do rotor $\lambda_{R}$ seja conhecida. O vetor $\lambda_{R}$ está a $\theta_{f}$ da referência estacionária, onde $\theta_{f}$ se refere ao ângulo do campo magnético. As correntes trifásicas no eixo $a b c$ podem ser transformadas para o eixo $d q$ de corrente no sistema de referência síncrona aplicando a seguinte transformação:

$$
\left[\begin{array}{l}
i_{q_{s}}^{e} \\
i_{d_{s}}^{e}
\end{array}\right]=\left[\begin{array}{ccc}
\sin \left(\theta_{f}\right) & \sin \left(\theta_{f}-\frac{2 \pi}{3}\right) & \sin \left(\theta_{f}+\frac{2 \pi}{3}\right) \\
\cos \left(\theta_{f}\right) & \cos \left(\theta_{f}-\frac{2 \pi}{3}\right) & \cos \left(\theta_{f}+\frac{2 \pi}{3}\right)
\end{array}\right]\left[\begin{array}{l}
i_{a_{s}} \\
i_{b_{s}} \\
i_{c_{s}}
\end{array}\right]
$$

a partir do qual o módulo vetor da corrente de estator, $i_{S}$, pode ser derivado como:

$$
i_{S}=\sqrt{\left(i_{q_{s}}^{e}\right)^{2}+\left(i_{d_{s}}^{e}\right)^{2}}
$$

onde o ângulo do vetor é determinado como segue: 


$$
\theta_{s}=\tan ^{-1}\left(\frac{i_{q_{s}}^{e}}{i_{d_{s}}^{e}}\right)
$$

sendo que $i_{q_{s}}^{e}$ e $i_{d_{s}}^{e}$ são as projeções do vetor de corrente do estator nos eixos $q$ e $d$, respectivamente. A magnitude do vetor da corrente de estator se mantém constante, conforme pode ser observada pela Figura 2.12.

O vetor de corrente $i_{S}$ produz um fluxo no rotor $\lambda_{R}$ e um torque $T$. A componente da corrente que produz o vetor de fluxo no rotor tem de estar em fase com $\lambda_{R}$. Portanto, projetando-se o vetor da corrente do estator sobre de $\lambda_{R}$ revela que a componente $i_{f}$ é a componente que produz o campo, conforme pode ser observada pela Figura 2.12. A componente perpendicular $i_{T}$ é, portanto, a componente responsável pela produção de torque.

Escrevendo o fluxo do rotor e o torque eletromagnético em termos dessas componentes, têm-se:

$$
\begin{gathered}
\lambda_{R} \propto i_{f} \\
T \propto \lambda_{R} i_{T} \propto i_{f} i_{T}
\end{gathered}
$$

Nota-se que $i_{f}$ e $i_{T}$ apresenta somente componente CC quando a máquina está em regime, pois a velocidade relativa com respeito ao campo do rotor é zero, ou seja, o vetor do fluxo do rotor possui a velocidade que se equivale à soma do escorregamento com a velocidade do rotor, que por sua vez, se iguala à velocidade síncrona. 


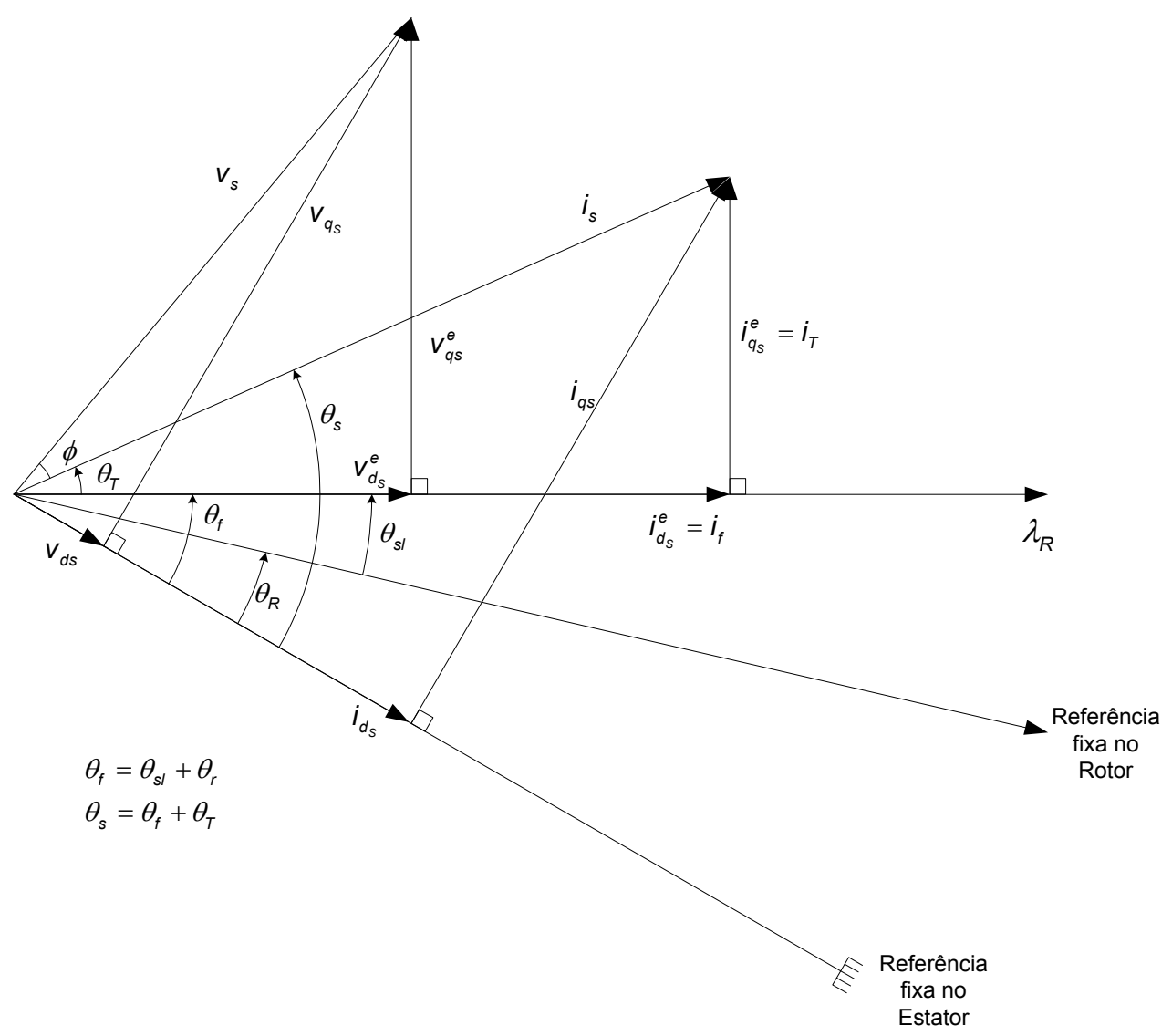

Figura 2.12 - Diagrama fasorial do controle vetorial.

A orientação de $\lambda_{R}$, considerando a referência síncrona e, portanto, as componentes que produzem o fluxo e torque da corrente são quantidades CC. Desta forma, estas são ideais para serem utilizadas como variáveis de controle, sendo que a largura de banda dos circuitos de controles não interferirá no processo destes sinais de controles CC.

Para a implementação do controlador vetorial, é necessário adquirir a posição instantânea do fluxo do rotor, $\theta_{f}$. Este ângulo pode ser escrito como:

$$
\theta_{f}=\theta_{R}+\theta_{s l}
$$

onde $\theta_{R}$ é a posição do rotor e $\theta_{s l}$ é o ângulo de escorregamento. Em termos das variáveis de velocidade e tempo, o ângulo do campo do rotor pode ser escrito como:

$$
\theta_{f}=\int\left(\omega_{R}+\omega_{s l}\right) d t=\int \omega_{s} d t
$$


O controle vetorial pode ser resumido nos seguintes procedimentos:

i.) Obter o ângulo do campo em relação à referência fixa do estator.

ii.) Calcular a componente da corrente responsável pela produção de fluxo, $i_{f}$, para um fluxo do rotor $\lambda_{R}$. Mediante o controle somente da corrente de campo, é possível controlar o fluxo do rotor. Esta característica se assemelha às máquinas $\mathrm{CC}$ com excitação independente, na qual a corrente de campo controla o fluxo magnético sem sofrer qualquer influência significativa da corrente de armadura.

iii.) A partir de $\lambda_{R}$ e do torque eletromagnético $T$, calcula-se a componente da corrente de estator responsável pela produção de torque, $i_{T}$. Controlando-se a componente $i_{T}$ quando o fluxo do rotor é constante, resulta-se em um controle independente do torque eletromagnético. Isto se assemelha ao caso da corrente de armadura controlando o torque eletromagnético em uma máquina CC com excitação independente, tendo a corrente de campo mantida constante. $\mathrm{O}$ desacoplamento completo entre o fluxo e as componentes que produzem torque em uma máquina de indução permite a realização dos passos (ii) e (iii).

iv.) Calcula-se o vetor da corrente de estator, $i_{s}$, a partir da soma vetorial de $i_{f} \operatorname{com} i_{T}$.

v.) Determina-se o ângulo de torque a partir das componentes de fluxo e de torque da corrente do estator, mediante a Equação (2.82).

vi.) Soma-se $\theta_{T}$ e $\theta_{f}$ para se obter o ângulo da corrente de estator, $\theta_{s}$. 
vii.) Por meio do ângulo da corrente de estator e sua magnitude, $\theta_{s} \mathrm{e} i_{s}$, calcula-se a corrente do estator mediante a transformação qd0 para abc.

$$
\left[\begin{array}{l}
i_{a_{s}} \\
i_{b_{s}} \\
i_{c_{s}}
\end{array}\right]=i_{S}\left[\begin{array}{c}
\sin \left(\theta_{s}\right) \\
\sin \left(\theta_{s}-2 \pi / 3\right) \\
\sin \left(\theta_{s} 2 \pi / 3\right)
\end{array}\right]
$$

viii.) Produzir essas correntes por meio do controle do inversor.

\subsubsection{Controle Direto de Torque}

Em vez do uso da corrente que é empregada no controle de fluxo orientado, a estratégia do DTC é caracterizada pelo controle direto do vetor fluxo de estator e do torque eletromagnético.

As vantagens do DTC consistem nas reduzidas oscilações do fluxo do estator e do torque eletromagnético (Vas, 1998). Embora não seja um aspecto intrinsecamente relacionado ao DTC, a escolha otimizada dos chaveamentos representa redução na freqüência de chaveamento do inversor e, por conseguinte, em redução de perdas. As outras vantagens do controle direto de torque são: o baixo esforço computacional e uma reduzida sensibilidade aos parâmetros do motor (Lins, 2001).

O torque eletromagnético (Vas, 1998) pode ser expresso por:

$$
T=-\frac{3}{2} \frac{p}{2} \frac{L_{m}}{L_{S S}^{\prime} L_{R R}}\left(\vec{\lambda}_{S \alpha \beta} \times \vec{\lambda}_{R \alpha \beta}\right)
$$

onde:

$$
L_{S S}^{\prime}=\left(1-\frac{L_{m}^{2}}{L_{S S} L_{R R}}\right) L_{S S}
$$

Com o auxílio da Figura 2.13 e da Equação (2.88), tem-se: 


$$
T=\frac{3}{2} \frac{p}{2} \frac{L_{m}}{L_{S S}^{\prime} L_{R R}}\left|\vec{\lambda}_{R \alpha \beta} \times \vec{\lambda}_{S \alpha \beta}\right| \sin (\gamma)
$$

onde $\gamma$ é o ângulo entre os vetores de fluxo do estator e do rotor.

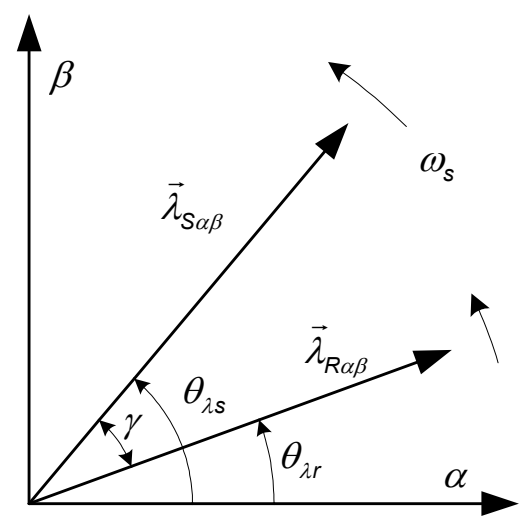

Figura 2.13 - Vetores de fluxo de estator e de rotor no plano $\alpha \beta$.

Conforme pode ser deduzido da Equação (2.90), se a magnitude dos fluxos do estator e rotor forem considerados constantes, o torque eletromagnético pode ser controlado alterando-se o ângulo $\gamma$ na direção do torque de referência. $\mathrm{O}$ ângulo $\gamma$ pode ser facilmente, e rapidamente, modificado pelo chaveamento apropriado do vetor de tensão do estator (Lins, 2001). Esta é a essência do controle direto de torque.

\subsection{Principais Tipos de Cargas Acopladas ao Motor de Indução}

Os principais tipos de cargas que são mais freqüentemente encontrados em ambientes industriais podem ser divididos em: quadrático, linear, constante e inverso (Goedtel, 2003). Uma breve descrição de cada uma dessas cargas será explanada nos itens subseqüentes. 


\subsubsection{Carga Quadrática}

A carga quadrática caracteriza-se por um conjugado resistente que varia com o quadrado da rotação. Suas principais aplicações são encontradas em ventiladores, misturadores, centrífugas, bombas centrífugas, exaustores e compressores (Dias e Lobosco, 1998). Matematicamente, esta pode ser representada pela seguinte equação:

$$
T(\omega)=a \omega^{2}+K
$$

onde a e K estão relacionadas à concavidade da parábola e ao conjugado inicial de partida, respectivamente. A Figura 2.14 (a) representa uma curva de torque de carga quadrática.

\subsubsection{Carga Linear}

A carga linear consiste de um conjugado resistente que apresenta uma variação linear com relação à rotação do eixo do motor. Este tipo de carga se encontra em aplicações como moinho de rolos, bombas de pistão, plainas e serras para madeira (Dias e Lobosco, 1998). A carga linear pode ser representada pela seguinte expressão:

$$
T(\omega)=a \omega+K
$$

onde a e $K$ estão relacionadas à inclinação e ao torque de carga inicial, respectivamente. A Figura 2.14 (b) descreve uma curva de carga linear. 


\subsubsection{Carga Inversa}

Este tipo de carga se comporta de forma inversa com a velocidade de rotação do motor, ou seja, seu valor diminui com o incremento de velocidade. As principais aplicações se concentram em fresadoras e mandriladoras (Dias e Lobosco, 1998). A carga inversa pode ser determinada pela seguinte expressão:

$$
T(\omega)=a e^{-b \omega}+K
$$

onde a está relacionada com o valor inicial do torque contando somente o primeiro termo de (2.93) e $K$ se refere ao valor mínimo do conjugado de carga. A Figura 2.14 (c) ilustra um conjugado de carga inverso.

\subsubsection{Carga Constante}

A carga constante caracteriza-se pela baixa ou nenhuma variação de conjugado resistente exigido do motor, permanecendo seu valor praticamente constante com o aumento de velocidade. As aplicações típicas deste tipo de carga residem em guinchos, guindastes e correias transportadoras (Dias e Lobosco, 1998). Uma carga constante pode ser representada pela seguinte expressão:

$$
T(\omega)=K
$$

onde $K$ representa o valor do torque de carga. A Figura 2.14 (d) representa a curva de carga constante utilizada para análise deste trabalho. 
(a) Carga Quadrática

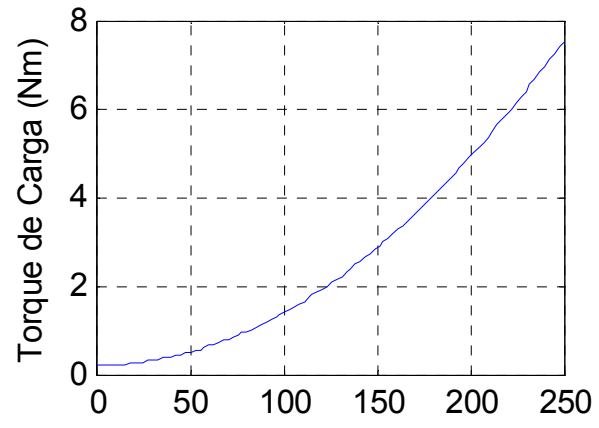

(c) Carga Inversa

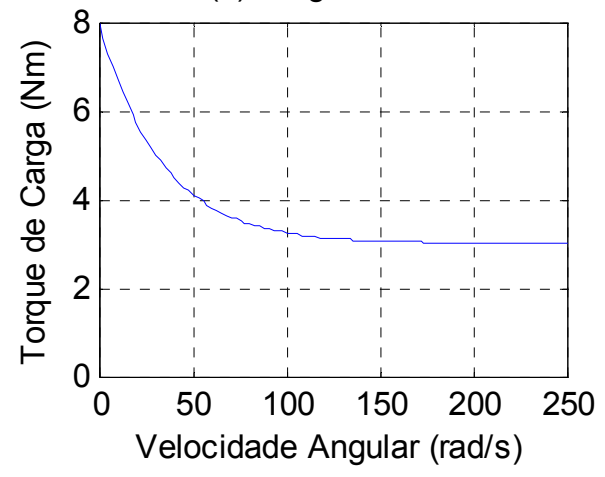

(b) Carga Linear

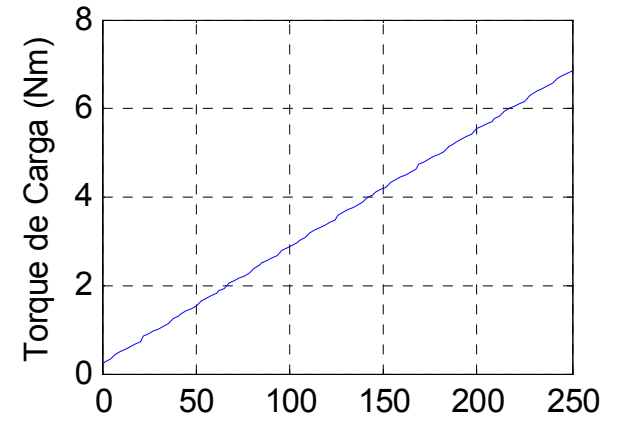

(d) Carga Constante

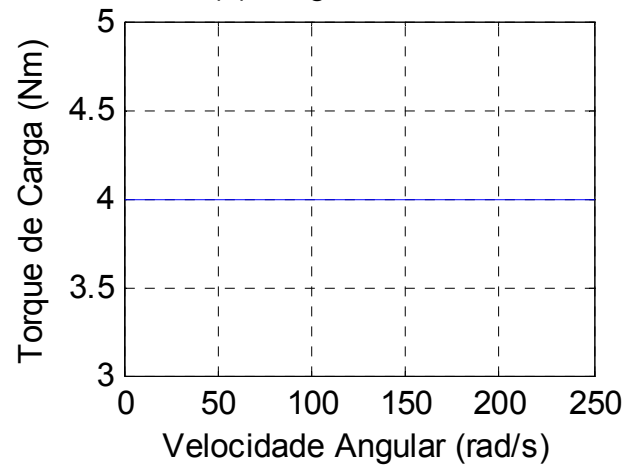

Figura 2.14 - Tipos de cargas empregadas na simulação. 


\section{Aspectos da Bancada de Ensaios Experimentais}

Nesta seção será explicitada a descrição dos principais componentes da estrutura do laboratório envolvidos no processo de aquisição de dados experimentais que serão aplicados para o estudo e a modelagem do sistema de controle inteligente de velocidade da máquina de indução, além de contribuir para o desenvolvimento de trabalhos paralelos desenvolvidos pelos integrantes do grupo de pesquisa.

A Figura 3.1 ilustra de maneira genérica a forma em que o laboratório de ensaios de máquinas elétricas está estruturado. A estrutura do laboratório de pesquisa consiste de uma bancada de ensaios, na qual se situa a máquina de indução trifásica, a máquina de corrente contínua, encoder e torquímetro; um quadro de comando no qual podem ser realizados o ajuste da tensão aplicada no motor e a maneira em que a mesma é alimentada; um circuito de alimentação da bobina de campo do gerador de corrente contínua, cuja carga é conectada à bobina de armadura; os circuitos aplicados para o condicionamento dos sinais dos sensores para a placa de aquisição de dados localizada no computador. 


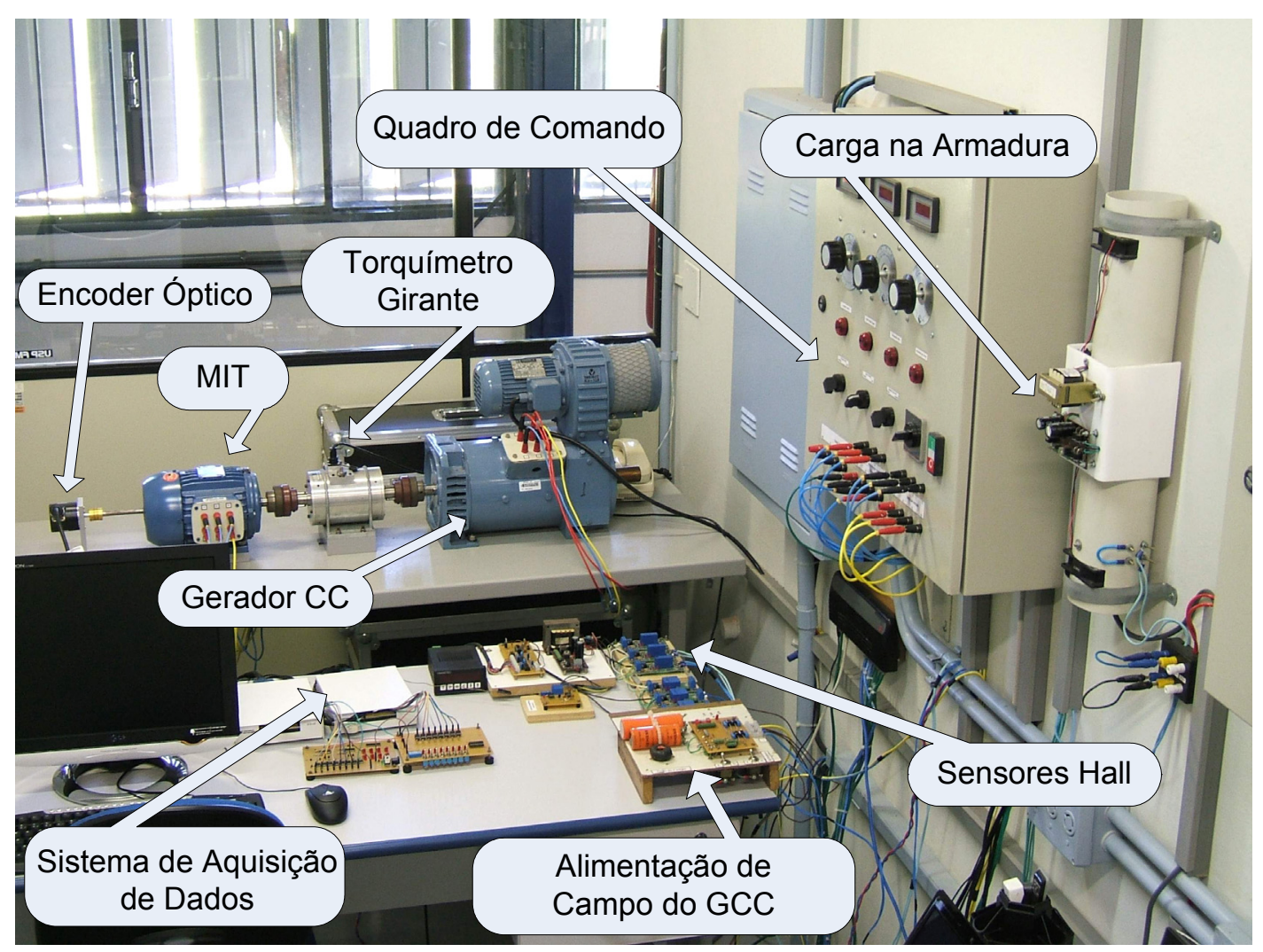

Figura 3.1 - Esquema geral do laboratório de ensaios de máquinas elétricas.

Nos seções seguintes serão discutidos com mais detalhes os principais itens contidos no laboratório de pesquisa. Deve ser ressaltado que esta estrutura é derivada de dois projetos FAPESP (Processos 05/58404-3 e 06/56093-3) e que estava inicialmente alocada na UNESP, Campus de Bauru. Toda a estrutura foi transportada para a USP, Campus de São Carlos, atual local de pesquisa, no segundo semestre de 2006, tendo de ser instalada e ajustada pelos próprios integrantes do grupo de pesquisa na nova localização. Deve-se também registrar que algumas das seções deste capítulo foram inspiradas a partir do trabalho de Goedtel (2007).

\subsection{A Bancada de Ensaios}

A bancada de ensaios é composta basicamente pela máquina de corrente contínua, motor de indução, torquímetro e encoder. A máquina de corrente contínua 
é utilizada como gerador, cujo eixo é acoplado ao MIT do tipo Gaiola de Esquilo por meio de um torquímetro girante. O gerador de corrente contínua (GCC) objetiva simular uma determinada carga acoplada ao eixo do MIT, pois o torque resistente imposto pelo gerador pode ser controlado conforme a sua carga acoplada no enrolamento de armadura ou mediante a variação de tensão do enrolamento de campo (Goedtel, 2007). Desta forma, é possível atribuir um torque resistente no eixo do MIT de forma a produzir conjugados de cargas do tipo constante, linear, quadrática ou inversa, as quais são mais comumente encontradas em aplicações industriais.

A Figura 3.2 ilustra a foto da bancada de ensaios. O bloco de refrigeração é composto por um motor de indução trifásico de 1/3 de cv, no qual está acoplado um ventilador. A entrada de ar é filtrada por meio de fibra sintética. Este dispositivo tem por finalidade o arrefecimento do calor gerado na MCC. O seu acionamento é obtido de forma independente com uma chave no painel de comando, tendo como inconveniente o ruído gerado em ensaios de longo prazo.

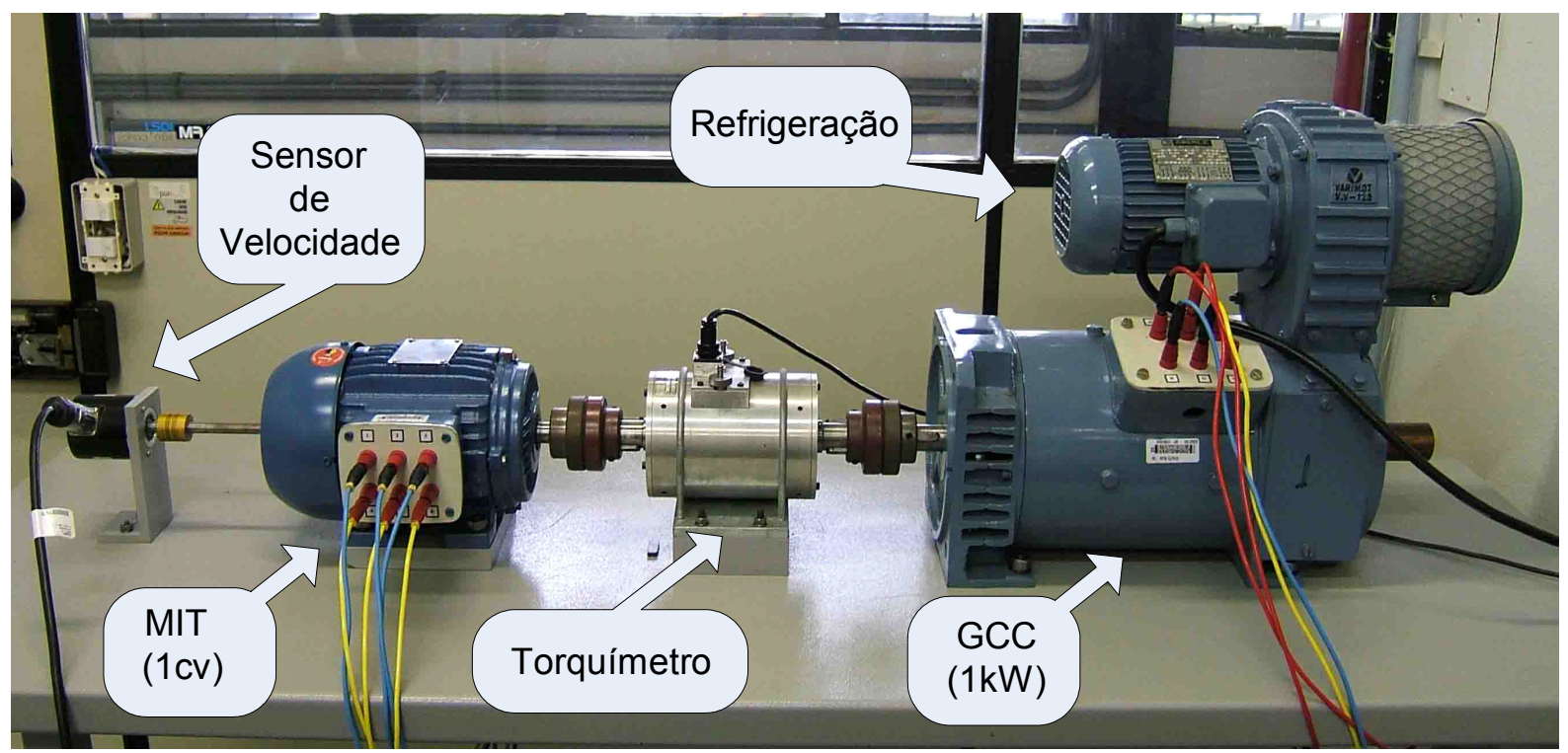

Figura 3.2 - Visão geral da estrutura da bancada de ensaios. 


\subsection{Quadro de Comando}

O quadro de comando é responsável pelo controle de modo que a máquina de indução possa ser acionada. A Figura 3.3 ilustra os principais componentes do quadro de comando, o qual constitui de chave geral, displays de informações, variadores de tensão, luzes de sinalizações, chaves seletoras, saídas trifásicas, conexões com o inversor e conexões com o motor de indução e chaves seletoras entre as conexões estrela-triângulo.

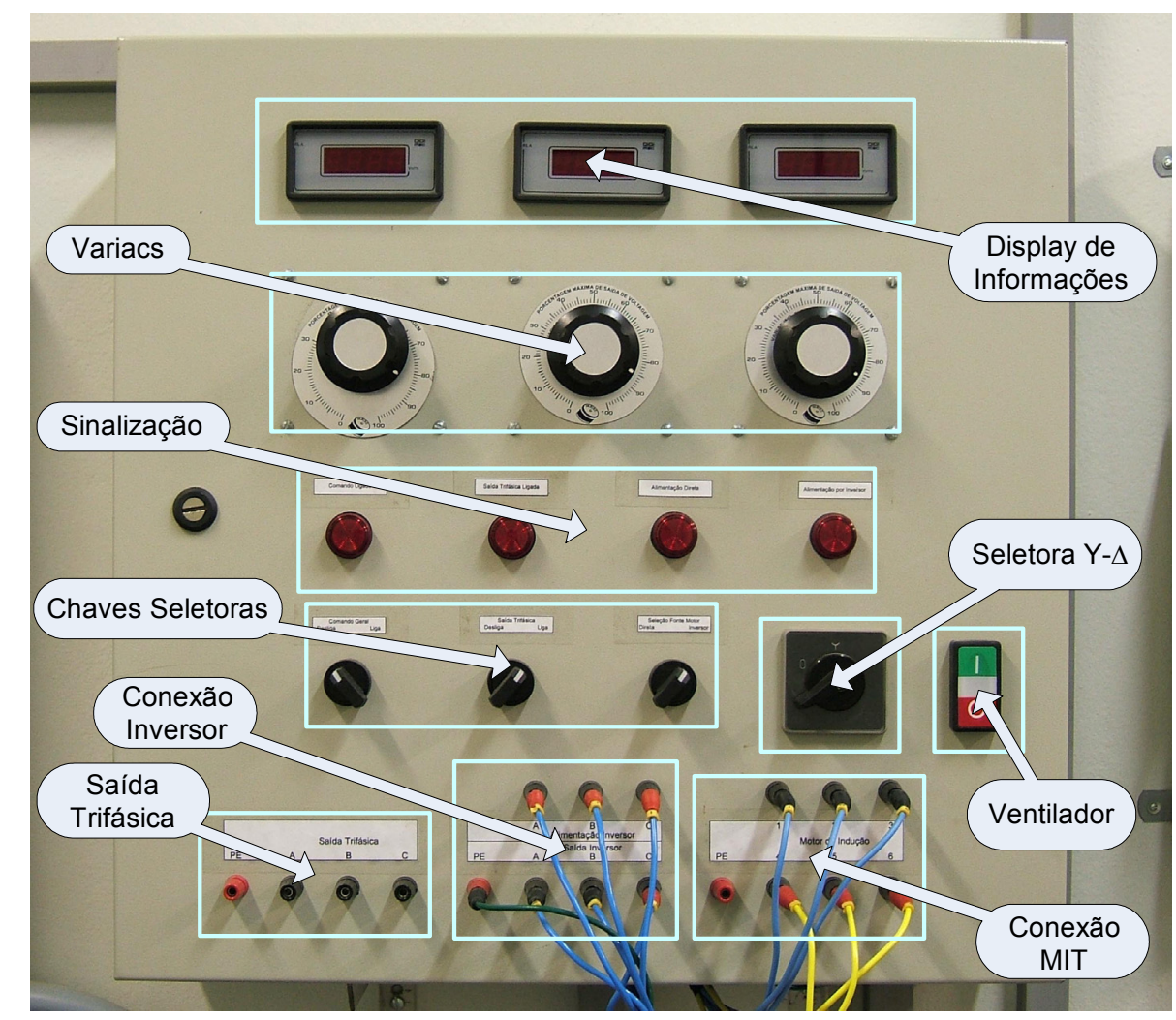

Figura 3.3 - Descrição do quadro de comando.

Nos displays de informações serão apresentados os valores da tensão de cada fase que são ajustadas pelos variadores de tensão localizados logo abaixo.

As chaves seletoras fornecem opções de ligar/desligar o comando geral, se a saída trifásica é ativada ou não, e se a fonte de alimentação do motor de indução será efetuada diretamente das fases ou pelo inversor de freqüência. 
As luzes de sinalização indicam ao operador as opções descritas pela chave seletora e se o quadro de comando está energizado ou não. Estas sinalizações são importantes para alertar o operador para que não efetue conexões equivocadas ou até mesmo evitar acidentes de trabalho.

A característica atraente do quadro de comando reside no fato de que, caso o operador decida mudar o modo de operação da máquina de indução, não há a necessidade de rearranjar todas as conexões. Por exemplo, a mudança de conexões de acionamento da máquina de indução de estrela para triângulo é realizada por meio de uma simples mudança na chave seletora, pois essas conexões são feitas internamente ao quadro de comando.

\subsection{Excitação do Enrolamento de Campo do GCC}

A fonte de corrente contínua empregada para alimentar o enrolamento de campo consiste de uma estrutura composta por quatro diodos (6 A - $600 \mathrm{~V}$ ), dois capacitores de $350 \mu \mathrm{F}$ x $400 \mathrm{~V}$ e $250 \mu \mathrm{F}$ x 450V, e um filtro $\pi$ formado por um indutor enrolado em um núcleo toroidal (Goedtel, 2007), conforme ilustrada na Figura 3.4.

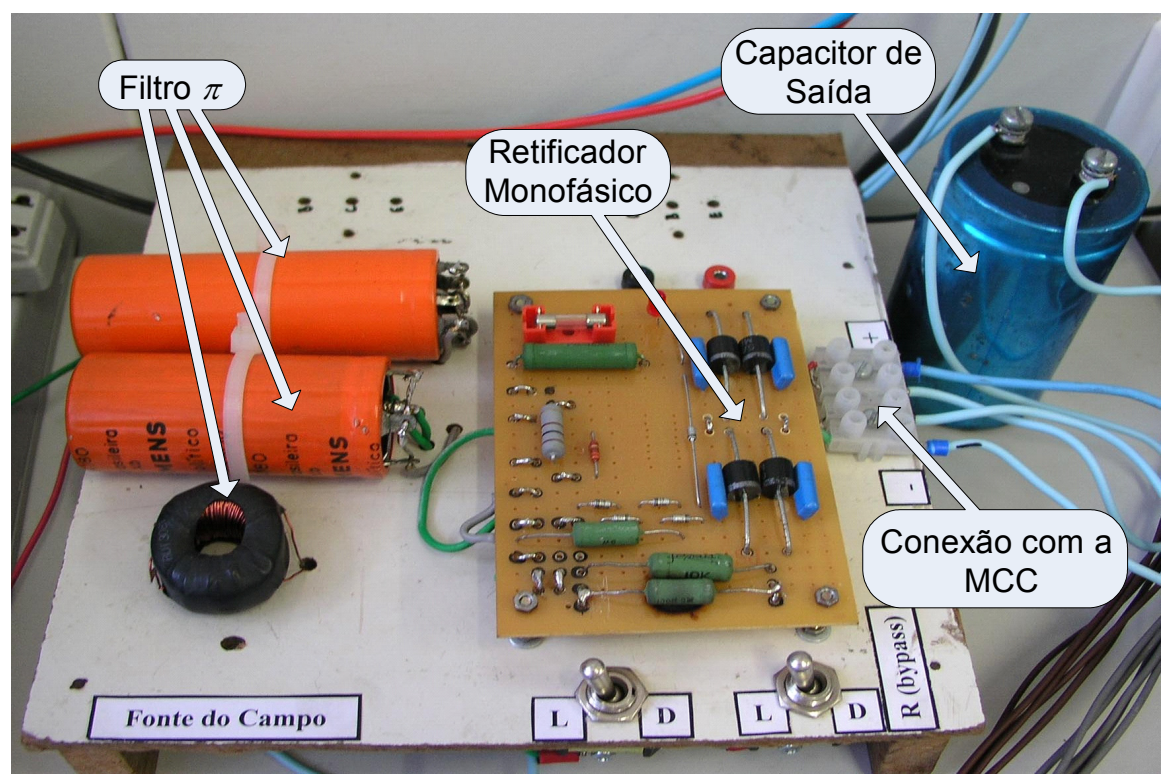

Figura 3.4 - Fonte de alimentação de campo. 
Um filtro capacitivo no valor de $400 \mu \mathrm{F} \times 200 \mathrm{~V}$ foi inserido na saída da ponte retificadora com o intuito de reduzir o ripple de tensão a um valor adequado para a alimentação do enrolamento de campo da máquina.

O valor da tensão de saída pode ser regulado por meio de um variador de tensão monofásico conectado na entrada da ponte retificadora. $\mathrm{O}$ variador de tensão, ilustrado na Figura 3.5, quando alimentado por tensões alternadas de 220 Vrms, pode ser ajustado para produzir uma faixa de tensão de até $240 \mathrm{Vrms}$. A potência do equipamento é de $1800 \mathrm{~W}$, sendo suficiente para realização de diversos tipos de ensaios experimentais de trabalhos desenvolvidos no grupo de pesquisa.

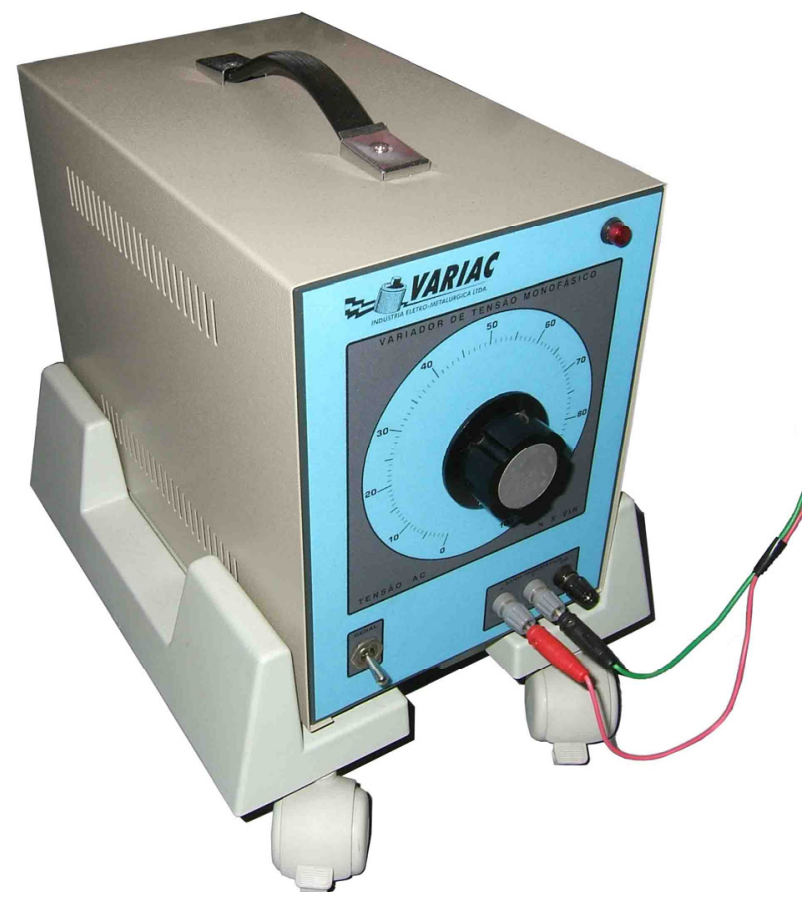

Figura 3.5 - Variador de tensão monofásico.

O variador de tensão monofásico desempenha um papel relevante para efetuar a variação da tensão de alimentação do enrolamento de campo, e conseqüentemente, proporcionar a variação do torque eletromagnético desenvolvida pelo GCC que será imposta ao eixo do MIT. 


\subsection{Circuito de Carga na Armadura do GCC}

A carga conectada no enrolamento de armadura do GCC é composta por uma resistência de chuveiro alocada no interior de um tubo de PVC, conforme ilustrada na Figura 3.6. Nas extremidades desta estrutura são fixados dois coolers (ventoinhas) do tipo encontrados em computadores pessoais, e em sua parte central se encontra uma fonte de $12 \mathrm{~V}$ responsável pelo acionamento do sistema de arrefecimento.

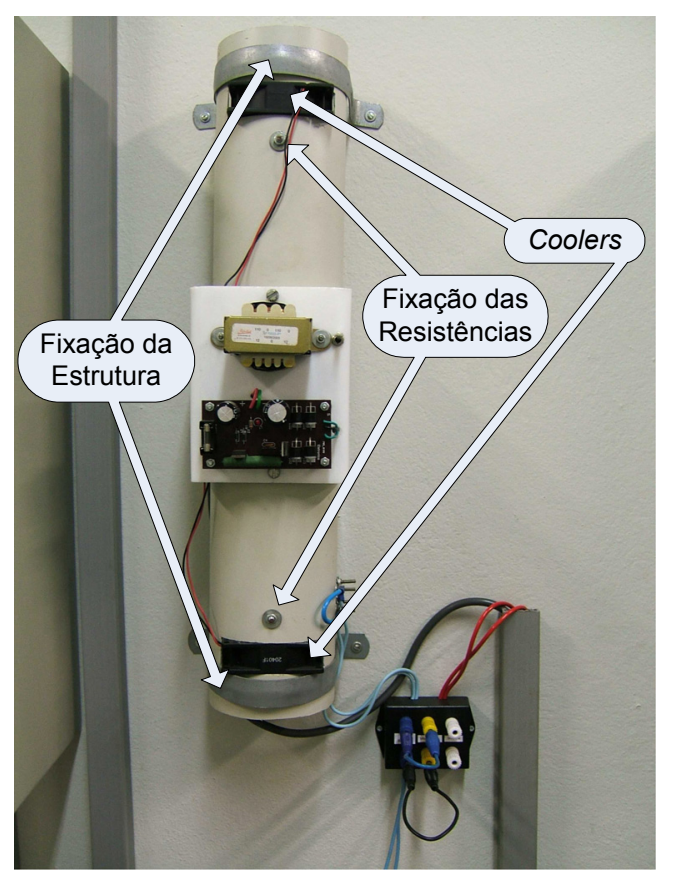

Figura 3.6 - Carga resistiva para o enrolamento de armadura.

\subsection{Sensores Hall de Corrente e Tensão}

O sensor Hall é um transdutor que se baseia na variação da sua tensão de saída em resposta às mudanças na densidade de fluxo magnético. Estes são comumente aplicados em sistemas de posicionamento, detecção de velocidade, medição de tensão e corrente elétrica. A capacidade de medir corrente contínua ou 
alternada com grande precisão a uma ampla largura de banda é a atraente característica na sua aplicação.

\section{- Sensor Hall de Corrente}

O sensor Hall de corrente utilizado na bancada de experimentos (Goedtel, 2007) é o LAH-25 NP do fabricante LEM. A corrente nominal deste dispositivo é de 25A. O condicionamento de sinal é realizado utilizando-se o amplificador operacional TL081 com ajuste de offset.

Durante o processo de desenvolvimento da placa, foram realizados a calibragem e o ajuste fino do desvio do dispositivo, e após a montagem completa com todos os elementos soldados, efetuaram-se testes para a determinação da precisão dos sensores. Como não há controle de ganho na saída dos sensores, não há controle sobre o erro de cada sensor. Entretanto, a correção é realizada via software, a qual é uma técnica muito utilizada em equipamentos industriais e que apresenta um baixo custo de condicionamento de sinal.

A Figura 3.7 representa um esquema ilustrativo dos sensores Hall de corrente utilizado neste projeto de pesquisa.

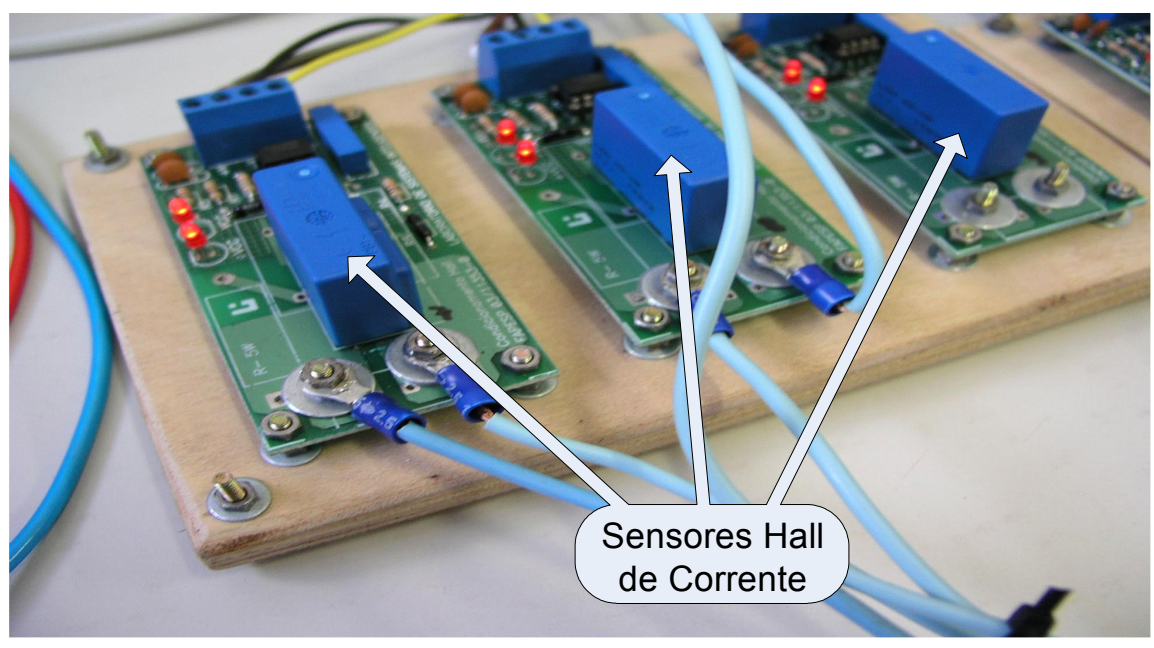

Figura 3.7 - Sensores Hall de corrente. 


\section{- Sensor Hall de Tensão}

O sensor Hall de tensão utilizado neste trabalho é o LV-20P do fabricante LEM. Assim como descrito no sensor Hall de corrente, utilizou-se uma placa responsável pelo condicionamento de sinal dos sensores Hall. A mesma placa é adaptada para receber os sinais dos sensores Hall tanto de corrente quanto de tensão, já que, desta forma, o custo de fabricação dos sensores seria reduzido. Esta metodologia é aplicada na indústria eletro-eletrônica com bastante freqüência.

Embora os dois sensores sejam diferentes, o seu princípio de funcionamento é semelhante. Em virtude disso, os mesmos ensaios realizados com o sensor Hall de corrente foram realizados com o sensor Hall de tensão com o intuito de se determinar a precisão e a confiabilidade do equipamento.

A Figura 3.8 representa um esquema ilustrativo dos sensores Hall de tensão utilizado neste projeto de pesquisa.

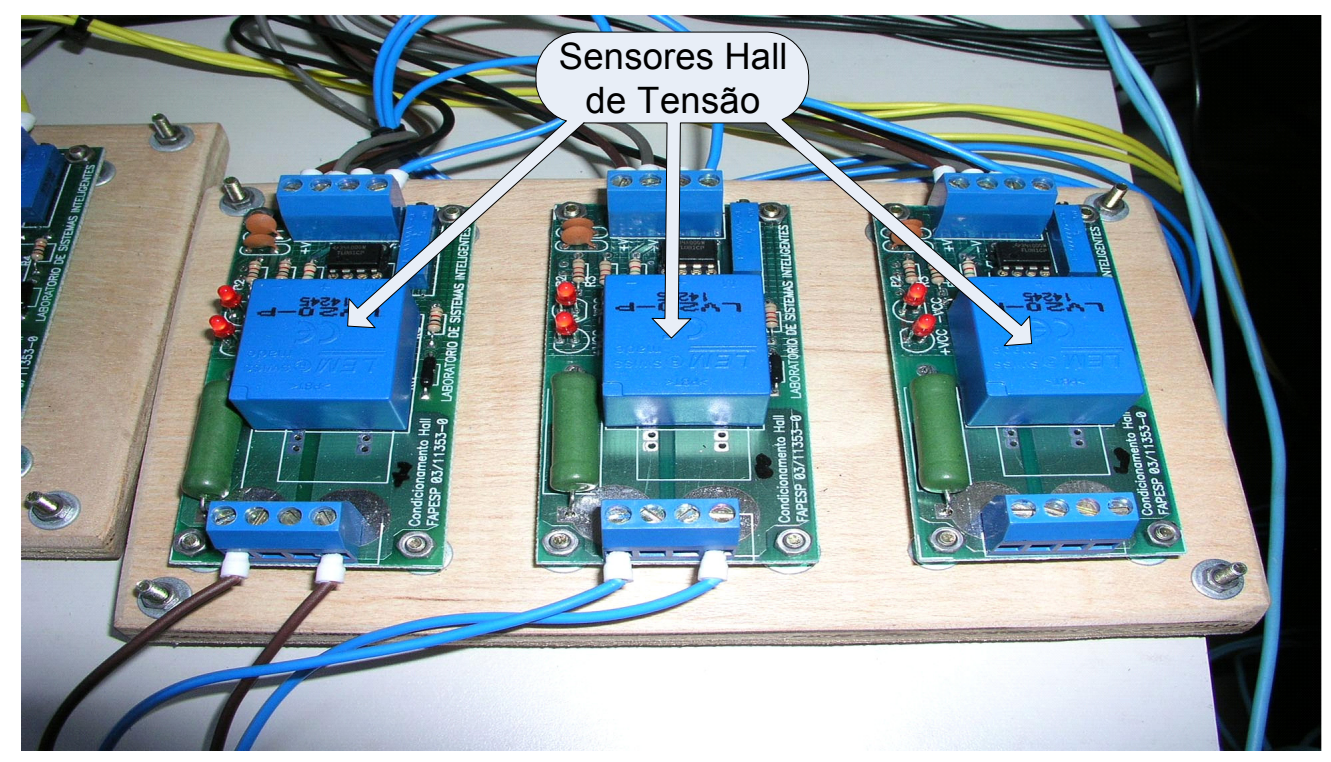

Figura 3.8 - Sensores Hall de tensão. 


\subsection{Encoder Óptico Incremental}

Os encoders ópticos são dispositivos eletromecânicos que convertem o movimento ou posição angular em uma série de pulsos gerados por meio de feixes de luzes que atravessam o encoder para iluminar fotossensores individuais. Basicamente, existem dois tipos de configurações: encoders ópticos lineares e encoders ópticos rotativos, sendo este último o mais usualmente aplicados na prática.

Dentre os encoders ópticos rotativos, podem ser encontrados dois tipos: o absoluto e o incremental. No primeiro, uma palavra ou seqüência de bits corresponde univocamente a uma posição do eixo em relação a uma determinada referência. Já no segundo, é produzida uma seqüência de pulsos cuja freqüência varia de forma proporcional à velocidade de rotação do eixo, motivo pelo qual este é o tipo aplicado neste trabalho, uma vez que há a necessidade de se medir a velocidade no eixo do motor de indução trifásico.

A Figura 3.9 representa o diagrama esquemático do funcionamento do encoder óptico incremental. Observa-se que os pulsos gerados pelo canal A são 90 graus defasado em relação ao canal B, cujo propósito consiste na determinação do sentido de rotação do eixo, a qual é realizada mediante a detecção de bordas de transição de níveis. O sentido de rotação será direto caso os pulsos do canal $A$ passa do nível baixo para o nível alto antes que os pulsos do canal B. Caso contrário, determina-se que o sentido de rotação é inverso. O último canal representado pela letra $Z$ sinaliza a indicação de uma volta completa. Este sinal é utilizado principalmente em medições de posição angular. 


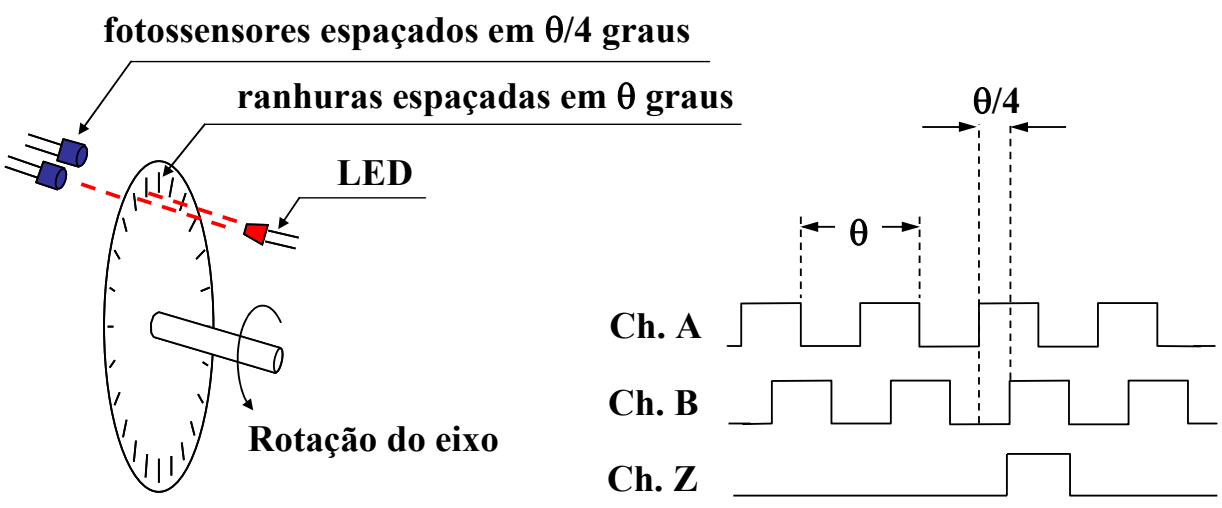

Encoder Óptico Incremental

Forma de onda na saída dos sensores

Figura 3.9 - Funcionamento do encoder óptico incremental.

Fonte:(Bormann, 2005)

O modelo do encoder óptico utilizado neste trabalho consiste no T8-5800, cujas principais características consistem na tolerância a grandes esforços axiais e radiais, o que propicia uma maior vida útil do dispositivo; e a saída do tipo push-pull, o que aumenta a imunidade ao ruído. O encoder utilizado desenvolve 2000 pulsos por rotação com saída A.A. $\bar{B} \cdot \bar{B}, Z . \bar{Z}$. A Figura 3.10 ilustra a foto do encoder óptico incremental do laboratório de pesquisa.

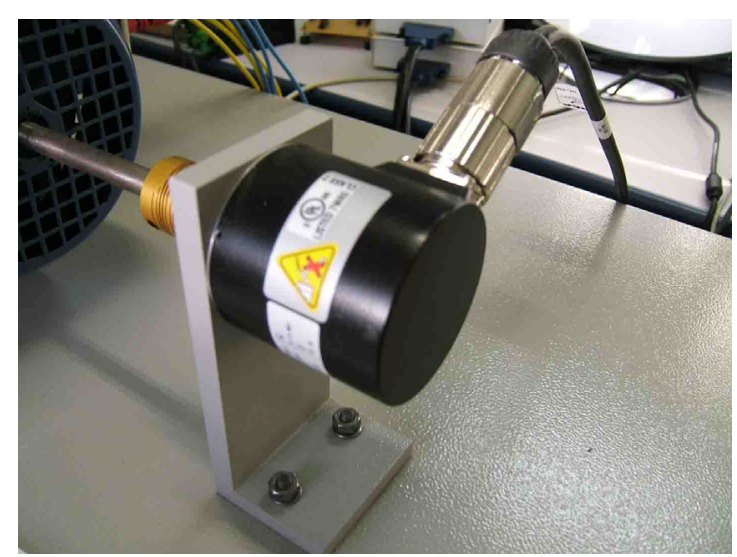

Figura 3.10 - Encoder óptico incremental T8-5800.

Como exemplo, seja uma máquina de indução trifásica de 4 pólos com rotação síncrona de $1800 \mathrm{rpm}$, o que equivale a 30 rotações por segundo. Isso 
produziria 60.000 pulsos por segundo $(60 \mathrm{kHz})$ em um encoder de 2000 pulsos por rotação.

\subsection{Sistema de Aquisição de Dados}

O sistema de aquisição de dados é de suma importância para efetuar análises e validação dos ensaios experimentais. O laboratório de pesquisa é equipado por uma placa de aquisição de dados da National Instruments do modelo NIDAQmx PCle-6259 que dispõe de uma quantidade de canais analógicos suficientes para aferição de diversos sinais envolvidos nos ensaios realizados.

As principais características da placa de aquisição de dados NIDAQmx PCle-6269 consistem na presença de 32 canais analógicos de entrada de 16 bits com taxa de aquisição de 1,25 mega-amostras por segundo; 4 canais analógicos de saída de 16 bits com taxa de 2,8 mega-amostras por segundo, e 48 canais de I/O digitais com capacidade de operar na freqüência de clock de até $10 \mathrm{MHz}$.

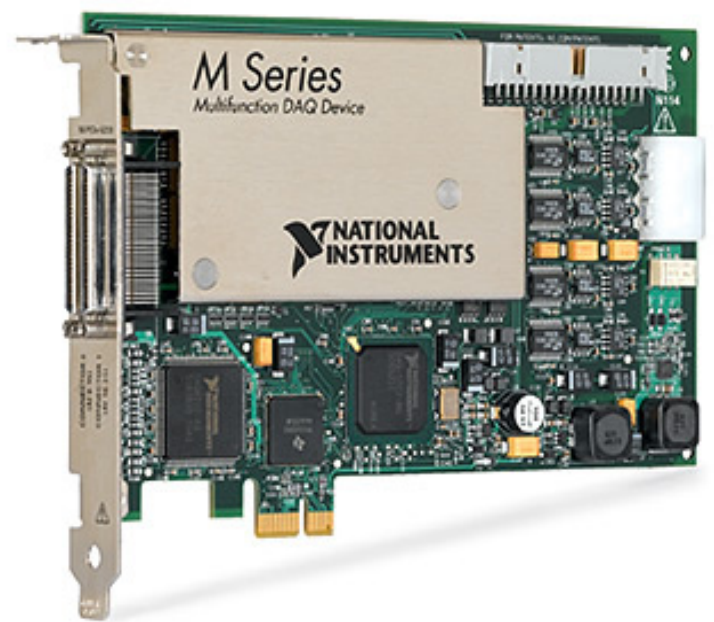

Figura 3.11 - Placa de aquisição de dados NIDAQmx PCle-6259.

A placa NIDAQmx PCle-6259 é conectada no barramento PCl-Express do computador. Desta forma, as interconexões com os dispositivos externos são realizadas por um bloco conector SCB-68 ilustrado pela Figura 3.12. Em tal bloco, 
além da interface de conexões relativas a todas as portas analógicas e digitais, permite-se a implementação de filtros de sinais em hardware.

Os sinais simultaneamente adquiridos pela placa de aquisição de dados consistem basicamente nas tensões e correntes das três fases do motor de indução antes do inversor trifásico, tensões e correntes de campo e armadura do gerador de corrente contínua, torque de carga mensurada pelo torquímetro, e finalmente a velocidade angular aferida pelo encoder óptico incremental.

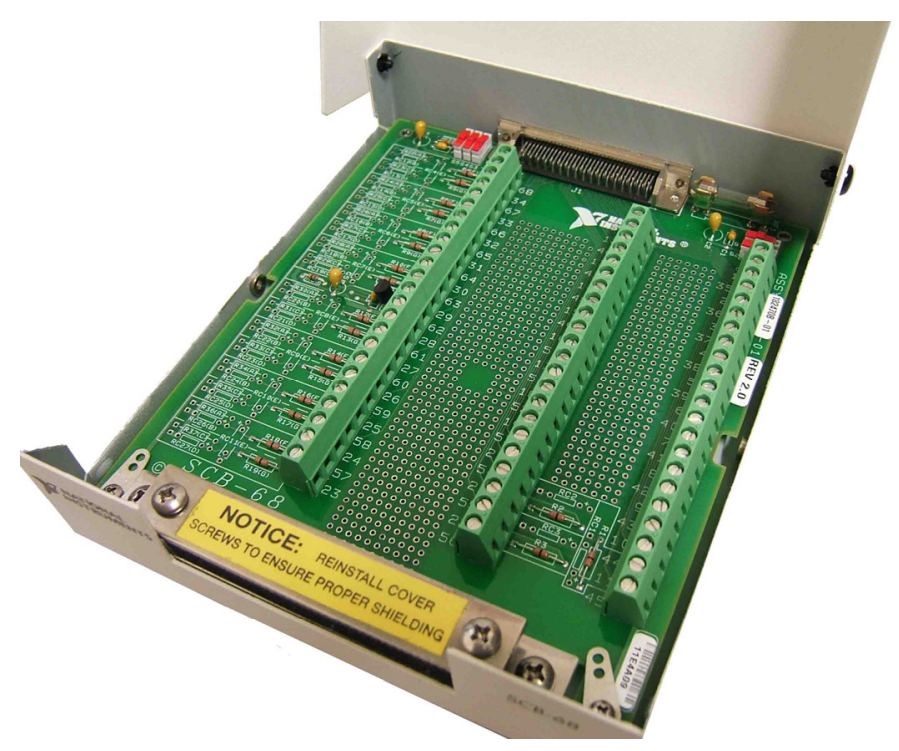

Figura 3.12 - Bloco de conexões SCB-68.

\subsection{Hardware de Interface com o DSP}

As portas digitais do DSP da Texas Instruments trabalham com tensões de 3,3 V para representar o nível lógico 1 e 0,0 V para o nível lógico 0. Desta forma, torna-se interessante desenvolver uma placa de interface com o sinal TTL, o qual é empregado na maioria das aplicações. Além disso, a implementação de um circuito de interface, isoladas de entrada/saída, é extremamente relevante no que diz 
respeito à proteção do DSP contra eventuais sobretensões ou erro de conexões efetuadas pelo operador.

O circuito de interface de uma entrada (1bit) digital opto-acoplada desenvolvida nesta dissertação é ilustrada na Figura 3.13. Os dispositivos externos que trabalham com sinal TTL são conectados nas portas INOPT e as entradas digitais do DSP são conectadas no emissor do transistor interno ao opto-acoplador 4N25. Quando um sinal TTL de entrada de nível lógico 1 (5 V) aciona o LED, o transistor entra na região de saturação fornecendo uma tensão de aproximadamente 3,3 V no emissor. Por outro lado, quando o LED não está polarizado, o transistor trabalha em corte proporcionando uma tensão nula no emissor. Cabe salientar que a referência do dispositivo TTL é diferente da referência do DSP, o que garante a isolação elétrica entre os dois dispositivos.

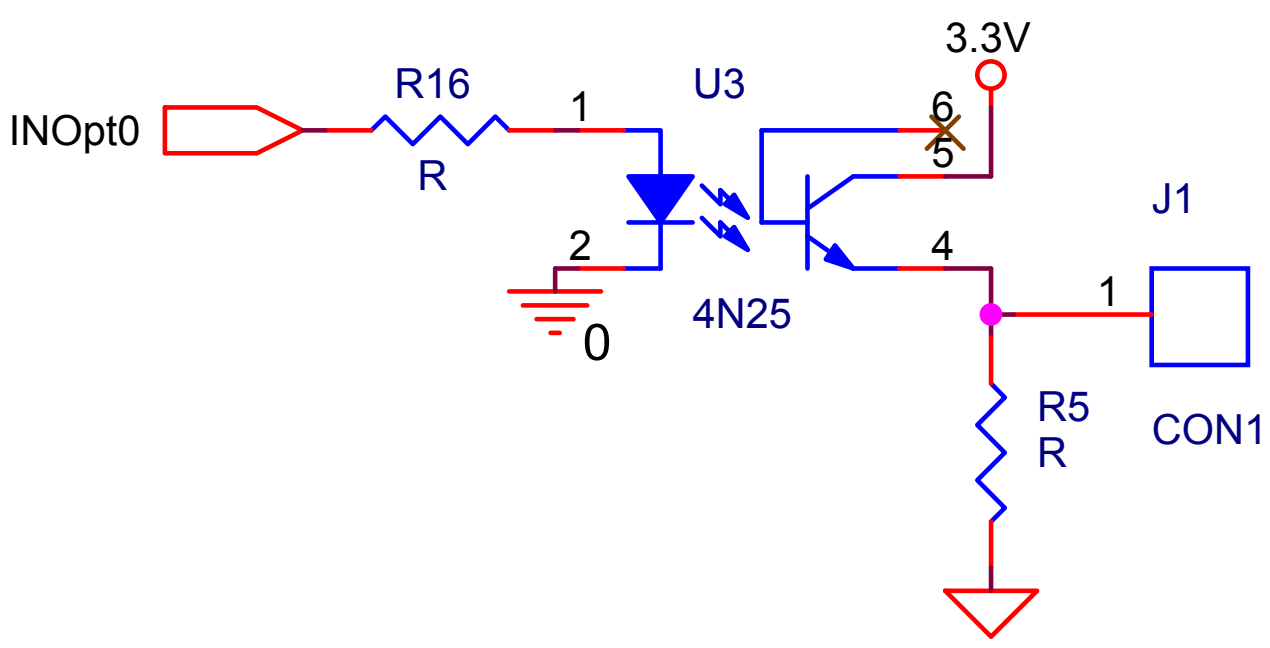

Figura 3.13 - Interface de entrada digital opto-acoplada.

Com base no circuito da Figura 3.13, desenvolveu-se uma placa de interface de entrada digital opto-acoplada de 8 bits, conforme ilustrada na Figura 3.14. Esta se constitui de LEDs sinalizadores das entradas ativas e interface com dispositivos TTL externos. 


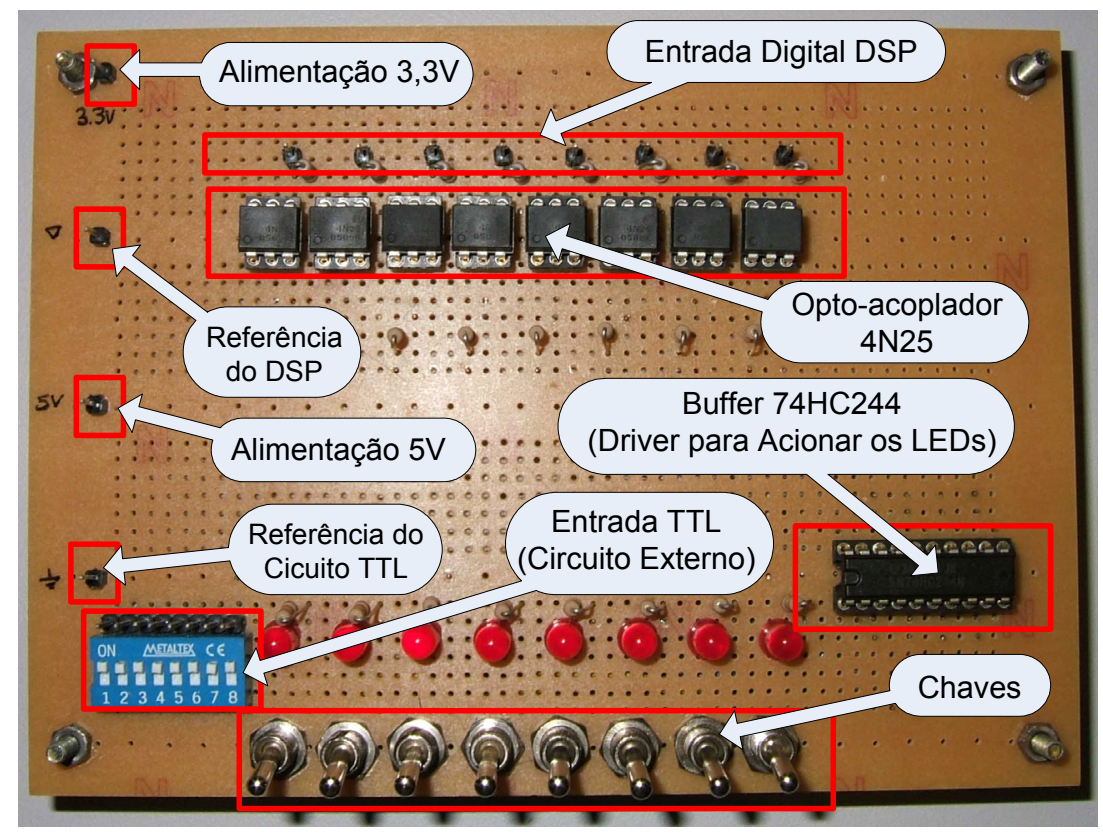

Figura 3.14 - Placa de interface de entrada digital opto-acoplada.

As chaves são utilizadas no caso em que se deseja realizar um teste rápido e simples com o DSP. Desta forma, ao invés de se conectar um dispositivo externo para gerar um determinado sinal TTL, basta ligar ou desligar as chaves. A alimentação de 3,3 V é fornecida pelo próprio Kit ezDSP da Spectrum Digital, e a alimentação de $5 \mathrm{~V}$ deve ser fornecida por uma fonte externa.

Por outro lado, o circuito de interface de uma saída (1bit) digital optoacoplada para um dispositivo TTL é ilustrado na Figura 3.15. A saída digital do DSP

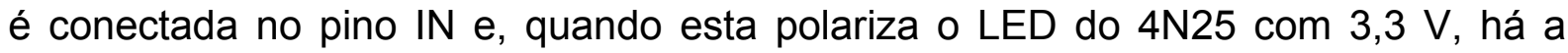
saturação do transistor que fornece então nível lógico 0 em seu coletor. $O$ circuito integrado 74HC132 de porta lógica NAND funciona como inversora, proporcionando nível lógico 1 TTL na saída da interface. 


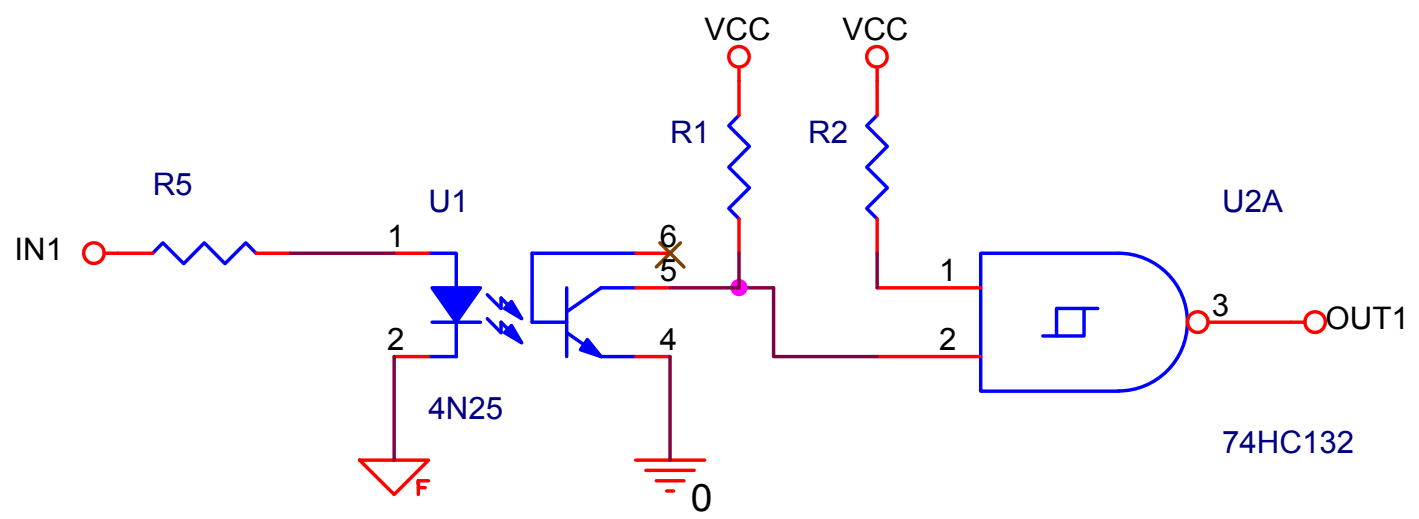

Figura 3.15 - Interface de saída digital opto-acoplada.

A partir do circuito da Figura 3.15, implementou-se uma placa de interface de saída digital opto-acoplada de 8 bits, conforme ilustrado na Figura 3.16. A placa de interface apresenta LEDs sinalizadores de saídas ativas, cujo objetivo é facilitar a análise do projeto em desenvolvimento. O circuito TTL é alimentado a partir do regulador de $5 \mathrm{~V}$ situado na diagonal superior esquerda da Figura 3.16.

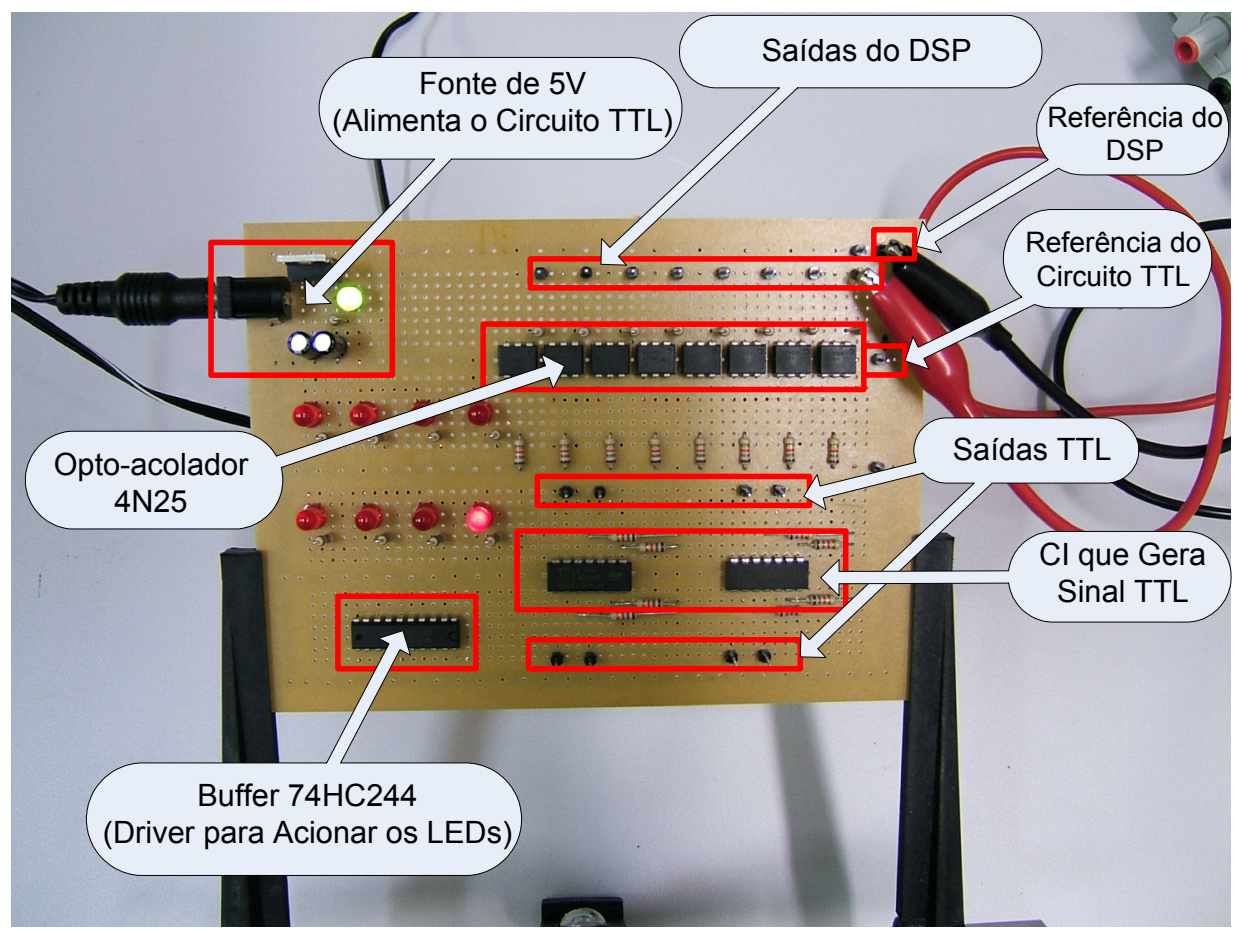

Figura 3.16 - Placa de Interface opto-acoplada de saída digital. 


\subsection{Inversor Trifásico}

O módulo de inversor trifásico empregado para desenvolver o acionamento do MIT consiste no inversor da Semikron SKS 26F B6U+B6Cl+E1CIF*2 10V6 ilustrado na Figura 3.17.

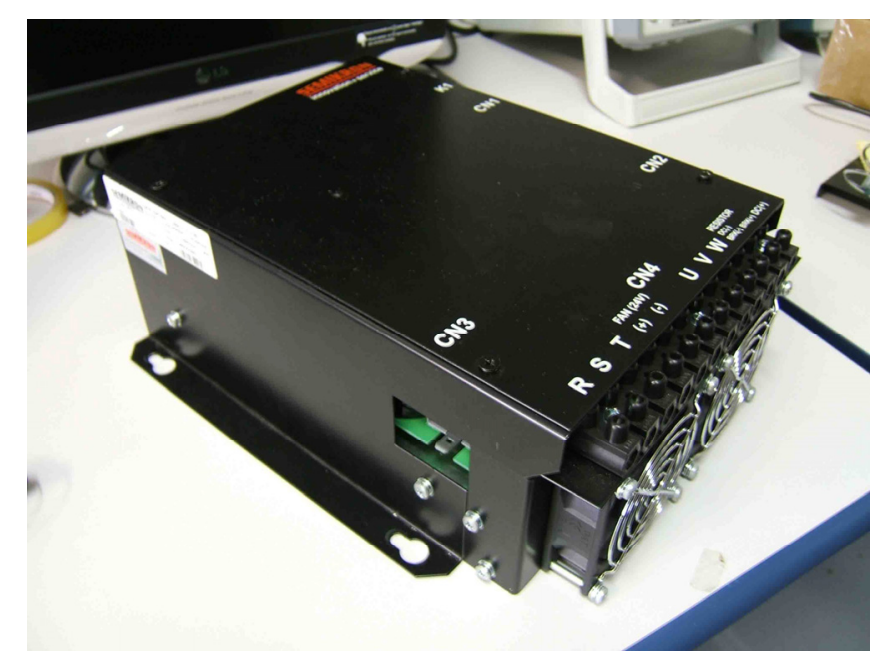

Figura 3.17 - Inversor trifásico da Semikron.

Suas principais especificações consistem na capacidade de corrente de saída de 26 A, tensão RMS de entrada do circuito retificador trifásico de $250 \mathrm{~V}$ e freqüência máxima de chaveamento de $20 \mathrm{kHz}$, sendo $10 \mathrm{kHz}$ recomendada pelo fabricante. A tensão máxima suportada no banco de capacitores do barramento CC é de $350 \mathrm{~V}$.

O diagrama esquemático do inversor trifásico é representado na Figura 3.18. As três fases da rede de alimentação são conectadas nos terminais $R, S$ e T. A tensão trifásica é retificada e convertida em tensão contínua no barramento $\mathrm{CC}$ do inversor. O acionamento do motor de indução é realizado mediante o chaveamento dos IGBTs Q1-Q6, cujas conexões com as bobinas são efetuadas mediante os terminais $\mathrm{U}, \mathrm{V}$ e $\mathrm{W}$. 
No momento em que o inversor é energizado, o banco de capacitores do barramento CC é carregado por meio do resistor R para limitar a corrente de InRush. Desta forma, após um período de tempo, o IGBT Q7 deve ser acionado para que a corrente de carga dos capacitores seja desviada do resistor.

O acionamento dos IGBTs Q1, Q2 e Q8 é realizado pelo driver associado aos conectores de CN1. O driver do Canal K1 é utilizado apenas para acionar o IGBT Q7. Os IGBT remanescentes podem ser comandados por meio dos drivers relativos ao canal $\mathrm{CN} 2$. O inversor também dispõe de sensores Hall de tensão internos que podem ser acessados pelos terminais do canal CN3.

A alimentação dos drivers é efetuada por meio de uma fonte de tensão contínua externa de $15 \mathrm{~V}$, já os sensores Hall requerem alimentação simétrica de +15 V e -15 V. A tensão de comando seguem a lógica CMOS, cujo nível alto é de $15 \mathrm{~V}$ e nível baixo consiste de $0 \mathrm{~V}$. Uma fonte de $24 \mathrm{~V}$ é requerida no caso em que se deseja acionar as ventoinhas para realizar a refrigeração forçada.

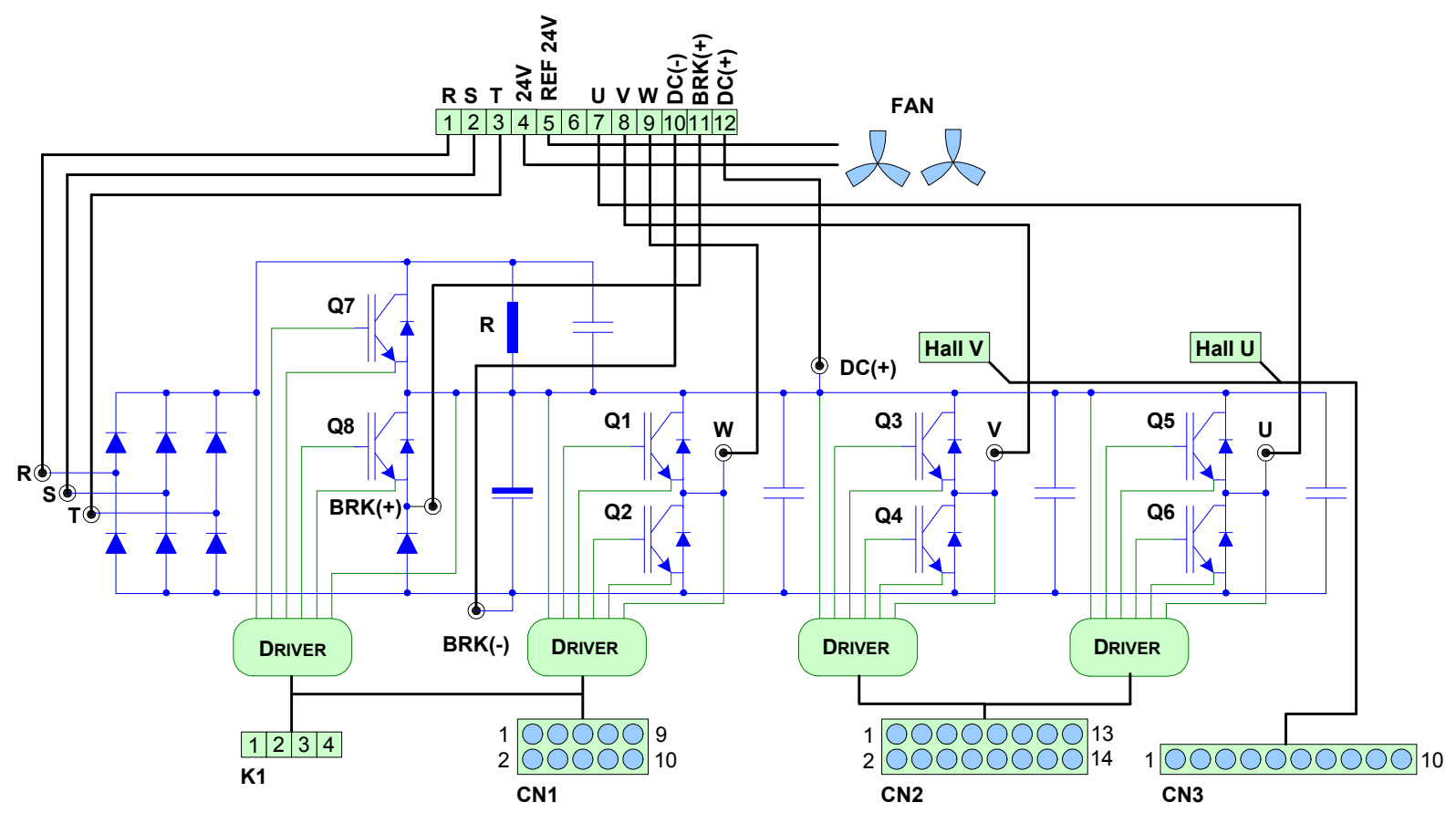

Figura 3.18 - Diagrama esquemático do inversor trifásico. 
Os drivers dos inversores da Semikron são acompanhados por um sistema de proteção contra inter-travamento que evita o acionamento simultâneo dos IGBTs superiores e inferiores por meio de emprego de um período de tempo morto (deadtime) de $4 \mu \mathrm{s}$. Além disso, no pior caso em que este fenômeno ocorra, o driver sinaliza ao sistema de acionamento para tomar medidas de desligamento de ambos os IGBTs. Desta forma, o inversor adquirido é bem protegido e robusto o suficiente para ser utilizado em ensaios experimentais de laboratório. 



\section{Abordagem Desenvolvida para Controle de Velocidade do MIT}

\subsection{Aspectos Fundamentais do Sistema Fuzzy}

O conceito de conjuntos fuzzy, introduzido em 1965 por Lofti A. Zadeh na Universidade da Califórnia em Berkeley, possibilitou o desenvolvimento de sistemas para solucionar problemas de diversas áreas de aplicações, tais como a automação e controle, a classificação de dados, a análise de decisão e a visão computacional.

Os sistemas fuzzy consistem de uma representação computacional inspirada na forma em que o raciocínio humano processa as informações em tomadas de decisões. Ao contrário da maioria dos métodos convencionais, cujas decisões são enquadradas em apenas um "sim" ou "não", são permitidas considerações abstratas representadas lingüisticamente, tais como "próximo de", "alto", "baixo", etc. O grau de pertinência a tais conjuntos lingüísticos é expresso numericamente por um intervalo de valor unitário variando entre 0 e 1 , na qual o valor 0 representa a exclusão e o valor 1 denota a inclusão total ao conjunto (Brown e Harris, 1994; Tsoukalas e Uhrig, 1997).

Desta forma, pela teoria clássica dos conjuntos, a expressão que define a função característica de um dado elemento pertencer ou não a um conjunto é definida formalmente como se segue. 
Considere um universo $U$, um elemento particular $x \in U$ e um conjunto $A \subseteq U$. A função característica $u_{A}(x): U \rightarrow\{0,1\}$ com relação ao conjunto $A$ é dado por:

$$
\left\{\begin{array}{l}
u_{A}(x)=1, \text { se } x \in A \\
u_{A}(x)=0, \text { se } x \notin A
\end{array}\right.
$$

cuja representação gráfica da função característica na teoria clássica dos conjuntos é ilustrada pela Figura 4.1. Nota-se que os valores rigorosamente abaixo de $m$ não pertencem ao conjunto $A$, ao passo que os valores acima de $m$ pertencem ao conjunto $A$.

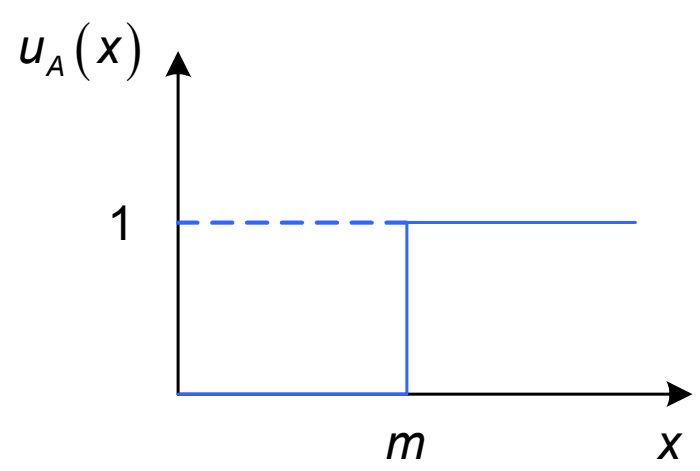

Figura 4.1 - Função característica da teoria clássica dos conjuntos.

Por outro lado, a proposição apresentada por Zadeh possui uma caracterização mais ampla, sugerindo que o conjunto $A$ não seja delimitado por uma faixa de valores bem definidos, mas que um determinado valor de $x$ possua uma pertinência ao conjunto $A$ com um grau definido entre 0 e 1 , conforme descrito a seguir:

$$
u_{A}(x): x \rightarrow[0,1] ; x \in X
$$

onde $u_{A}(x)$ representa o grau de pertinência de $x$ ao conjunto $A$, sendo $X$ o seu universo de discurso de definição. 
A função que define o relacionamento entre a variável $x$ e o grau de pertinência $u(x)$ a um determinado conjunto $A$ é denominada de função de pertinência. Os principais formatos utilizados na prática são as funções triangulares, trapezoidais e as gaussianas (Brown e Harris, 1994; Tsoukalas e Uhrig, 1997; Mathworks, 2007), conforme ilustrados na Figura 4.2.
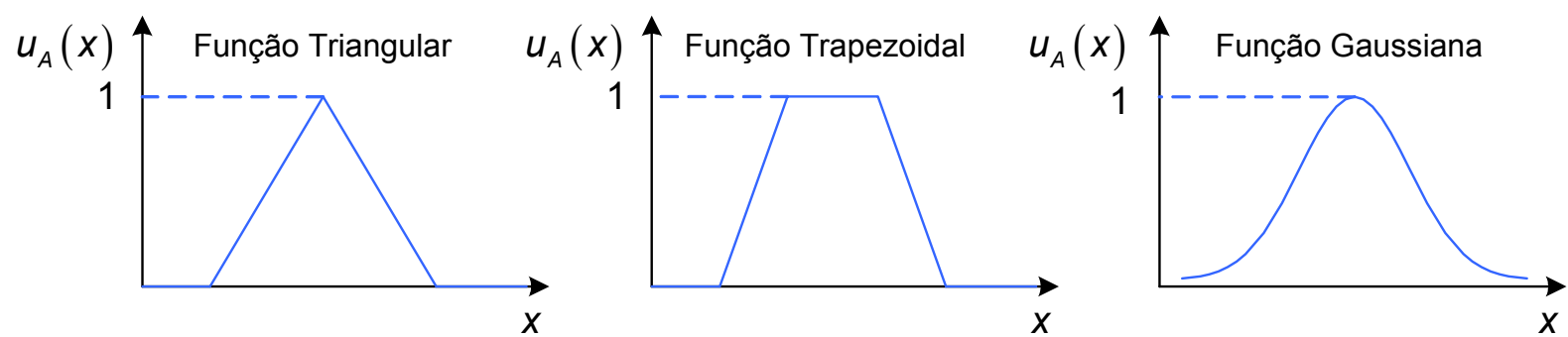

Figura 4.2 - Funções de pertinência dos conjuntos fuzzy.

\subsubsection{Sistemas de Inferência Fuzzy}

O processo de inferência do sistema fuzzy é realizado conforme o diagrama de blocos representado na Figura 4.3. As variáveis de entrada do processo são auferidas por meio de sensores, cujos valores não fuzzy são fuzzificados mediante a “Interface de Fuzzificação".

No bloco "Processo de Inferência Fuzzy", as entradas são processadas por meio de um conjunto de regras lingüísticas definidas na "Base de Conhecimento", fornecendo então a resposta ou a ação de controle em sua saída.

O valor é defuzzificado na "Interface de Defuzzificação" para que os atuadores sejam devidamente acionados. Os detalhes de cada bloco serão descritos na seqüência. 


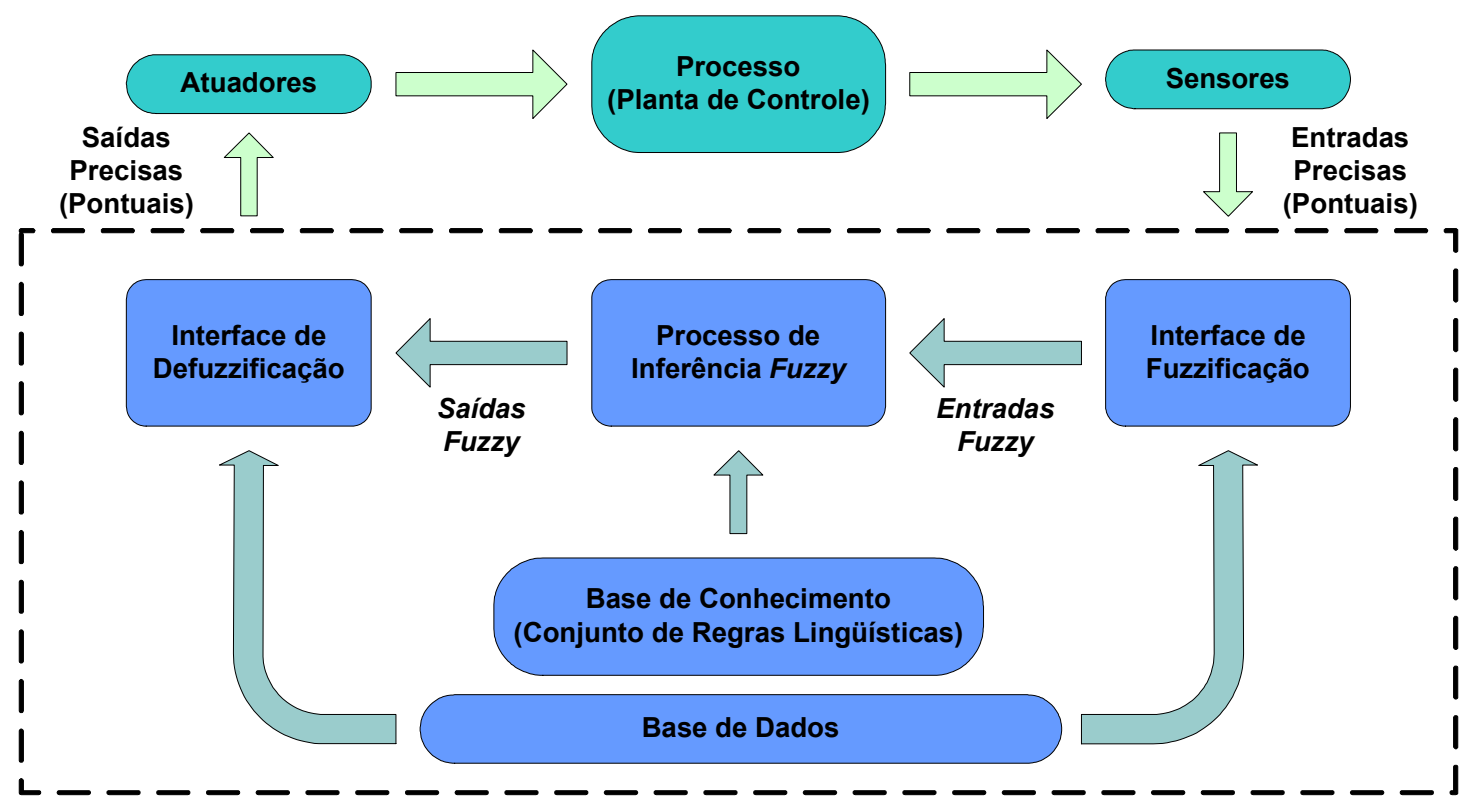

Figura 4.3 - Modelo genérico de um sistema de inferência fuzzy.

\section{- Interface de Fuzzificação}

As entradas precisas (pontuais) são apresentadas ao sistema fuzzy por meio de medições ou observações de dados realizados por sensores. Desta forma, a interface de fuzzificação consiste na identificação de quais variáveis lingüísticas as entradas pertencem e seus respectivos grau de pertinência. $\mathrm{Na}$ interface de fuzzificação também ocorre a ativação da regras associadas às variáveis lingüísticas ativadas.

\section{- Base de Conhecimento}

A base de conhecimento representa o conjunto de regras lingüísticas na forma de "Se (antecedente) então (conseqüente)" que definem o mapeamento das decisões associadas ao controle do processo. As regras podem ser fornecidas por especialistas em forma de sentenças lingüísticas e se constituem de um aspecto fundamental no projeto de um sistema de inferência fuzzy, visto que o desempenho 
será confiável somente se as regras que definem a estratégia forem consistentes. Basicamente, as regras são apresentadas conforme o seguinte exemplo:

Se (velocidade é "alta”) e (aceleração é "baixa”)

$$
\text { então (pressão no freio é "média”) }
$$

Se (velocidade é "baixa") e (aceleração é "média")

$$
\text { então (pressão no freio é "baixa") }
$$

Entretanto, a extração de um conjunto de regras especialistas pode não ser uma tarefa fácil por mais que os mesmos conheçam profundamente o problema em questão. Portanto, alternativamente ao uso de especialistas para a definição da base de regras, existem métodos de extração de regras a partir de dados numéricos.

Os formatos das funções de pertinências que constituem os termos lingüísticos (triangulares, trapezoidais ou gaussianas) são definidos e seus parâmetros são ajustados pelo projetista. É possível efetuar uma sintonia manual das funções de pertinências dos conjuntos, embora seja comum se empregarem métodos automáticos. A integração entre sistemas de inferências fuzzy com redes neurais artificiais e/ou algoritmos genéticos tem se mostrado adequada para a sintonia de funções de pertinências, assim como para a geração automática de regras.

\section{- Base de Dados}

Armazena definições das funções de pertinência que constituem a base de conhecimento na forma de discretizações e normalizações dos universos de discurso, bem como as partições fuzzy de entrada e saída, de forma que todo o processo de inferência seja computacionalmente viável. 


\section{- Processo de Inferência Fuzzy}

A partir dos conjuntos e das regras lingüísticas definidas na base de conhecimento, as operações dos conjuntos fuzzy são realizadas no estágio de inferência. As operações fuzzy consistem no processamento (implicação) das regras lingüísticas ativadas de forma a produzir um conjunto fuzzy resultante da contribuição de todas essas regras. Dentre os métodos de implicação, pode-se citar o método de Mamdani, Zadeh e Larsen (Tsoukalas e Uhrig, 1997; Baturone et al., 2000).

\section{- Defuzzificação}

Uma vez obtido o conjunto fuzzy de saída através do processo de inferência, no processo de defuzzificação é efetuada a interpretação dessa informação para saídas precisas (pontuais). Isto se faz necessário, já que, em aplicações práticas são requeridos valores precisos, ao invés de quantificações fuzzy. Existem diversas metodologias de defuzzificação, sendo o método do centro de área e o método da média dos máximos os mais utilizados (Brown e Harris, 1994; Tsoukalas e Uhrig, 1997; Baturone et al., 2000; Mathworks, 2007). No primeiro método, a saída é determinada extraindo-se o valor no universo que divide a área sob a curva da função de pertinência em duas partes iguais. No segundo, a saída precisa é obtida tomando-se a média entre os dois elementos extremos no universo de discurso que correspondem aos maiores valores da função de pertinência do conseqüente.

\subsubsection{Método de Implicação de Mamdani}

O sistema de inferência fuzzy do tipo Mamdani (Brown e Harris, 1994; Tsoukalas e Uhrig, 1997; Mathworks, 2007) se caracteriza, principalmente, pela 
simplicidade de implementação computacional, o que torna a metodologia mais comumente empregada na maioria das aplicações. Sua estrutura é baseada no esquema geral ilustrado pela Figura 4.3. Desta forma, o primeiro passo a ser realizado consiste na fuzzificação das entradas, ou seja, a conversão das entradas precisas em valores fuzzy equivalentes aos graus de pertinência associados aos termos lingüísticos ativados.

Para uma melhor compreensão, supondo um determinado sistema fuzzy responsável pelo controle de frenagem de automóvel possua entradas relacionadas à variável lingüística "Velocidade" associada aos termos lingüísticos "Baixa”, "Média" e "Alta", e à variável lingüística "Aceleração" associada aos termos lingüísticos "Baixa", "Média" e "Alta". No exemplo ilustrado na Figura 4.4, o termo lingüístico "Baixa" da variável lingüística "Velocidade" recebe um determinado valor preciso de 0,3; o qual é fuzzificado mediante a função de pertinência, resultando no valor fuzzy 0,7 . Desta forma, pode-se afirmar que a velocidade é baixa com 0,7 ou $70 \%$ de grau de pertinência.

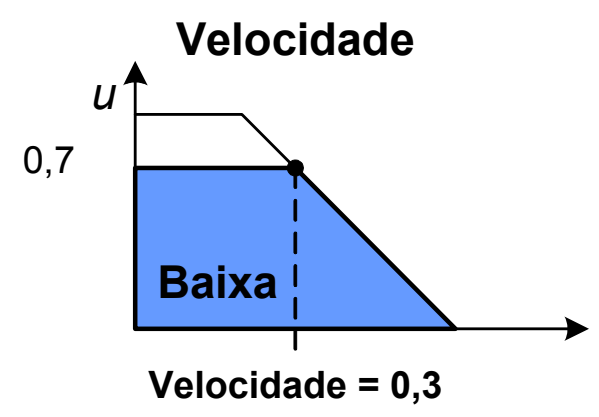

Figura 4.4 - Fuzzificação das Entradas.

Uma vez definida o tipo de função de pertinência a ser utilizada, tornar-se-á necessário implementar a base de conhecimento do sistema de inferência a partir das definições de regras fuzzy, as quais são compostas por estruturas de decisão do tipo "Se-Então". A construção de tais regras, fundamentadas na manipulação do 
conhecimento mediante a caracterização dos aspectos qualitativos em formas de sentenças lingüística, torna o sistema mais claro e simples de ser compreendido, auxiliando no seu desenvolvimento e manutenção.

As regras fuzzy podem ser divididas em duas parcelas, ou seja, a antecedente e a conseqüente (Mathworks, 2007). Na primeira são realizadas as operações fuzzy com as variáveis lingüísticas de entradas, geralmente do tipo OR ou AND, as quais se referem às condições que implicam em uma determinada ação explícita para a parcela conseqüente, na qual está alocada a função de pertinência de saída. Na Figura 4.5 é descrito o processo de implementação de uma regra fuzzy dependentes de duas entradas.

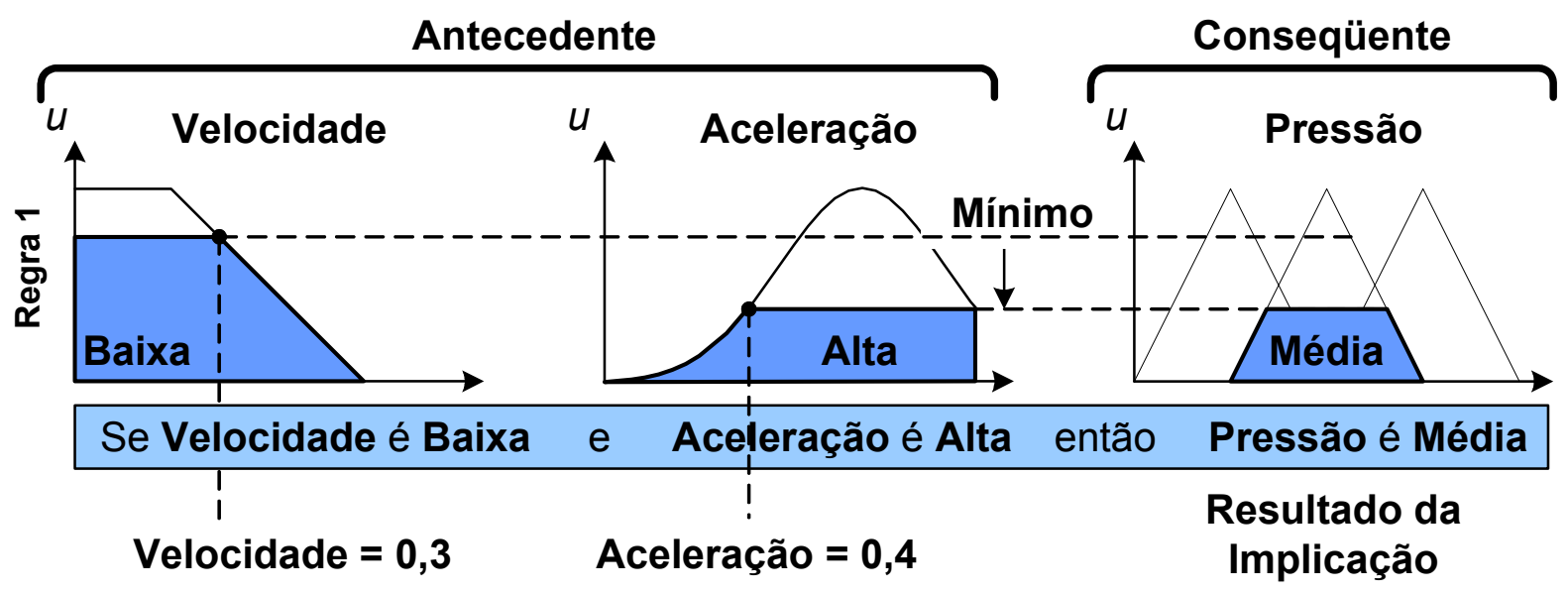

Figura 4.5 - Implementação completa de uma regra fuzzy.

A velocidade de 0,3 e a aceleração de 0,4 ativam os termos lingüísticos "Baixa" e "Alta" das variáveis lingüísticas "Velocidade" e "Aceleração", respectivamente, conforme ilustrado na Figura 4.5. Conseqüentemente, a regra lingüística "Se velocidade do automóvel é baixa e a aceleração é alta então a pressão nos freios é média" é ativada. A operação AND (e) realiza o mínimo entre os graus de pertinência associado às variáveis lingüísticas "Velocidade" e "Aceleração". Em seguida, a implicação de Mamdani ceifará o conjunto referente ao 
termo lingüístico "Média" da variável de saída "Pressão", considerando para tanto o valor resultante da operação AND efetuada na etapa antecedente. A região resultante representa a contribuição de uma regra para a ação de pressionar os freios. Um esquema generalizado para mais de uma regra ativada é ilustrado na Figura 4.6.

$\mathrm{Na}$ Figura 4.6, descreve-se o procedimento das associações de todas as regiões fuzzy de saída advindas da contribuição de cada regra lingüística ativadas pelo sistema de inferência.

A agregação de todas as implicações provenientes de suas respectivas regras fuzzy visam a obtenção de uma única função de pertinência de saída pela qual será extraído o valor preciso da pressão do freio. Em virtude da agregação se consistir da união dos conjuntos resultantes da implicação, a ordem de execução das regras se torna não importante, facilitando a implementação. Finalmente, o valor de saída pode ser determinado por qualquer método de defuzzificação. Neste caso, aplicou-se o cálculo do centro de área da região fuzzy resultante da agregação. 


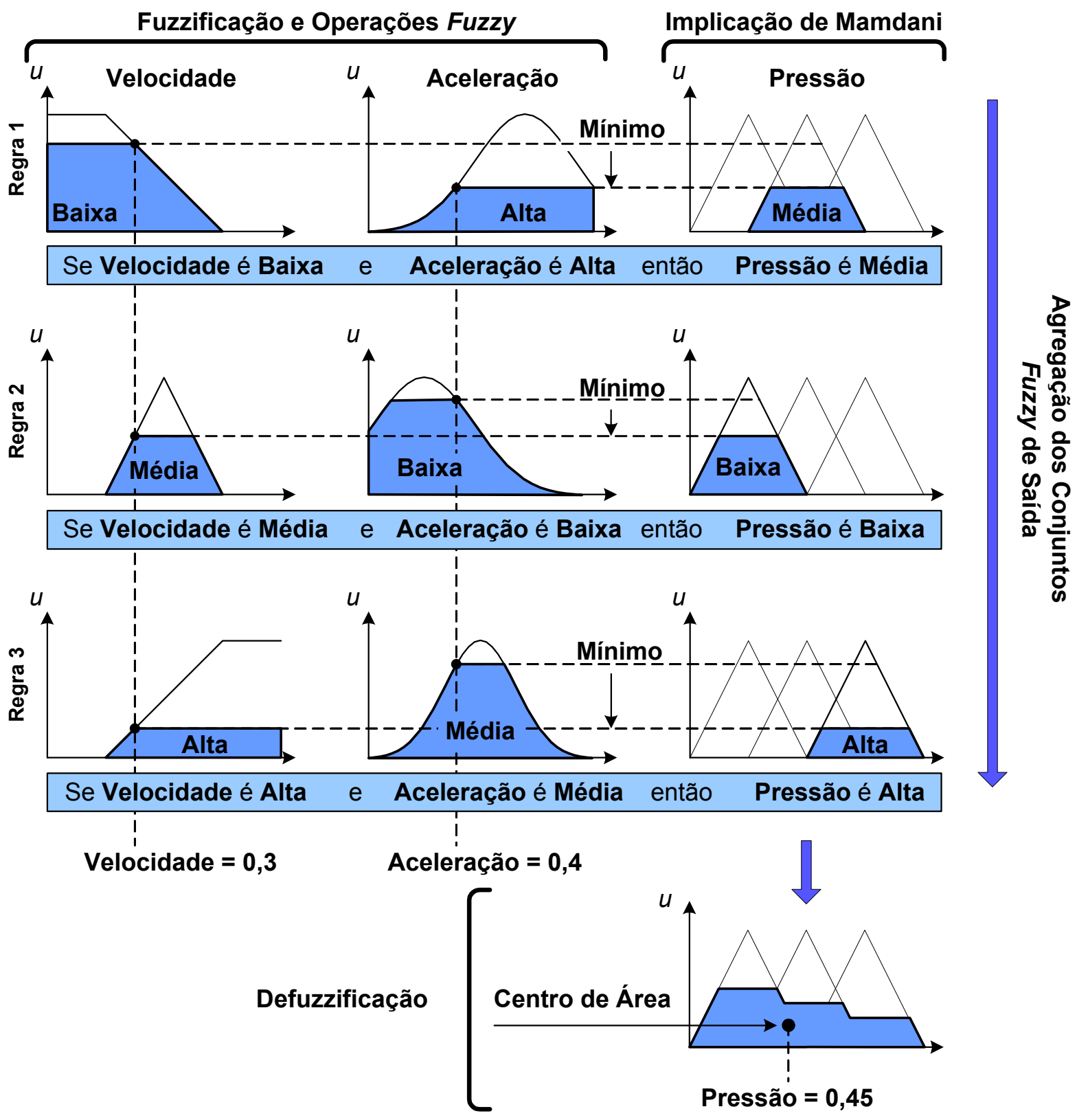

Figura 4.6 - Método de Implicação de Mamdani.

\subsection{Controle Escalar V/f Fuzzy de Velocidade}

\subsubsection{Introdução}

Muitos trabalhos têm sido publicados abordando-se o controle vetorial (Bim, 2001; Cirrincione et al., 2003; Cruz e Paredes, 2003b; 2003a), já que este produz melhores respostas dinâmicas. Por outro lado, o controle escalar (El-Saady et al., 
1994; Tae-Chon et al., 2001; Islam et al., 2005) apresenta uma estrutura mais simples caracterizada pelo baixo erro em regime permanente.

Nesta dissertação é proposto um controlador fuzzy de velocidade de MITs, no qual o enfoque principal consiste no estudo dinâmico do controlador frente às variações de tensão e carga. A metodologia de controle empregada se baseia no ajuste de tensão e freqüência (Volts/Hertz) de modo que se mantenha o fluxo constante. Simulações computacionais são apresentadas com o intuito de analisar o desempenho do controlador fuzzy de velocidade, visando à implementação em hardware.

O diagrama de blocos do controlador fuzzy proposto é ilustrado na Figura 4.7. O sinal de erro $e_{r}(k)$ e a variação do erro de ${ }_{r}(k)$, determinada por meio da diferença entre a amostragem atual e a anterior, são utilizados como variáveis lingüísticas de entrada do controlador fuzzy. Estas são fuzzificadas de modo que sejam quantificadas para um universo de discurso comum. Os resultados são avaliados pelas regras fuzzy de controle devidamente implementadas. A saída do sistema fuzzy é então defuzzificada e quantificada visando incrementar ou decrementar a freqüência de referência do inversor. Este valor, somado à freqüência anterior, resulta na freqüência adequada no instante atual.

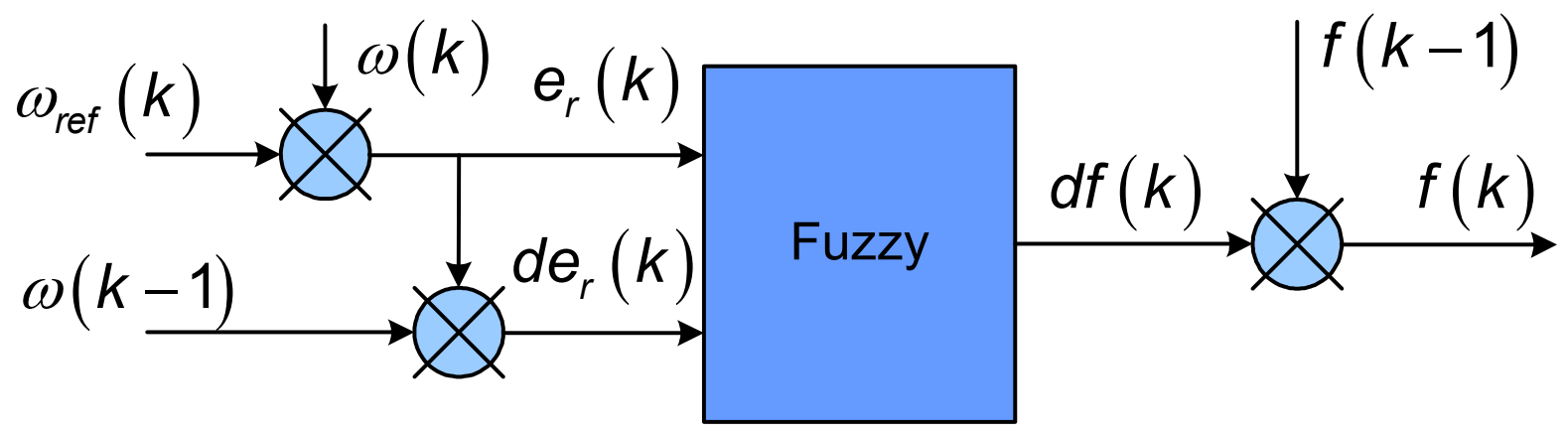

Figura 4.7 - Diagrama de blocos do controlador fuzzy. 
O controlador fuzzy será utilizado para se efetuar a análise de seu desempenho frente aos tipos de cargas que são comumente encontrados em setores industriais, tais como cargas lineares, constantes, quadráticas e inversas. Com o intuito de se analisar o desempenho do controlador fuzzy, utilizou-se a modelagem vetorial da máquina de indução deduzida na Seção 2.2.5.

\subsubsection{Tensões Aplicadas no MIT}

Neste trabalho, em virtude da disponibilidade dos parâmetros mensurados em laboratório (Gonzaga e Jr, 2005), utilizou-se um MIT com rotor bobinado, no qual seus enrolamentos foram curto-circuitados. Desta forma, a tensão do rotor é nula. As tensões aplicadas no estator são transformadas ao modelo $d q$ mediante as seguintes expressões:

$$
\begin{gathered}
v_{S_{d}}=\sqrt{\frac{2}{3}}\left(v_{S_{a}}+v_{S_{b}} \cos (-\delta)+v_{S_{c}} \cos (\delta)\right) \\
v_{S_{q}}=\sqrt{\frac{2}{3}}\left(-v_{S_{b}} \sin (-\delta)-v_{S_{c}} \sin (\delta)\right)
\end{gathered}
$$

As tensões da rede são representadas por:

$$
\left[\begin{array}{l}
v_{S_{a}} \\
v_{S_{b}} \\
v_{S_{c}}
\end{array}\right]=\sqrt{2} V_{R M S}\left[\begin{array}{c}
\cos \left(\omega_{s} t\right) \\
\cos \left(\omega_{s} t-\delta\right) \\
\cos \left(\omega_{s} t+\delta\right)
\end{array}\right]
$$

e

$$
\begin{aligned}
& \omega_{s}=2 \pi f_{s} \\
& \delta=2 \pi / 3
\end{aligned}
$$

onde $V_{R M S}$ é a tensão eficaz, $f_{s}$ é a freqüência do estator e $\delta$ é o ângulo de defasagem entre as fases. 


\subsubsection{Parâmetros da Máquina}

Os parâmetros do motor de indução pertencente à Escola de Engenharia de São Carlos (EESC-USP) foram obtidos mediante ensaios experimentais descritos em Gonzaga et. al (2005). Os dados da placa do motor e seus parâmetros são denotados conforme a Tabela 4.1. Cabe salientar que embora as simulações sejam realizadas com parâmetros diferentes do MIT utilizado na bancada experimental, não haverá alteração na metodologia empregada para desenvolver o controlador fuzzy Volts/Hertz de velocidade.

Tabela 4.1 - Parâmetros do MIT.

\begin{tabular}{|l|c|}
\hline Potência & $P_{m e c}=2500 \mathrm{~W}$ \\
\hline Corrente Nominal de Estator e Rotor & $I_{N}=8,8 \mathrm{~A}$ \\
\hline Tensão Nominal & $V_{N}=127 / 220 \mathrm{~V}$ \\
\hline Número de Pólos & $p=4$ \\
\hline Resistência de Estator & $R_{S}=0,855 \Omega$ \\
\hline Resistência de Rotor & $R_{R}=0,686 \Omega$ \\
\hline Indutância de Estator & $L_{S}=0,102 \mathrm{H}$ \\
\hline Indutância Mútua do Estator & $M_{S}=0,0398 \mathrm{H}$ \\
\hline Indutância de Rotor & $L_{R}=0,102 \mathrm{H}$ \\
\hline Indutância Mútua do Rotor & $M_{R}=0,0434 \mathrm{H}$ \\
\hline Indutância Mútua Estator/Rotor & $M_{S R}=0,0923 \mathrm{H}$ \\
\hline Momento de Inércia do Rotor & $J=0,0347 \mathrm{~kg} \cdot \mathrm{m}^{2}$ \\
\hline Momento de Inércia da Carga & $J_{c}=0,0708 \mathrm{~kg} \cdot \mathrm{m}^{2}$ \\
\hline Coeficiente de Atrito Viscoso & $B=0,021 \mathrm{Nms} / \mathrm{rad}$ \\
\hline Coeficiente de Atrito Viscoso da Carga & $B_{c}=0,014 \mathrm{Nms} / \mathrm{rad}$ \\
\hline
\end{tabular}

\subsubsection{Projeto do Controlador Fuzzy}

A Figura 4.8 representa o diagrama completo do sistema de controle fuzzy de velocidade. O controlador recebe o erro de velocidade e a sua variação no intervalo de uma amostragem. O sistema fuzzy processa essas informações e 
fornece a quantidade de acréscimo ou decréscimo de freqüência de referência do inversor. Com o intuito de manter o fluxo constante, a tensão também é alterada de forma a produzir uma tensão adequada. Neste trabalho não foi realizada a modelagem matemática do inversor. Portanto, a simulação foi realizada alimentando a máquina com tensões senoidais obtidas pela Equação (4.5).

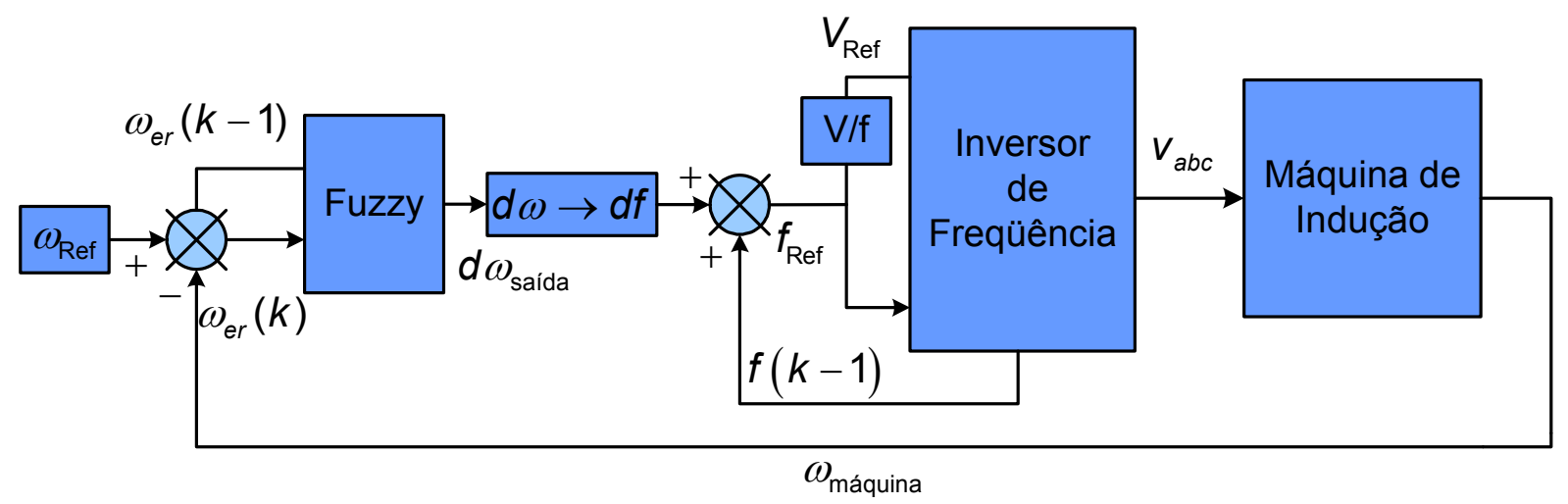

Figura 4.8 - Diagrama de blocos do sistema de controle V/f fuzzy.

Ajustou-se o fluxo magnético para uma operação com tensão eficaz de $127 \mathrm{~V}$ com freqüência de $60 \mathrm{~Hz}$, os quais correspondem à tensão eficaz nominal e à freqüência nominal da máquina, respectivamente. A análise do controlador fuzzy foi limitada a $10 \%$ da freqüência nominal até $20 \%$ acima do seu valor, visto que o controle V/f fuzzy não é adequado para baixas velocidades. Portanto, a freqüência de alimentação varia entre $6 \mathrm{~Hz}$ e $72 \mathrm{~Hz}$ com variação de tensão eficaz entre 12,7 V e $152,4 \mathrm{~V}$.

O controlador fuzzy foi dimensionado com base nas funções de pertinências descritas pela Figura 4.9. Todas as variáveis lingüísticas do sistema de controle fuzzy (erro de velocidade, variação do erro e variação de freqüência) foram enquadradas em um universo de discurso comum com valores entre $[-1,1]$. 


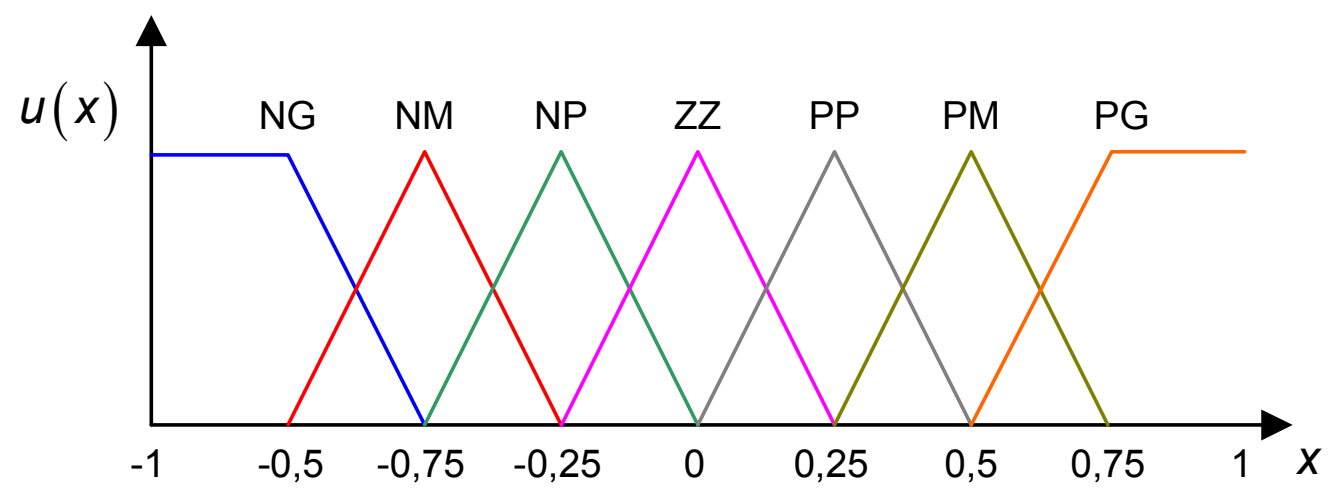

Figura 4.9 - Funções de pertinências do sistema fuzzy.

onde NG é "Negativo e Grande", NM é "Negativo e Médio", NP é "Negativo e Pequeno", ZZ é "Zero ou Neutro", PP é "Positivo e Pequeno", PM é "Positivo e Médio" e PG é "Positivo e Grande”.

Portanto, por meio de um único conjunto de funções de pertinência é possível mapear simultaneamente as três variáveis envolvidas no sistema fuzzy, ou seja, ao invés de se ter uma função de pertinência distinta para cada variável lingüística, utiliza-se apenas uma função de pertinência, onde as outras variáveis aproveitam a mesma função nos processos envolvidos no sistema fuzzy. Com esta simplificação, o sistema se torna vantajoso quanto à disponibilidade de memória, a qual é crítica na implementação do hardware.

Vale salientar que neste caso as funções de pertinências para cada variável lingüísticas possuem o mesmo formato, sendo suas bases proporcionais à extensão do universo de discurso. Por outro lado, se a sintonização do sistema exigir que os termos lingüísticos tenham funções de pertinências diferentes para cada variável lingüística, esta metodologia de simplificação não seria aplicável, tendo-se de construir uma função de pertinência para cada variável lingüística.

Assim sendo, conforme a ilustração esquemática da Figura 4.10, o sinal de entrada da variável lingüística erro de velocidade, com universo de discurso entre $[-120,120]$, é inicialmente dividido por 120 antes de entrar no processo de 
fuzzificação. A variação do erro foi ajustada ao universo de discurso entre [-1, 1], e, portanto, não houve a necessidade de condicionar o sinal. Já a variável lingüística de saída, dada pela variação da freqüência, cujo universo de discurso está entre $[-3,3]$, foi multiplicada por 3 , pois o sistema fuzzy retorna valores entre $[-1,1]$ na saída. As faixas de valores definidos neste processo foram determinadas por meio de análises do comportamento da planta por intermédio de sucessivas simulações, possibilitando, desta forma, a extração de informações relevantes para a modelagem do sistema fuzzy.

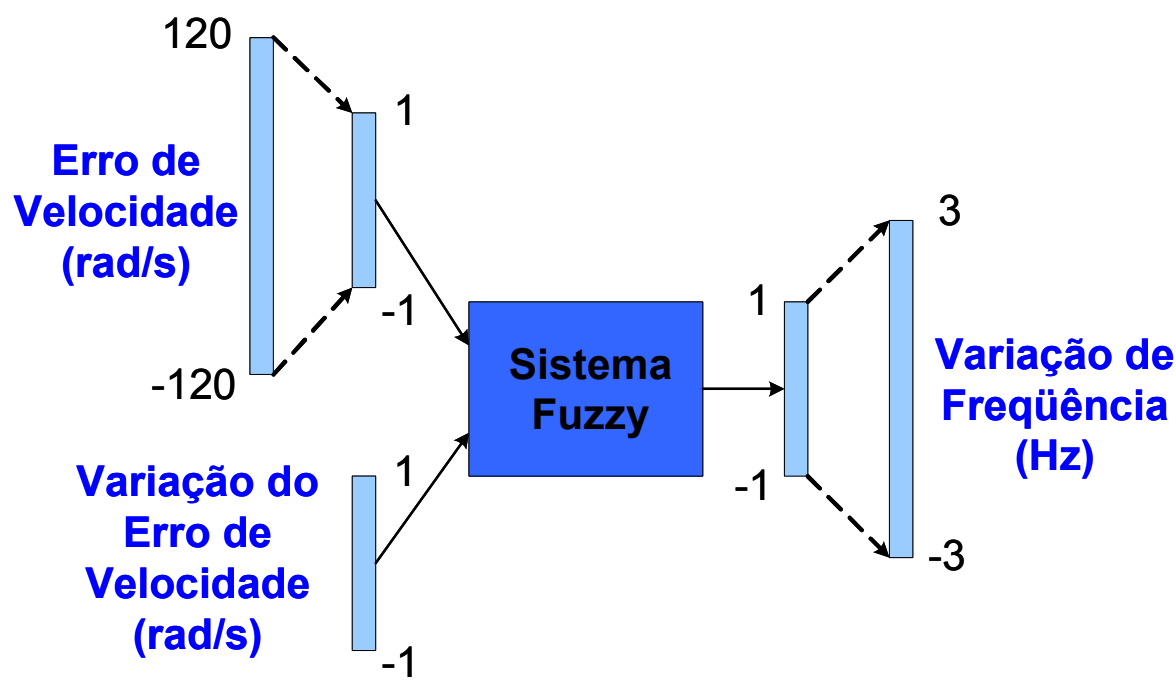

Figura 4.10 - Normalização das variáveis lingüísticas.

As regras fuzzy podem ser implementadas com base no conhecimento especialista do processo, as quais são tratadas de forma lingüística na estrutura "seentão". Por esta razão, os sistemas fuzzy são projetados mediante os conceitos qualitativos do processo, o que torna possível simplificar a modelagem do problema, já que se dispensa de conhecimentos detalhados, precisos e até mesmo do modelo matemático representativo da planta de controle.

As três primeiras regras do sistema de controle fuzzy são representadas como segue: 
Se (erro é NG) e (variação do erro é NG)

Então (variação da freqüência é NG)

Se (erro é NM) e (variação do erro é NG)

Então (variação da freqüência é NG)

Se (erro é PN) e (variação do erro é NG)

Então (variação da freqüência é NP)

De forma sintetizada, a base de todas as regras aplicadas, conforme a sintaxe anterior, é descrita pela Tabela 4.2.

Tabela 4.2 - Base de regras do sistema de controle fuzzy.

\begin{tabular}{|c|c|c|c|c|c|c|c|c|}
\hline & \multicolumn{7}{|c|}{ Erro de Velocidade } \\
\hline & & NG & NM & NP & ZZ & PP & PN & PG \\
\hline \multirow{7}{*}{ 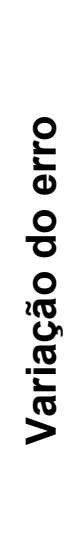 } & NG & NG & NG & NG & NM & NM & NP & $\mathrm{ZZ}$ \\
\hline & NM & NG & NM & NM & NP & NP & ZZ & PP \\
\hline & NP & NM & NM & NP & NP & ZZ & PP & PP \\
\hline & ZZ & NM & NP & NP & ZZ & PP & PP & PM \\
\hline & PP & NP & NP & $\mathrm{ZZ}$ & PP & PP & PM & PM \\
\hline & PN & NP & ZZ & PP & PP & PM & PM & $P G$ \\
\hline & PG & ZZ & PP & PM & PM & $P G$ & PG & PG \\
\hline
\end{tabular}

O operador de implicação de Mamdani, ilustrado pela Figura 4.11, foi escolhido devido a sua maior simplicidade computacional. Neste exemplo genérico, ilustram-se as duas regras ativadas pelos valores de erro $\left(\omega_{e r}\right)$ e variação de erro da velocidade $\left(d \omega_{e r}\right)$. Para a "Regra 1", os termos lingüísticos ativados por $\omega_{e r}$ e $d \omega_{e r}$ são "NG" e "NP", respectivamente. Aos valores de $\omega_{e r}$ e $d \omega_{e r}$ estão associados os seus graus de pertinência $u_{R_{1}}\left(\omega_{e r}\right)$ e $u_{R_{1}}\left(d \omega_{e r}\right)$. No processo de implicação de 
Mamdani, basta efetuar o mínimo entre tais valores e realizar o corte no termo lingüístico de saída associado à "Regra 1", respectivamente (“NG”), resultando na região ativa destacada na Figura 4.11. Este método simplifica e reduz de forma significativa o esforço computacional e alocação de memória, as quais são requeridas no método genérico e convencional do processo de implicação.

Em virtude da variação de erro $\left(d \omega_{e r}\right)$ ativar dois termos lingüísticos, têm-se, então, duas regras ativadas. A "Regra 2" consiste nos termos lingüísticos "NG" e "NM" para $\omega_{e r}$ e $d \omega_{e r}$, respectivamente. Pelo mesmo processo descrito no parágrafo anterior, a região ativa, "NM", para a "Regra 2" é ilustrada em destaque pela Figura 4.11.

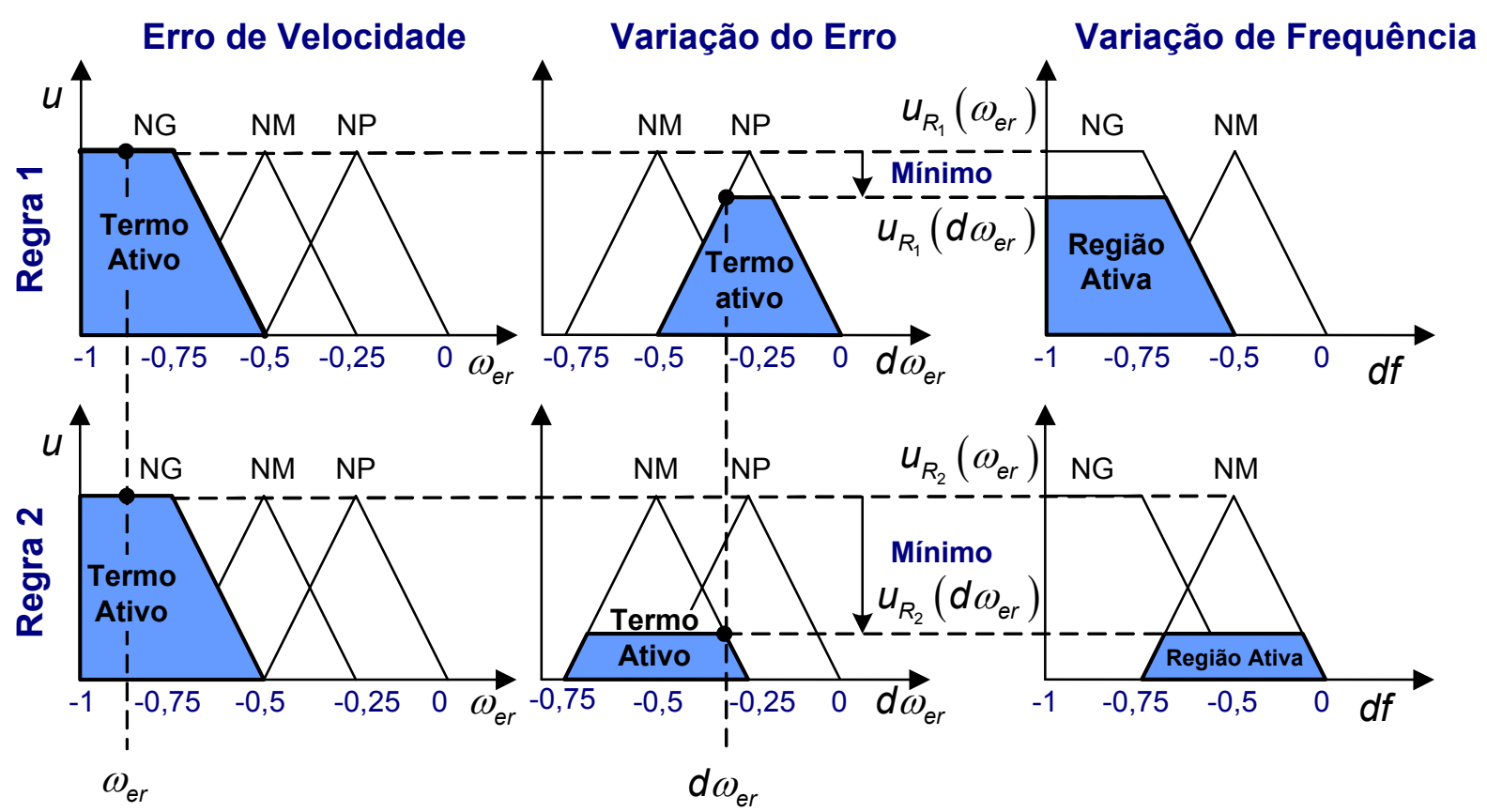

Figura 4.11 - Método de implicação de Mamdani para o controlador fuzzy.

Após determinar as regiões ativas de todas as regras ativadas pelas variáveis de entrada $\omega_{e r}$ e $d \omega_{e r}$, efetuou-se o processo de agregação que consiste na união (operador $M A X$ ) de todas as contribuições individuais de cada regra ativa, conforme descrito na Figura 4.12. 


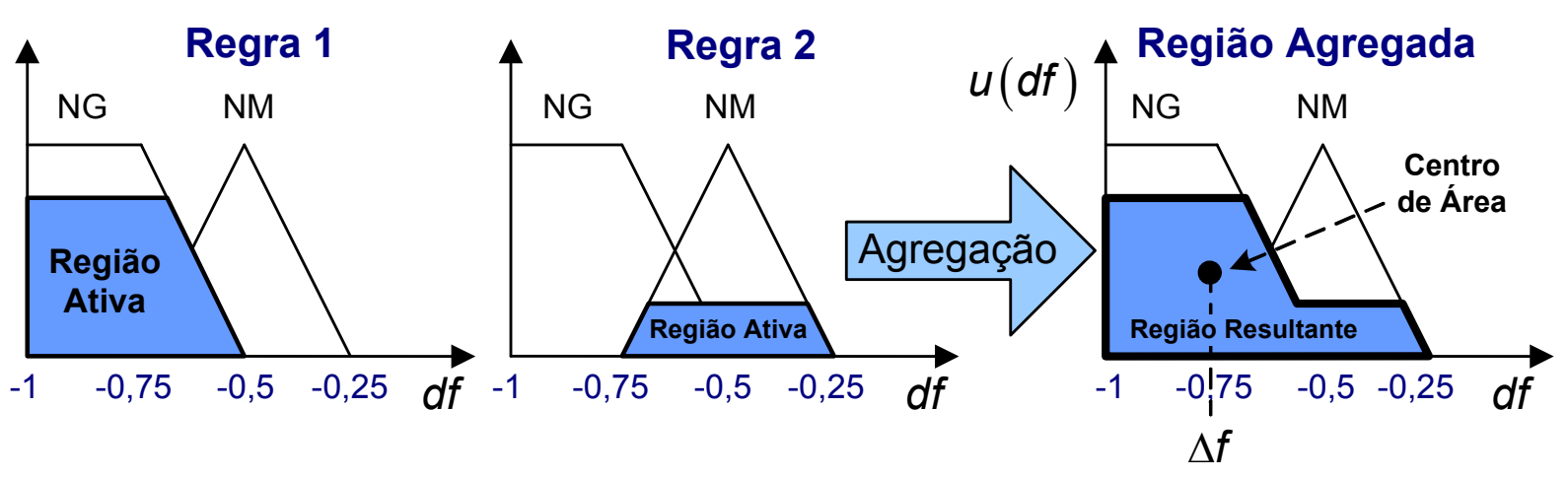

Figura 4.12 - Agregação e defuzzificação.

O valor de saída $\Delta f$ do controlador fuzzy, o qual representa a variação a ser aplicada na freqüência de referência do chaveamento do inversor, é determinado pelo método de defuzzificação do centro de área, e pode ser obtido a partir da expressão definida como segue:

$$
\Delta f=\frac{\sum_{k=1}^{N} u\left(d f_{k}\right) d f_{k}}{\sum_{k=1}^{N} u\left(d f_{k}\right)}
$$

onde $N$ é o número de discretizações, $d f_{k}$ representa o valor discreto de $d f$ e $u\left(d f_{k}\right)$ é o respectivo grau de pertinência associado a cada $d f_{k}$ pertencente à região ativada.

\subsection{Resultados de Simulações Computacionais}

Neste item serão apresentados os resultados da simulação computacional do desempenho do sistema de controle fuzzy de velocidade executado no Matlab $^{T M} /$ Simulink $^{T M}$, cujo diagrama de blocos é ilustrado na Figura 4.13.

O bloco de condicionamento de sinal localizado na entrada do controlador fuzzy tem a função de assegurar que os valores de entrada se enquadrem dentro do universo de discurso. Por exemplo, o universo de discurso do erro de velocidade foi 
definido como sendo [-120, 120], conforme foi descrito na seção anterior. Entretanto, eventualmente, o erro pode também ocupar valores fora desse domínio. Assim, caso isto aconteça, tais valores deverão ser considerados como os limites extremos do universo de discurso.

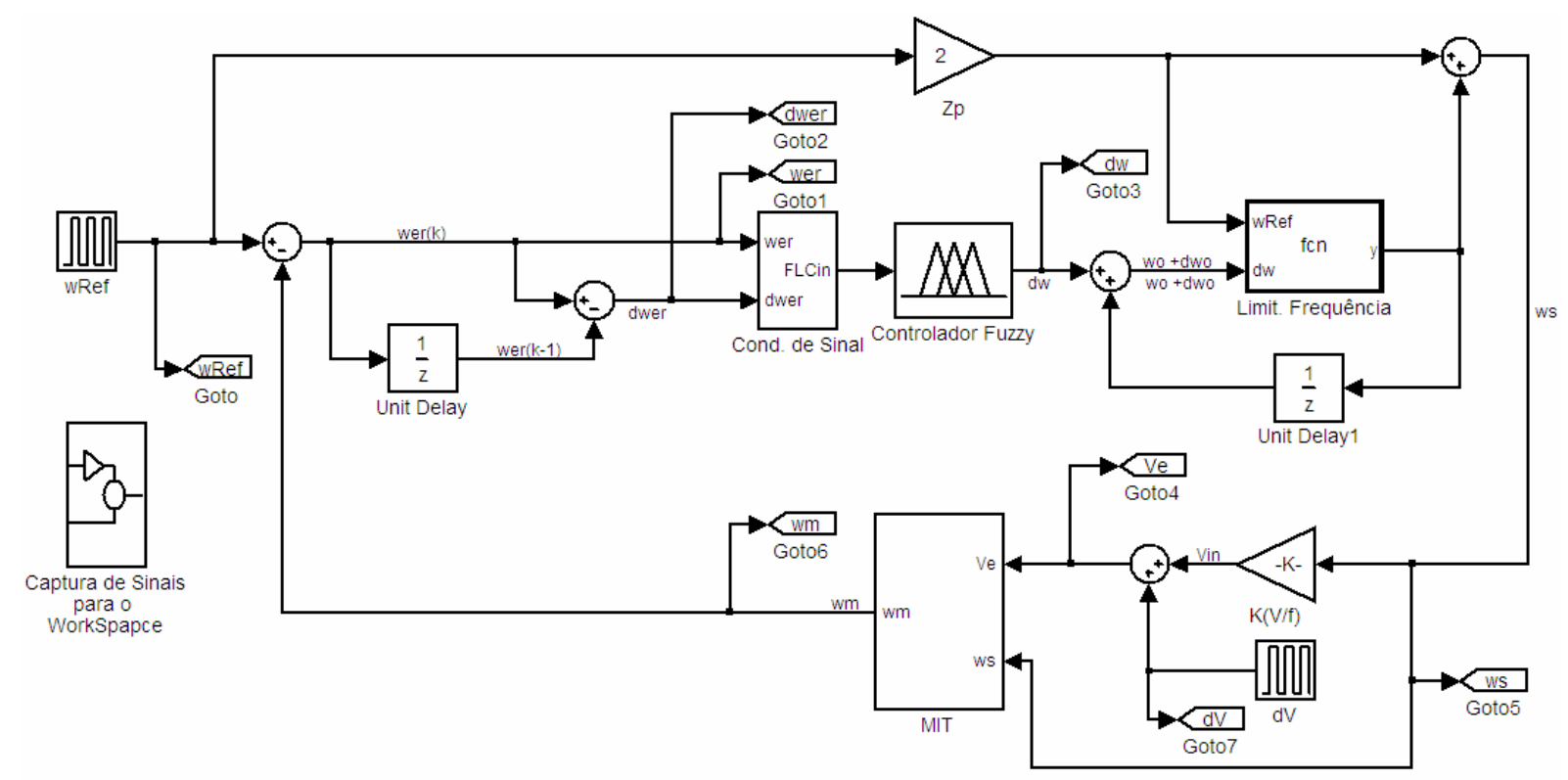

Figura 4.13 - Diagrama de blocos do controlador fuzzy no simulink.

O bloco limitador de freqüência situado na saída do controlador fuzzy está encarregado de limitar a freqüência de acionamento de $10 \%$ da freqüência nominal até $20 \%$ acima do seu valor.

Com intuito de analisar o comportamento dinâmico do controlador fuzzy de velocidade, realizaram-se os seguintes ensaios de simulação computacional: análise dinâmica da máquina para cada tipo de carga frente aos degraus e rampas de referência de velocidade; análise do comportamento frente à variação de tensão de alimentação e, por fim, resposta do controlador aos degraus de torque de carga.

Deve ser ressaltado que o projeto do sistema de controle e as simulações contidas nesta dissertação foram realizadas sem considerar o estudo detalhado da análise de estabilidade planta do sistema. 


\subsubsection{Resposta à Carga Quadrática}

A Figura 4.14 ilustra o desempenho do controlador fuzzy frente aos degraus e rampas de referência de uma máquina sob carga quadrática. Nota-se que o mesmo é capaz de fornecer a relação tensão/freqüência adequada de forma que a velocidade angular acompanhe a velocidade de referência.
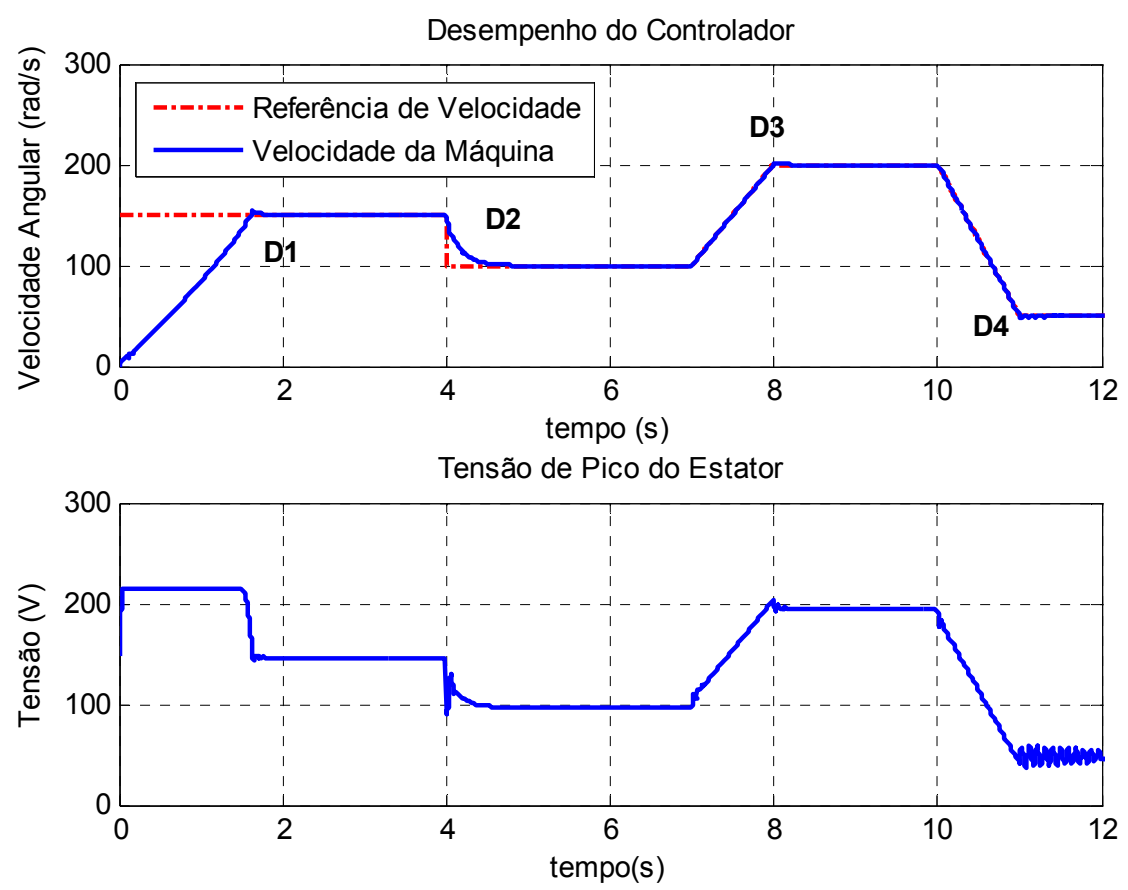

Figura 4.14 - Desempenho do controlador fuzzy frente aos degraus e rampas de referência.

Com intuito de se analisar os detalhes, a Figura 4.15 descreve as regiões indicadas por "D1", "D2", "D3" e "D4" da Figura 4.14, as quais estão associadas às legendas "Detalhe 1", "Detalhe 2", "Detalhe 3" e "Detalhe 4", respectivamente. Vale salientar que esta observação é válida para os gráficos conseguintes.

Mediante as observações realizadas na Figura 4.15, nota-se que no degrau e rampa de subida, o sistema apresentou um pequeno overshoot. O erro de velocidade do motor em regime permanente foi menor que 0,5 rad/s. Em "Detalhe 4", 
observa-se que as oscilações de velocidade que podem estar associadas ao chaveamento de regras lingüísticas do sistema fuzzy.
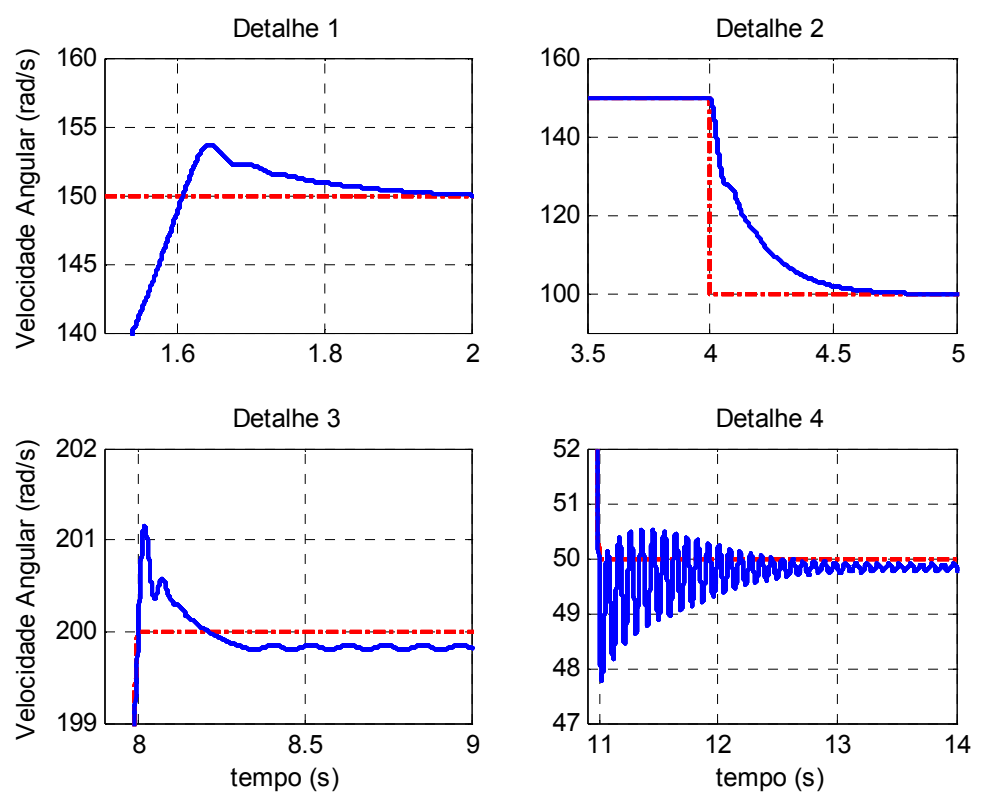

Figura 4.15 - Detalhes da Figura 4.14.

Nota-se também que a tensão de pico de alimentação atingiu um valor levemente superior a $200 \mathrm{~V}$. Isso se deve ao fato de que, na partida, a freqüência de alimentação de referência alcançou o seu limite, ou seja, 20\% acima da freqüência nominal. Assim sendo, para se manter o fluxo constante, a tensão de pico de referência também foi elevada a $20 \%$, ou seja, a tensão de pico máximo será de $215 \mathrm{~V}$.

A Figura 4.16 representa a análise do controlador fuzzy frente às variações de tensão de alimentação. Para tanto, estabeleceu-se uma velocidade de referência de $150 \mathrm{rad} / \mathrm{s}$, analisando-se a variação de velocidade quando se aplicava um degrau de incremento ou decremento de tensão. Conforme pode ser observado na Figura 4.17, o controlador fuzzy é capaz de compensar a variação de tensão, mantendo o erro de velocidade menor que $0,5 \mathrm{rad} / \mathrm{s}$. 

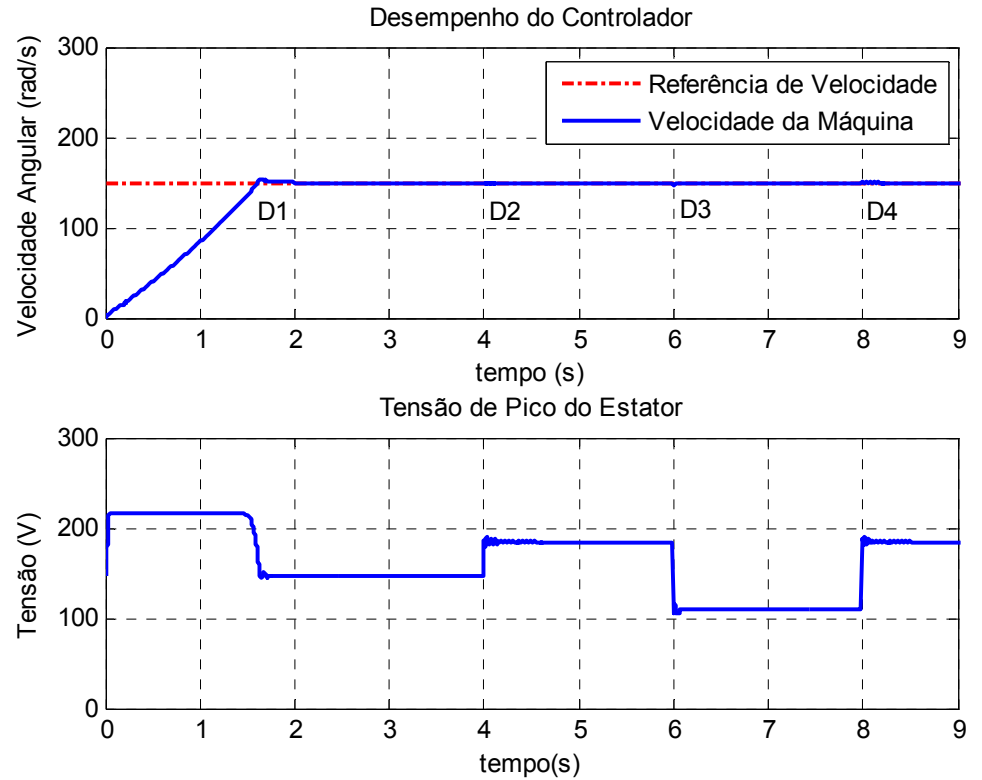

Figura 4.16 - Desempenho do controlador fuzzy frente às variações de tensão.
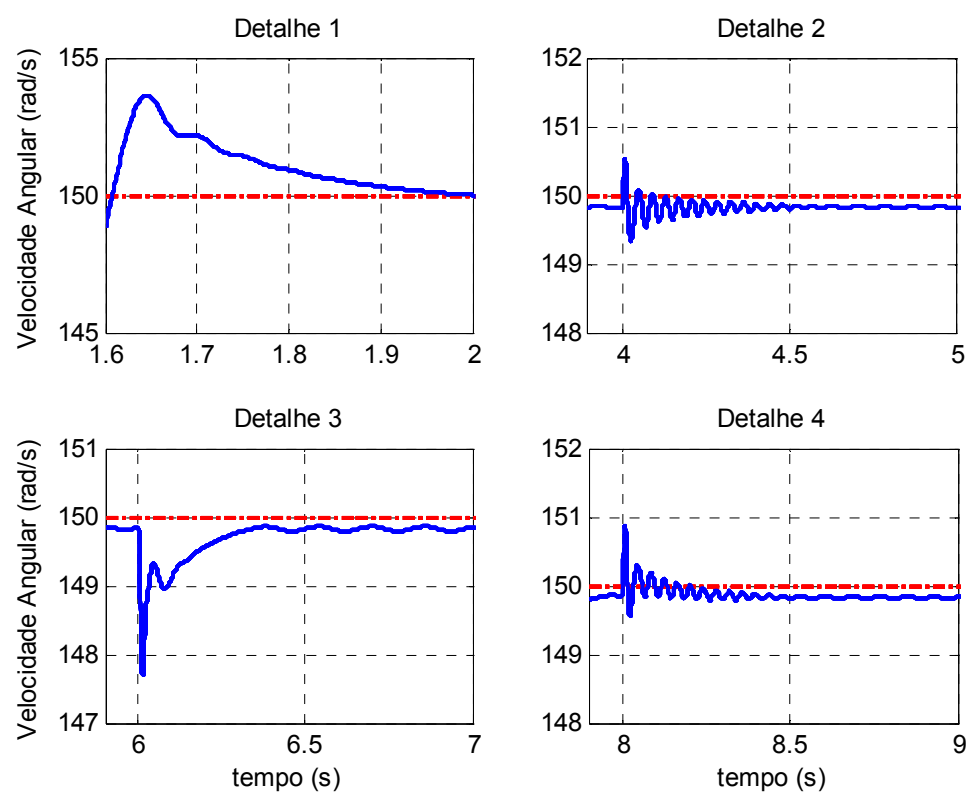

Figura 4.17 - Detalhes da Figura 4.16.

\subsubsection{Resposta à Carga Linear}

A Figura 4.18 descreve a resposta do controlador fuzzy submetido às variações de referência de velocidade para uma carga de característica linear. Os mesmos procedimentos de ensaios de simulação computacional realizados na carga 
quadrática também foram efetuados para a carga linear com o intuito de se analisar as diferenças nos resultados para cargas diferentes.
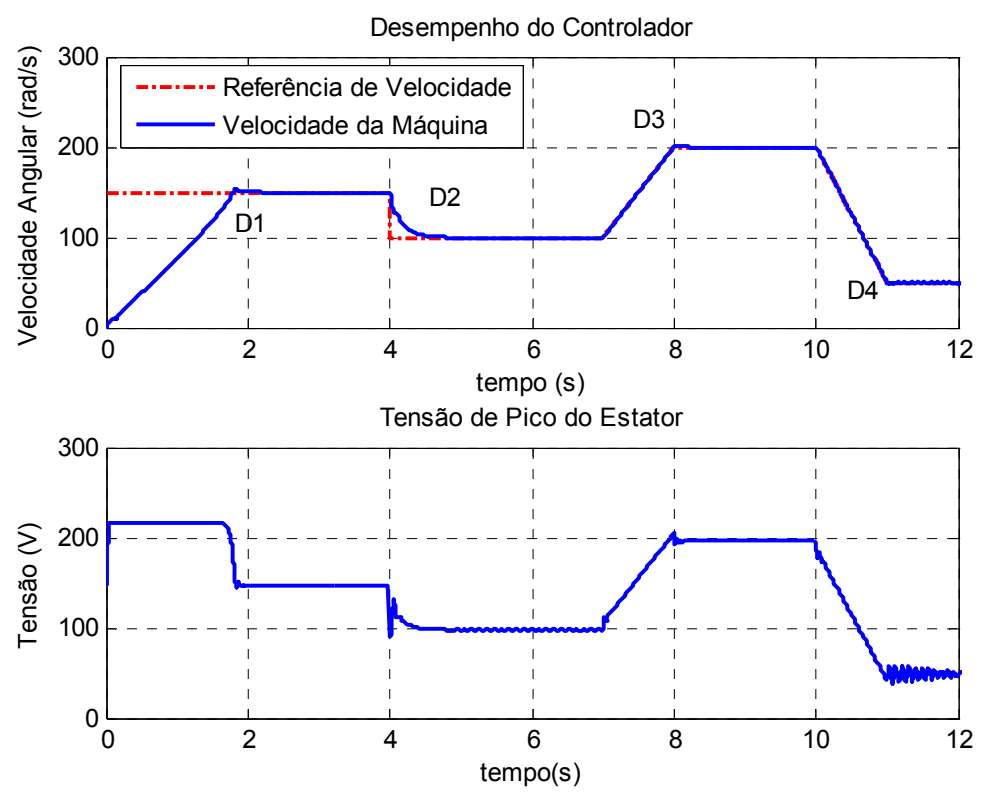

Figura 4.18 - Desempenho do controlador fuzzy frente aos degraus e rampas de referência.

A partir da análise da Figura 4.18 e Figura 4.19, nota-se que o controlador foi capaz de acompanhar a velocidade de referência. Os resultados foram semelhantes àqueles obtidos para carga quadrática, apresentando-se um baixo erro de velocidade de regime. Pela própria característica do método de controle, a resposta do controlador frente às variações bruscas, como degraus de referências, são mais lentos. 

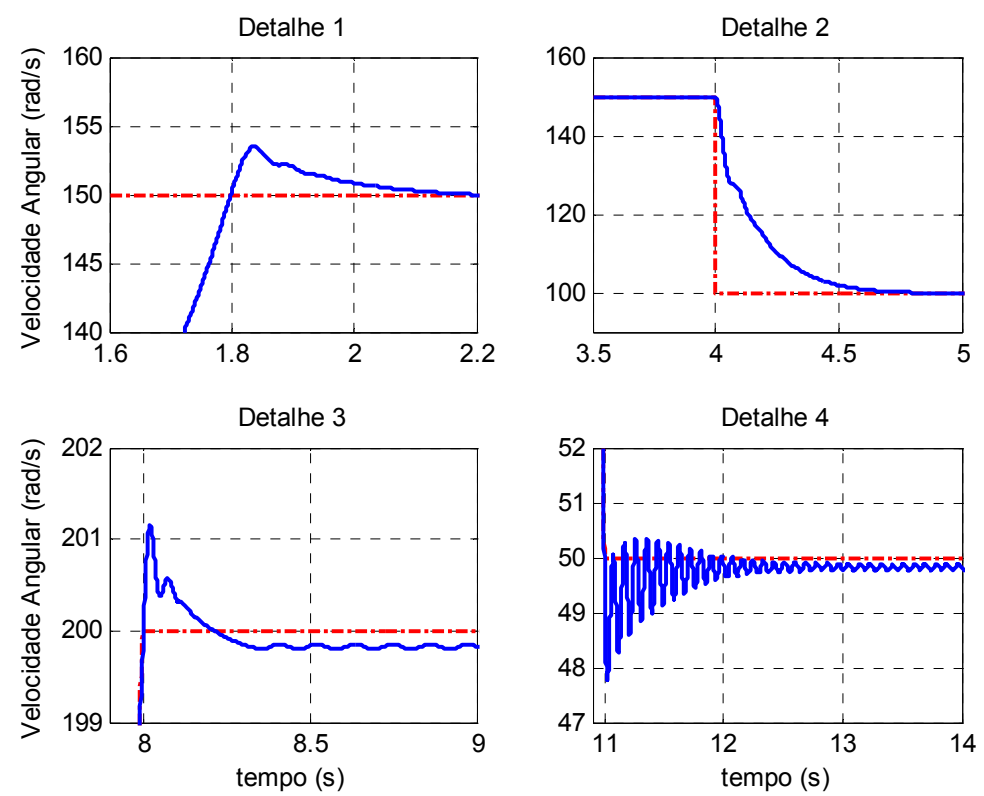

Figura 4.19-Detalhes da Figura 4.18.

A Figura 4.20 representa a análise do controlador fuzzy frente às variações de tensão de alimentação do motor de indução sob a ação de uma carga linear.
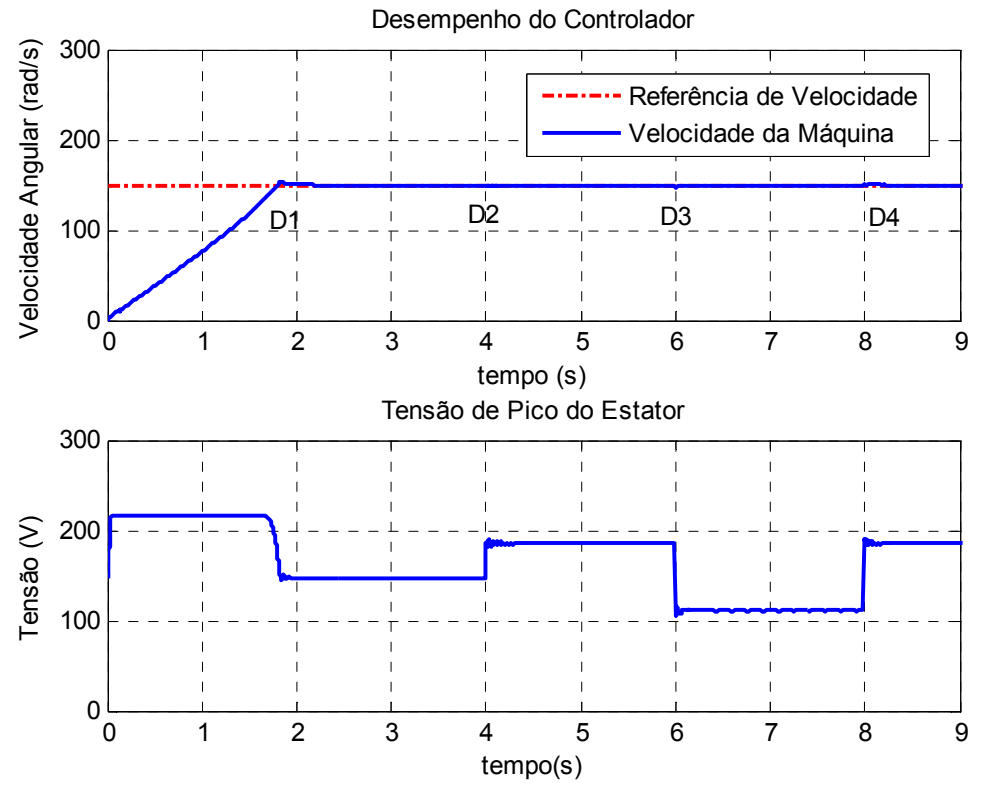

Figura 4.20 - Desempenho do controlador fuzzy frente às variações de tensão. 
A análise das Figura 4.20 e Figura 4.21 revela que, para uma carga linear, o controlador não sofreu grandes influências às variações de tensão, mantendo-se o seu controle com baixo erro de velocidade em regime.
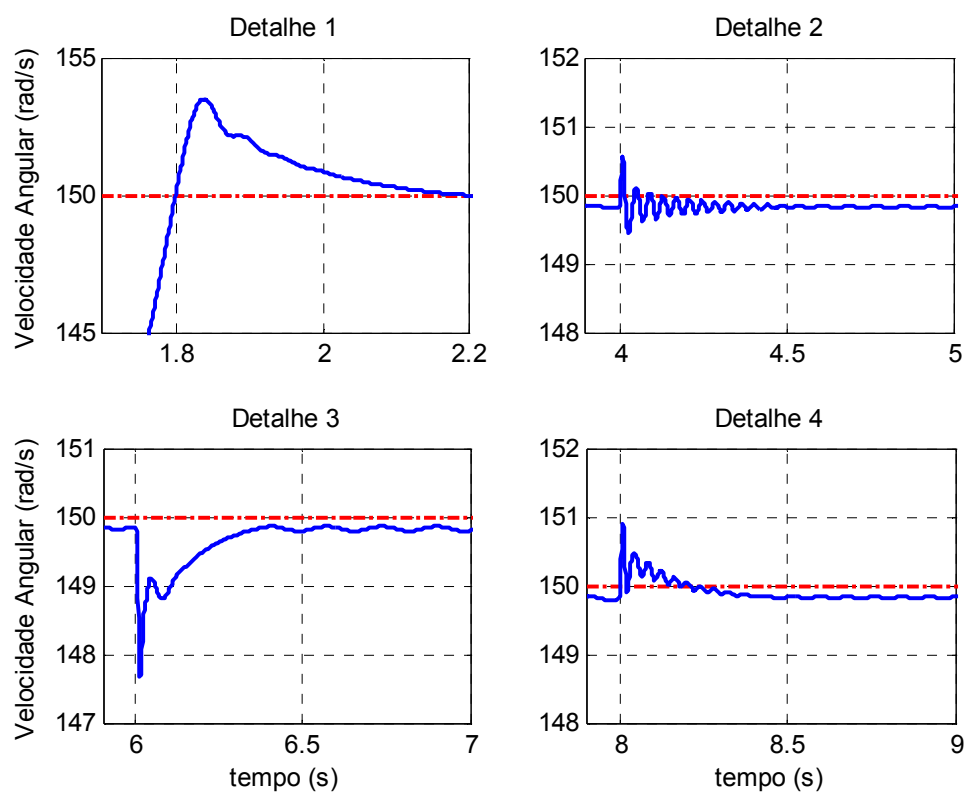

Figura 4.21 - Detalhes da Figura 4.20.

\subsubsection{Resposta à Carga Inversa}

As Figura 4.22 e Figura 4.23 denotam o comportamento do controlador fuzzy do motor de indução sob uma carga inversa frente às variações de referência de velocidade. Uma característica marcante que diferencia das outras cargas reside no tempo elevado de partida da máquina. Isto se deve a fato de que o torque resistente de partida é elevado devido à característica da carga inversa. A resposta do controlador se mostrou eficiente, apresentando baixo sobre-sinal e erro de velocidade em regime. 

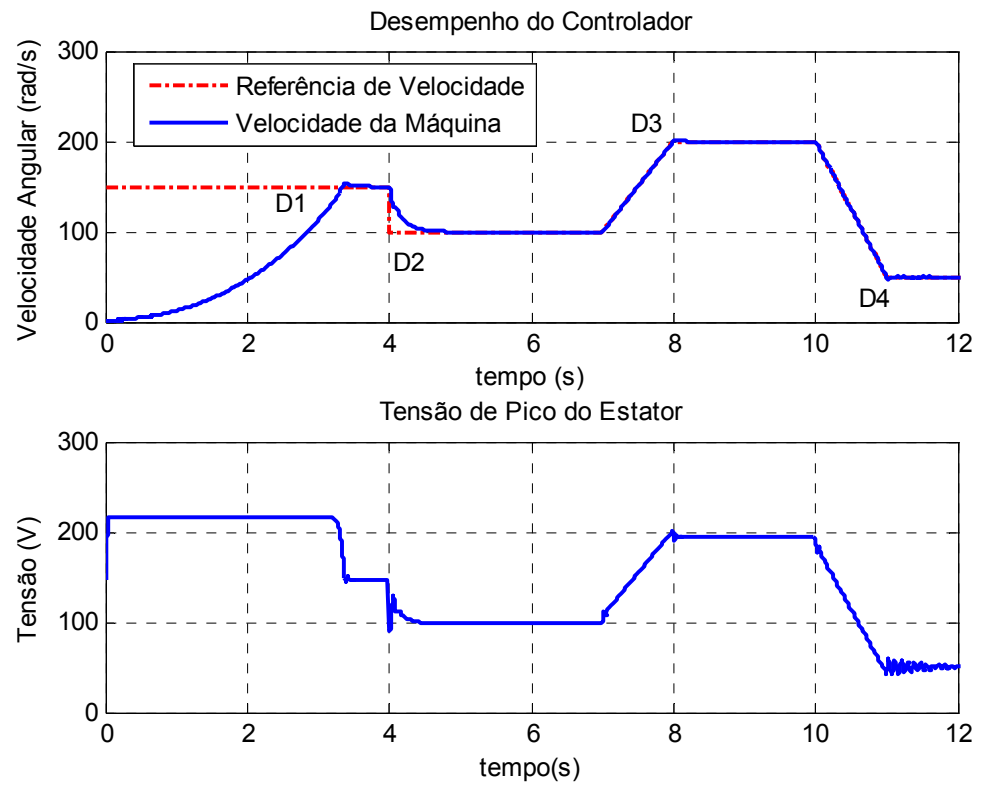

Figura 4.22 - Desempenho do controlador fuzzy frente aos degraus e rampas de referência.
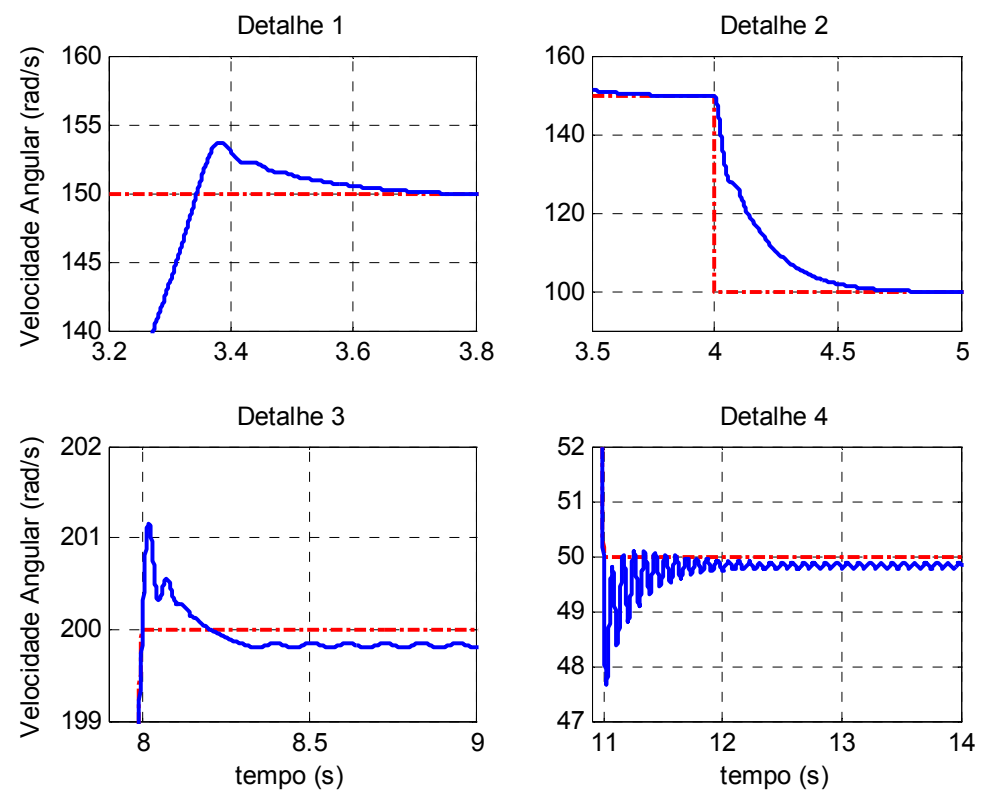

Figura 4.23 - Detalhes da Figura 4.22.

O desempenho do controlador fuzzy frente às variações de tensão de alimentação do motor de indução sob uma carga inversa é denotado pela Figura 4.24 e Figura 4.25. 

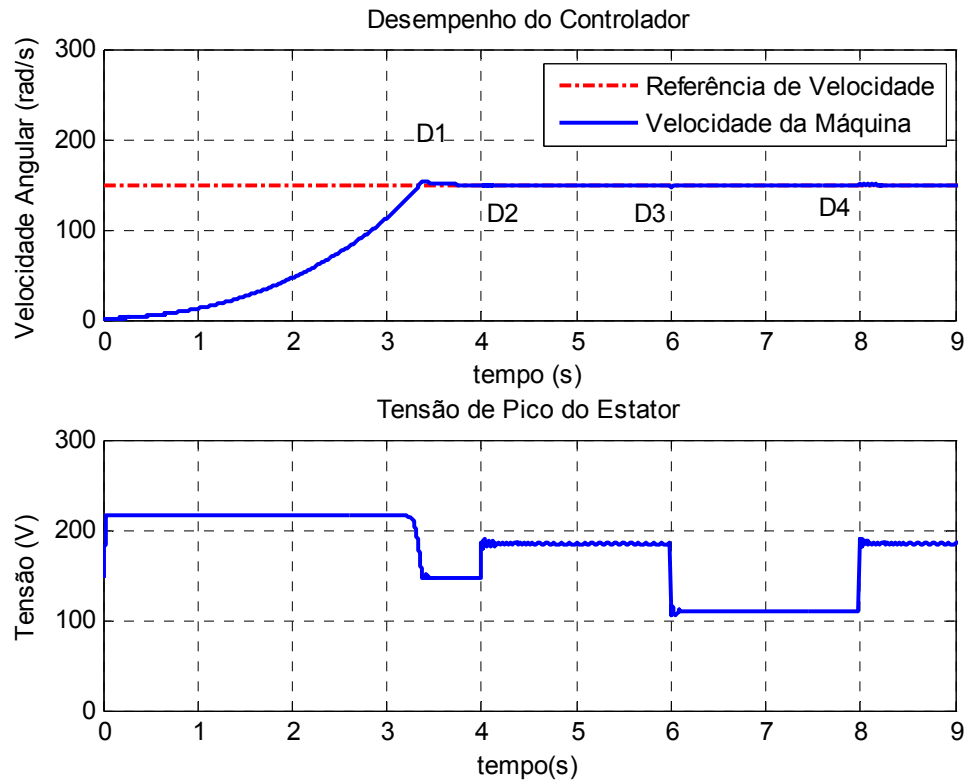

Figura 4.24 - Desempenho do controlador fuzzy frente às variações de tensão.
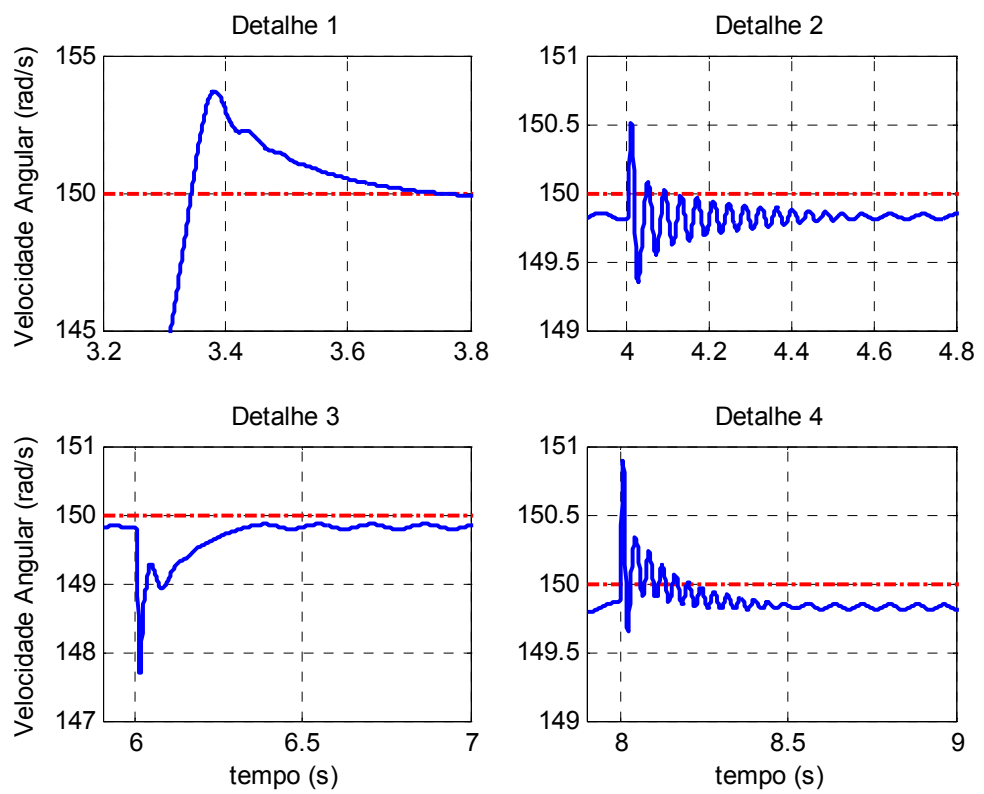

Figura 4.25 - Detalhes da Figura 4.24.

Conforme ilustrado na Figura 4.24 e Figura 4.25, nota-se que o controlador obteve resultados satisfatórios para aplicações que não exigem erros superiores a 5 $\mathrm{rad} / \mathrm{s}$. 


\subsubsection{Resposta à Carga Constante}

A Figura 4.26 e Figura 4.27 descrevem a resposta do controlador fuzzy submetido às variações de referência de velocidade para uma carga de característica constante. Observa-se que o controlador se mostrou eficiente, sendo capaz de acompanhar a curva de referência a de velocidade.
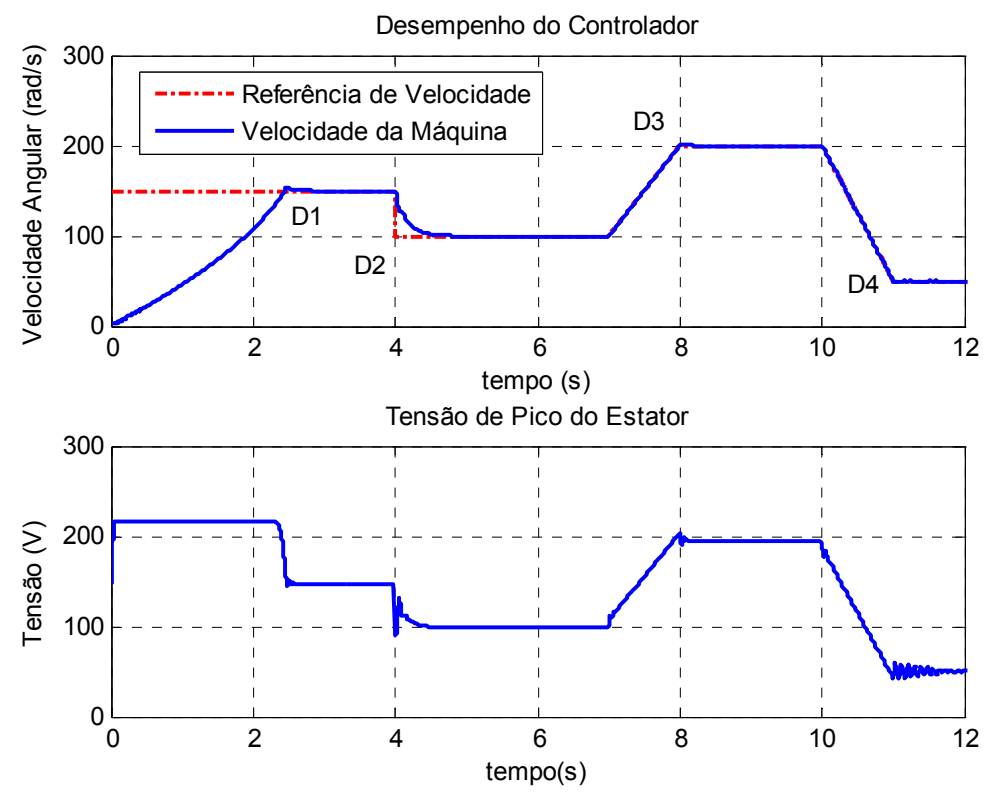

Figura 4.26 - Desempenho do controlador fuzzy frente aos degraus e rampas de referência.

O desempenho do controlador fuzzy frente às variações de tensão de alimentação do motor de indução é denotado pela Figura 4.28 e Figura 4.29. Para uma carga constante, o controlador demonstrou não sofrer influências no seu controle com a variação da tensão de estator. 

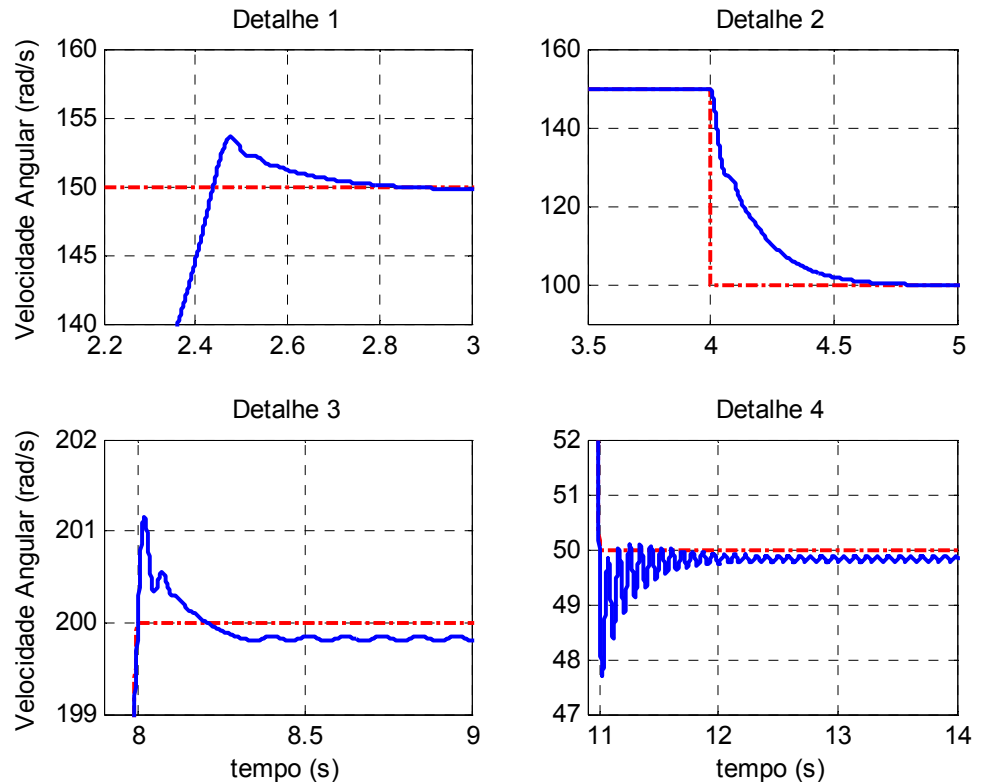

Figura 4.27 - Detalhes da Figura 4.26.
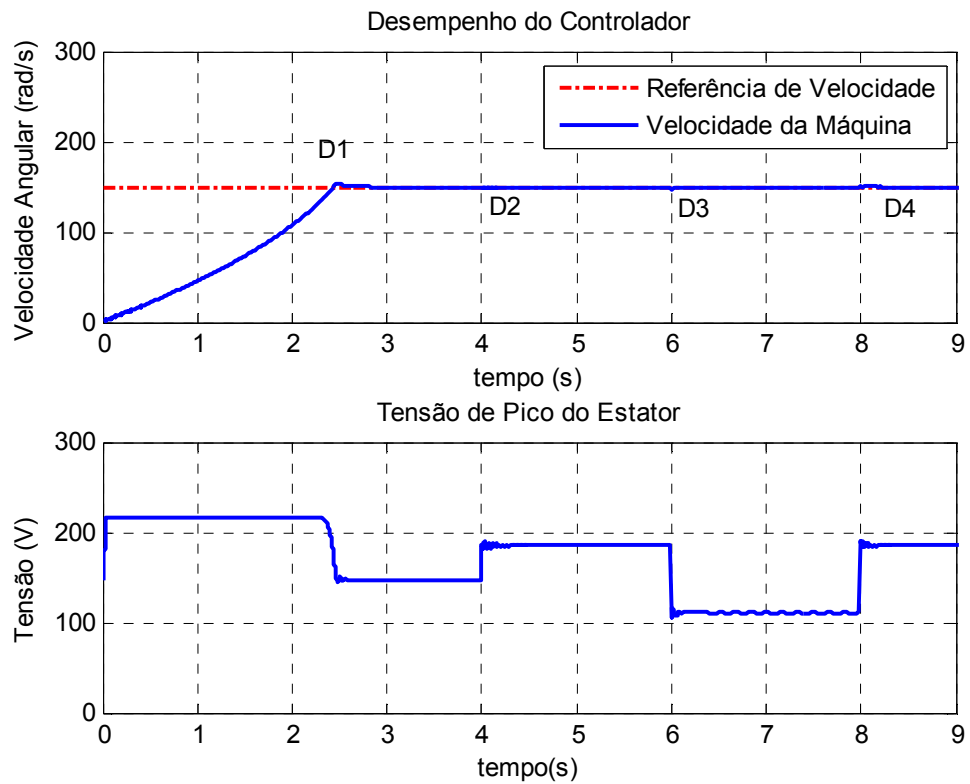

Figura 4.28 - Desempenho do controlador fuzzy frente às variações de tensão. 

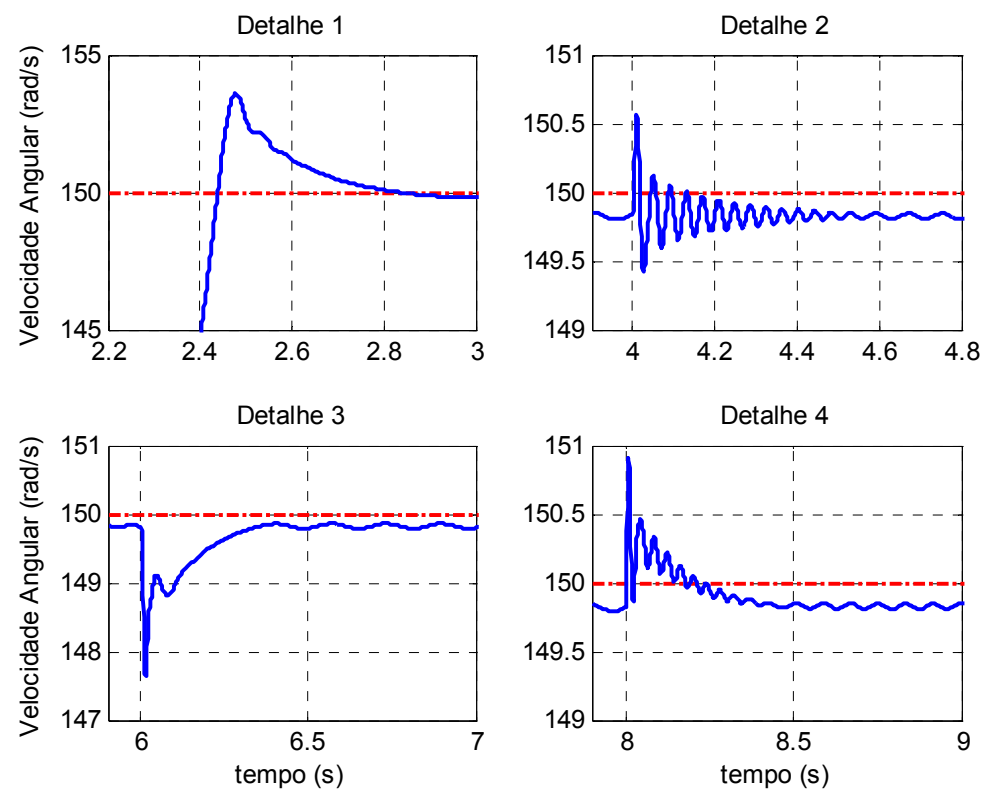

Figura 4.29 - Detalhes da Figura 4.28.

\subsubsection{Resposta aos Degraus de Torque de Carga}

Por fim, analisou-se o desempenho do controlador fuzzy frente aos degraus de torque de carga. Para tanto, partiu-se a máquina com 1,0 Nm. A partir deste valor, aplicaram-se degraus de torque, conforme ilustrado pela Figura 4.30.
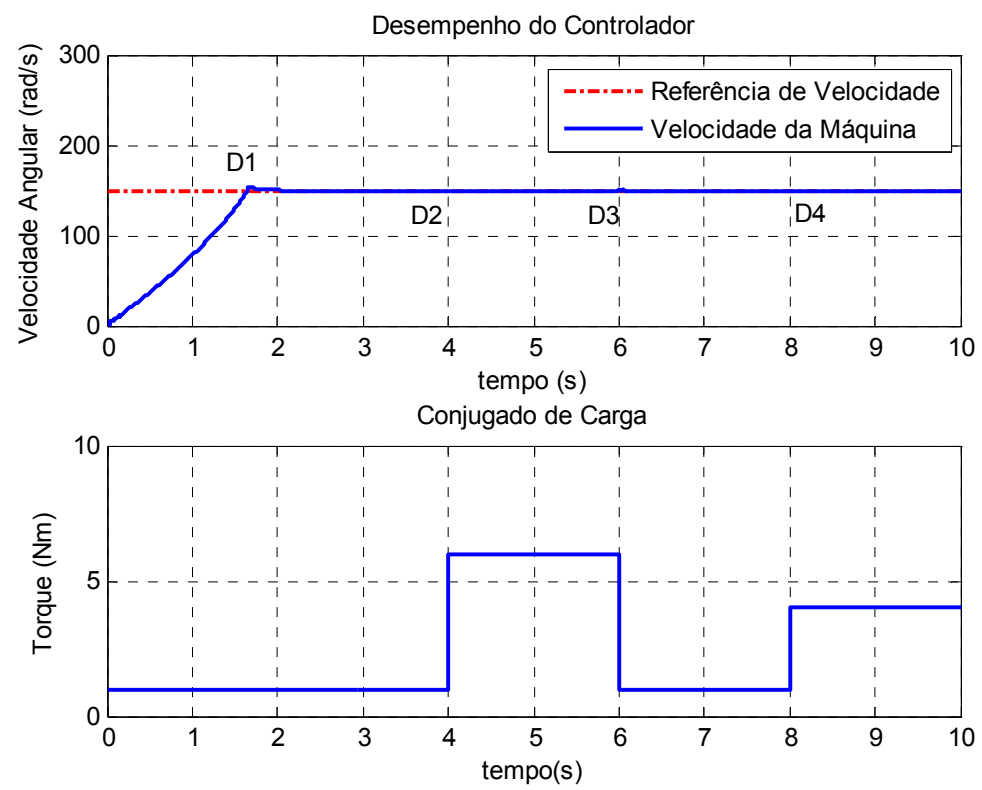

Figura 4.30 - Desempenho do controlador em resposta aos degraus de torque de carga. 
Manteve-se a velocidade de referência a $150 \mathrm{rad} / \mathrm{s}$ para se avaliar adequadamente a influência do degrau de torque na velocidade da máquina.

A Figura 4.30 e a Figura 4.31 revelam que o controlador fuzzy é capaz de compensar adequadamente as influências decorridas da variação brusca de torque de carga, evidenciando a eficiência no seu desempenho.
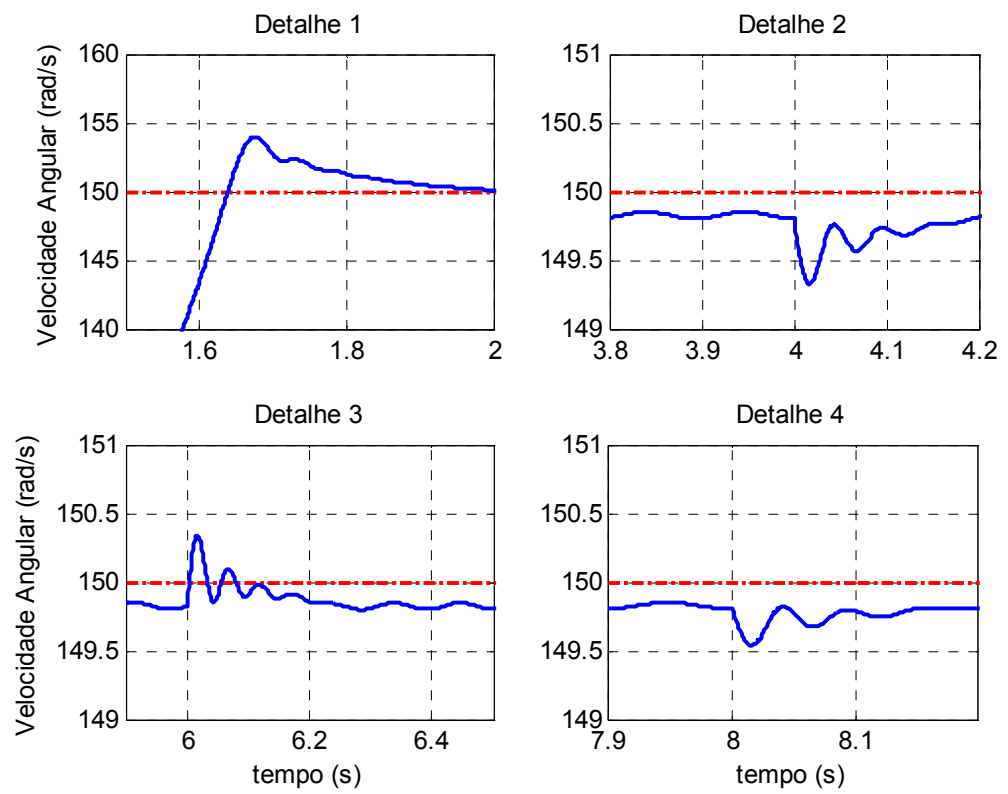

Figura 4.31 - Detalhes da Figura 4.30. 


\section{Projeto do Sistema de Controle Fuzzy Embarcado em DSP}

\subsection{Aspectos Gerais do Sistema de Controle}

Nesta seção serão explicitados os aspectos relacionados ao desenvolvimento do sistema de controle fuzzy de velocidade do MIT. Neste contexto, as descrições dos principais periféricos do DSP TMS320F2812, bem como suas metodologias de ajustes visando à geração de sinais de controle de acionamento do inversor trifásico, serão explanadas sucintamente, sendo necessário a consulta da documentação técnica fornecida pela Texas Instruments (Bormann, 2005; SPRS174N, 2006) para obter informações mais detalhadas sobre o assunto.

O esquema geral de controle do MIT em Hardware é descrito na Figura 5.1. Os pulsos gerados pelo encoder óptico incremental são fornecidos aos canais do DSP, o qual calcula a velocidade angular mediante a aferição da freqüência dos sinais de entrada. O algoritmo de controle fuzzy utiliza as informações da velocidade angular mensurada para processá-las de forma a produzir ondas PWM com modulação senoidal, a qual é responsável pelo acionamento dos IGBTs do inversor trifásico da Semikron. Este, por sua vez, aciona o MIT de modo que o mesmo desenvolva a velocidade de referência. 


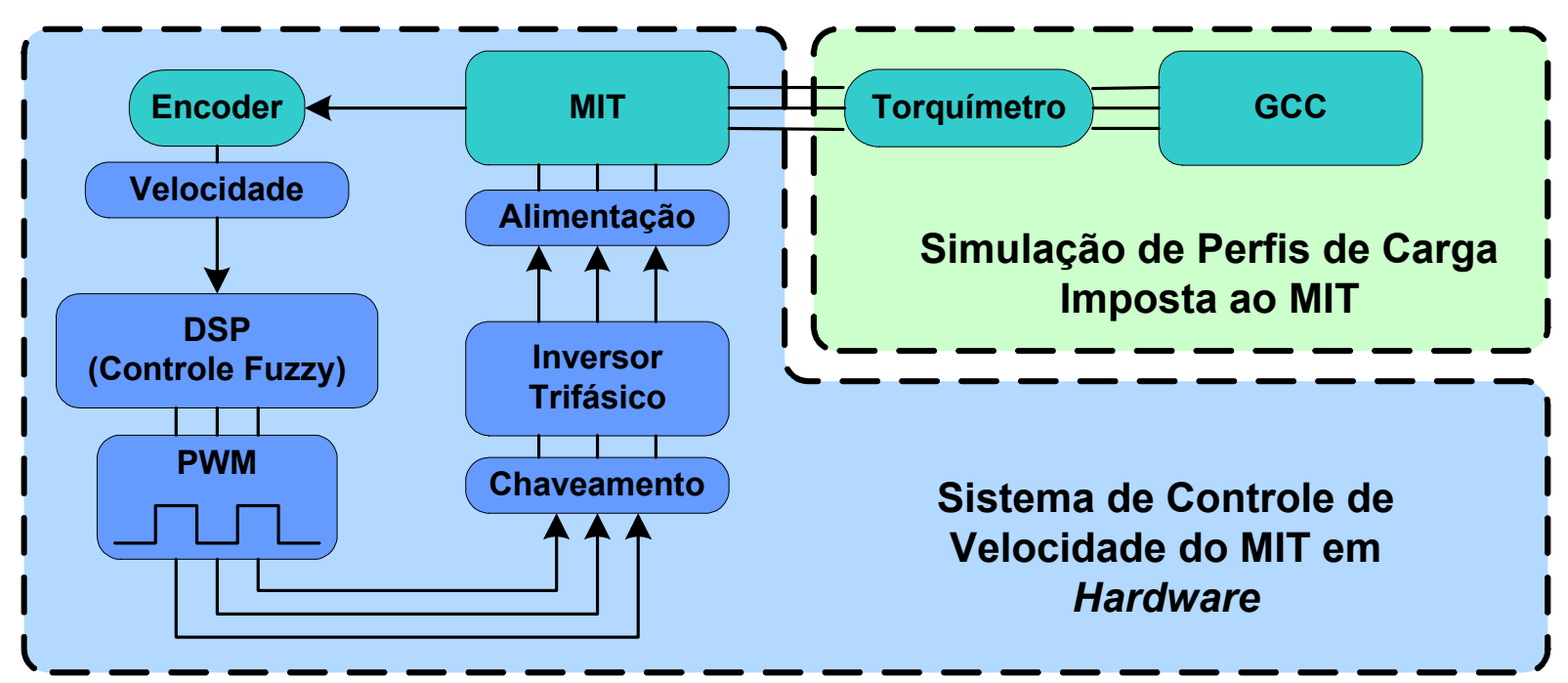

Figura 5.1 - Diagrama de blocos do sistema de controle de velocidade do MIT em hardware.

A aplicação de diversos tipos de cargas imposta ao eixo do MIT, principalmente aqueles que representam a maioria das cargas encontradas em setores industriais, é de extrema relevância tanto para a análise de desempenho do algoritmo de controle de velocidade do MIT quanto para inúmeras aplicações e projetos envolvidos pelo laboratório de pesquisa, tais como estimação de torque de carga (Goedtel, 2003; Silva, 2007) e estimação de velocidade do MIT (Goedtel, 2007).

O esquema inicial desenvolvido para se efetuar a geração de torque de carga a partir de um GCC é ilustrado na Figura 5.2. A alimentação da rede é convertida em tensões contínuas por meio de um conversor CA/CC. Em seguida, emprega-se um módulo de potência da International Rectifier, IRAMX16UP60B, na estrutura de Ponte $\mathrm{H}$ com o intuito de gerar uma tensão modulada em largura de pulsos (PWM) que alimenta o enrolamento de campo do GCC. Conseqüentemente, por meio do controle de ciclo de trabalho do PWM, possibilita-se a variação do fluxo do enrolamento de campo que está diretamente relacionada com o torque eletromagnético do gerador, conforme descrito nas Equações (2.65) e (2.68). 


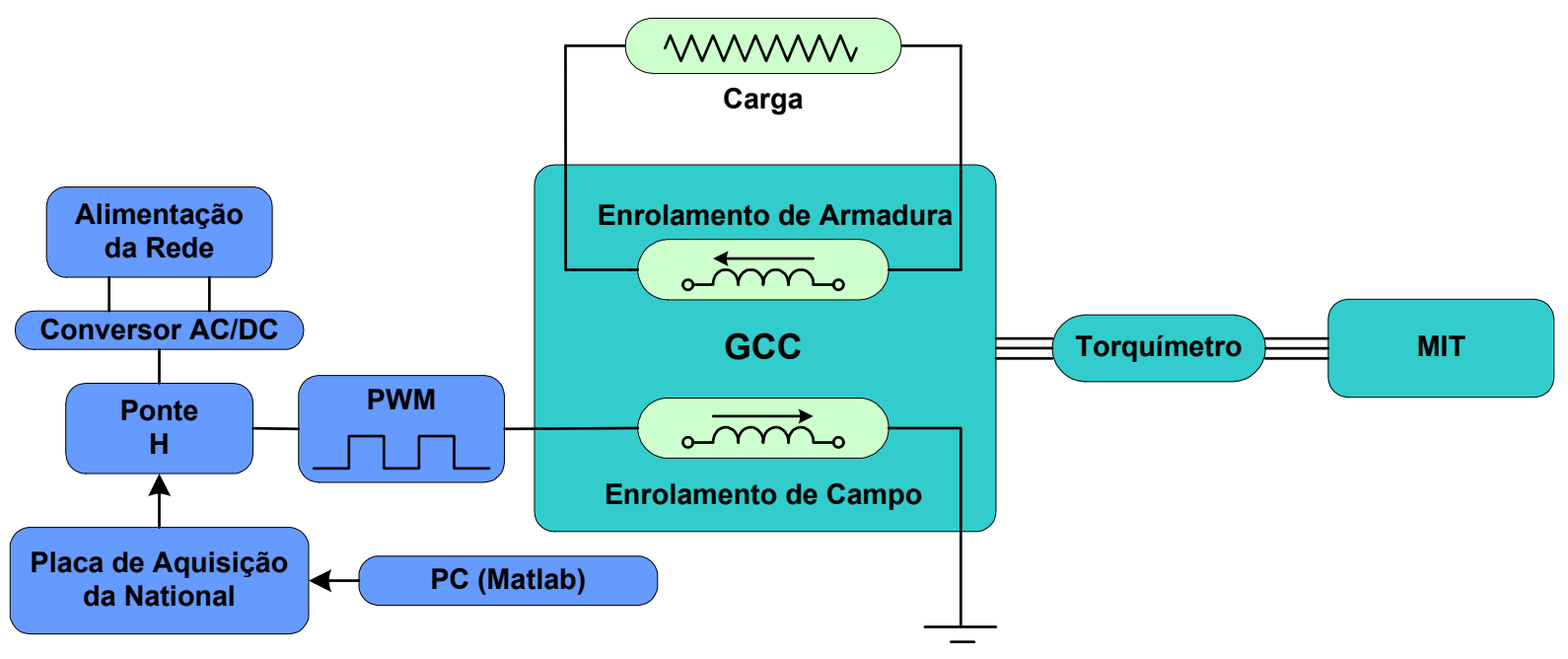

Figura 5.2 - Diagrama de blocos do esquema de geração de perfis de carga imposta ao MIT.

O algoritmo de controle será implementado no ambiente Matlab ${ }^{T M}$ por meio do pacote Matlab ${ }^{\mathrm{TM}} /$ Real-Time Windows Target $^{\mathrm{TM}}$, cujo desenvolvimento é realizado dentro do Matlab ${ }^{T M} /$ Simulink $^{T M}$. Os sinais de PWM de referência desenvolvidos pelo algoritmo são enviados à Ponte H por intermédio da placa de aquisição da National Instruments, a qual também apresenta interfaces digitais de saída. Vale salientar que esta fase ainda está em estudo, no entanto, testes preliminares para efetuar um simples controle de um motor de corrente contínua já foram realizados.

A integração do pacote de ferramentas computacionais do Matlab ${ }^{T M} \operatorname{com}$ os recursos presentes no laboratório se torna interessante, uma vez que possibilita a implementação rápida de algoritmos que podem ser testados e validados em um tempo hábil de projeto.

\subsection{Aspectos Fundamentais de DSP}

O Processador Digital de Sinal (DSP) é um dispositivo especificamente projetado para realizar operações matemáticas voltada à manipulação de dados digitais advindos de sinais de sensores. O objetivo é processar os dados de forma 
rápida e eficiente para viabilizar a aplicação em sistemas de tempo real. Para tanto, dentre as diversas funções implementadas em hardware que visam aprimorar o seu desempenho, destaca-se a operação "Multiplicar e Acumular", visto que a maioria dos algoritmos que envolvem o processamento digital de sinais requer que seja efetuada a somatória dos produtos de dois ou mais sinais ao longo de uma determinada janela de dados. Esta instrução otimizada em hardware torna o sistema mais rápido e adequado para aplicações em tempo real.

O Digital Signal Controller (DSC) consiste de um tipo de micro-controlador, cujo poder de processamento é fornecido por um DSP combinado com memórias e periféricos embarcados em um único dispositivo. Desta forma, para sistemas de controle em tempo real de alto desempenho, nas quais exigem uma carga elevada de cálculos matemáticos, o DSC se torna o elemento mais efetivo para soluções de aplicações de tal porte.

Nos catálogos da Texas Instruments, os DSP/DSC são enquadrados nas famílias C2000, C5000 e C6000.

O ramo da família C6000 consiste das series de DSP mais potentes no que diz respeito ao poder de processamento. São encontrados processadores digitais tanto de ponto fixo quanto de ponto flutuante. Os campos de aplicações são: processamento de imagem, áudio, servidores de multimídia, estação base para comunicação wireless, etc.

A família C5000 é focada em sistemas que requerem uma elevada taxa de eficiência no consumo de energia por mega-instruções por segundo (MIPS). Sua principal área de aplicação reside no desenvolvimento de tecnologias para celulares.

Finalmente, a família C2000 se enquadra na categoria de DSP de baixo custo, cuja principal área de atuação consiste em sistemas de controle digital e 
controle de máquinas elétricas. Este é um dos principais motivos pelo qual o DSP da Texas Instruments TMS320F2812 pertencente a esta série foi adquirido para o laboratório de pesquisa. A Figura 5.3 ilustra o kit de desenvolvimento ezDSP TMS320F2812 fabricado pela empresa Spectrum Digital.

DSP TMS320F2812 consiste na "Arquitetura Havard", na qual o barramento de dados e o barramento de programa são independentes entre si, o que possibilita buscar dois operandos da memória à unidade central de processamento em um único ciclo de clock. Devido à habilidade de leitura simultânea de operandos advindos tanto da memória de dados quanto da memória de programa, a Texas Instruments o denomina de "Arquitetura Havard Modificada".

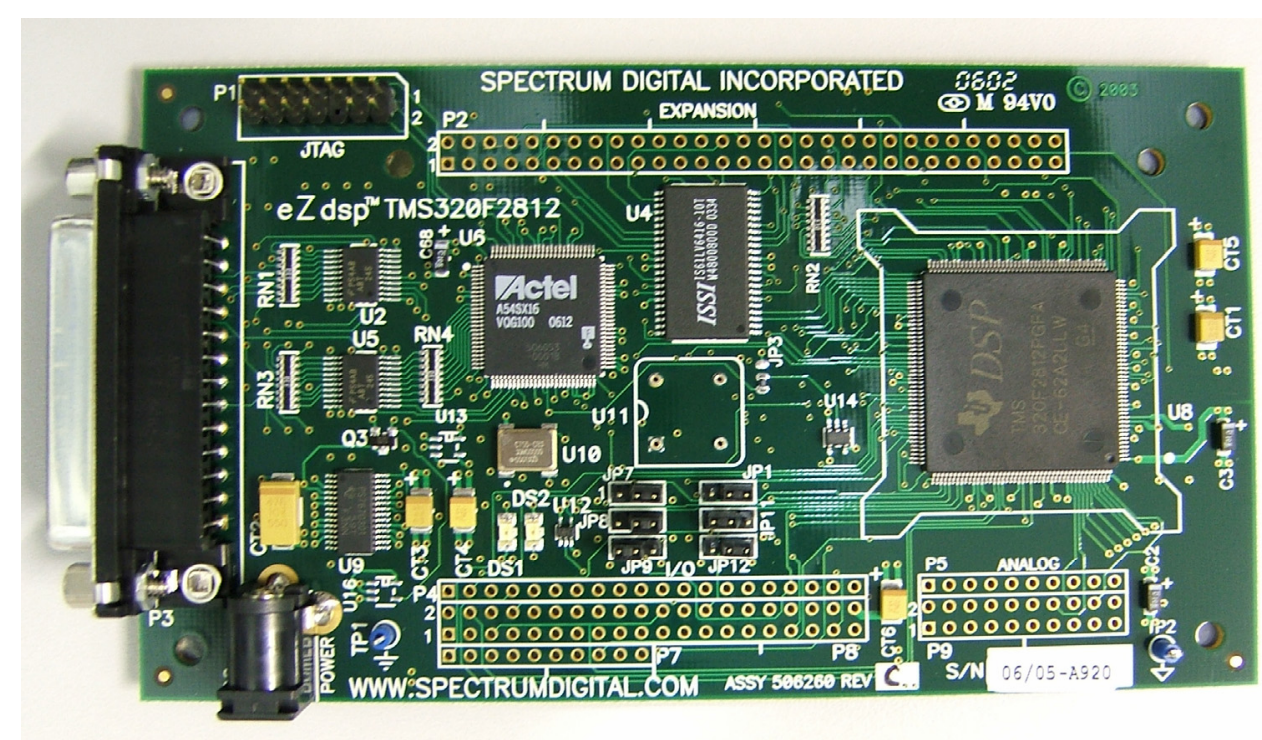

Figura 5.3 - Kit de desenvolvimento eZDSP-TMS320F1812.

Dentre as principais características fundamentais do F2812, destacam-se:

- Trabalha com clock de $150 \mathrm{MHz}$, na qual uma instrução é realizada em apenas um ciclo, ou seja, o DSP é capaz de realizar 150 MIPS. Isso equivale a aproximadamente 6,67 ns de tempo gasto para uma instrução.

- A memória interna consiste de até $128 \mathrm{k}$ x 16 de memória Flash, $1 \mathrm{k}$ x 16 de memória OTP (One-Time Programmable), dois blocos L0 e L1 de 
4k x 16 de memória SARAM (Single-Access Memory), um bloco H0 de 8k x 16 SARAM e finalmente dois blocos M0 e M1 de $1 \mathrm{k} \times 16$ de SARAM. Com memória externa, a mesma pode ser expandida em até $1 \mathrm{MB}$ de memória total.

- Apresenta suporte para interrupções de até 45 dispositivos; três Timers de 32 bits; 56 portas de I/O para propósito genérico, 16 canais de PWM compartilhadas com as portas de I/O e 16 canais de conversores A/D de 12bits.

- Contém periféricos, EVA e EVB (Event Manager A e B), voltados para aplicações específicas de controle de máquinas elétricas, nos quais apresentam um conjunto de registradores que podem ser configurados para desenvolver formas de onda dos sinais de PWMs responsáveis pelo acionamento do inversor.

- Dispõe-se de periféricos para leitura de sinais de encoder, QEP (Quadrature Encoder Pulse Unit), que possibilitam mensurar grandezas como velocidade, posição e sentido de rotação. Além disso, a unidade pode quadruplicar, em hardware interno, a freqüência dos pulsos do encoder contribuindo para a melhoria da resolução da medição da grandeza de interesse.

- Constitui de interfaces seriais, tais como: SPI (Serial Peripheral Interface), SCI (Serial Comunications Interfaces), eCAN (Enhanced Controller Área Network) e McBSP (Multichannel Buffered Serial Port). 


\subsubsection{Clock Module}

O DSP TMS320F2812 trabalha com um oscilador externo com freqüência reduzida com o intuito de minimizar os efeitos de distúrbios eletromagnéticos. No caso do kit de desenvolvimento utilizado nesta dissertação, o ezDSP TMS320F2812, emprega-se um oscilador de $30 \mathrm{MHz}$. Para atingir a freqüência interna de $150 \mathrm{MHz}$ é necessário configurar adequadamente o registrador Phase-Locked Loop Control Register (PLLCR). A Figura 5.4 ilustra o diagrama esquemático do módulo que define a freqüência de trabalho do DSP.

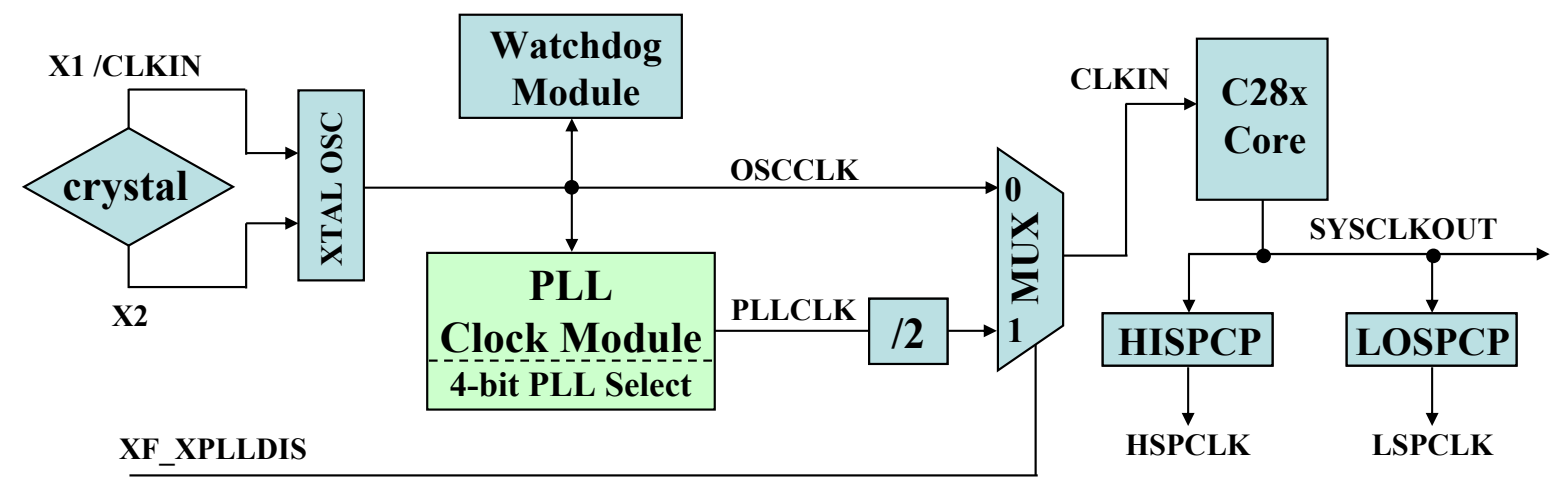

Figura 5.4 - Representação interna do conjunto: oscilador e PLL clock module.

Fonte: (Bormann, 2005)

O sinal de clock de $30 \mathrm{MHz}$ gerado pelo cristal do oscilador externo é fornecido diretamente ao Watchdog Module e PLL Clock Module, conforme a Figura 5.4 .

O Watchdog Module consiste de um contador contínuo que, quando o mesmo atinge o seu valor máximo, reinicializa a CPU ou executa uma determinada rotina de interrupção, a menos que uma determinada seqüência de instruções seja executada para reinicializar o contador. Esta função é empregada como ação de segurança para casos como falhas ou travamentos de execução de um determinado trecho de código do programa. 
O PLL clock module, pertencente ao registrador PLLCR (PLL Clock Control Register), constitui-se de 4 bits que define o fator de multiplicação da freqüência de oscilação de entrada, conforme descrito na Figura 5.4. De acordo com os valores contidos na Tabela 5.1, a definição do clock interno da CPU para 150MHz pode ser realizada mediante a atribuição dos bits 3 até 0 do registrador PLLCR para 1010 (binário), visto que a freqüência de entrada é multiplicada por 10 e, em seguida, dividida por 2 .

Tabela 5.1 - Definição do registrador PLLCR para o fator de multiplicação de freqüência.

\begin{tabular}{|c|c|c|c|c|c|}
\hline \multirow{12}{*}{$\begin{array}{l}\text { PLLCR } \\
\text { bits 15:4 } \\
\text { reserved }\end{array}$} & DIV3 & DIV2 & DIV1 & DIV0 & Clock Frequency (CLKIN) \\
\hline & $\mathbf{0}$ & $\mathbf{0}$ & $\mathbf{0}$ & $\mathbf{0}$ & OSCCLK x 1 / 2 (no PLL) \\
\hline & $\mathbf{0}$ & $\mathbf{0}$ & $\mathbf{0}$ & 1 & OSCCLK x 1 / 2 \\
\hline & $\mathbf{0}$ & $\mathbf{0}$ & 1 & $\mathbf{0}$ & OSCCLK x $2 / 2$ \\
\hline & 0 & $\mathbf{0}$ & 1 & 1 & OSCCLK x 3 / 2 \\
\hline & $\mathbf{0}$ & 1 & $\mathbf{0}$ & $\mathbf{0}$ & OSCCLK x 4 / 2 \\
\hline & $\mathbf{0}$ & 1 & 0 & 1 & OSCCLK x 5 / 2 \\
\hline & $\mathbf{0}$ & 1 & 1 & $\mathbf{0}$ & OSCCLK x 6 / 2 \\
\hline & $\mathbf{0}$ & 1 & 1 & 1 & OSCCLK x $7 / 2$ \\
\hline & 1 & $\mathbf{0}$ & $\mathbf{0}$ & $\mathbf{0}$ & OSCCLK x 8 / 2 \\
\hline & 1 & $\mathbf{0}$ & $\mathbf{0}$ & 1 & OSCCLK x 9 / 2 \\
\hline & 1 & $\mathbf{0}$ & 1 & $\mathbf{0}$ & $\operatorname{OSCCLK} \times 10$ / 2 \\
\hline
\end{tabular}

Fonte:(Bormann, 2005)

Cabe observar que os procedimentos supracitados para a definição da freqüência de trabalho da CPU somente serão válidos quando o registrador XF_XPLLDIS estiver ativando adequadamente o MUX da Figura 5.4; caso contrário, o sinal do oscilador será conectado diretamente à CPU. Por padrão, o DSP se inicia com freqüência de trabalho proveniente do PLL Module.

Os registradores HISPCP (High Speed Prescaler Clock Register) e LOSPCP (Low Speed Clock Prescaler Clock Register) representados na Figura 5.4 podem ser ajustados de forma a dividir a freqüência de entrada (SYSCLKOUT). O sinal resultante pode ser utilizado pelos periféricos do DSP, tais como Timers do Event 
Manager, conversores A/D, entre outros. A configuração adequada de tais registradores é relevante visto que a geração de sinais PWM é realizada a partir do módulo Event Manager, em que a base de tempo se baseia no clock fornecido na saída do HISPCP. Os detalhes sobre o registrador podem ser encontrados em SPRS174 (2006), SPRU078 (2006) e Bormann (2005).

\subsubsection{Portas de I/O}

Todas as entradas e saídas digitais estão agrupadas em Portas denominadas de GPIO-A, B, D, E, F e G, em que o termo "GPIO" provém de "General Purpose Input Output". A família c28x é equipada com diversas unidades interna com funções especiais, tais como geração de sinais PWM, captura de pulsos originados por encoders para medição de velocidade e posição angular, comunicação entre periféricos externos, entre outros, as quais são compartilhadas (multiplexadas) com as I/O digitais. Desta forma, um único pino físico do DSP pode ser definido como I/O digital ou como função especial. Os detalhes sobre quais são as funções atribuídas a cada pino podem ser encontrados na documentação técnica da Texas Instruments (Bormann, 2005; SPRS174N, 2006; SPRU078, 2006).

Os principais registradores relacionados ao manuseio das portas GPIO são os seguintes:

- GPxMUX: Consiste de um registrador de 16 bits responsável pela definição da porta "x" como I/O digital ou função especial, onde "x" pode $\operatorname{ser} A, B, D, E, F$ ou $G$.

- GPxDIR: Este registrador de 16 bits efetua o controle da direção do fluxo de dados dos pinos configurados como I/O digital pelo GPxMUX, ou seja, os define como entrada ou saída digital. 
- GPxQUAL: Caso as portas A, B, D ou E sejam definidas como entrada digital, a função "Input Qualification Feature" pode ser ativada pelo registrador GPXQUAL, de forma que a entrada digital só será reconhecida caso o nível lógico se mantenha por determinados ciclos de clock. Esta função é relevante para aplicações que apresentam ruídos digitais, como, por exemplo, o acionamento manual de uma chave.

- GPxDAT: Neste registrador de 16 bits são armazenados os dados relativos às entradas e saídas digitais. O nível lógico do sinal conectado no pino configurado como entrada digital pode ser adquirido por meio da leitura deste registrador. Por outro lado, quando se deseja atribuir um nível lógico no pino de saída digital, basta efetuar a operação de escrita neste registrador.

\subsubsection{Sistema de Interrupções}

As interrupções são definidas como eventos assíncronos gerados por unidades de hardwares internos ou externos que causam uma interrupção na execução do programa atual do DSP para tratar rotinas dedicadas. Após o término da rotina de interrupção, o programa principal reiniciará a execução do ponto em que havia sido interrompido.

A família de DSP C28x dispõe-se de 16 linhas de interrupções, conforme ilustrado na Figura 5.5. As linhas NMI (Non Maskable Interrupt) e $\overline{\mathrm{RS}}$ (Reset) são não mascaráveis, ou seja, a requisição de interrupção não pode ser negada. Desta forma, uma vez que o sinal da linha se torna ativa, a execução do programa principal será suspendida para atender a rotina dedicada de interrupção. Por outro lado, as 14 linhas restantes, INT1-INT14, são mascaráveis. Portanto, uma máscara deve ser 
definida no registrador IER (Interrupt Enable Register) para selecionar quais linhas terão permissão para receber requisição de interrupções, conforme ilustrado na Figura 5.6.

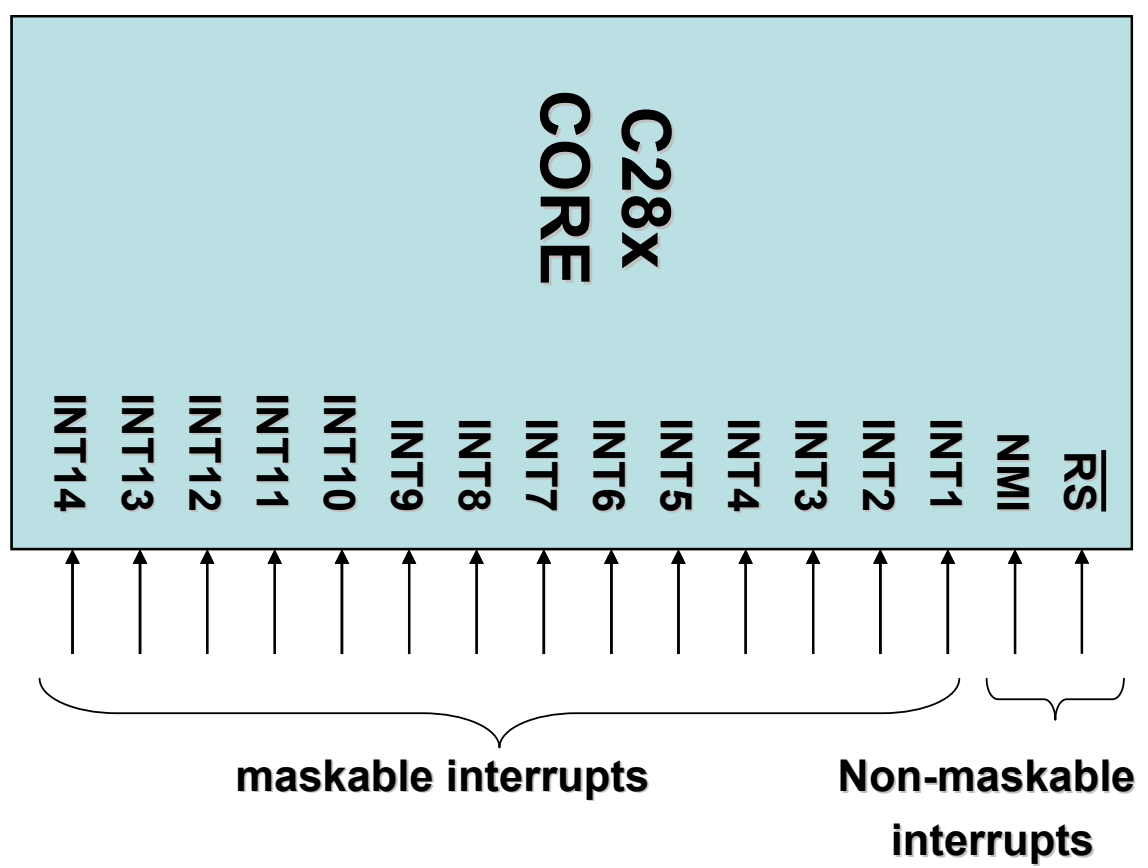

Figura 5.5 - Linhas do sistema de interrupções do DSP.

Fonte: (Bormann, 2005)

O registrador IFR (Interrupt Flag Register) consiste de um Latch que retém o sinal de requisição de interrupção oriundo dos periféricos relativos aos terminais INT1-INT14, até que os mesmos sejam atendidos de acordo com a máscara definida pelo registrador IER. O registrador INTM (Interrupt Mask) pode ser comparado a uma chave global que habilita/desabilita todas as interrupções relativas às linhas INT1-INT14. Uma vez que a interrupção seja reconhecida pela CPU, a flag do registrador IFR é reinicializada. 


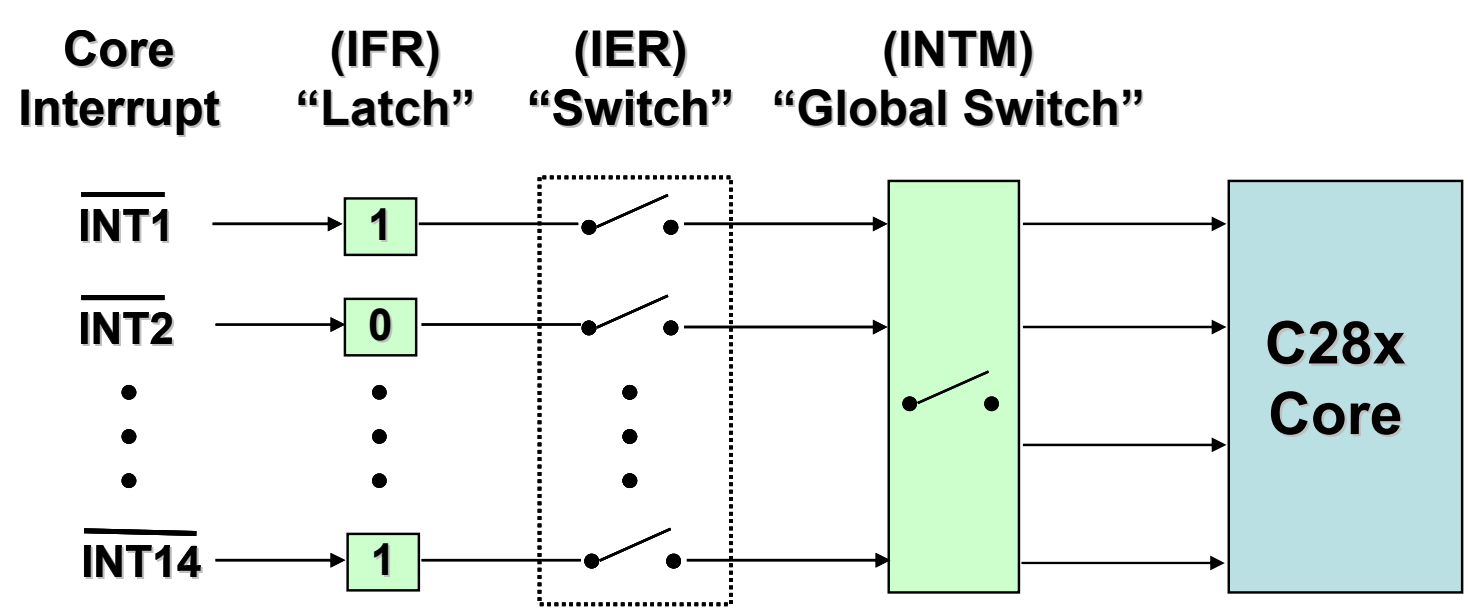

Figura 5.6 - Processo de máscara de interrupções.

Fonte: (Bormann, 2005)

O DSP constitui de uma variedade de periféricos ( $E V$, Timers, QEP, etc.) que podem exigir da CPU a execução de suas rotinas de interrupções. Certamente, as 14 linhas de interrupções apresentadas na Figura 5.5 seriam insuficientes para atender todos esses periféricos, sendo necessária a utilização de uma única linha para múltiplas fontes. Em virtude de cada linha de interrupção estar associada a um endereço no espaço de memória que serão alocados os códigos da rotina de interrupção, é necessário identificar por software os periféricos na entrada da função para executar a rotina apropriada. Entretanto, este método proporciona um custo computacional adicional que pode limitar algumas aplicações de tempo real.

Para contornar tal problema, o DSP dispõe de uma unidade de expansão de endereços para alocação de rotinas de interrupções denominada de PIE (Peripheral Interrupt Expation), a qual aumenta a capacidade de atendimento para 96 periféricos, conforme ilustrada na Figura 5.7. 


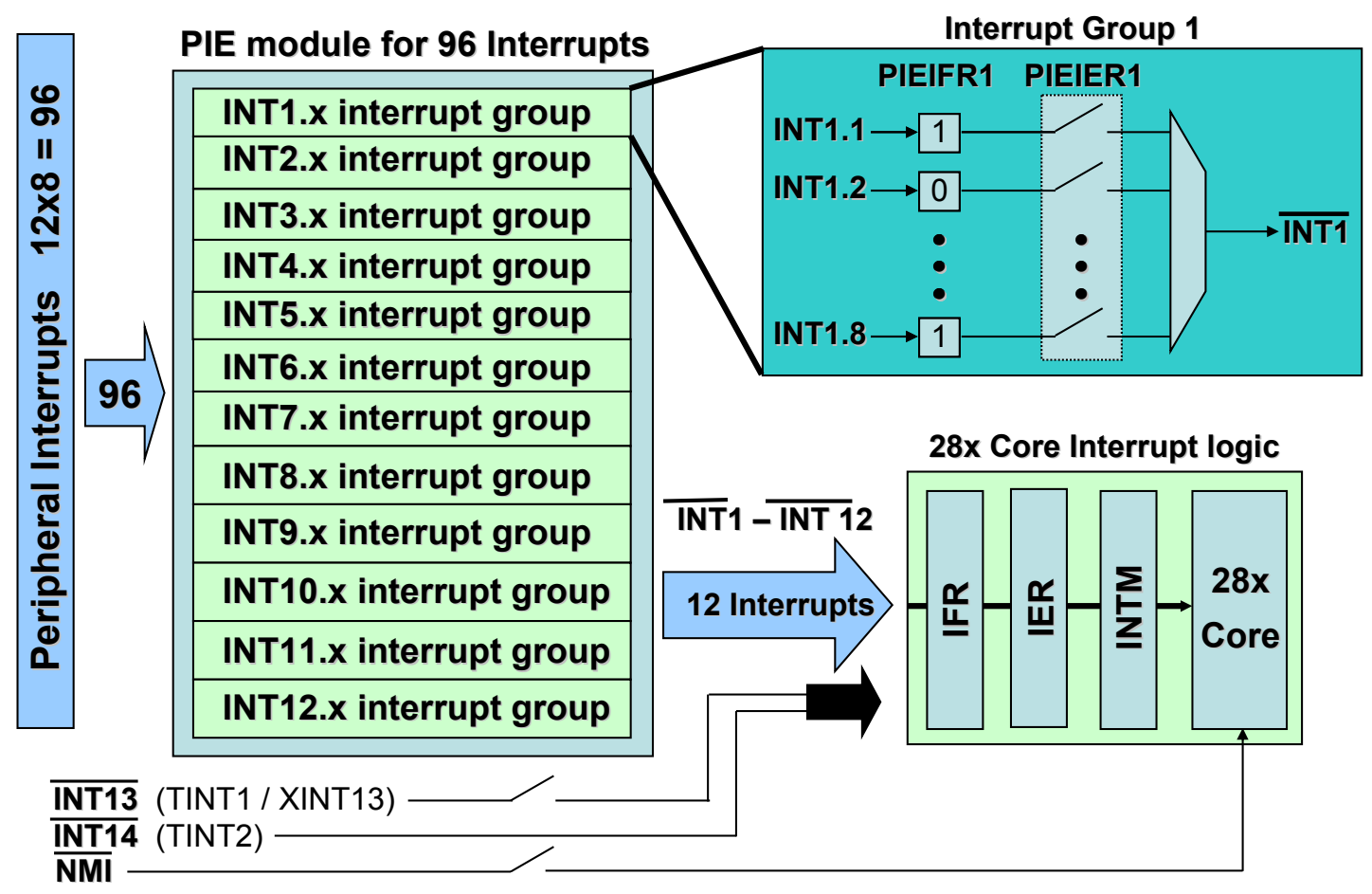

Figura 5.7 - Diagrama de esquemático do PIE.

Fonte: (Bormann, 2005)

As linhas de interrupções INT1-INT12 são conectadas à unidade PIE, nas quais cada uma delas pode atender um grupo de até 8 periféricos. Por meio dos registradores PIEIFR (PIE Interrupt Flag Register) e PIEIER (PIE Interrupt Enable), possibilita-se selecionar quais periféricos serão atendidos para executar a rotina de interrupção.

Por exemplo, a interrupção de underflow do Timer 0 da CPU está associada ao sétimo bit da linha TINT1, ou seja, bit TINT1.7. No momento em que o contador do Timer0 atinge o valor zero, o registrador PIEIFR1, assim como o IFR, mantém o sinal de requisição de interrupção ativo. Caso o PIEIER1 esteja habilitado, a linha INT1 se torna ativa, proporcionando a execução da rotina de interrupção. Após o sinal de reconhecimento da CPU, o estado do IFR1 e PIEIFR1 é reinicializado.

Este Timer foi empregado nesta dissertação para definir a base de tempo da aplicação de 1us, cuja rotina de interrupção consiste no incremento de um 
contador. Desta forma, caso uma determinada rotina exija que seja executada a cada $20 \mathrm{~ms}$, basta que a diferença no valor do contador seja de $20 \mathrm{~ms} / 1 \mu \mathrm{s}=20.000$ unidades.

Uma diversidade de periféricos está associada a cada linha de interrupções. Os detalhes dessas informações podem ser encontrados na documentação técnica da Texas Instruments. (Bormann, 2005; SPRS174N, 2006; SPRU078, 2006).

\subsubsection{Event Manager}

O Event Manager consiste de um módulo que contém múltiplas funções internas implementadas em hardware, tais como geração de PWM, aferição de velocidade e posição angular, sincronização de conversores A/D, que são dedicadas a uma ampla faixa de aplicações voltadas ao controle digital de máquinas elétricas.

Dentre os principais periféricos, destacam-se 4 Timers/Counters para propósito genérico, registradores de comparação para geração simultânea de até 16 PWM, sendo 12 PWM especialmente dedicados ao acionamento de 2 inversores trifásicos, nos quais contém lógica de tempo morto (Dead Band) que evita o acionamento simultâneo dos transistores superiores (TOP) e inferiores (BOT) da ponte H, unidades CAP/QEP (Capture/Quadrature Encoder Pulse) para aferição de velocidade, e finalmente, registradores dedicados à inicialização da operação dos conversores $A / D$.

O EV constitui de dois módulos simétricos, EVA e EVB. A Figura 5.8 representa o diagrama de blocos relativo a um dos módulos (EVA), visto que a estrutura do EVB é semelhante ao EVA. 


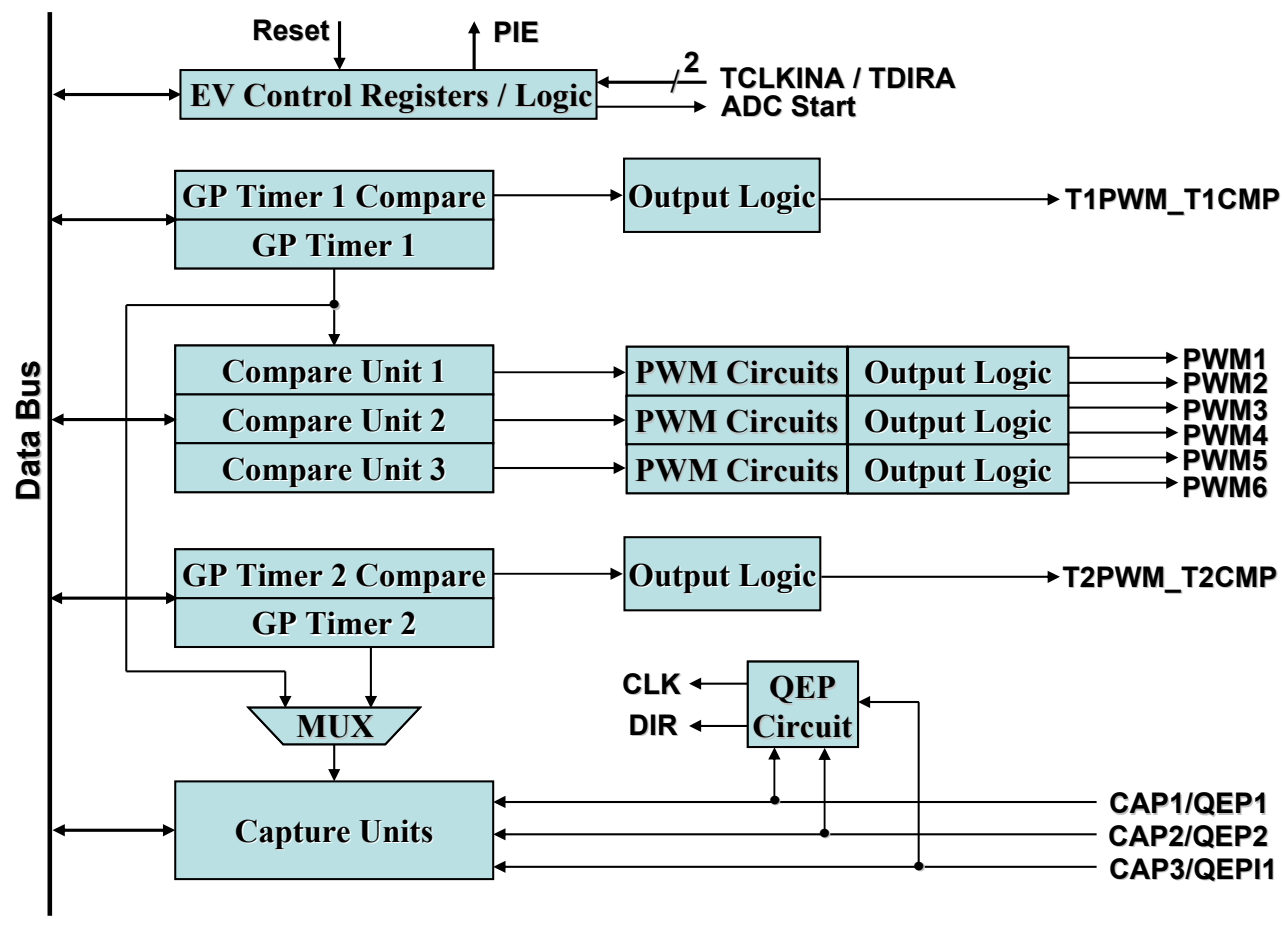

Figura 5.8 - Diagrama de blocos da unidade Event Manager A.

Fonte: (Bormann, 2005)

\section{- General-Purpose Timer}

O contador do EVATimer para propósito genérico (General Purpose Timer ou GP Timer) pode trabalhar no modo contínuo crescente (continuous-up mode) e no modo contínuo crescente/decrescente (continuous-up/down mode). A base de tempo para incrementar o contador pode ser fornecida por um oscilador externo (TCLKIN) ou por meio do sinal de clock definido pelo registrador HISPCP. Para o caso do EVATimer2, ainda pode ser utilizado o sinal de clock proveniente do circuito QEP, o qual está diretamente relacionado com os pulsos gerados pelo encoder, conforme pode ser observado na Figura 5.9. O registrador TPS (Timer Pre-Scaler) contido no registrador de controle TxCON ( Timer "x" Control Register) ainda pode definir a escala de divisão do sinal de clock de entrada, possibilitando uma gama de possibilidades de temporização. 


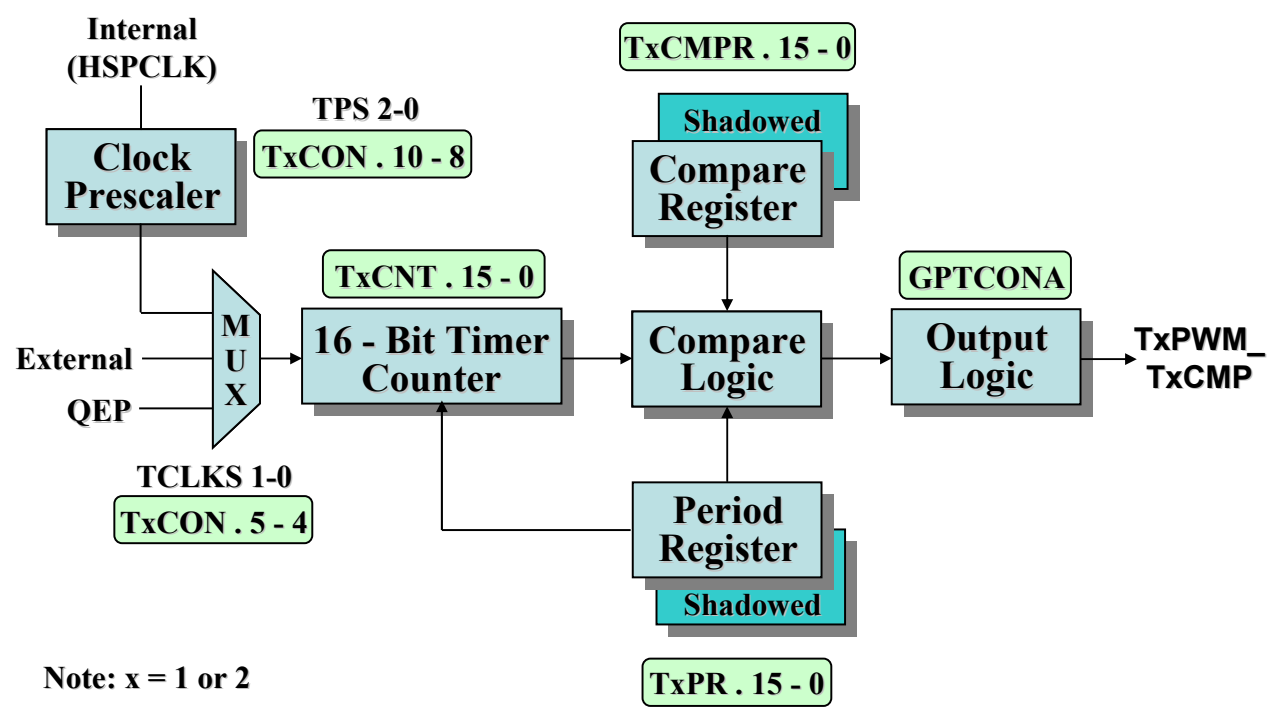

Figura 5.9 - Diagrama de blocos do GP-Timer (EVA).

Fonte: (Bormann, 2005)

O EV Timer trabalhando no modo contínuo crescente incrementa o valor do seu contador (TxCNT - Timer " $x$ " Counter Register) a cada ciclo de clock e, quando atingir o valor definido pelo registrador TxPR (Timer " $x$ " Period Register), o seu valor é reinicializado. Cabe ressaltar que "x" pode assumir valores 1 ou 2 para EVA e 3 e 4 para EVB. Este modo é empregado para desenvolver formas de PWM assimétricos.

Já o modo contínuo crescente/decrescente trabalha de forma semelhante, porém, ao invés de reinicializar o contador TxCNT quando atingir o valor TxPR, o seu valor é decrementado. Este modo é utilizado para desenvolver formas de PWM simétricos. A Figura 5.10 ilustra os modos de operações continuous-up e continuousup/down. Ainda existem mais dois outros modos de operações do Timer que não serão tratadas nesta dissertação. Desta forma, para maiores detalhes de operação, sugere-se a leitura da documentação técnica da Texas Instruments (Bormann, 2005; SPRS174N, 2006; SPRU065, 2006). 


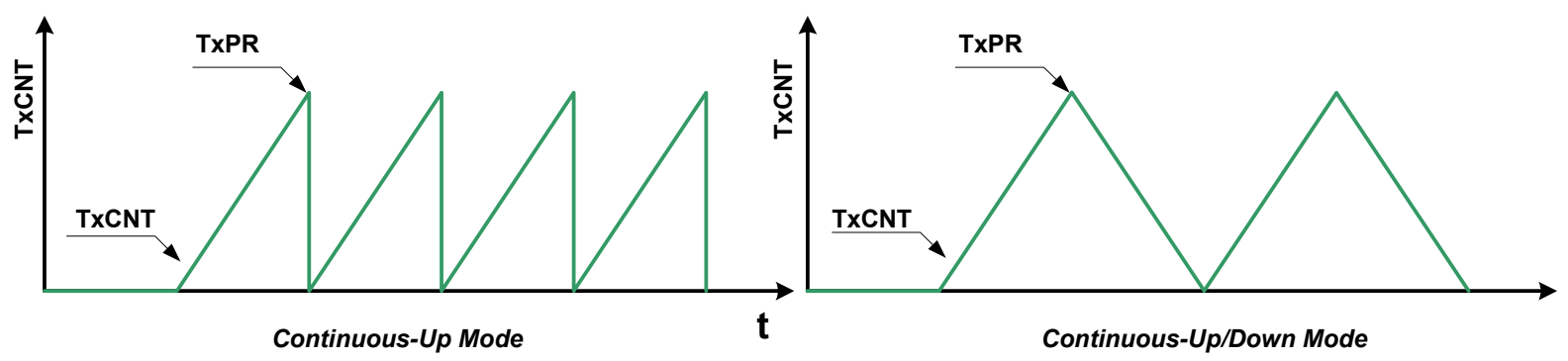

Figura 5.10 - Modos de operações dos Timers do EV.

O registrador de comparação TxCMPR é empregado para efetuar a geração de PWM no pino TxPWM_TxCMP, conforme o exemplo da ilustração da Figura 5.11. O oscilador e o período (TxPR) definem a freqüência e o TxCMPR determina o ciclo de trabalho do PWM. Enquanto o contador TxCNT for menor que o valor atribuído ao TxCMPR, a saída se mantém no nível alto. Por outro lado, quando o valor do TxCNT superar o valor de comparação, a saída se altera para o nível baixo. Esta lógica de saída (Active Low) pode ser invertida por meio do registrador GPTCONA para Active High.

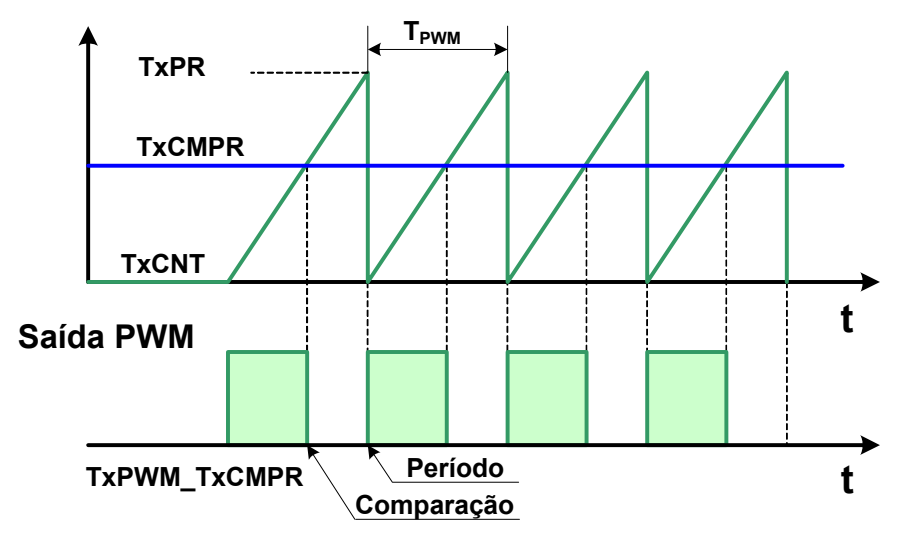

Figura 5.11 - Princípio de geração de ondas PWM.

Deve ser frisado que os registradores TxPR e TxCMPR são duplicados (shadowed), ou seja, os mesmos podem ser programados de tal forma que seus valores não sejam alterados imediatamente durante a execução do programa. Por exemplo, suponha-se que um determinado algoritmo de controle exija que o valor do ciclo de trabalho do PWM seja alterado com o tempo. Para tanto, o valor TxCMPR 
deve ser modificado pelo programa durante sua execução. No entanto, o algoritmo requer que a alteração seja realizada somente no final do período, ou seja, quando o valor de TxCNT atinja o valor TxPR. Neste caso, o valor recente de comparação é armazenado no seu registrador duplicado, e descarregado para TxCMPR quando TxCNT alcançar o valor de TxPR. Este procedimento é relevante para a geração de sinais PWM com modulação senoidal.

Para complementar, no momento em que o contador se iguala ao valor do registrador de comparação ou de período, são gerados sinais de interrupções que podem ser utilizados para desenvolver rotinas dedicadas, conforme a necessidade do projetista. A geração de PWM com modulação senoidal também utiliza este recurso, sendo relevante para o desenvolvimento deste projeto de pesquisa.

Em suma, os principais registradores para a geração de um PWM pelo pino TxPWM_TxCMP são os seguintes:

- TxCNT: Registrador de 16 bits que funciona como contador, cujo valor é incrementado com freqüência dependente da sua fonte de clock, a qual pode advir de osciladores externos, circuito de QEP ou pelo HISPCLK.

- TxPR: Consistem de um registrador de 16 bits que define o valor máximo de contagem do TxCNT.

- TxCMPR: Registrador de comparação que pode ser empregado para definir o ciclo de trabalho de uma onda PWM.

- TxCON: Registrador de controle, no qual se define a fonte de clock do TxCNT, a escala de divisão de freqüência do contador (TPS), o modo de operação do EVATimer (continuous-up, continuous-up/down, etc) e o modo em que o registrador TxCMPR e TxPR é carregado (imediatamente, 
no underflow de TxCNT, etc). Ainda, por meio deste registrador, habilitase o Timer e sua operação de comparação.

- GPTCONA: Este registrador define a lógica de saída no pino TxPWM_TxCMPR como forced low, active low, active high e forced high. O primeiro e o último modo força o nível de saída como baixo e alto, respectivamente, independente das condições do Timer. O GPTCONA também habilita a saída por meio do bit TCOMPOE (Timer Compare Output Enable), além de possuir funções para ativar a inicialização do conversor A/D.

\section{- Compare Units}

A unidade Compare Units, certamente, consiste de um dos módulos mais importantes para a realização do controle de máquinas elétricas. Como pode ser notada na Figura 5.8, cada EV contém 3 unidades de comparação dedicadas especificamente para desenvolver ondas PWM. A Figura 5.12 ilustra os detalhes do diagrama de blocos de Compare Units representado na Figura 5.8, bem como seus principais registradores de controle.

O princípio de operação é similar ao descrito na seção anterior. A sua base de tempo, o modo de operação e o período do PWM são definidos pelos registradores do EVATimer1, ou seja, T1CON e T1PR. Entretanto, cada Compare Unit contém um registrador de comparação CMPRx, cuja função é similar ao TxCMPR, que possibilita a geração de 3 ondas PWMs de mesma freqüência com ciclos de trabalho diferentes. Para cada onda gerada, ainda é possível aplicar a lógica invertida para obter mais 3 ondas PWM com a mesma freqüência e ciclo de trabalho, porém, defasadas em 180 graus. Nota-se que os pares de PWM, cuja 
lógica de saída são invertidas entre si, são ideais para o acionamento de MOSFET/IGBTs de inversores trifásicos.

Por meio do registrador de controle ACTRA, representado na Figura 5.12, configura-se a lógica de acionamento de todos os 6 PWM de saída. Dentre as opções, pode-se definir como active low, active high, force low e force high. Os pares de PWMy e PWMy+1, em que $y=1,3,5$, gerados pelo mesmo registrador de comparação CMPRx, são ideais para efetuar o acionamento dos IGBTs, TOP e BOT, quando PWMy e PWMy+1 são ajustados, respectivamente, para active high e active low, ou vice-versa. Os estados force high e force low podem ser empregados para efetuar o desligamento de ambos os IGBTs, TOP e BOT, como medidas de segurança.

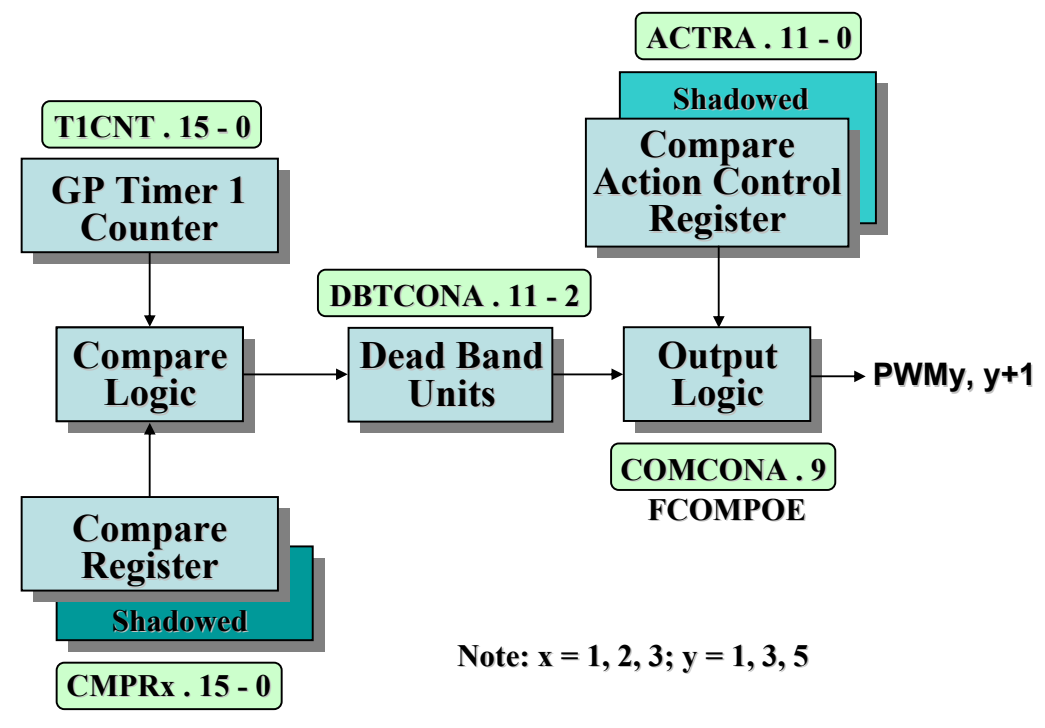

Figura 5.12 - Diagrama de blocos do Compare Units (EVA).

Fonte: (Bormann, 2005)

Mediante o registrador CONCONA pode ser definido os instantes em que os registradores de recarga, CMPRx e ACTRA, são descarregados. Desta forma, os valores de CMPRx e ACTRA pode ser atualizados imediatamente, no momento de underflow do EVATimer1, ou no instante em que T1CNT atinge o valor de T1PR. O 
CONCONA também é responsável por habilitar a operação de comparação (CENABLE), bem como a saída PWM (FCOMPOE).

Em se tratando de eletrônica de potência, cuidados devem ser tomados no acionamento dos IGBTs superiores (TOP) e inferiores (BOT), por meio de ondas PWM com lógica invertida, visto que o tempo de ligamento é inferior ao tempo de desligamento, conforme pode ser notado na Figura 5.13.

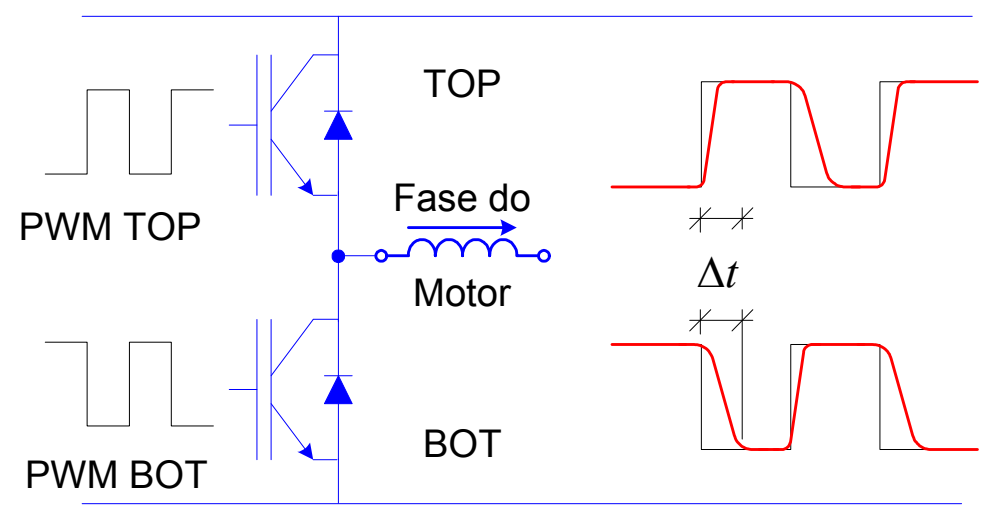

Figura 5.13 - Acionamento simultâneo do IGBTs TOP/BOT.

A partir desta observação, ambos os IGBTs, TOP e BOT, são acionados simultaneamente por um pequeno período de tempo $\Delta t$. Este fenômeno pode ocasionar sérios danos, além de proporcionar sobre-aquecimentos e diminuição de vida útil do inversor. Com o propósito de solucionar este problema, é possível implementar via software um pequeno atraso (dead-time) no acionamento dos IGBTs. Entretanto, o DSP da Texas Instruments dispõe-se de um módulo, DeadBand Unit, para tratar o problema em hardware sem nenhum custo de processamento adicional da CPU. A Figura 5.14 descreve o formato dos sinais de PWM resultados no TOP e BOT da ponte inversora. Nota-se que durante o tempo de espera delimitado por dead-time o IGBT está totalmente desligado até que o outro seja ligado, evitando o acionamento simultâneo dos IGBTs TOP e BOT. 


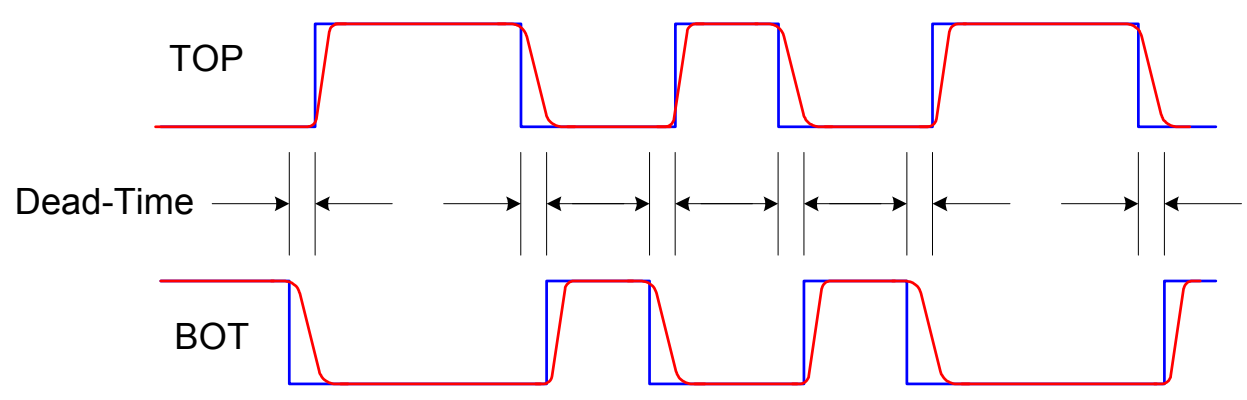

Figura 5.14 - Forma do sinal PWM após a configuração do dead-time.

A estrutura interna do módulo Dead-Band Unit consiste de um circuito temporizador, em que se define o tempo dead-time mediante a configuração do registrador DBTCONA. Detalhes podem ser encontrados na documentação técnica da Texas Instruments (Bormann, 2005; SPRU065, 2006).

\section{- Quadrature Encoder Pulse Unit}

O módulo Quadrature Encoder Pulse Unit é essencial para a medição de velocidade e posição angular, bem como o sentido de rotação. A velocidade angular pode ser determinada mediante a contagem do número de pulsos gerados pelo encoder em um intervalo fixo de tempo, conforme a Equação (5.1).

$$
\omega_{k}=\frac{x_{k}-x_{k-1}}{\Delta t}
$$

em que, $\omega_{k}$ e $x_{k}$ é a velocidade angular e o valor do contador de pulsos no instante $k$, e $\Delta t$ é um intervalo fixo de tempo definido pelo projetista.

Este método de cálculo de velocidade angular é eficiente para altas velocidades. No entanto, em virtude do número de pulsos contados no intervalo de tempo $\Delta t$ ser diminuído conforme a velocidade é reduzida, aumenta-se então o erro de quantização. 
Desta forma, uma alternativa para a medição de baixas velocidades consiste em determinar o tempo decorrido a um intervalo de pulso fixo, conforme descrito na Equação (5.2).

$$
\omega_{k}=\frac{\Delta x}{t_{k}-t_{k-1}}
$$

em que $\omega_{k}$ e $t_{k}$ é a velocidade angular e o tempo no instante discreto $k$, e $\Delta x$ é um número fixo de pulsos definido pelo projetista.

Este método, no entanto, não é ideal para aferição de velocidades altas. Portanto, para se obter uma ampla faixa de medição, uma solução comum é mesclar as duas técnicas alternado-as entre algoritmos de cálculo de velocidades baixas e altas.

Nesta dissertação, empregou-se o circuito QEP ilustrado na Figura 5.8 apenas para efetuar a medição da velocidade. Desta forma, utilizaram-se somente os canais A e B do encoder incremental. Uma característica importante deste circuito que merece destaque reside na habilidade de detecção de bordas, tanto de subida quanto de descida, de ambos os sinais provenientes do canal $A$ e $B$. Conseqüentemente, a resolução de um encoder incremental de 2000 pulsos/rotação é aumentada para 8000 pulsos/rotação.

Os pulsos gerados pelo encoder e quadruplicados por meio da lógica contida no circuito QEP, são empregados como fonte de oscilação do EVATimer2 para incrementar o contador T2CNT. Desta forma, a velocidade pode ser mensurada verificando-se a variação do contador em determinado período de tempo, conforme a Equação (5.1). Este método de medição de velocidade é razoável, em virtude da alta resolução do encoder, além do MIT operar em uma velocidade elevada. O valor de $\Delta t$ pode ser obtido mediante a contagem de interrupção do Timer 0 da CPU, uma 
vez que, neste trabalho, a interrupção do Timer 0 foi definida para ocorrer a cada $1 \mu s$.

\subsection{Projeto do Sistema de Controle em DSP}

Nesta seção será apresentada a metodologia de desenvolvimento do algoritmo do sistema de acionamento e controle do MIT embarcado no DSP da Texas Instruments TMS320F2812.

A programação do dispositivo foi realizada por meio do software Code Composer $^{\odot}$ versão 3.1 , fornecido pela própria Texas Instruments no ato de sua aquisição. As linguagens de programação suportadas pelo Code Composer $^{\odot}$ consistem na linguagem $\mathrm{C} / \mathrm{C}++$ e assembly. Em virtude da facilidade de programação, optou-se pela linguagem C para desenvolver o sistema de controle.

A Texas Instruments fornece bibliotecas para programação na linguagem $\mathrm{C} / \mathrm{C}++$, nas quais contém as definições de endereços de registradores de periféricos, mapas de alocação de memórias de programa e de dados, entre outros. Desta forma, recomenda-se a consulta de sua documentação técnica para maiores detalhes (SPRU509C, 2001; Bormann, 2005; SPRC097, 2007).

Como alternativa de programação do dispositivo, pode-se empregar o Toolbox Matlab ${ }^{T M} /$ Link for Code Composer ${ }^{T M}$ da Mathworks, o qual se constitui de blocos com funções específicas para os DSPs da Texas Instruments, tais como medição de velocidade angular, geração de PWM, conversão $A / D$, entre outros. Os blocos são configurados na plataforma Matlab ${ }^{T M} /$ Simulink $^{T M}$. Por meio de linha de comando é possível acessar áreas de memórias alocadas no DSP, bem como efetuar a depuração do programa. Embora os blocos de funções para a configuração dos periféricos já estejam implementados, bastando apenas o ajuste de seus 
parâmetros, o código gerado automaticamente pelo $M a t l a b^{T M}$ é de difícil depuração. Desta forma, a dificuldade de integração de diversos módulos exigidos no sistema de controle, além da necessidade de adaptação dos códigos durante o projeto, optou-se pelo desenvolvimento em Linguagem C. Devido ao nível de personalização, o código pode ser desenvolvido de forma mais compacta, o que possibilita desenvolver um sistema mais simples, rápido e otimizado, tornando-o mais apto para o controle em tempo real.

Antes de se iniciar a programação do sistema de acionamento e controle do MIT, uma série de registradores deve ser definida e inicializada. Nos próximos tópicos serão discorridos os procedimentos adotados para desenvolver o sistema.

\subsubsection{Inicialização do Sistema}

$\mathrm{Na}$ inicialização do sistema de controle deste trabalho foram ajustados os registradores PLLCR, WDCR, HISPCP, LOSPCP e PLCKCR para definir a freqüência de trabalho do DSP, configurar a operação do watchdog, determinar a freqüência e habilitação de sinais de clock dos periféricos.

A freqüência de trabalho da CPU pode ser determinada da seguinte forma:

$$
f_{C P U}=30 \cdot P^{\prime} \text { LLCR.DIV } \quad[\mathrm{MHz}]
$$

em que PLLCR.DIV consiste em um conjunto de bits pertencentes ao registrador PLLCR. O símbolo "*” (asterisco) representa o valor configurado por PLLCR.DIV. Por exemplo, a codificação binária 1010 para PLLCR.DIV retorna PLLCR.DIV* equivalente a 5, de acordo com a Tabela 5.1.

Definiram-se os bits do registrador PLLCR para multiplicar por 10 e dividir por 2 a freqüência de $30 \mathrm{MHz}$ do oscilador externo. Portanto, o DSP foi configurado para trabalhar na freqüência de $150 \mathrm{MHz}$. O Watchdog foi desabilitado por meio do 
registrador WDCR, em virtude da alteração freqüente do programa durante o projeto do sistema de controle.

A freqüência do clock de trabalho definida pelo registrador PLLCR é dividida por um fator de divisão ajustado pelo registrador HISPCP. O sinal resultante pode ser empregado em periféricos do Event Manager. Desta forma, a oscilação de HISPCLK pode ser determinada conforme a seguinte equação:

$$
\text { HISPCLK }=\frac{f_{C P U}}{\text { HISPCP }^{*}}
$$

Definiu-se o fator de divisão para 2, ou seja, a freqüência de oscilação do clock na saída do HISPCLK é de $75 \mathrm{MHz}$. Para que este sinal de clock possa ser utilizado pelos periféricos do Event Manager A, ativou-se o registrador PCLKCR (Peripheral Clock Control Register).

As seqüências de códigos em linguagem C descritas no Quadro 5.1 demonstram o procedimento para desenvolver as configurações supracitadas:

Quadro 5.1 - Código para inicialização do sistema.

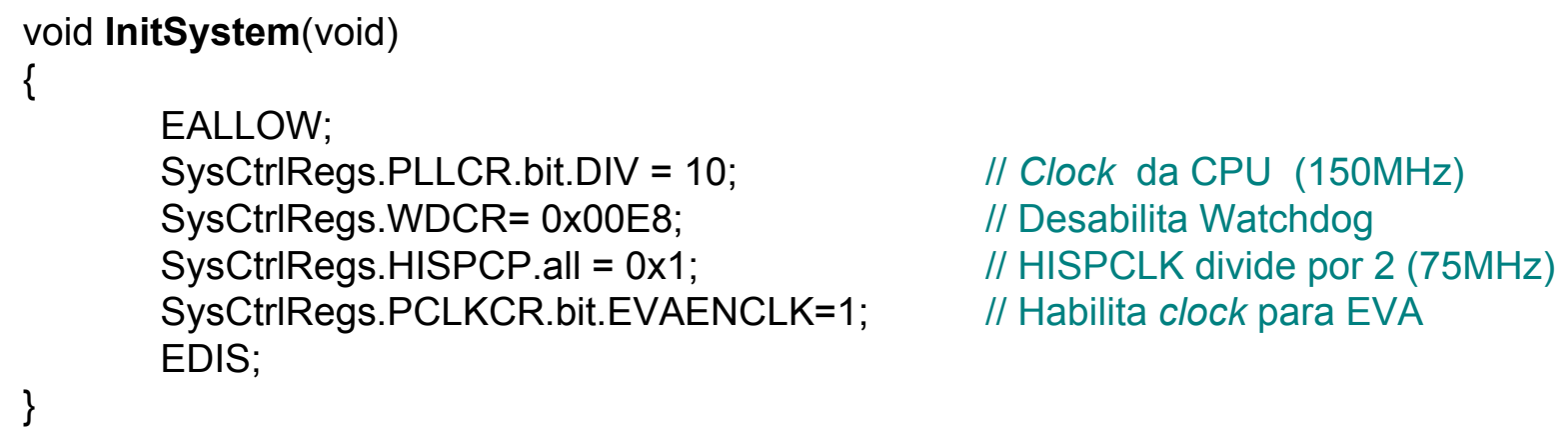

\subsubsection{Configuração das Portas de I/O Digitais}

O acionamento do inversor trifásico é realizado por meio de sinais PWM, e a velocidade angular do eixo do MIT é aferida pelas medições dos pulsos originados pelo encoder. Tanto a geração de PWM quanto a captação de pulsos se tratam de 
funções especiais das portas digitais, as quais devem ser configuradas pelo registrador GPAMUX. Os sinais de PWM1-PWM6 são funções especiais das portas digitais A0-A5 do DSP, enquanto que a unidade QEP captura os pulsos advindos do encoder por meio das portas digitais A8-A10. A saída digital A6 foi definida para acionar o IGBT Q7 da Figura 3.18, que desabilita o resistor bypass de proteção contra corrente de in-rush quando os capacitores do barramento CC estão carregados. A saída digital A7 foi utilizada para acionar a placa NIDAQ para iniciar a aquisição dos dados de um ensaio experimental. Portanto, as portas digitais foram definidas conforme os códigos descritos no Quadro 5.2.

Quadro 5.2 - Código para configuração das portas de I/O digitais.

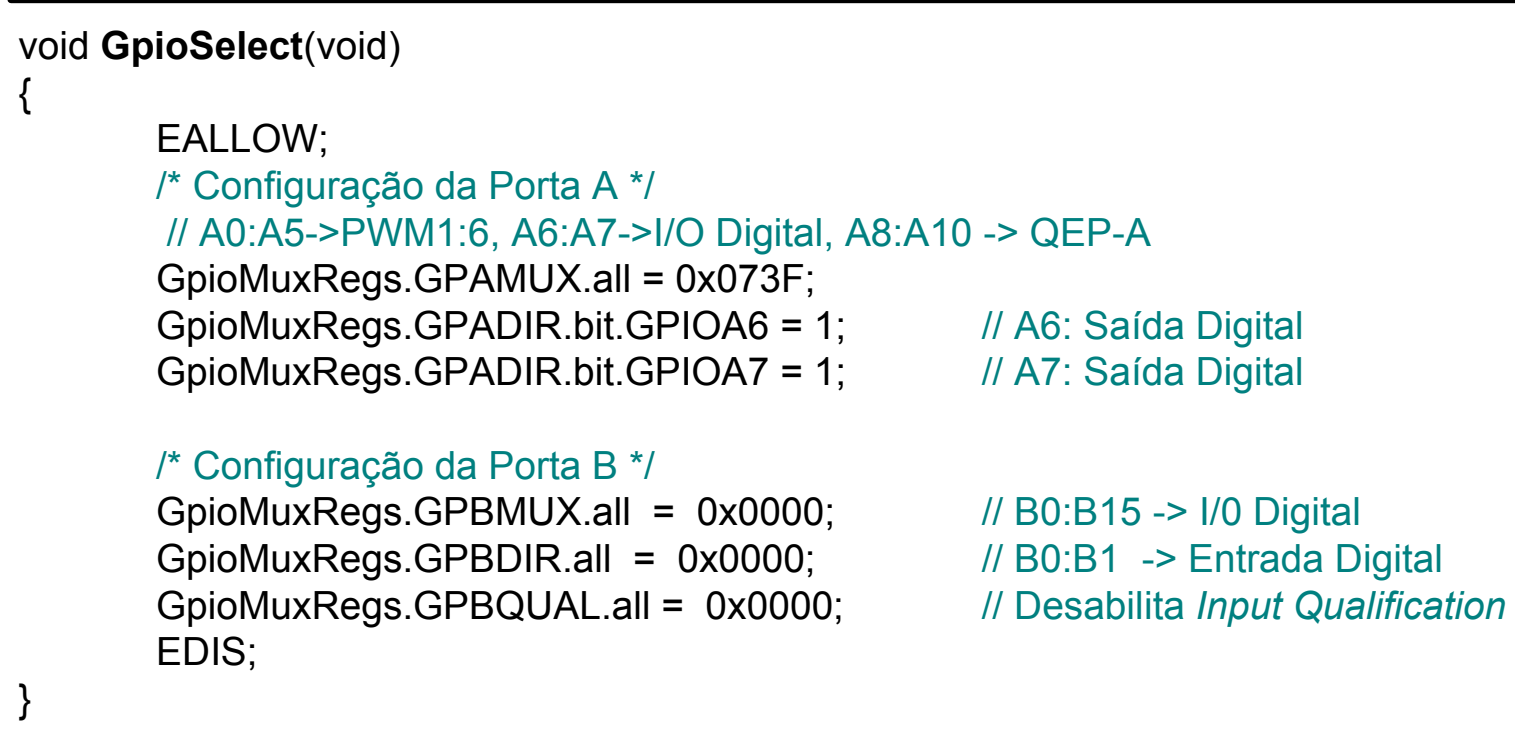

\subsubsection{Configuração dos Registradores Event Manager}

Nesta subseção será descrita as considerações relevantes dos registradores do Event Manager A para desenvolver os sinais PWM de acionamento do inversor trifásico, bem como a configuração do QEP para a aferição da velocidade angular.

Os principais registradores do Event Manager A para a geração de PWM são os seguintes: T1CON, T1PR, COMCONA, ACTRA e DBTCONA. 
Por meio de T1CON configurou-se a fonte de clock para HISPCLK de $75 \mathrm{MHz}$, definida na Subseção 5.3.1, a qual foi dividida pelo fator de pré-escala de 8 (T1CON.TPS). Desta forma, a freqüência resultante de incremento do contador T1CNT é de $75 \mathrm{MHz} / 8$. O bloco de código para a configuração do registrador T1CON é descrito no Quadro 5.3.

Quadro 5.3 - Configuração do Registrador T1CON.

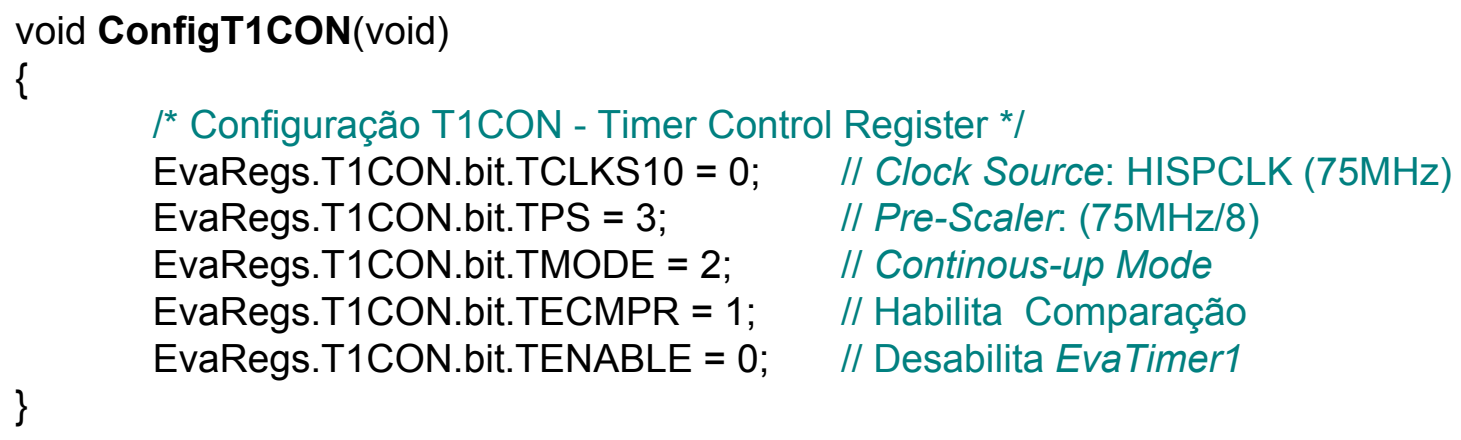

Definindo-se o modo de operação do EVATimer1 como continuous-up mode, a freqüência do PWM pode ser obtida ajustando-se o registrador T1PR, conforme a Equação (5.5).

$$
f_{P W M}=\left(\frac{\text { HISPCLK }}{\text { T1CON.TPS }}\right) \cdot \frac{1}{\text { T1PR }}
$$

A freqüência de PWM escolhida para o acionamento do inversor trifásico consiste de $10 \mathrm{kHz}$. Para tanto, o valor que deve ser carregado no registrador T1PR é de 937, de acordo com a Equação (5.5). Em primeiro instante, por meio do registrador CMPRx, definiu-se o ciclo de trabalho constante de $50 \%$ para todas as saídas PWM. O bloco de código referente à configuração da freqüência e ao ciclo de trabalho é descrito no Quadro 5.4. 
Quadro 5.4 - Código para a geração PWM com ciclo de trabalho constante.

\section{void ConfigPWM(void)}

\{

/* Configura PWM (10kHz, 50\% de ciclo de trabalho - Inicial) *

EvaRegs.T1PR = 937;

$/ /$ freq PWM $=10 \mathrm{kHz}$

EvaRegs.CMPR1 = EvaRegs.T1PR/2;

//Largura do Pulso 1

EvaRegs.CMPR2 = EvaRegs.T1PR/2;

//Largura do Pulso 2

EvaRegs.CMPR3 = EvaRegs.T1PR/2;

//Largura do Pulso 3

\}

No passo anterior, definiu-se apenas a freqüência e o ciclo de trabalho, restando ainda ajustar a lógica de acionamento de suas saídas mediante o registrador ACTRA. Portanto, configuraram-se as portas PWM1, PWM3, PWM5 para active low, ou seja, a saída é ativa em nível baixo quando o valor T1CNT for maior que o comparador CMPRx. Estes sinais são conectados nos IGBTs superiores (TOP) de cada fase U, V e W. Por outro lado, as portas PWM2, PWM3, PWM6 foram ajustadas como active high, que apresenta a lógica invertida para o acionamento dos IGBTs inferiores (BOT) de cada fase U, V e W. O bloco de código desenvolvido para configurar o registrador ACTRA é descrito pelo Quadro 5.5.

Quadro 5.5 - Configuração do registrador ACTRA.

\section{void ConfigACTRA(void)}

\{

/* ACTRA - Compare Action Control Register */

EvaRegs.ACTRA.bit.CMP1ACT = 0x1;

IIActive Low : TopW

EvaRegs.ACTRA.bit.CMP2ACT = 0x2;

IIActive High : BotW

EvaRegs.ACTRA.bit.CMP3ACT $=0 \times 1$;

I/Active Low : TopU

EvaRegs.ACTRA.bit.CMP4ACT =0x2;

IIAcitve High : BotU

EvaRegs.ACTRA.bit.CMP5ACT $=0 \times 1$;

IIActive Low : TopV

EvaRegs.ACTRA.bit.CMP6ACT = 0x2;

I/Acitve High : BotV

\}

Por meio do registrador de controle CONCONA habilita-se a operação de comparação que é realizada entre os registradores T1CNT e CMPRx, bem como as portas de saídas PWM1-6 para meio físico. A atualização dos registradores ACTRA 
e CMPRx (Reload Condition), caso o valor destes se alterem durante a execução, é realizada imediatamente para ACTRA e no underflow de T1CNT para CMPRx. O bloco de código referente à configuração do registrador COMCONA é descrito no Quadro 5.6.

Quadro 5.6 - Configuração do registrador COMCONA.

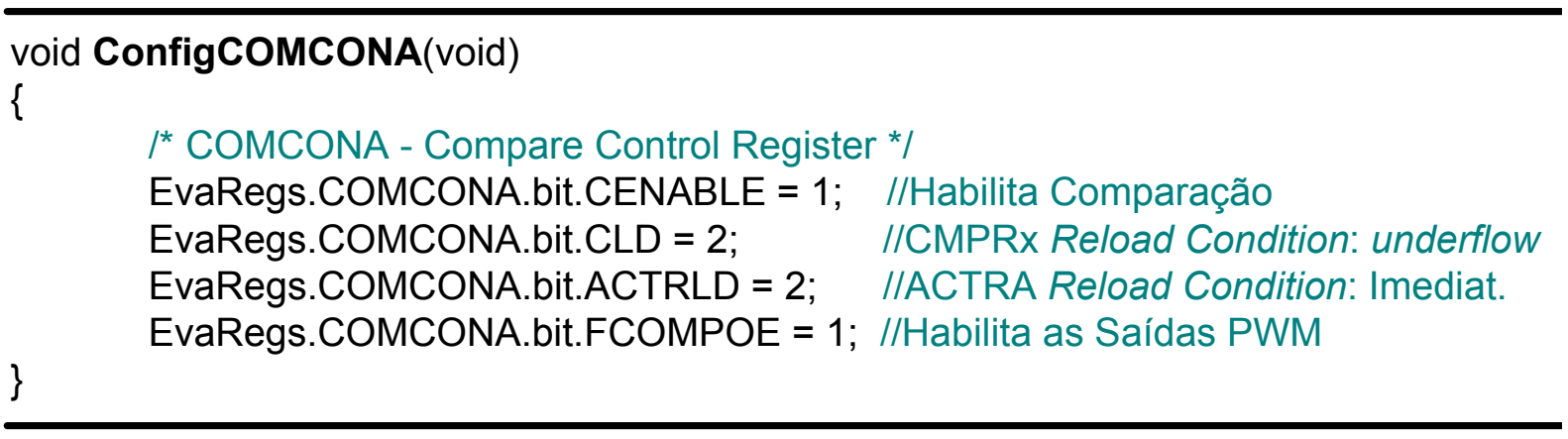

As configurações realizadas em um conjunto de registradores até o momento são perfeitamente funcionais para gerar os sinais PWM com freqüência de $10 \mathrm{kHz}$ e $50 \%$ de ciclo de trabalho. No entanto, embora o inversor trifásico utilizado neste trabalho seja protegido por inter-travamento, por segurança, optou-se para realizar a configuração do dead-time por meio do registrador DBTCONA.

Para configurar o dead-time, o Dead-Band Unit utiliza o oscilador proveniente de HISPCLK $(75 \mathrm{MHz})$ como fonte de clock para um Timer interno. Desta forma, o dead-time pode ser definido por meio da configuração do fator de divisão DBTPS(Dead-Band Timer Prescaler) e do período do Timer DBT, de acordo com a Equação (5.6).

$$
T_{\text {Dead-Time }}=\left(\frac{\text { DBTPS }^{*}}{\text { HISPCLK }}\right) \cdot \text { DBT }
$$

Neste trabalho, o dead-time foi configurado para 4us. Para tanto, definiu-se o fator de divisão de HISPCLK para 32 e período do Timer do Dead-Band para 10 . O 
bloco de código que exemplifica a configuração dos registradores DBTCONA é ilustrado no Quadro 5.7.

Quadro 5.7 - Configuração do registrador DBTCONA.

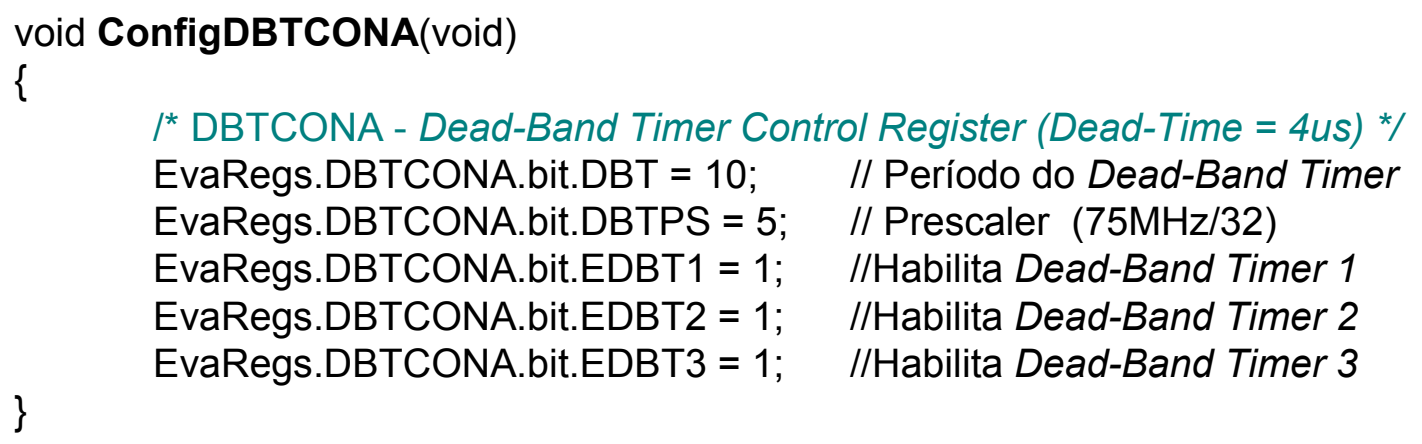

\subsubsection{Inicialização dos Vetores de Interrupções}

Nesta subseção serão explicitadas as configurações dos registradores de interrupção do sistema de controle fuzzy de velocidade.

Os periféricos utilizados neste trabalho que exigem rotinas de interrupções consistem no Timer 0 da CPU e Compare Units do Event Manager A. O Timer 0 é utilizado para definir a base de tempo mínimo de operação do sistema de controle, a qual foi definida para $1 \mu$ s por meio dos seguintes códigos:

ConfigCpuTimer(\&CpuTimer0,150, 1);

CpuTimerORegs.TCR.bit.TSS = 0;

em que o primeiro parâmetro da função ConfigCpuTimer() define o CPUTimer utilizado, o segundo parâmetro se refere à freqüência de trabalho da CPU e o último consiste no tempo, em microssegundos, para gerar interrupção. O segundo código é responsável para iniciar a contagem do TimerO.

O Compare Units é empregado para realizar a geração dos sinais de PWM com modulação senoidal. Os detalhes das rotinas de interrupções de tais periféricos serão explanados nos tópicos subseqüentes. 
Por meio das funções InitPieCtrl() e InitPieVectTable() ilustrada no bloco de código descrito no Quadro 5.8, inicializam-se os registradores de controle e habilita o módulo de expansão de endereços PIE. O conjunto de códigos, comentado por "Endereço das Rotinas de Interrupções", define que as rotinas de interrupções dos periféricos descritos à esquerda da igualdade estejam endereçadas nas funções rotuladas conforme a parcela à direita da igualdade. Por exemplo, a rotina de interrupção do periférico Timer 0 da CPU, endereçada no vetor PIE em TINTO, será implementada na função desenvolvida e rotulada pelo projetista por cpu_timer0_isr(). Os códigos restantes descritos na seqüência são responsáveis para habilitar as linhas de interrupções dos periféricos utilizados.

Quadro 5.8 - Código para configuração do sistema de interrupção.

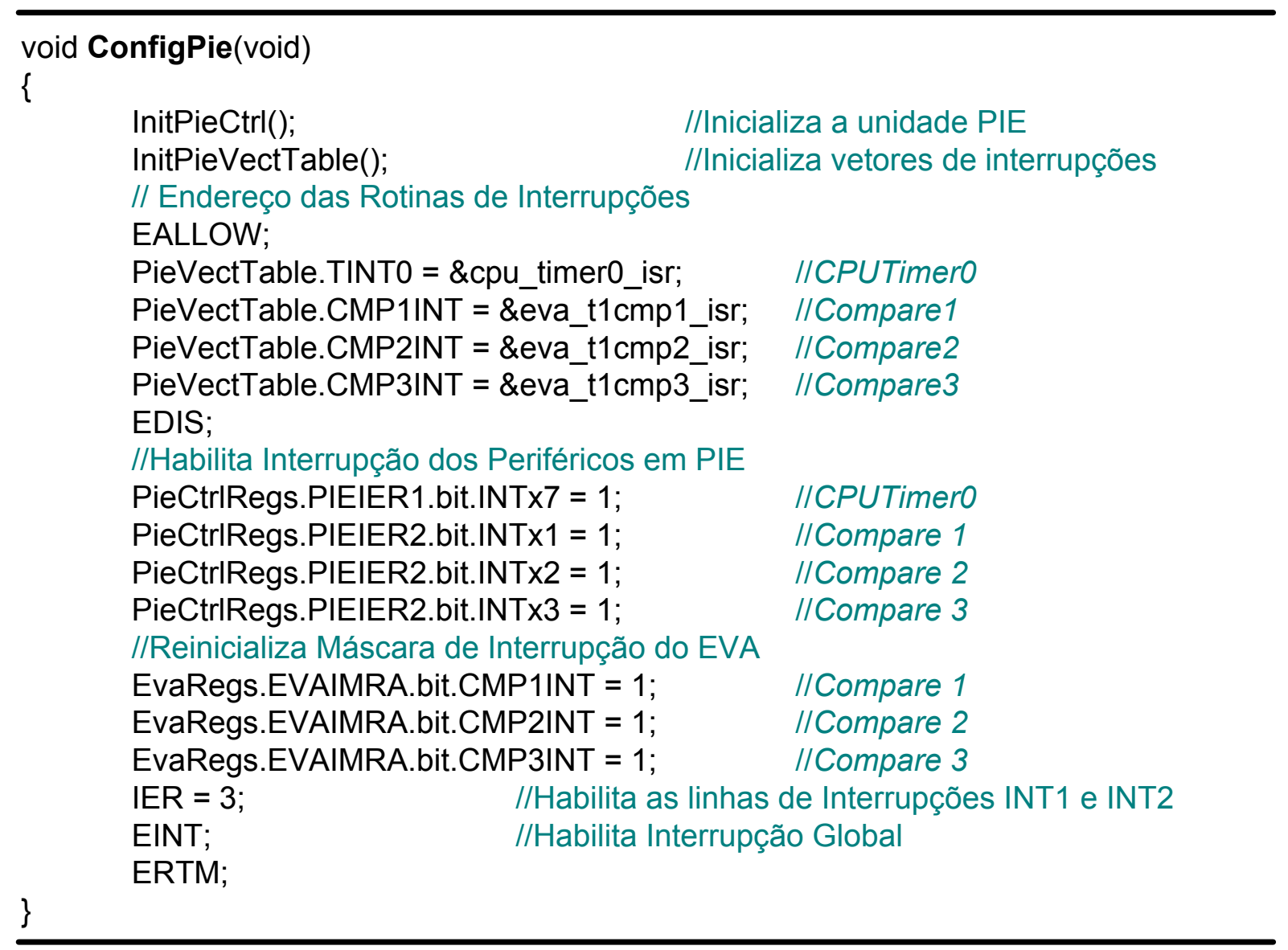




\subsubsection{Geração de Sinais PWM com Modulação Senoidal}

Nesta subseção serão explanados os aspectos fundamentais relativos à geração de sinais PWM com modulação senoidal. Uma portadora triangular é comparada com uma onda senoidal, originando-se um sinal PWM com a largura de pulso proporcional à amplitude da onda de referência. A Figura 5.15 representa o esquema ilustrativo da modulação PWM senoidal. Esta técnica possibilita reduzir o fator de distorção e os harmônicos de mais baixas ordens de forma significativa, o que contribui para a redução do aquecimento do motor e para o aumento de sua vida útil.
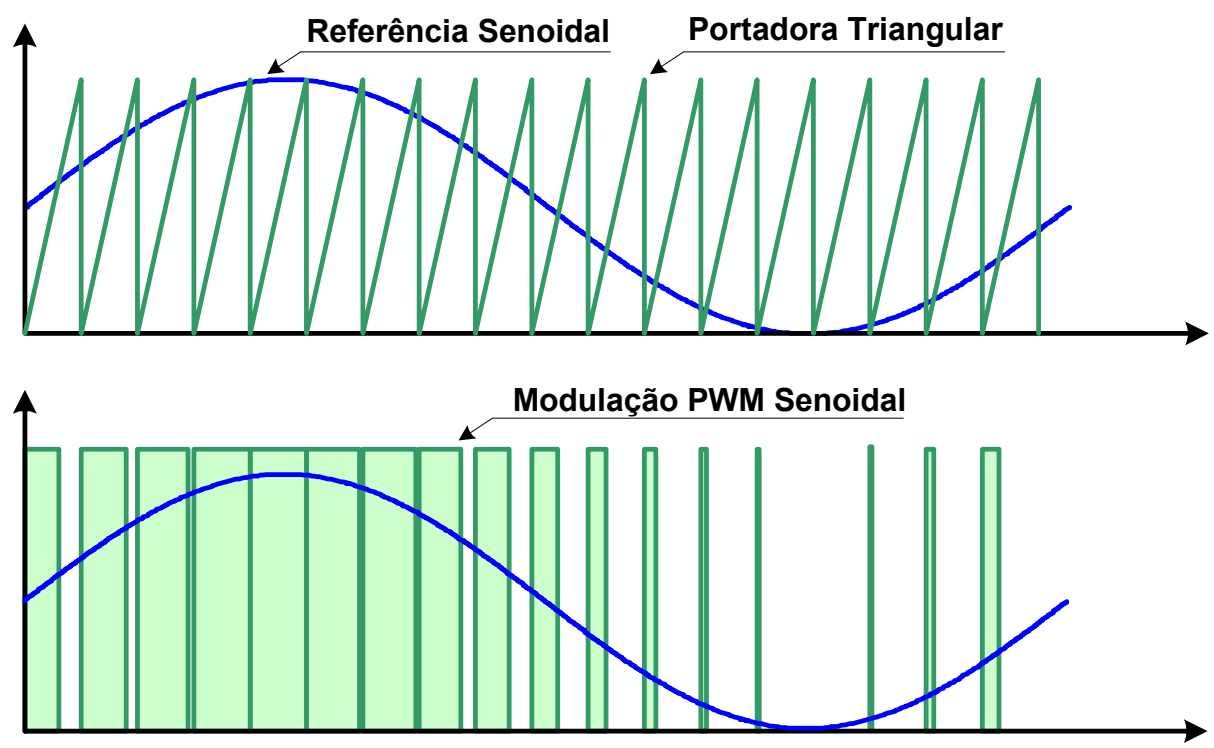

Figura 5.15 - Modulação PWM senoidal.

A freqüência da portadora triangular está diretamente relacionada com a freqüência do sinal PWM, a qual, na prática, é definida na ordem de $20 \mathrm{kHz}$. No entanto, conforme as recomendações adotadas pela Semikron, a freqüência máxima de chaveamento recomendada do inversor é de $10 \mathrm{kHz}$, sendo, portanto, esta a freqüência adotada neste trabalho. 
A freqüência da onda senoidal de referência determina a freqüência da componente fundamental da onda PWM de saída, e a sua amplitude controla a tensão RMS. Para obter uma tensão RMS reduzida, basta diminuir a amplitude do sinal conforme ilustra a Figura 5.16. A aplicação da onda de referência maior que a portadora implica em uma tensão RMS superior, no entanto, proporciona o aumento de distorções harmônicas, as quais podem provocar efeitos nocivos ao motor de indução.
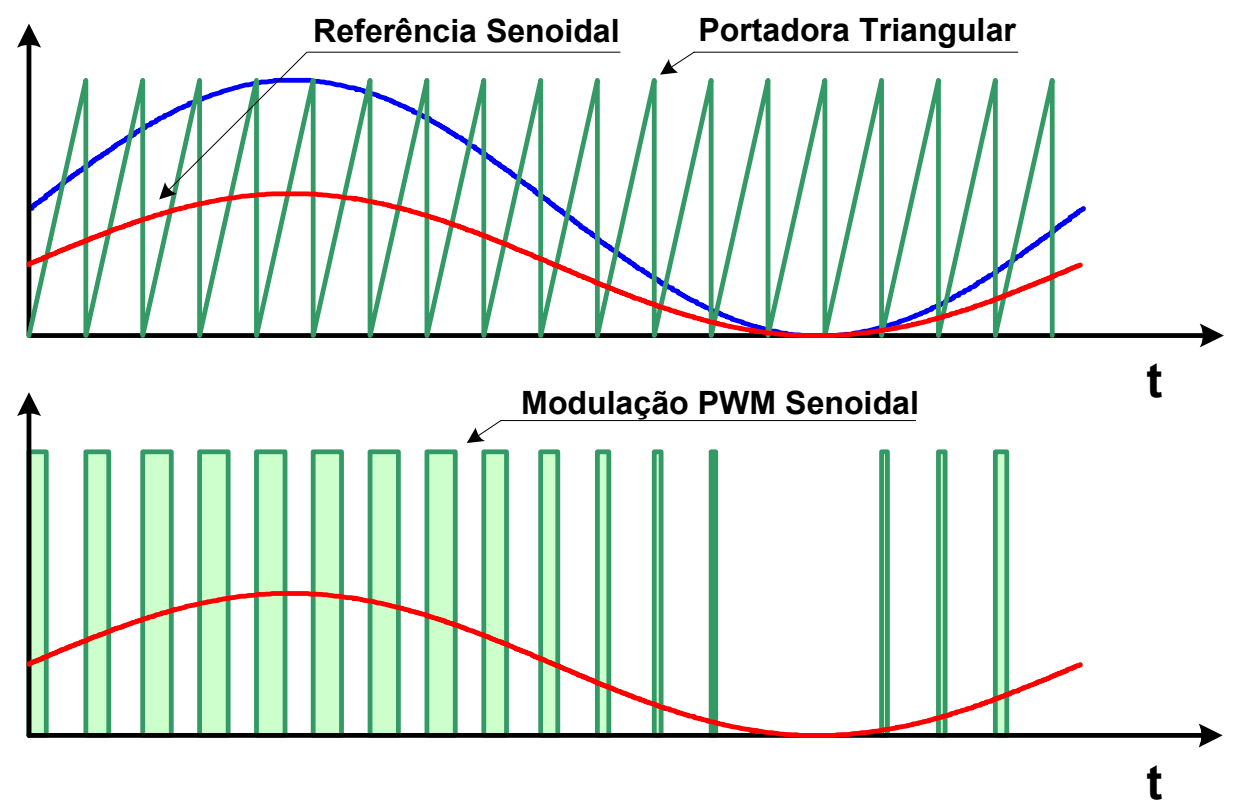

Figura 5.16 - Controle de amplitude da componente fundamental de saída.

Com o propósito de desenvolver a modulação PWM senoidal por meio do DSP, realiza-se a alteração no valor dos registradores de comparação CMPRx do Event Manager no instante adequado, visto que os mesmos estão diretamente relacionados com a largura do pulso do PWM. A Figura 5.17 representa o esquema de geração de ondas PWM senoidais por meio de registradores do Event Manager.

O cálculo do novo valor de CMPRx é realizado durante a rotina de interrupção gerada no momento em que T1CNT se iguala ao CMPRx atual. No instante da interrupção, determina-se a amplitude da senóide, e a partir deste, 
calcula-se o seu valor proporcional que será carregado no CMPRx ao final do ciclo de T1CNT. No momento em que o registrador T1CNT atinge o valor de CMPRx novamente, uma nova interrupção é gerada e o valor CMPRx será calculado de acordo com a proporção da amplitude senoidal atual.

Nota-se que, em uma análise rigorosa, a largura de pulso determinada a cada ciclo só é carregada no instante seguinte, ou seja, a onda de saída PWM é atrasada em 1 ciclo. Além disso, a largura será ligeiramente mais estreita durante a subida e mais larga na descida da onda senoidal de referência, visto que o valor é calculado no instante da interrupção, ao invés do ponto de encontro da senóide com o valor de T1CNT. Entretanto, em virtude da freqüência da portadora ser muito alta em relação à referência senoidal, as distorções citadas são desprezíveis e não afetam o desempenho da máquina.

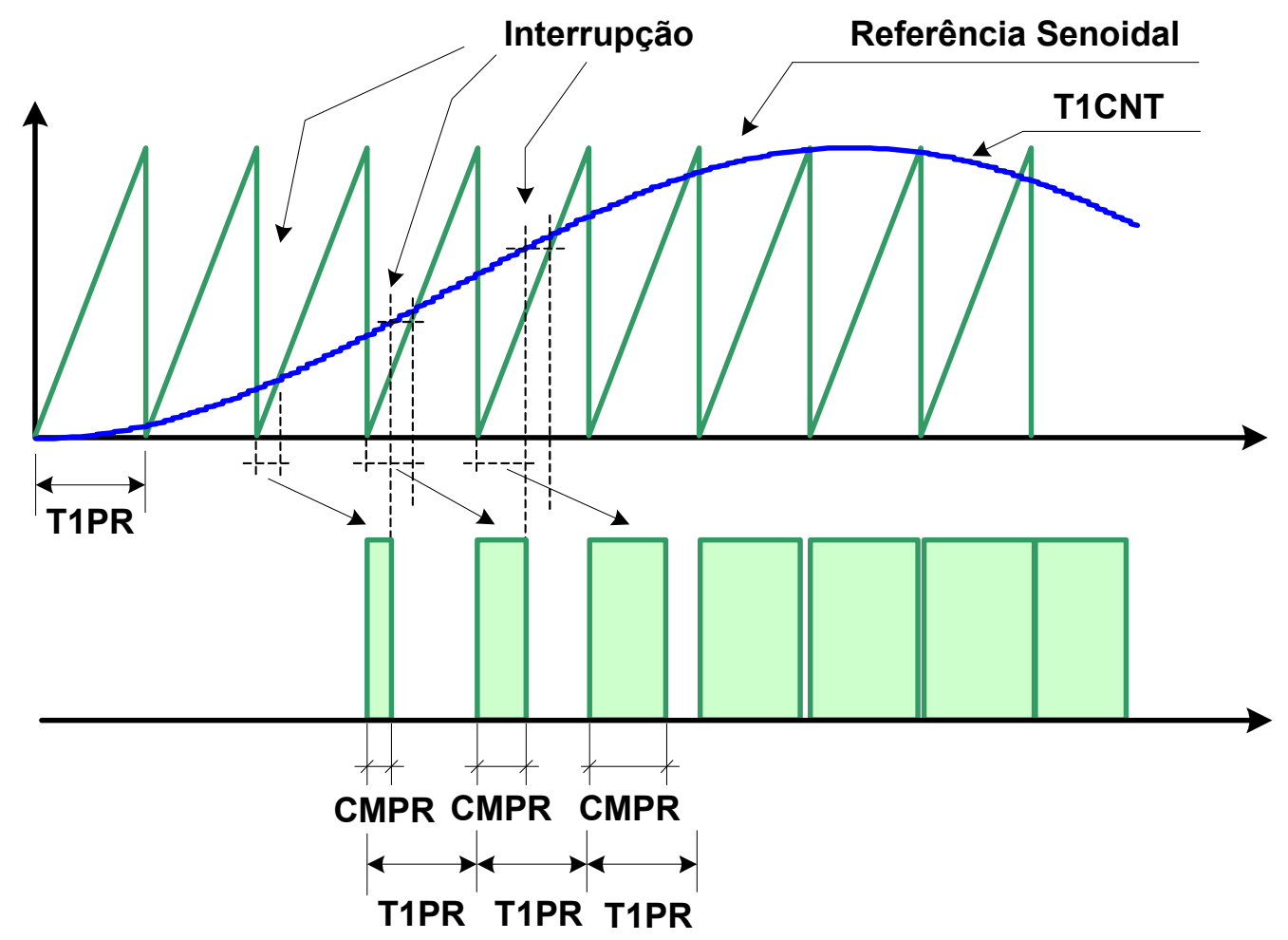

Figura 5.17 - Geração de PWM com modulação senoidal pelos registradores do Event Manager. 
A portadora triangular é gerada em hardware na medida em que o contador T1CNT incrementa o seu valor, no entanto, a onda senoidal de referência deve ser obtida por software em linhas de comandos na programação do DSP.

Uma alternativa seria determinar o valor da amplitude da senóide no instante da interrupção utilizando a função "sin(x)" da biblioteca do compilador C, "math.lib". Entretanto, em se tratando de uma função realizada em ponto flutuante, ao passo que o DSP TMS320F2812 consiste de um processador de ponto fixo, o compilador gera uma elevada quantidade de instruções em assembly, aumentando significativamente o custo computacional, o que pode afetar o desempenho do algoritmo de controle em tempo real.

$\mathrm{Na}$ prática, armazenam-se os valores comumente pré-calculados das amplitudes da senóide na memória de dados na forma de um vetor. Ao invés de se calcular cada valor durante a execução da rotina de interrupção, efetua-se apenas uma consulta por indexação.

O DSP da Texas Instrumens da família C28x já apresenta os valores de 512 posições de senos armazenados na área de memória BOOT-ROM no formato de IQ30 de 32 bits.

A notação IQ (Integer-Quotient) consiste em uma definição de ponto flutuante que é manipulada de forma mais eficiente por processadores de ponto fixo. A Texas Instruments oferece a biblioteca "IQmathLib" que constitui de um pacote de funções direcionadas à manipulação de dados definidos no formato $I Q$, tais como operação de multiplicação, divisão, conversão de tipos de dados, etc. Maiores detalhes sobre esta notação podem ser encontrados na documentação técnica da Texas Instruments em SPRC087 (2003) e Bormann (2005). 
A base de tempo para a geração da onda senoidal de referência pode ser adquirida com o auxílio da rotina de interrupção da CPUTimerO descrito pelo bloco de código do Quadro 5.9.

Quadro 5.9 - Rotina de Interrupção do CPUTimerO.

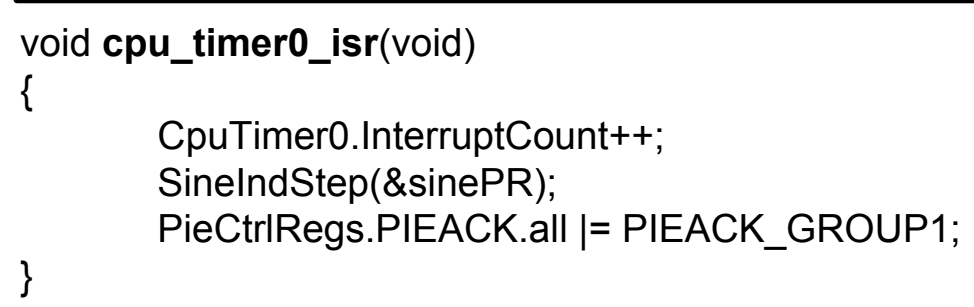

Conforme foi descrito nas subseções anteriores, a interrupção da CPUTimerO é realizada a cada $1 \mu \mathrm{s}$. A variável "CpuTimerO.InterrupCount", a qual consiste de um contador de interrupções, servirá de auxílio para definir o período da senóide de referência.

Seja um vetor de valores de seno discretizados em 512 pontos, na qual se deseja desenvolver uma onda senoidal de período de $60 \mathrm{~Hz}$. Para tanto, é necessário percorrer o vetor discretizado em 1/60 s. Conseqüentemente, o tempo para incrementar o índice do vetor em uma unidade será de:

$$
\frac{1}{60 \cdot 512} \approx 32,55 \mu \mathrm{s}
$$

Como a base de tempo mínimo definida pela rotina de interrupção é de $1 \mu \mathrm{s}$, o tempo de espera deverá ser arredondado para 33 unidades de interrupções. Ou seja, para cada 33 unidades de variação no contador de interrupções, realiza-se um incremento no índice no vetor de seno.

A função genérica que permite a geração da onda senoidal de referência é descrita pelo bloco de código descrito no Quadro 5.10, no qual a variável indsin é o índice do vetor de seno e sinePR é o tempo de espera em microssegundos para incrementar o índice em 1 posição. 
Quadro 5.10 - Rotina para desenvolver o incremento do índice da tabela de seno.

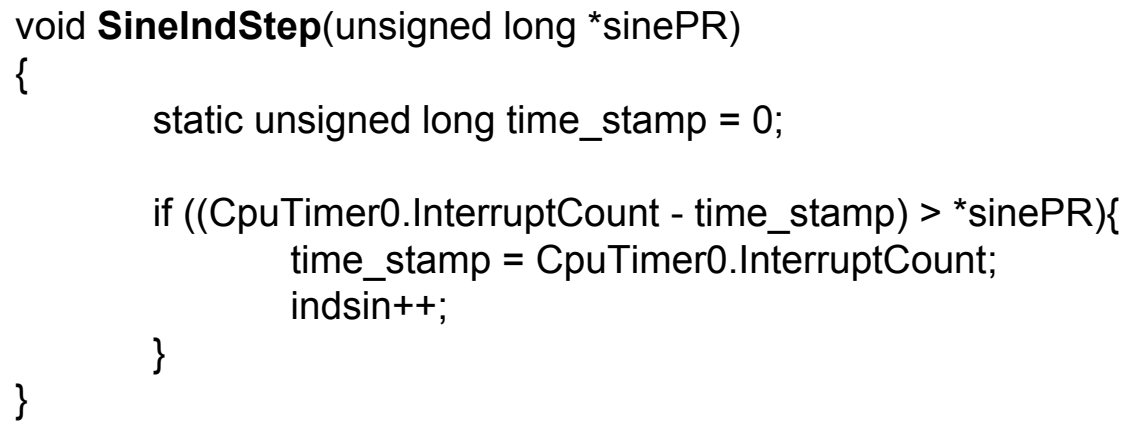

O valor de sinePR para uma dada freqüência de entrada pode ser determinada pela Equação (5.7).

$$
\text { sinePR }=\frac{1}{512 \cdot f_{\text {sine }}}
$$

em que $f_{\text {sine }}$ é a freqüência da onda senoidal de referência. Nota-se que a variável sinePR é inteira de 32 bits, na qual a parte fracionária da Equação (5.7) é arredondada.

A rotina de interrupção para a determinação do valor de CMPR1 é realizada conforme o bloco de código descrito no Quadro 5.11. O valor da senóide de referência é adquirido pela tabela de seno, sine_table, indexada pela variável indsin. $\mathrm{Na}$ instrução descrita interna ao comentário "Seno de referência", é efetuado o produto da amplitude da senóide (soma-se 1 unidade para obter a referência com valores sempre positivos) pelo valor de ganho de amplitude sineAmp, o qual define o valor RMS de saída. 
Quadro 5.11 - Rotina de Interrupção de atualização de CMPR1 para a geração $P W M$ senoidal.

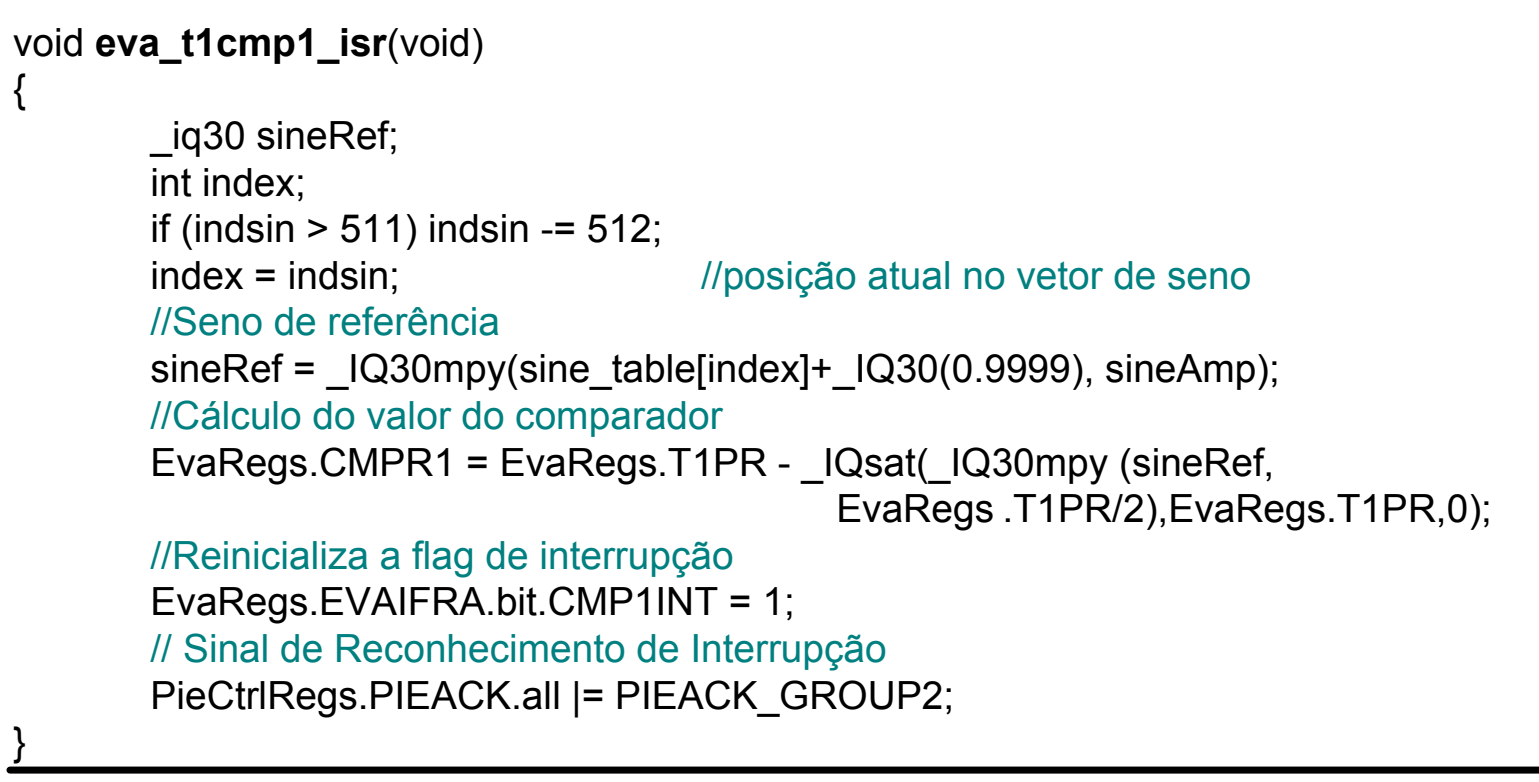

O valor de CMPR1 é determinado pela Equação (5.8).

$$
\text { CMPRx }=\text { TxPR }- \text { sineRef } \cdot \text { TxPR/2 }
$$

em que sineRef é a onda senoidal de referência. Note que esta expressão é válida para o cálculo dos 3 registradores de comparação, CMPR.

A rotina de interrupção dos registradores CMPR2 e CMPR3 para a geração de sinais PWM é descrito pelo bloco de código ilustrado no Quadro 5.12 e Quadro 5.13. 
Quadro 5.12 - Rotina de interrupção de atualização de CMPR2 para a geração PWM senoidal adiantada em 120 graus.

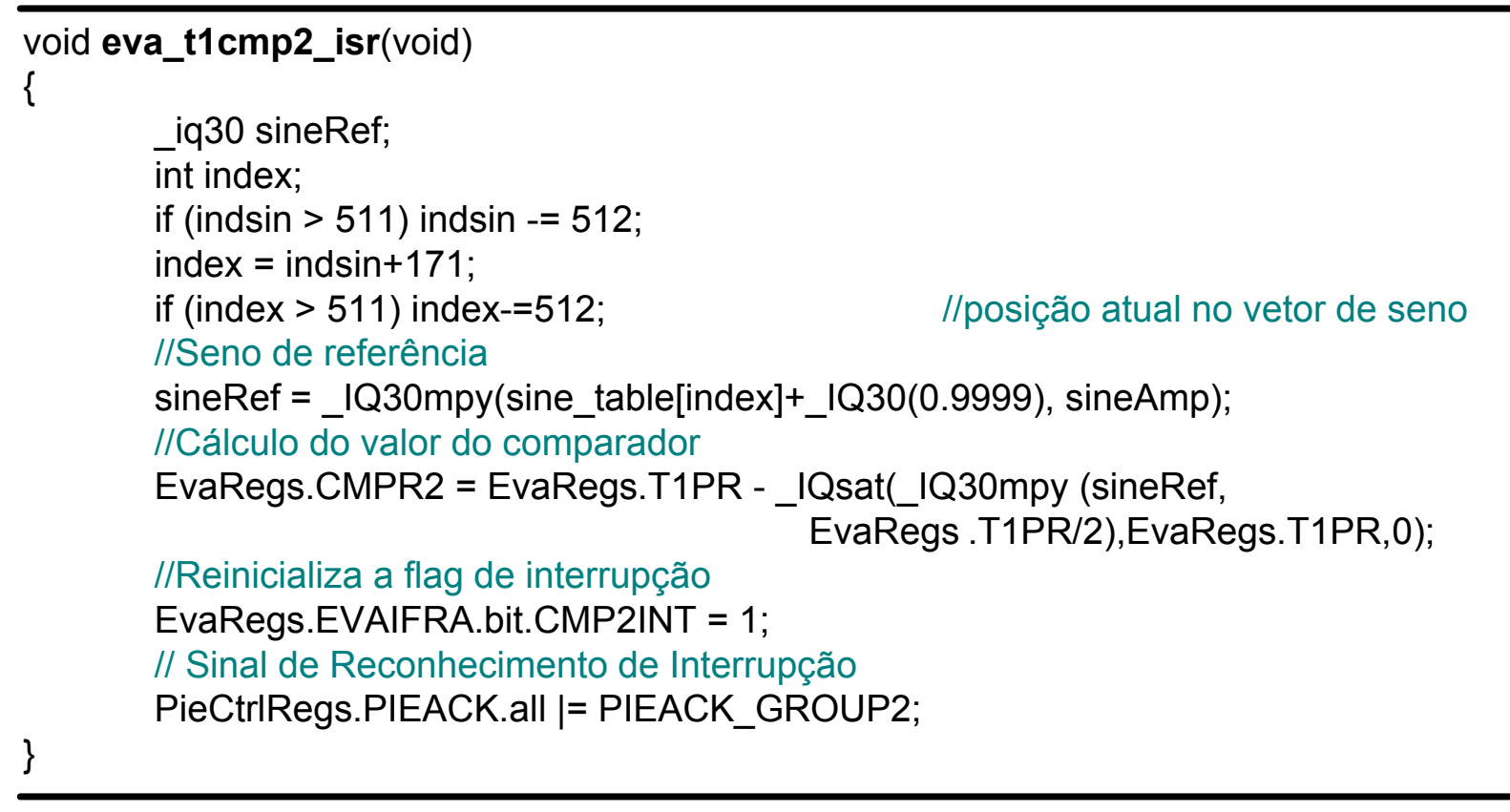

A diferença em tais rotinas, comparando-se com a determinação de CMPR1, consiste na indexação da tabela de seno, visto que a senóide de CMPR2 é adiantada e CMPR3 é atrasada em 120 graus com relação à CMPR1. Como o valor de indsin está associado ao seno do canal CMPR1, é necessário recalcular o índice para CMPR2 e CMPR3 de forma que as mesmas estejam defasadas em 120 graus. O deslocamento para a onda de referência adiantada de 120 graus pode ser determinado por uma simples regra de três como segue:

$$
\text { defasagem }\left(120^{\circ}\right)=\frac{120}{360} \cdot 512 \approx 171
$$

De forma similiar, calcula-se a defasagem do deslocamento para a onda de referência atrasada em 120 graus (ou adiantada de 240 graus) como segue:

$$
\text { defasagem }\left(240^{\circ}\right)=\frac{240}{360} \cdot 512 \approx 342
$$


Quadro 5.13 - Rotina de Interrupção de atualização de CMPR2 para a geração $P W M$ senoidal atrasada em 120 graus.

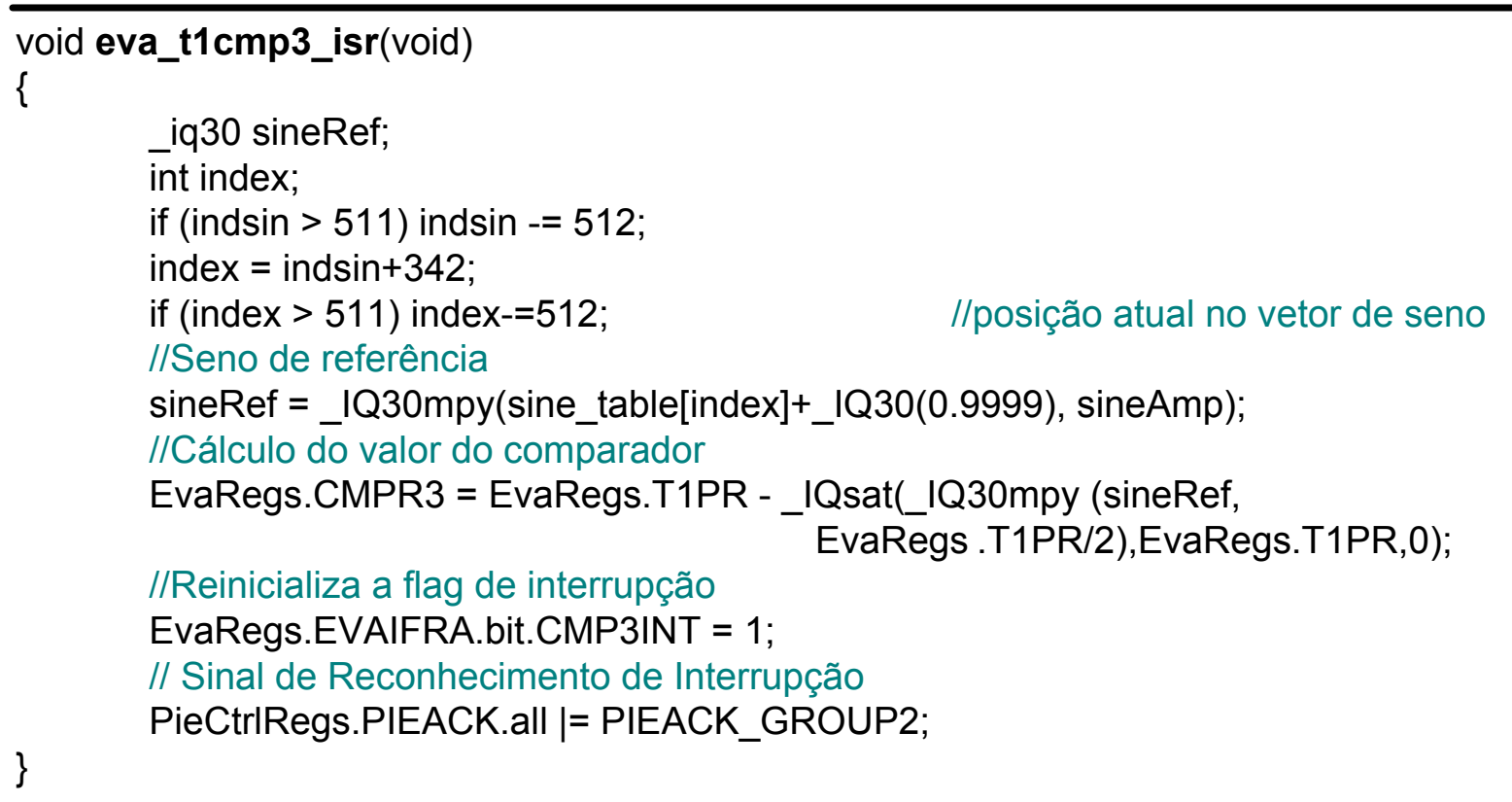

\subsubsection{Cálculo da Velocidade Angular}

O cálculo da velocidade angular é realizado mediante a avaliação do contador T2CNT. Considerando-se um encoder de resolução de 2000 pulsos por rotação, a qual é quadruplicada pelo QEP antes do contador, determina-se a velocidade em rpm (rotações por minuto ) por meio da Equação (5.9).

$$
\text { velocidade }=\frac{\Delta \mathrm{T} 2 \mathrm{CNT}}{\Delta t} \cdot \mathrm{QEPScaler} \quad(\mathrm{rpm})
$$

em que $\Delta$ T2CNT é a variação no valor do contador no intervalo de tempo $\Delta t$. QEPScaler é uma constante defina por:

$$
\text { QEPScaler }=\frac{60}{4 \cdot 2000}
$$

O cálculo da velocidade é determinado na entrada do sistema fuzzy, o qual é executado a cada $\Delta t=20 \mathrm{~ms}$, tempo suficiente para que haja uma grande variação 
no T2CNT. Conseqüentemente, possibilita-se a medição com alta resolução a uma ampla faixa de velocidade nos limites práticos do MIT.

A função em linguagem C para determinar a velocidade é descrita pelo bloco de códigos ilustrado no Quadro 5.14.

Quadro 5.14 - Código para o cálculo da velocidade angular.

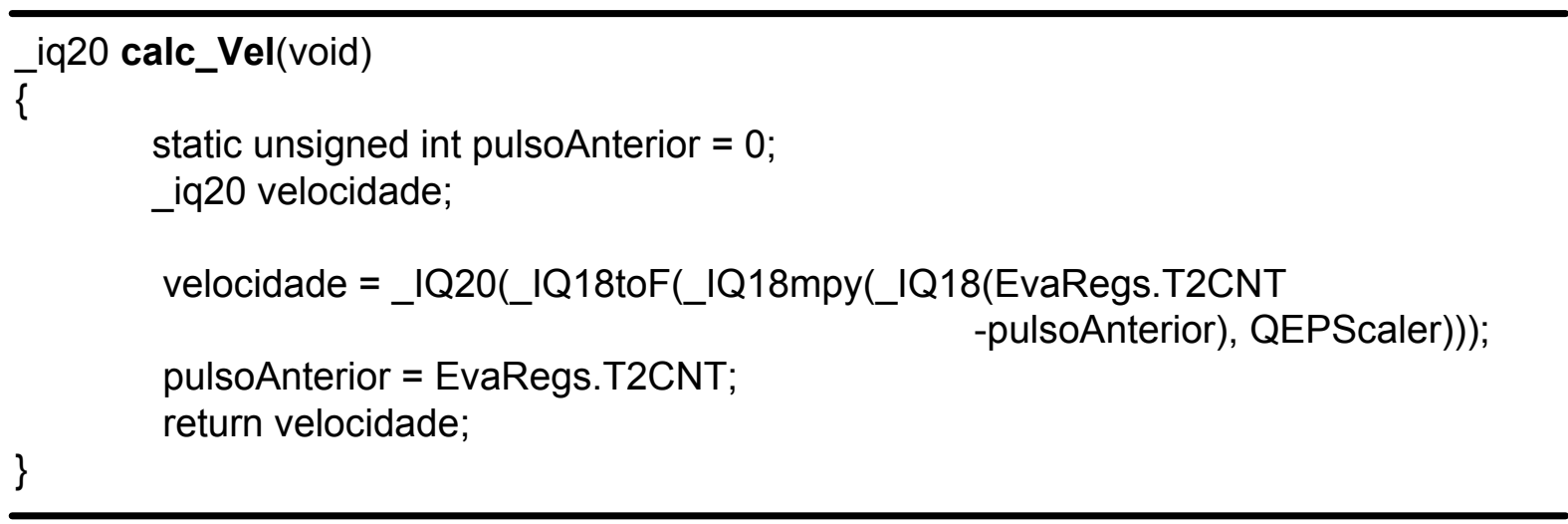

\subsubsection{Projeto do Controlador Fuzzy Embarcado}

O desenvolvimento do sistema fuzzy embarcado foi projetado idealizando-se uma possível aplicação em processadores digitais de arquitetura mais simples.

Em situações práticas e de tempo real, na qual o tempo de execução é crítico, é possível efetuar a inferência mediante uma indexação por tabela, ou seja, mapeiam-se todos os pontos discretos possíveis de entrada e os associam à saída defuzzificada, e então, os armazenam na memória de dados em formato de uma tabela. Assim, por uma simples indexação, o processo de inferência é realizado. Cabe ressaltar que, para tanto, é necessária uma elevada disponibilidade de memória.

Neste sentido, procurou-se efetuar as devidas simplificações para reduzir a quantidade de memória exigida, bem como minimizar o número de instruções realizadas no processo de inferência. Desta forma, a escolha do método de 
implicação de Mamdani foi devido à sua simplicidade em relação ao método convencional de implicação, no qual exige um maior número de instruções e memória. A técnica de aproveitar uma função de pertinência para as outras variáveis do processo é também vantajosa, em virtude de exigir menos memória.

Considerando que o processador empregado é de ponto fixo, projetou-se o sistema de inferência fuzzy baseando-se apenas em variáveis do tipo inteiros de 16 e 32 bits. Conforme os resultados obtidos pela simulação computacional, o desempenho do sistema de controle foi satisfatório mesmo se empregando funções de pertinências triangulares simétricas. A estratégia adotada nesta dissertação consiste em aproveitar tais características com o intuito de modelar um sistema de inferência mais simples e eficiente.

Visto que as funções de pertinências são triangulares e simétricas para todas as variáveis de entrada e saída, discretizou-se uma reta em um vetor de 512 posições com valores variando-se de 0 a 1000. A partir desta, é possível determinar qualquer outra reta paralela, conforme descrito pela Figura 5.18. Nota-se que o vetor é acessado por indexação obedecendo-se o critério de que o índice 0 representa a primeira posição do vetor.

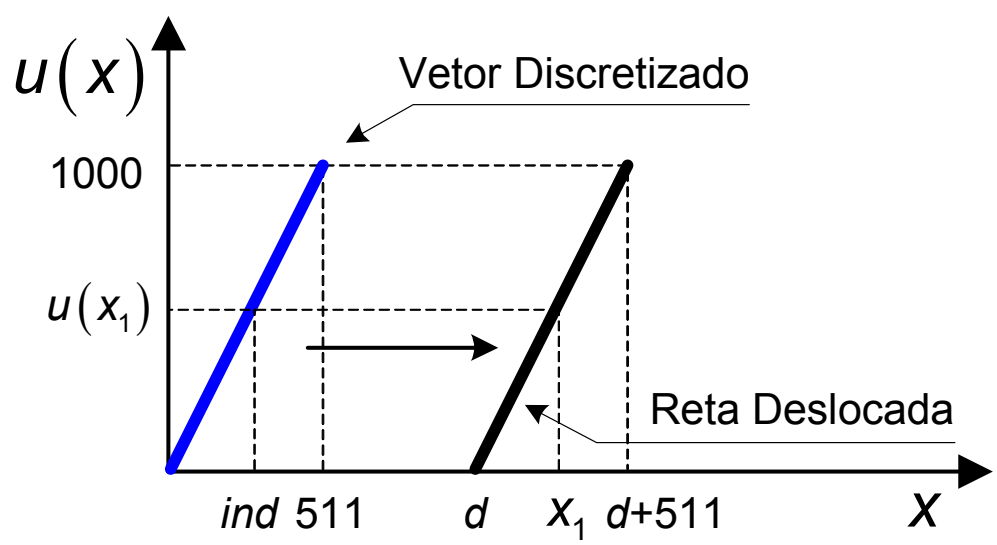

Figura 5.18 - Determinação da reta paralela ao vetor de discretização. 
Seja um valor $x_{1}$ pertencente ao intervalo $[d, d+511]$. Para determinar o seu grau de pertinência é necessário acessar o índice do vetor discretizado adequadamente. Para tanto, basta subtrair o valor de $x_{1}$ em $d$ posições, ou seja:

$$
\text { ind }=x_{1}-d
$$

Procedendo-se de forma similar aos passos adotados no esquema anterior, também é possível determinar o valor da reta antiparalela ilustrada na Figura 5.19.

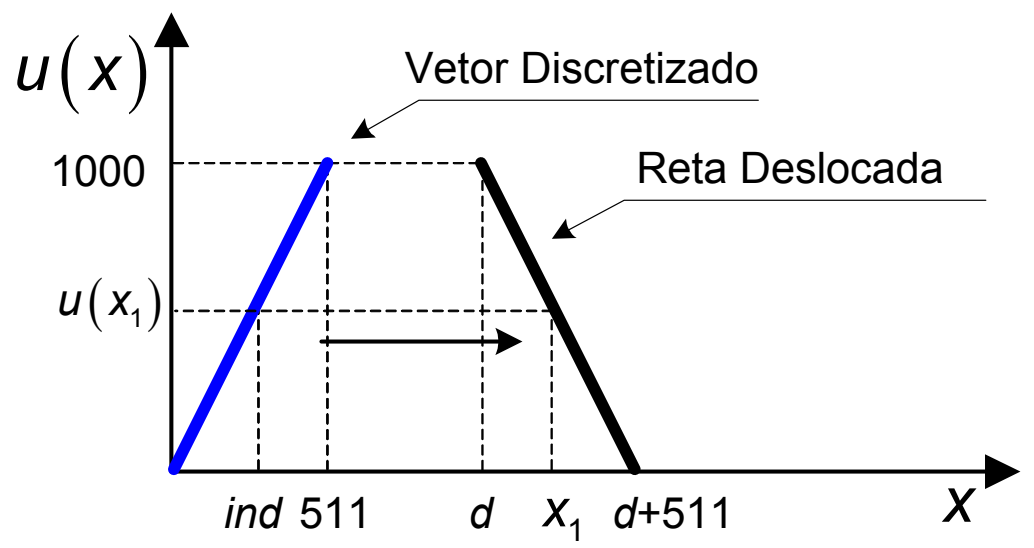

Figura 5.19 - Determinação da reta antiparalela ao vetor de discretização.

Portanto, seja um valor $x_{1}$ pertencente ao intervalo $[d, d+511]$. O cálculo do índice do vetor de discretização que retorna o valor equivalente ao de pertinência da reta deslocada pode ser efetuado como segue:

$$
\text { ind }=(d+511)-x_{1}
$$

Estendendo-se o raciocínio, possibilita-se a obtenção do grau de pertinência de qualquer variável lingüística, conforme a ilustração da Figura 5.20, por meio de um simples cálculo de readequação de índice. 


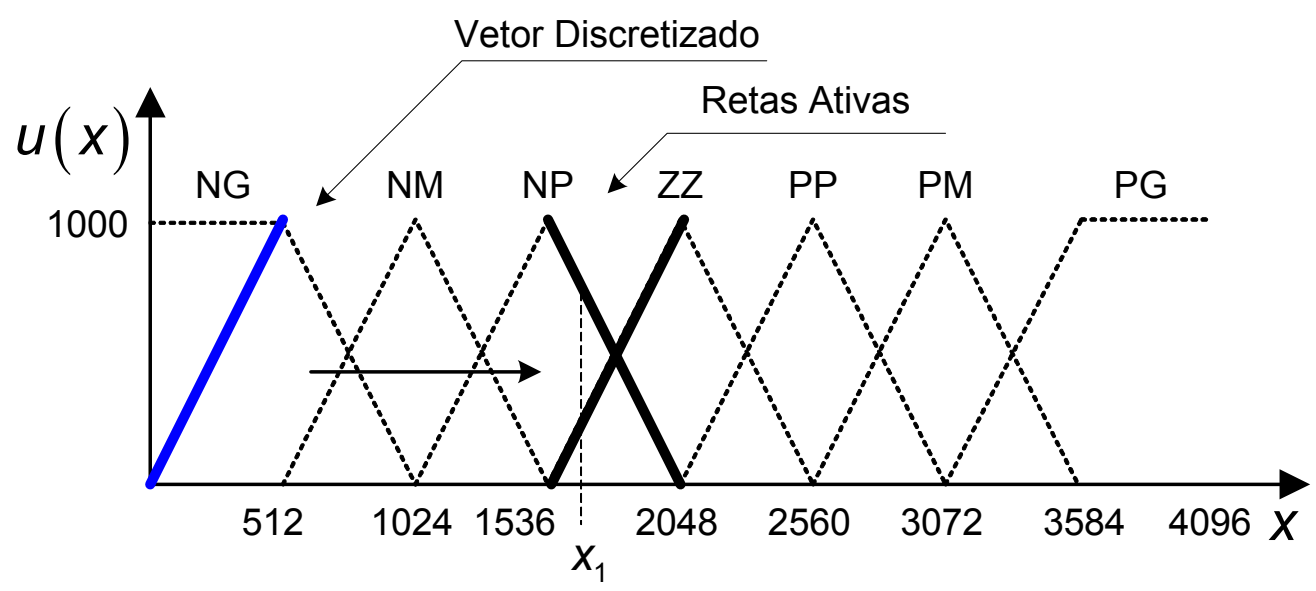

Figura 5.20 - Determinação das retas ativas dos conjuntos fuzzy.

$\mathrm{Na}$ Figura 5.20, observa-se que os termos lingüísticos "NG" e "PG" consistem de funções trapezoidais. Em virtude da base superior ser uma constante e igual 1000, basta aplicar o teste de condição "se $x_{1}$ for menor que 512 ou maior que 3584, então $u\left(x_{1}\right)=1000 . "$

Este método de simplificação proporciona uma economia significativa no recurso de memória apesar do leve aumento no custo computacional, comparandose com o método tradicional de armazenar cada função de pertinência em um vetor de dados discretizados.

A conversão de valores em ponto flutuante no intervalo de $[-1,1]$, conforme o projeto realizado da Subseção 4.2.4, para o intervalo de $[0,4096]$ em ponto fixo, pode ser realizado conforme a seguinte expressão:

$$
x_{\text {integer }}=4096 \cdot\left(x_{\text {float }}+1\right) / 2
$$

em que $x_{\text {float }}$ é o valor definido em ponto flutuante e $x_{\text {integer }}$ é o valor convertido em ponto fixo para ser utilizado no sistema de inferência fuzzy embarcado.

Os procedimentos adotados para efetuar inferência de Mamdani, agregação e a defuzzifição são realizados de forma similar aos passos descritos na Subseção 4.2.4. 
A variação de freqüência de referência do inversor, resultante da defuzzificação do sistema fuzzy, deve ser convertida do formato ponto fixo para ponto flutuante mediante a seguinte expressão:

$$
x_{\text {float }}=\frac{2 \cdot x_{\text {integer }}}{4096}-1
$$

De forma similar à metodologia de projeto descrita na Subseção 4.2.4, os valores de universo de discurso do erro de velocidade e da variação do erro de velocidade são divididos por um fator de ganho para se enquadrar no intervalo de [-1 1]. Após inúmeros ensaios experimentais, determinou-se o fator de ganho de 200 rpm para a variável lingüística "erro de velocidade", 200 rpm para a variável lingüística "variação de erro de velocidade" e $1 \mathrm{~Hz}$ para a variável lingüística variação de freqüência de referência de acionamento. Vale salientar que o processo de inferência fuzzy é realizado a cada $20 \mathrm{~ms}$.

\subsection{Resultados Experimentais}

Nesta seção, serão apresentados os resultados de ensaios experimentais para efetuar a validação do sistema de controle fuzzy de velocidade proposta nesta dissertação de mestrado.

A tensão de cada fase $\mathrm{R}, \mathrm{S}$ e T aplicadas no inversor trifásico consistiram de 127 Vrms. Mediante a análise do circuito interno ilustrado na Figura 3.18, nota-se que o banco de capacitores é carregado pela tensão de linha, ou seja, 220 Vrms, o que proporciona uma tensão contínua no barramento CC de aproximadamente $311 \mathrm{~V}$.

A razão $V / f$ foi determinada a partir dos valores nominais de placa do motor de indução, ou seja, 220 Vrms para $60 \mathrm{~Hz}$. Neste sentido, procurou-se aplicar a freqüência de referência tal que a amplitude do valor RMS varie proporcionalmente à 
variação da freqüência de modo que o fluxo possa ser mantido constante. Vale ressaltar que o controle de fluxo não é realizado em malha fechada, ou seja, caso haja uma variação na tensão de alimentação, o fluxo pode se deslocar do ponto de projeto.

Considerando o acionamento da máquina de indução com a tensão no barramento CC de $311 \mathrm{~V}$ a $60 \mathrm{~Hz}$, observou-se que o valor RMS foi de $190 \mathrm{Vrms}$. Esta tensão não é suficiente para acionar a máquina com a constante pré-ajustada de $220 \mathrm{Vrms} / 60 \mathrm{~Hz}$, a qual se reduz a $86,4 \%$ deste valor.

Neste contexto, o sistema de controle proposto permitiu o acionamento na freqüência máxima de $60 \mathrm{~Hz}$, no entanto, procurou-se efetuar os ensaios com velocidades inferiores para que o fluxo não seja enfraquecido ao ponto de prejudicar a operação do MIT. Portanto, a injeção de sinais de terceira harmônica na referência senoidal serão tópicos que serão levados em consideração em trabalhos futuros para solucionar este problema.

Por outro lado, o acionamento do MIT para velocidades inferiores a $20 \%$ da velocidade nominal não foi considerado nos ensaios experimentais, visto que o acionamento e controle fuzzy desenvolvido neste trabalho foi projetado para operar com melhores resultados em velocidades acima deste valor.

Portanto, os limites de operação do sistema de acionamento em conjunto com a técnica de controle escalar V/f fuzzy adotada nesta dissertação são enquadrados nas velocidades superiores a $20 \%$ e inferiores a $90 \%$ da velocidade nominal. Considera-se também a faixa de operação sob condições de carga desde a vazio até o torque de $4,0 \mathrm{Nm}$.

Os ensaios experimentais realizados consistiram na análise de desempenho do sistema de controle fuzzy sob condições de variação em degrau de referência de 
velocidade, variação em rampa da referência de velocidade, e finalmente, variação em degrau do conjugado de carga.

\subsubsection{Resposta ao Degrau de Referência}

Neste ensaio, partiu-se o MIT com a referência de velocidade angular de 900 rpm, e após 3 segundos de operação, aplicou-se um degrau de referência de 1600 rpm. O desempenho do controlador fuzzy frente à variação do degrau de referência pode ser avaliado mediante a análise da Figura 5.21. Nota-se que no primeiro degrau (900 rpm) de referência, a amplitude das oscilações de velocidade é inferior às oscilações observadas no segundo degrau (1600 rpm). Isto se deve ao fato de que a resolução da freqüência de acionamento é diminuída conforme aumenta a velocidade de acionamento, a qual está diretamente relacionada com a variável sinePR do programa que define o tempo em $\mu$ s para incrementar o índice do vetor discretizado da senóide de referência.

Conforme mencionado nas seções anteriores, a senóide apresenta 512 pontos. Para se conseguir uma freqüência de acionamento de $60 \mathrm{~Hz}$ necessitaria de $32,55 \mu \mathrm{s}$. No entanto, em se tratando de uma base de tempo de $1 \mu \mathrm{s}$, o valor teve de ser arredondado para $32 \mu$ s causando a distorção na resolução.

A curva de velocidade ilustrada na Figura 5.21 foi mensurada pelo encoder e calculada pelo próprio DSP. Desta forma, o tempo de aquisição entre as amostras consiste de $20 \mathrm{~ms}$. 


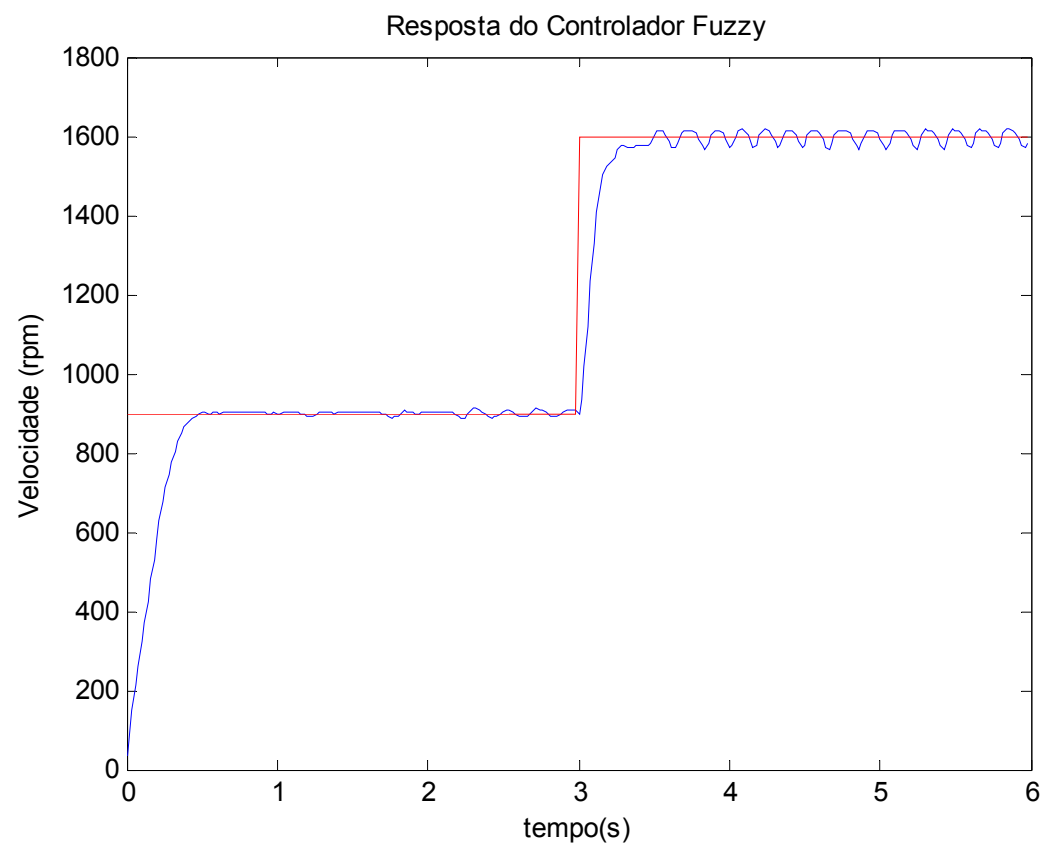

Figura 5.21 - Resposta do controlador fuzzy ao degrau de referência.

A Figura 5.22 representa o torque de carga que foi determinado pela Equação (2.67) utilizando-se a tensão de campo e a corrente de armadura mensurada pelos sensores Hall conectados na placa de aquisição de dados.

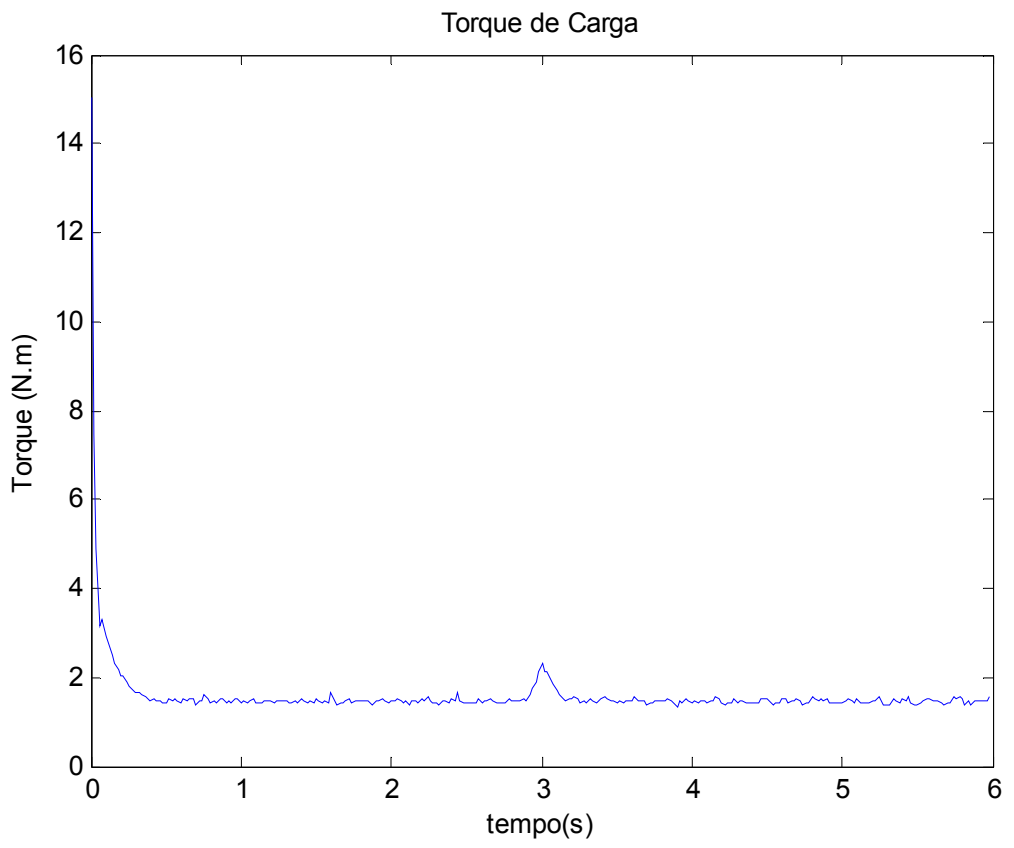

Figura 5.22 - Torque de carga aplicado ao eixo do MIT. 
O erro de velocidade ao longo do tempo pode ser analisado por meio da Figura 5.23. As linhas horizontais representam o centro dos termos lingüísticos, ou seja, os topos das funções de pertinência triangulares. A partir deste gráfico, observa-se que o erro do controlador no instante entre 4 e 6 segundos apresenta uma amplitude de pico-a-pico de aproximadamente $50 \mathrm{rpm}$. Nesse trecho, a velocidade de referência de velocidade é de 1600 rpm, conforme a Figura 5.21.

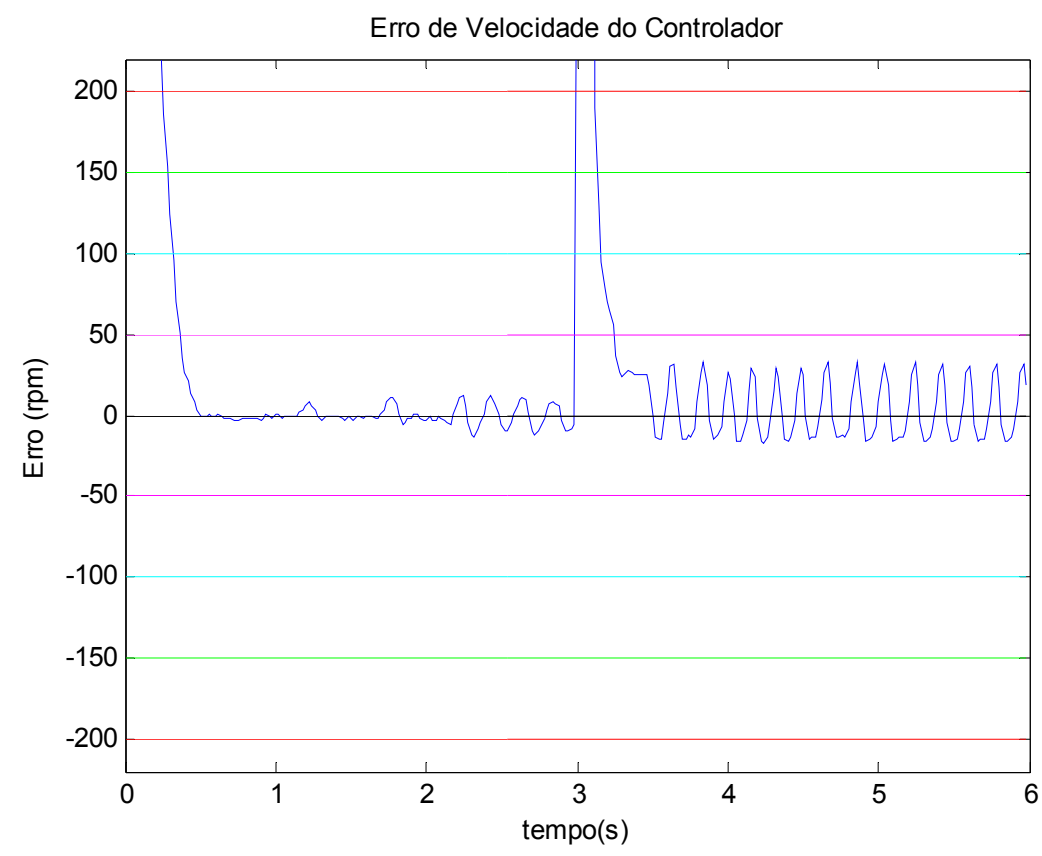

Figura 5.23 - Erro de velocidade do controlador fuzzy.

A freqüência de referência na saída do sistema fuzzy é representada na Figura 5.24. Uma técnica de acionamento empregada para elevar a velocidade de resposta foi implantar uma condição no código do sistema de controle. Caso o erro de velocidade exceda o universo de discurso da variável lingüística "velocidade", o sistema imediatamente aplica uma freqüência próxima à velocidade do motor. A partir deste ponto, o sistema fuzzy é encarregado de efetuar o ajuste fino. 


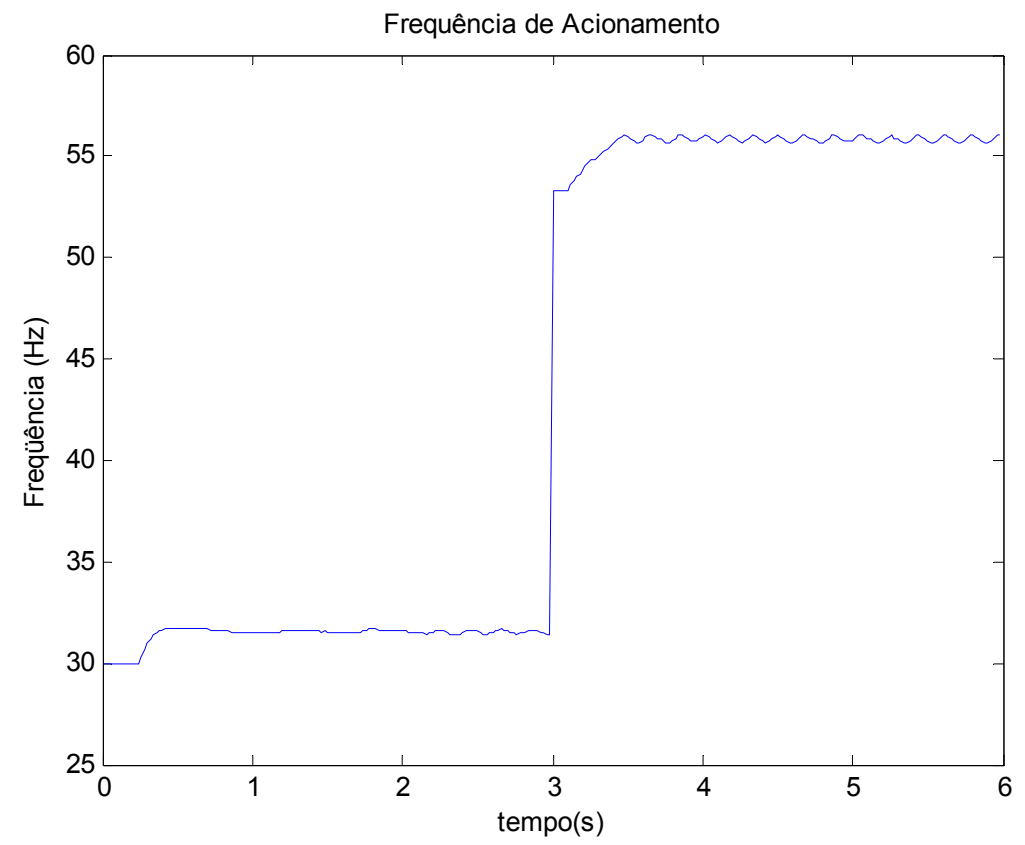

Figura 5.24 - Freqüência de acionamento.

A Figura 5.24 representa o valor em ponto flutuante relativo à freqüência de acionamento. No entanto, a onda senoidal de referência gerada pelo DSP é determinada a partir da variável sinePR, cujo formato é ponto fixo.

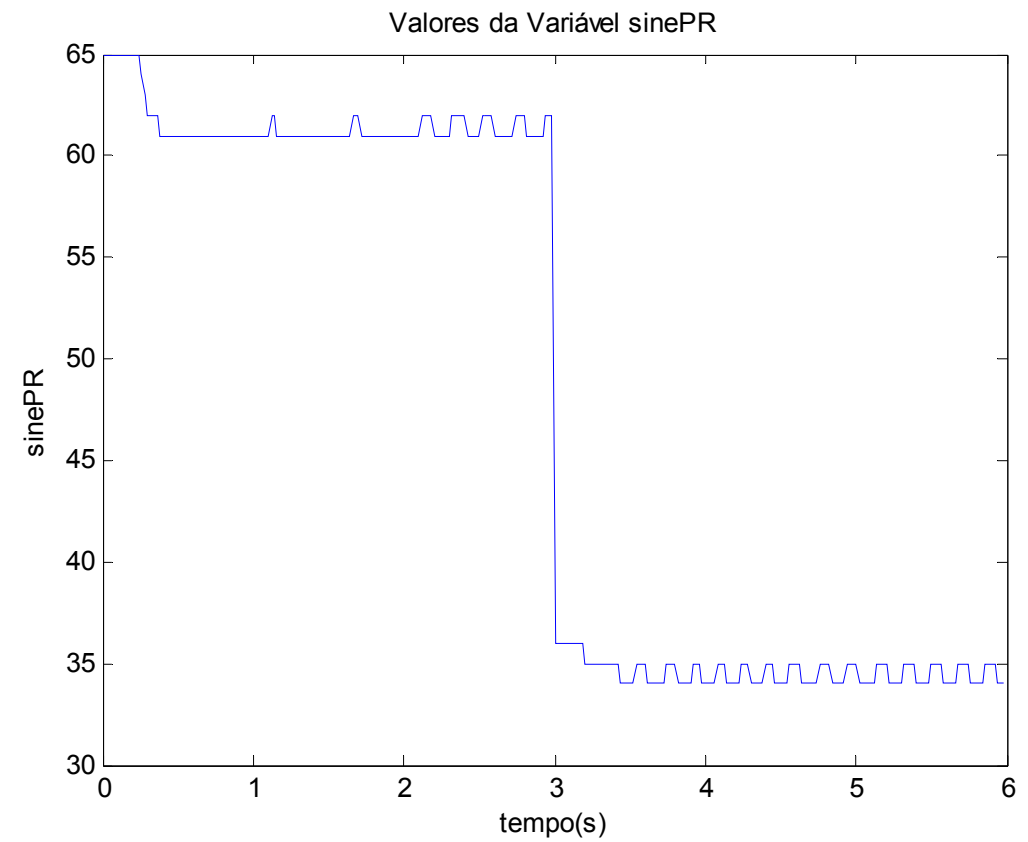

Figura 5.25 - Valores da variável sinePR. 
A Figura 5.25 representa os valores de sinePR atribuídos durante o tempo de ensaio. Nota-se que seu valor oscila em 1 unidade, ou seja, de 34 para 35 no trecho entre 4 e 6 segundos. Esta pequena variação é responsável pela oscilação na velocidade observada na Figura 5.21. Tal fenômeno ocorre em virtude da referência de velocidade associada à carga aplicada exija do sistema de controle uma freqüência tal que o valor de sinePR se situe entre 34 e 35 . No arredondamento, estes valores se tornam oscilantes.

\subsubsection{Resposta à Rampa de Referência}

O ensaio para avaliar a resposta do sistema de controle à rampa de referência foi realizado da seguinte forma: acionou-se a máquina com referência de velocidade inicial de $900 \mathrm{rpm}$ cujo valor foi incrementado gradativamente na forma de uma reta até atingir o valor de 1600 rpm, conforme a Figura 5.26.

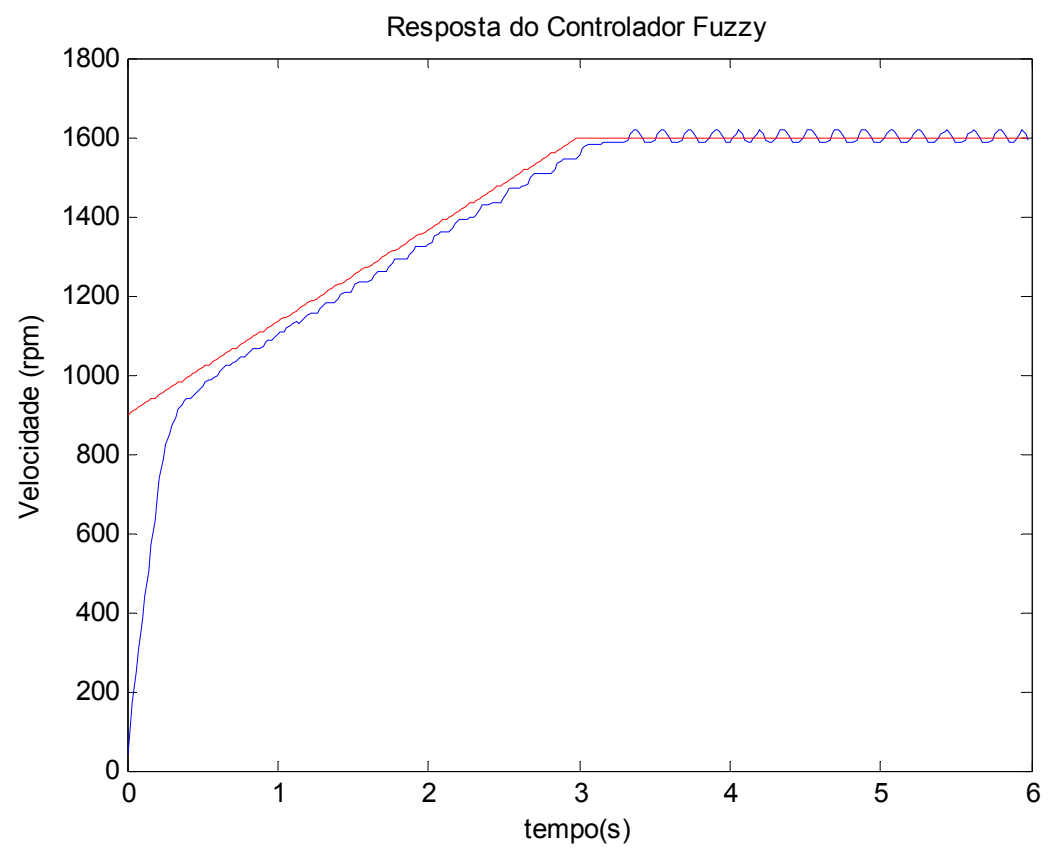

Figura 5.26 - Resposta do controlador fuzzy à rampa de referência. 
A Figura 5.26 ilustra o desempenho do sistema de controle fuzzy frente a uma variação rampa de referência de velocidade. Observa-se que a velocidade angular desenvolvida pelo MIT foi capaz de acompanhar a rampa de referência com um determinado erro que pode ser avaliado mediante a Figura 5.28.

O torque de carga de aproximadamente $2,0 \mathrm{Nm}$, aplicado no eixo do motor de indução ao longo do tempo, é representado pela Figura 5.27.

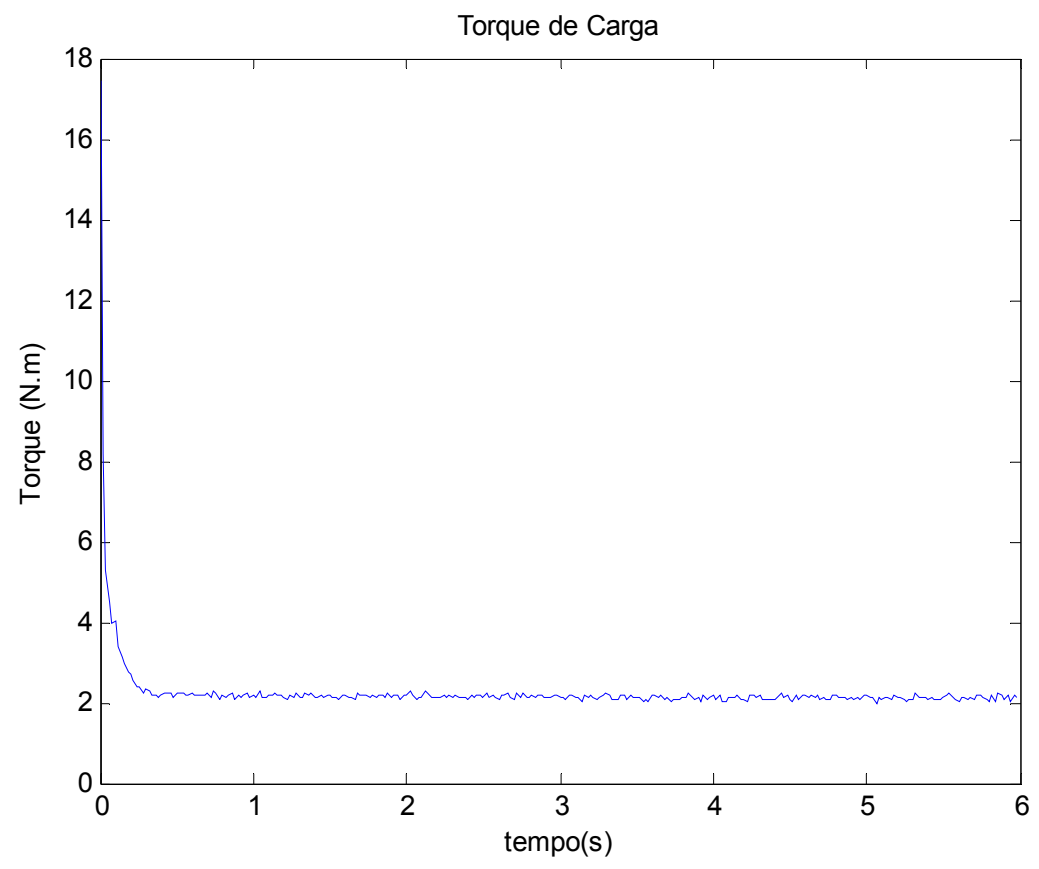

Figura 5.27 - Torque de carga.

A Figura 5.28 ilustra o erro de velocidade em rotações por minuto (rpm) desenvolvido pelo controlador fuzzy. A partir deste, nota-se que durante a rampa de referência, o erro da velocidade constitui-se de aproximadamente $50 \mathrm{rpm}$ ao longo dos 3 segundos. Em 1 segundo, a velocidade angular do motor situa-se ao redor dos 1000 rpm. Desta forma, o erro relativo do controlador nesse instante consiste de apenas $5 \%$. 


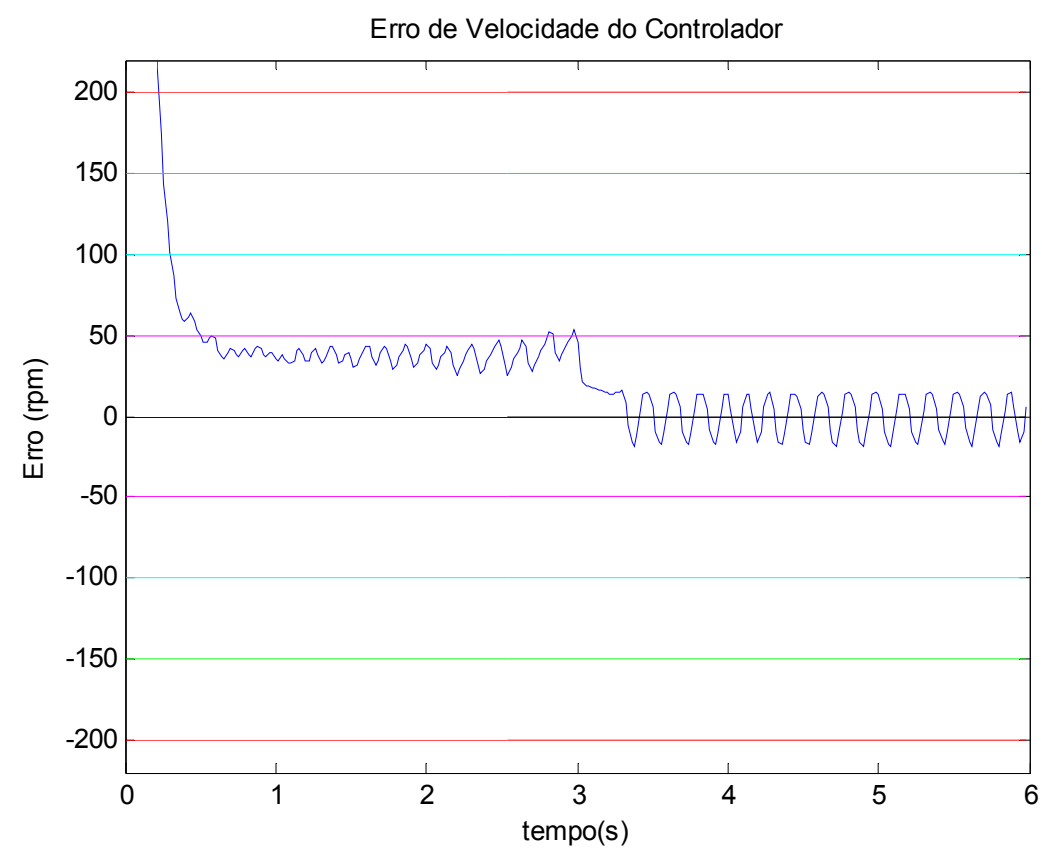

Figura 5.28 - Erro de velocidade do controlador fuzzy.

A curva de freqüência de acionamento do MIT ao longo do ensaio é ilustrada na Figura 5.29.

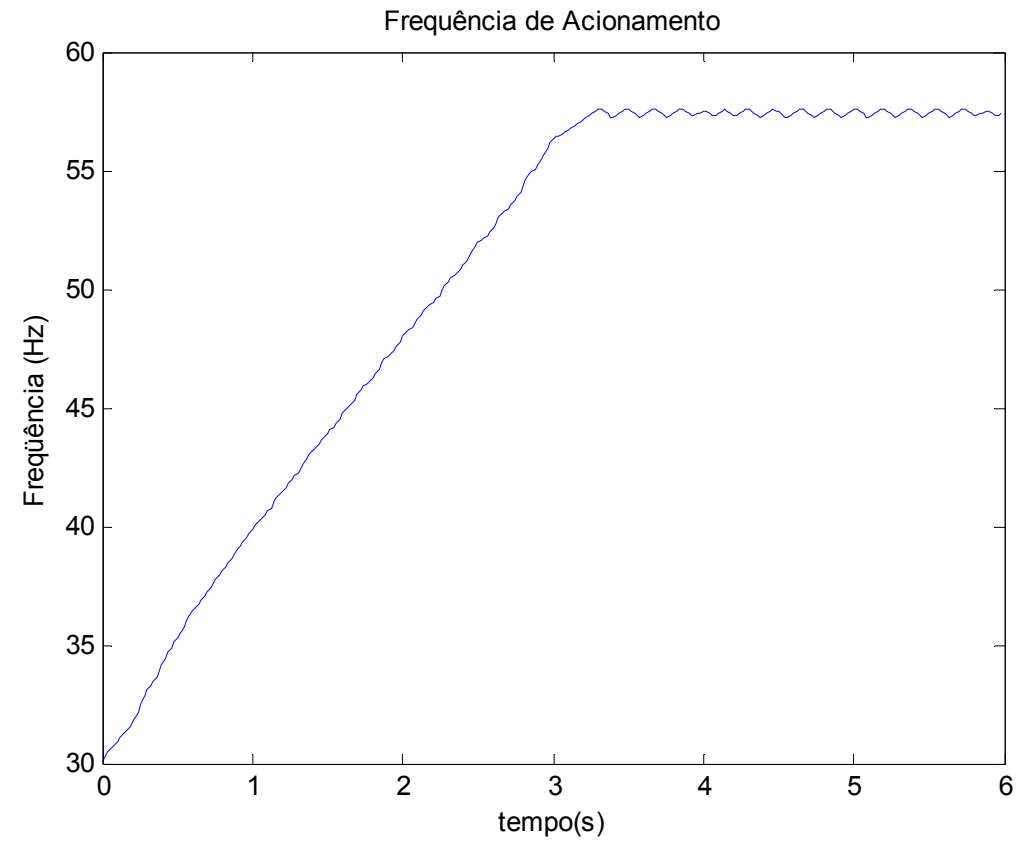

Figura 5.29 - Freqüência de acionamento do MIT. 
A Figura 5.30 representa os valores atribuídos à variável sinePR durante o tempo de ensaio. Dada à característica da rampa de referência, o seu decaimento é realizado de forma mais suave. Nota-se também que os valores de sinePR oscilam em 1 unidade no período entre 4 e 6 segundos proporcionando a oscilação de velocidade no MIT.

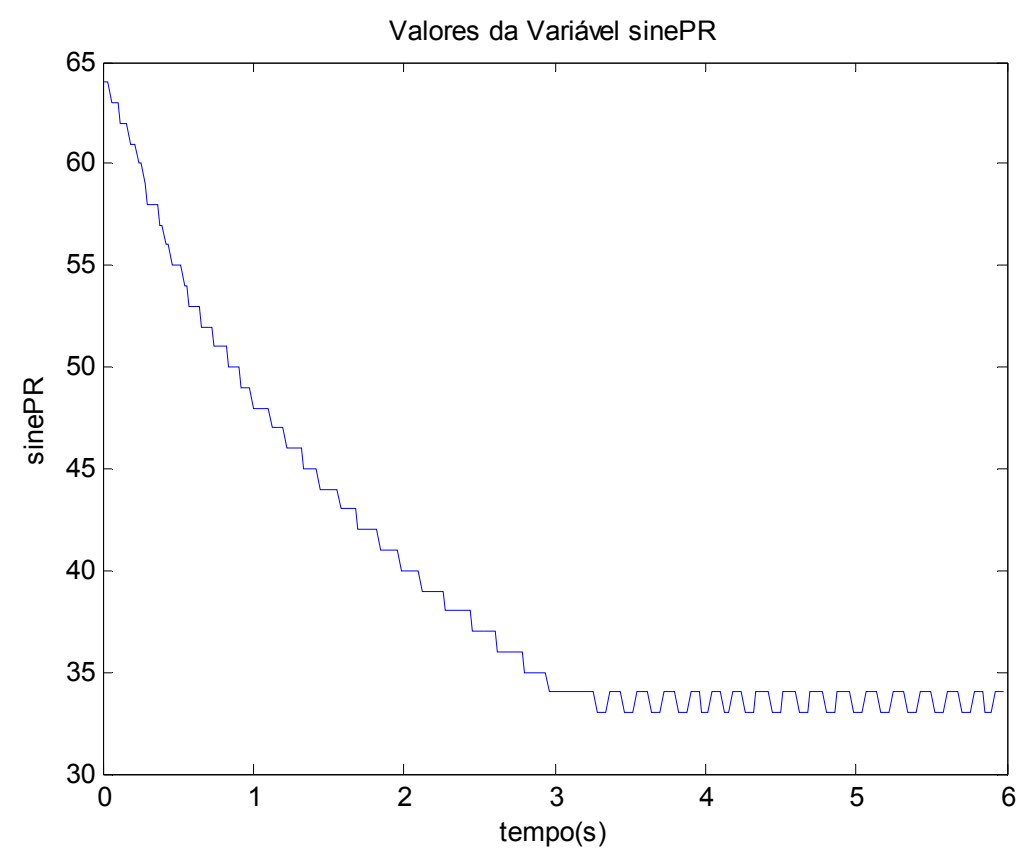

Figura 5.30 - Valores da variável sinePR.

\subsubsection{Resposta ao Degrau de Torque de Carga}

O ensaio realizado para efetuar a análise do controlador fuzzy frente às variações de carga consiste na aplicação de um torque inicial de aproximadamente 2,0 Nm e, em seguida, aumentou-se a tensão de campo do gerador de corrente contínua por meio de um variador de tensão monofásico de forma a proporcionar um torque de carga de 4,0 N.m. A Figura 5.31 representa o torque de carga aplicado no eixo do MIT ao longo do tempo. 


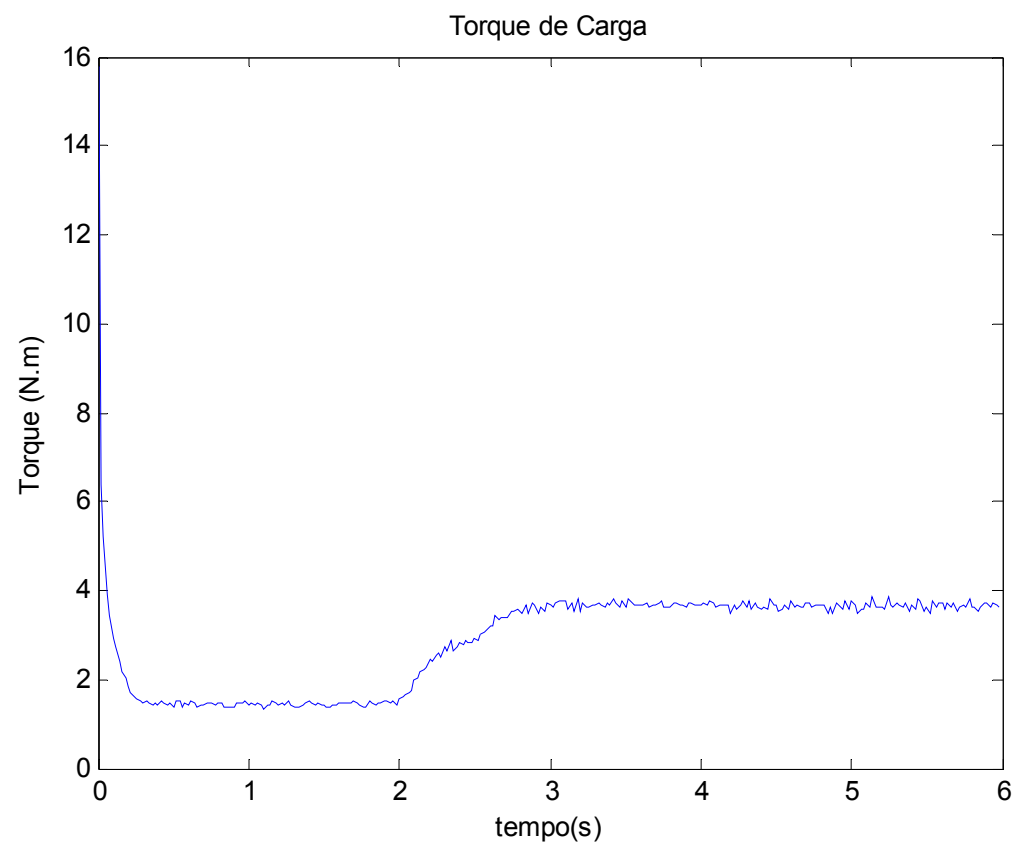

Figura 5.31 - Torque de carga.

A Figura 5.32 ilustra o desempenho do sistema de controle fuzzy frente às variações de torque de carga. Nota-se que no instante em que a carga aumenta, a velocidade do motor de indução tende levemente a se reduzir.

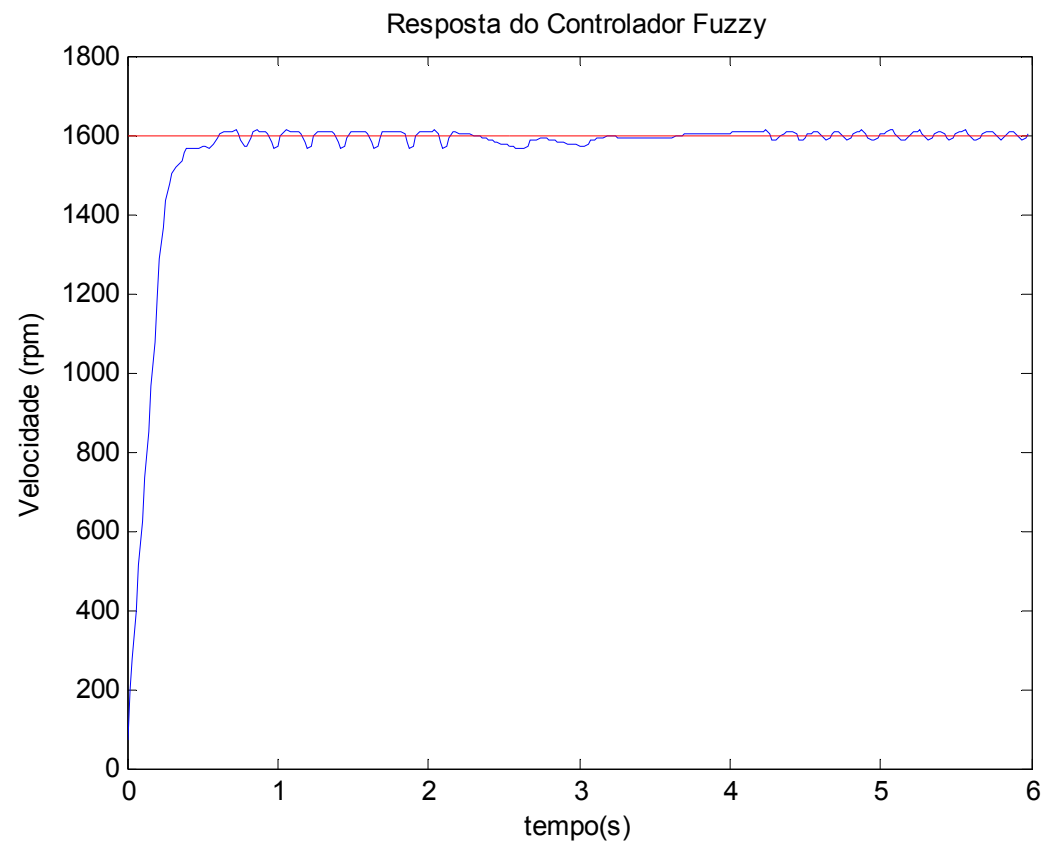

Figura 5.32 - Resposta do controlador fuzzy frente à variação de carga. 
No entanto, o controlador fuzzy efetuou a correção da velocidade, conforme pode ser notada no gráfico de erro da Figura 5.33.

Nesta curva, observa-se que o erro de velocidade entre a referência e o motor se limita a uma faixa menor que $50 \mathrm{rpm}$, ou seja, menos de $5 \%$ com relação à velocidade de referência.

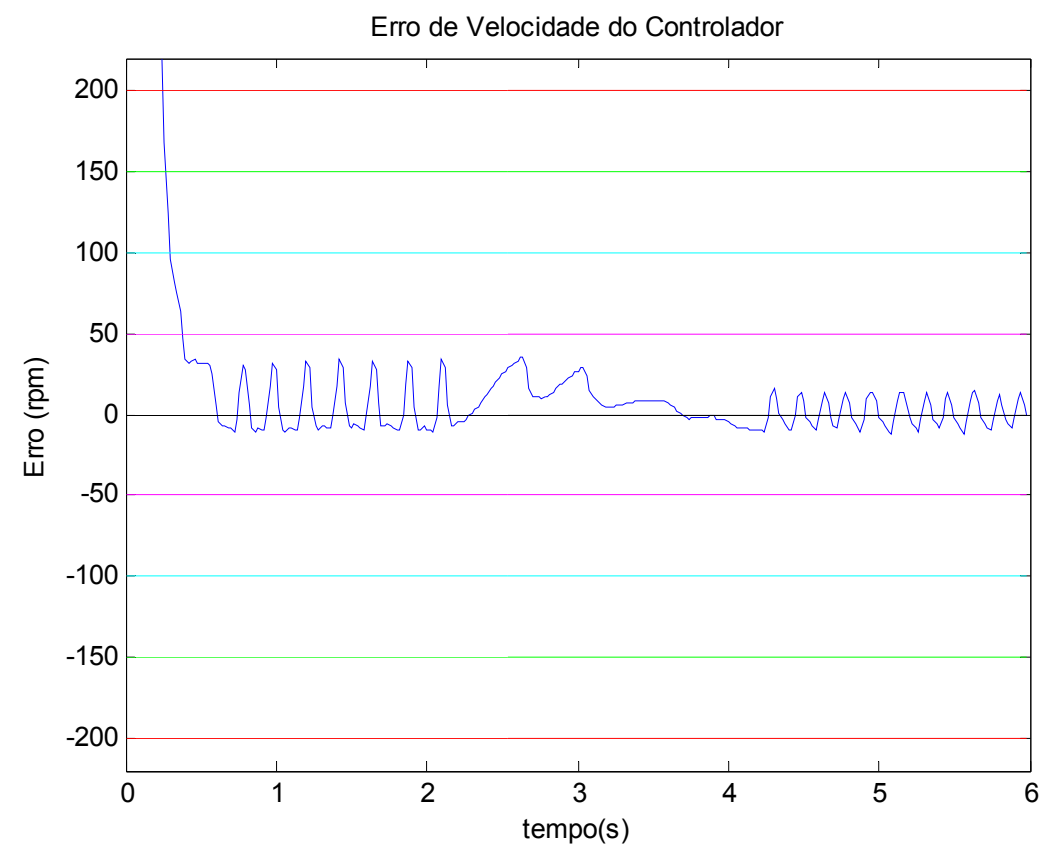

Figura 5.33 - Erro de velocidade do controlador fuzzy.

A Figura 5.34 ilustra a freqüência de acionamento ao longo do tempo. Notase que no instante da aplicação do torque de carga, o sistema de controle fuzzy identifica a queda de velocidade angular do MIT proporcionando a ação de controle de aumentar a freqüência de acionamento de tal forma que a queda seja compensada. 


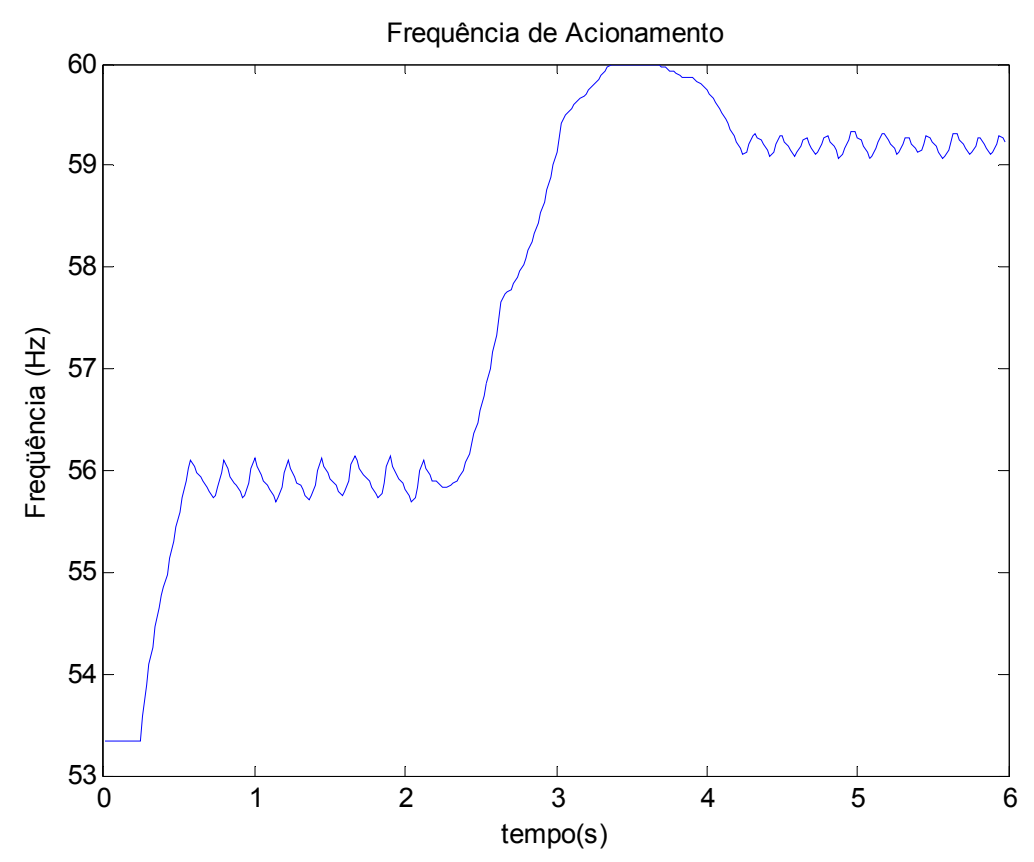

Figura 5.34 - Freqüência de acionamento.

A Figura 5.35 ilustra os valores atribuídos à variável sinePR para que o DSP forneça os sinais PWM com freqüência fundamental adequada.

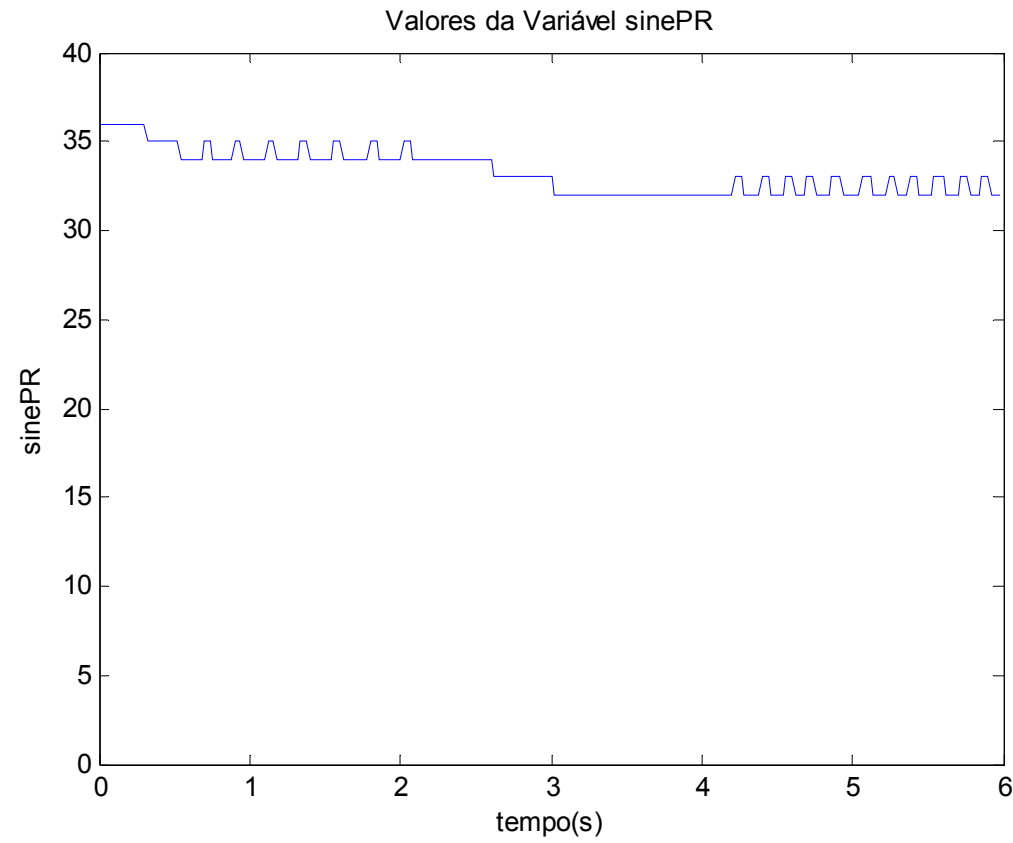

Figura 5.35 - Valores da variável sinePR. 
Um ponto relevante que deve ser observado nesta curva consiste na oscilação do valor de sinePR no instante entre 1 e 2 segundos e 4 e 6 segundos. Em ambos os intervalos, observam-se variações de 1 unidade nos valores de sinePR. No entanto, na curva de erro representado na Figura 5.33, nota-se que a amplitude do erro do primeiro trecho é maior que o segundo. Isto se deve ao fato de que a carga imposta ao eixo do MIT absorve as variações de velocidade.

\subsubsection{Aprimoramento dos Resultados Experimentais}

Mediante as observações efetuadas durante os 3 ensaios experimentais, a resolução do sinePR diminui conforme o sistema exige um acionamento com freqüência superior. As oscilações de velocidade são maiores quando a referência de velocidade é alta e quando a carga imposta ao eixo é relativamente baixa. Isso se deve ao fato do sistema de controle não ser possível encontrar o meio termo entre um valor de sinePR e outro.

Para contornar este problema, uma das soluções seria diminuir o número de pontos de discretização da senóide de referência, já que desta forma, o tempo esperado para incrementar o índice no vetor será maior, o que acarreta em um valor maior na variável sinePR. Entretanto, é necessário efetuar um estudo criterioso visto que a resolução da senóide discretizada em si será deteriorada.

Outra alternativa consiste na diminuição da base de tempo mínima, a qual foi configurada para $1 \mu \mathrm{s}$. No entanto, esta solução não seria adequada, pois o sistema será sobrecarregado para atender as interrupções do TimerO.

Portanto, optou-se por diminuir os pontos de discretização da senóide de referência com o objetivo de aumentar a resolução da freqüência de acionamento do MIT, conforme a Tabela 5.2. 
Tabela 5.2 - Resolução da freqüência de acionamento do MIT.

\begin{tabular}{|c|c|c|c|}
\hline \multicolumn{2}{|c|}{ Senóide de 512 pontos } & \multicolumn{2}{c|}{ Senóide de $\mathbf{6 4}$ pontos } \\
\hline sinePR & freqüência & sinePR & freqüência \\
\hline 32 & 61,04 & 259 & 60,32 \\
\hline 33 & 59,19 & 260 & 60,10 \\
\hline 34 & 57,45 & 261 & 59,87 \\
\hline
\end{tabular}

Os valores da freqüência de acionamento contidos na Tabela 5.2 são determinados conforme a seguinte expressão:

$$
f=\frac{1}{\mathrm{NP} \cdot \operatorname{sinePR} \times 10^{-6}}
$$

Em que NP é o número de pontos da senóide de referência discretizadas.

Observa-se na Tabela 5.2 que a resolução da freqüência de acionamento é aprimorada, visto que com a diminuição do número de pontos, o valor de sinePR aumenta. Conseqüentemente, a variação de 1 unidade em sinePR provoca menos variações na freqüência de acionamento.

Após tais procedimentos, efetuaram-se os ajustes finos do sistema de controle fuzzy de forma a se alcançar melhores resultados para todos os ensaios: degraus de referência de velocidade, rampa de velocidade e degrau de torque de carga aplicada ao eixo do MIT.

Desta forma, os valores do universo de discurso das variáveis lingüísticas "erro de velocidade" e "variação de erro de velocidade" foram alteradas para os intervalos de $[-100,100] \mathrm{rpm}$ e $[-150,150] \mathrm{rpm}$, respectivamente.

\subsubsection{Resposta ao Degrau de Referência (Aprimorado)}

Com base nos procedimentos tomados na subseção anterior, realizou-se a avaliação do sistema de acionamento e controle fuzzy reajustado em resposta aos degraus de referência de velocidade, conforme ilustrado na Figura 5.36. 


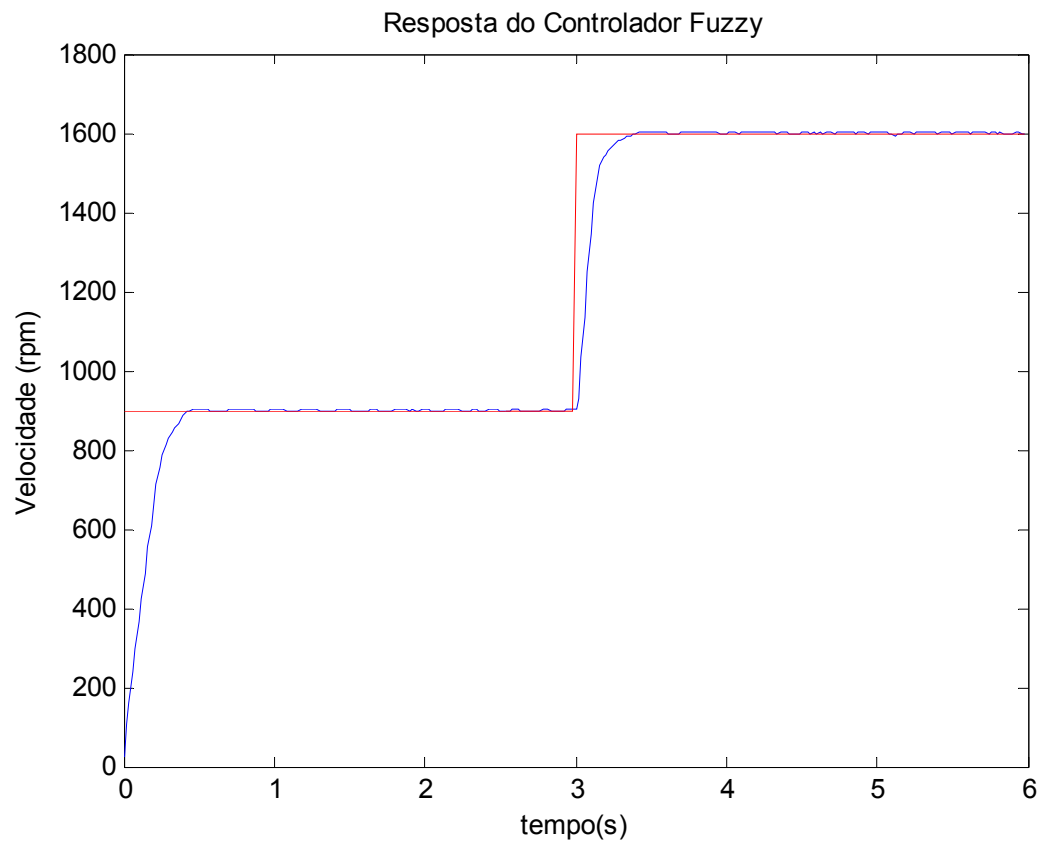

Figura 5.36 - Resposta do controlador fuzzy ao degrau de referência.

Neste ensaio, partiu-se a máquina com referência de velocidade de 900 rpm, e após 3 segundos, alterou-se instantaneamente a referência para 1600 rpm. Observa-se que as oscilações contidas no ensaio da Subseção 5.4 .1 forma claramente reduzidas.

Os erros entre a velocidade desenvolvida pelo MIT e a referência de velocidade durante o ensaio a degrau pode ser avaliados com mais detalhes mediante a Figura 5.37. As oscilações de velocidade tanto no primeiro degrau de referência (900 rpm) quanto no segundo degrau de referência (1600 rpm) apresentam oscilações de amplitudes menores que 10 rpm pico-a-pico. Desta forma, comparando-se com os resultados do ensaio anterior o sistema apresentou uma melhoria, em que os erros de velocidade foram reduzidos de $50 \mathrm{rpm}$ pico-a-pico para 10 rpm pico-a-pico. 


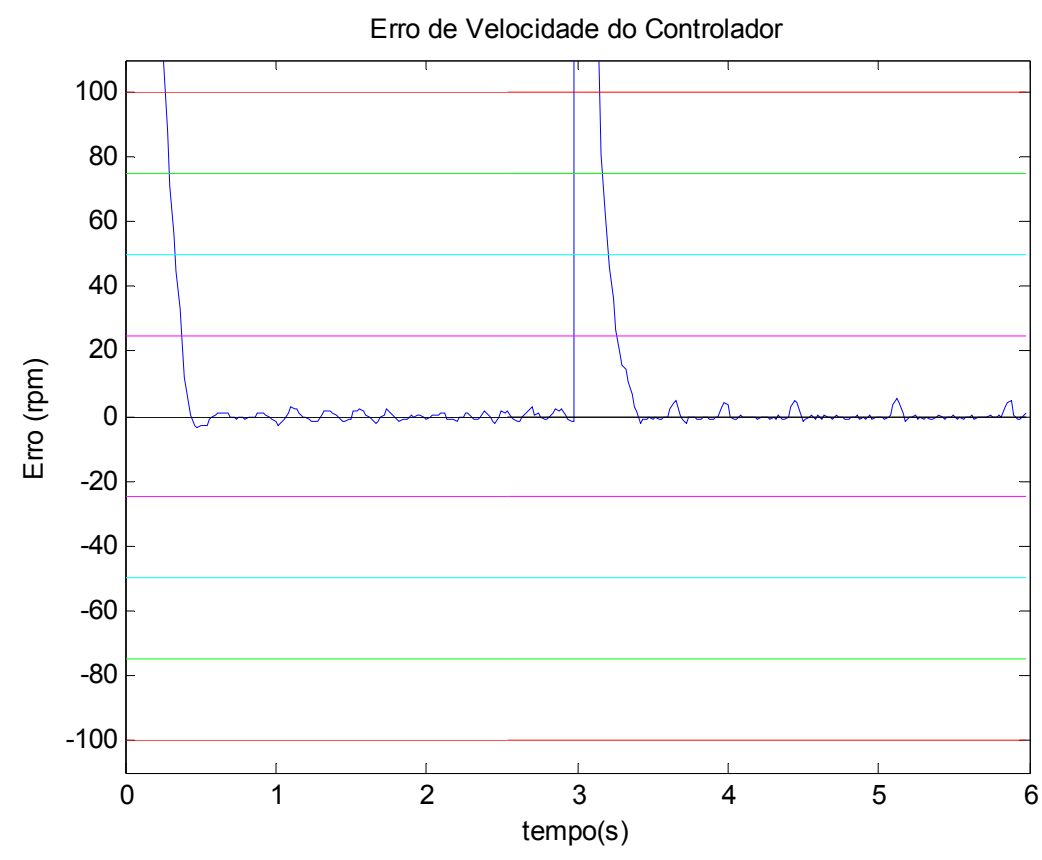

Figura 5.37 - Erro de Velocidade do controlador fuzzy.

A curva de freqüência de acionamento do MIT ao longo do ensaio é ilustrada na Figura 5.38. Nota-se que a freqüência de acionamento se tornou menos oscilatória.

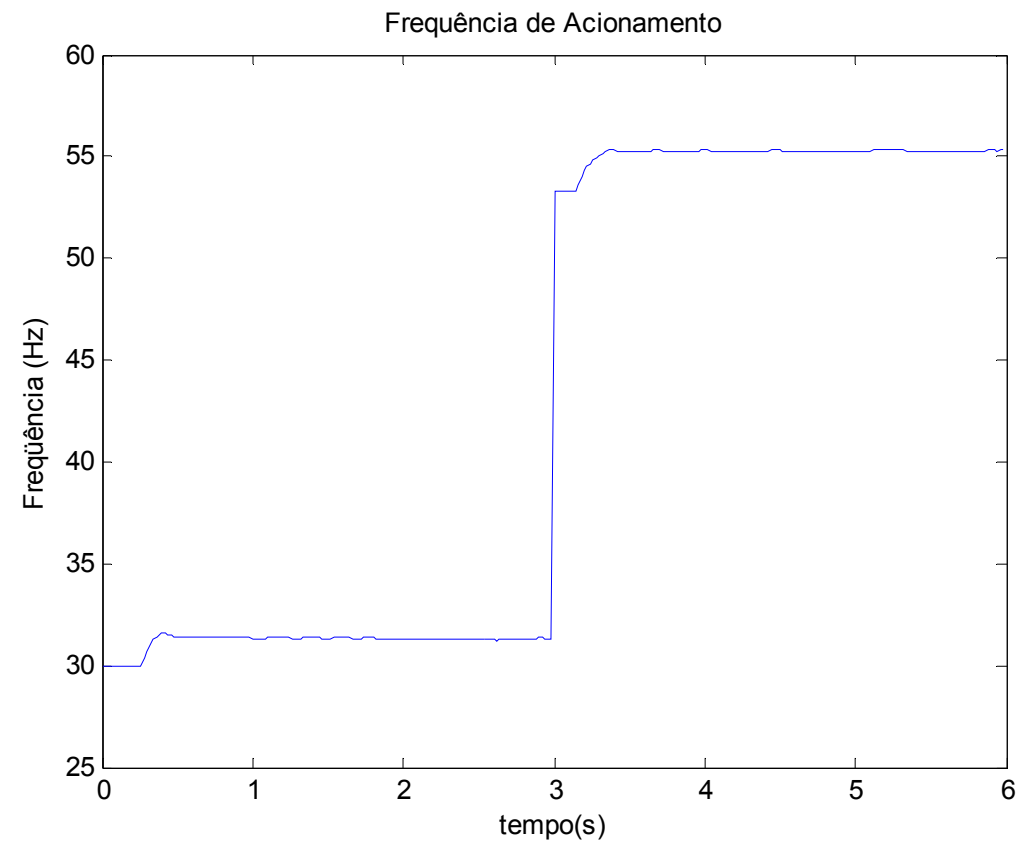

Figura 5.38 - Freqüência de acionamento do MIT. 
A Figura 5.39 ilustra os valores atribuídos à variável sinePR para que o DSP forneça os sinais PWM com freqüência fundamental adequada. Nota-se que os valores atribuídos à variável sinePR constituem de valores superiores para desenvolver freqüências de acionamento semelhantes ao ensaio degrau da Subseção 5.4.1. Desta forma, a oscilação em 1 unidade no valor de sinePR não proporciona a variação significativa na freqüência de acionamento.

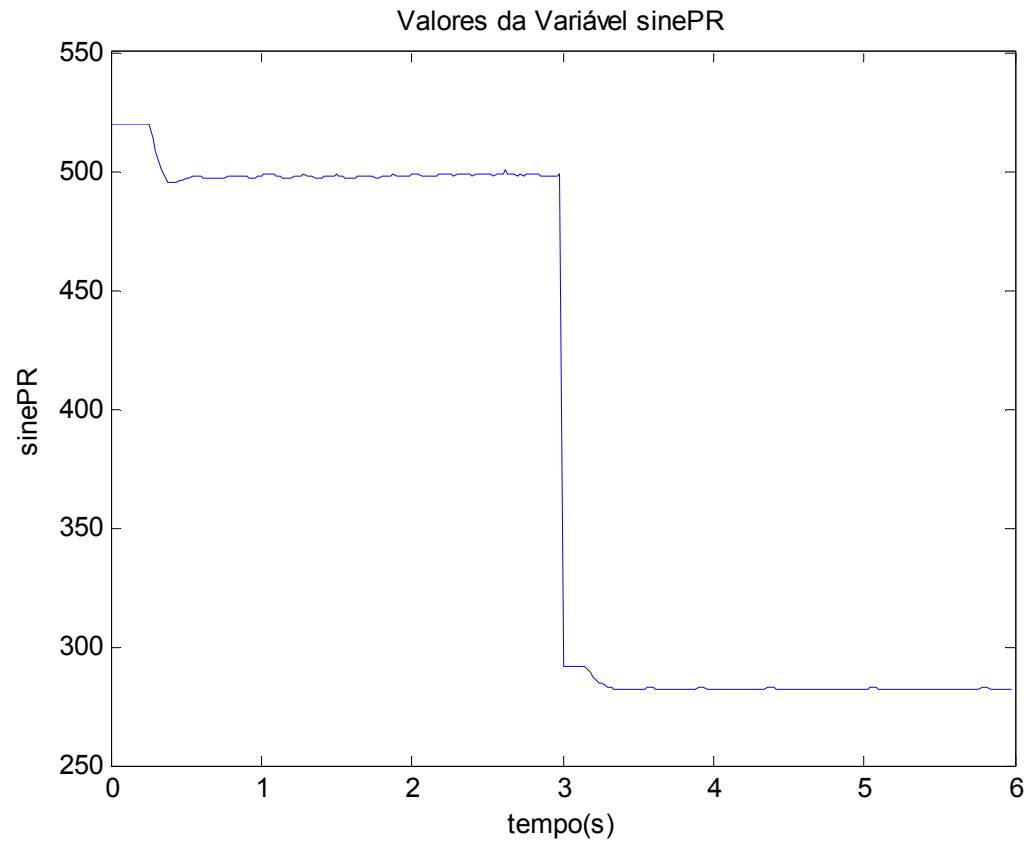

Figura 5.39 - Valores da variável sinePR.

Analisando-se o trecho entre 3 e 6 segundos do ensaio experimental, aparentemente não apresenta nenhuma oscilação no valor de sinePR. Entretanto, por meio da Figura 5.40 é possível observar esta região com maiores detalhes. Nota-se que, ainda há oscilações unitárias nos valores da variável sinePR, no entanto, os mesmos não proporcionam variação significativa na freqüência de acionamento. Conseqüentemente, as oscilações na velocidade desenvolvida pelo MIT são suprimidas. 


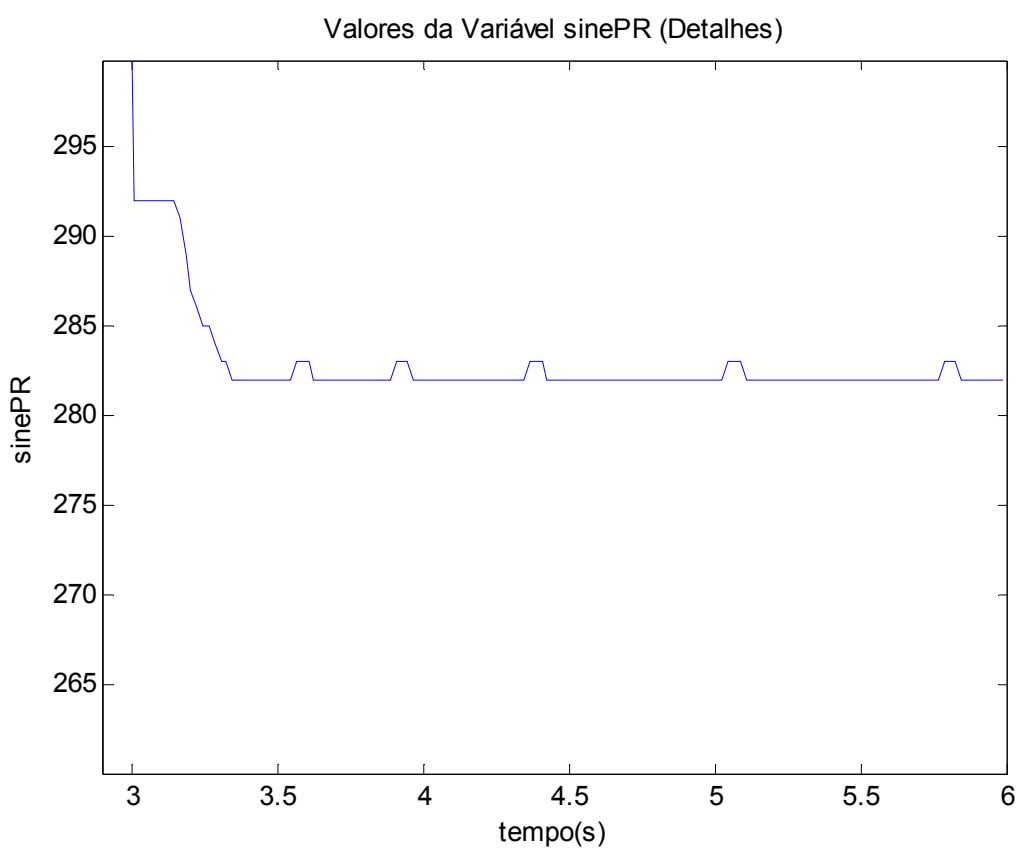

Figura 5.40 - Valores da variável sinePR (Detalhes).

\subsubsection{Resposta à Rampa de Referência (Aprimorado)}

A resposta do controlador fuzzy à rampa de referência de velocidade é ilustrada na Figura 5.41. Comparando-se com a resposta obtida no ensaio descrito pela Subseção 5.4 .2 , nota-se que tanto as oscilações de velocidade contida na rampa de velocidade quanto no trecho de referência constante foram significativamente reduzidas.

A Figura 5.42 ilustra os detalhes dos erros de velocidade do controlador fuzzy desenvolvidos ao longo do ensaio experimental. Durante a rampa de velocidade, o erro de velocidade foi em torno de $20 \mathrm{rpm}$. Em comparação com o ensaio descrito na Subseção 5.4.2, houve uma redução do erro de velocidade de 50 rpm para 20 rpm, além de suprimir suas oscilações durante a subida. 


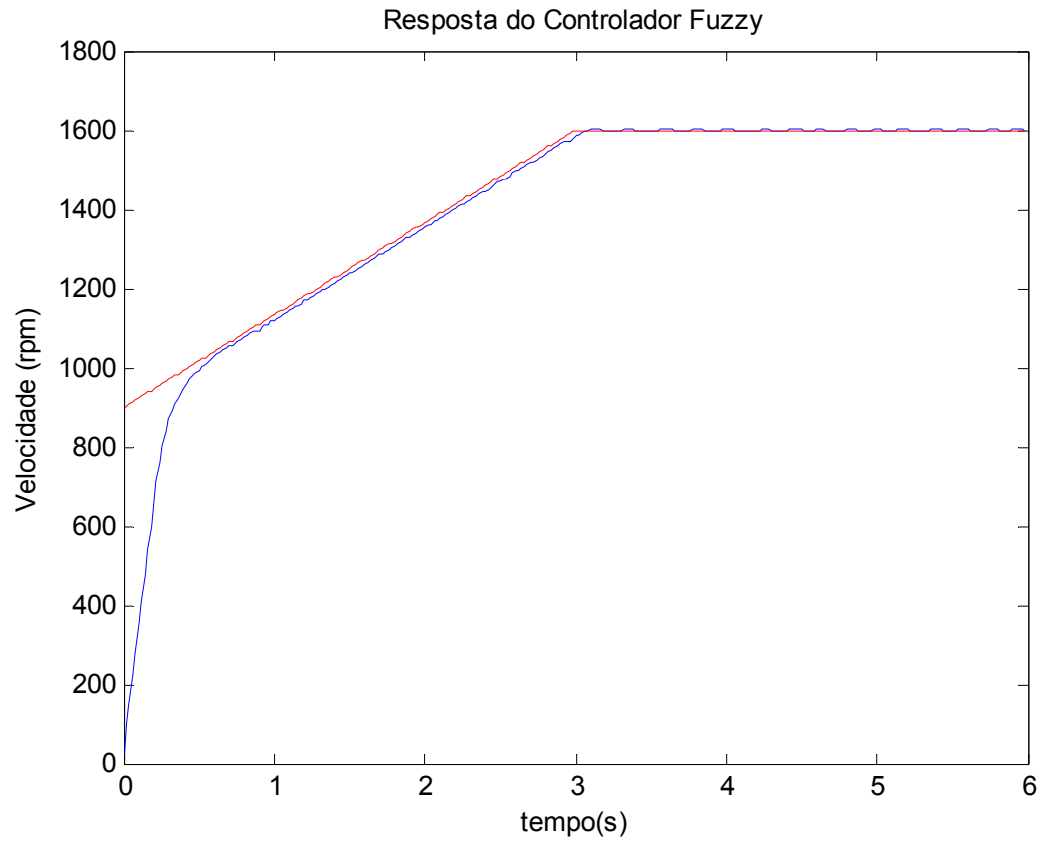

Figura 5.41 - Resposta do controlador fuzzy à rampa de referência.

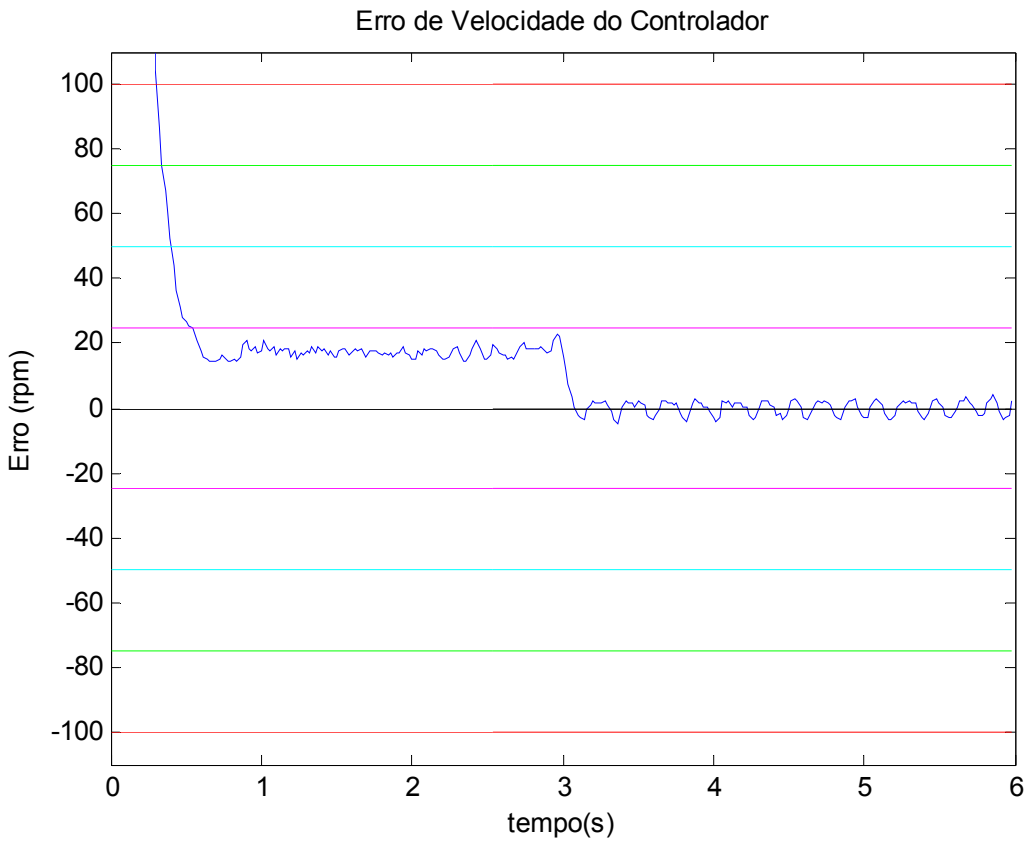

Figura 5.42 - Erro de velocidade do controlador fuzzy. 


\subsubsection{Resposta ao Degrau de Torque (Aprimorado)}

O desempenho do controlador fuzzy em resposta ao degrau de torque de carga é ilustrado na Figura 5.43. Neste ensaio, variou-se manualmente o torque de carga aplicado ao eixo do MIT de $0,5 \mathrm{Nm}$ a $4,0 \mathrm{Nm}$, no instante próximo a 3 segundos, por meio do variador de tensão monofásico conectado à fonte do enrolamento de campo do GCC.

Na Figura 5.43, observa-se que a velocidade do MIT tende a diminuir com a aplicação do torque de carga. No entanto, o controlador fuzzy foi capaz de elevar a freqüência de acionamento para compensar a queda de velocidade proporcionada pela carga, corrigindo a velocidade do eixo do MIT.

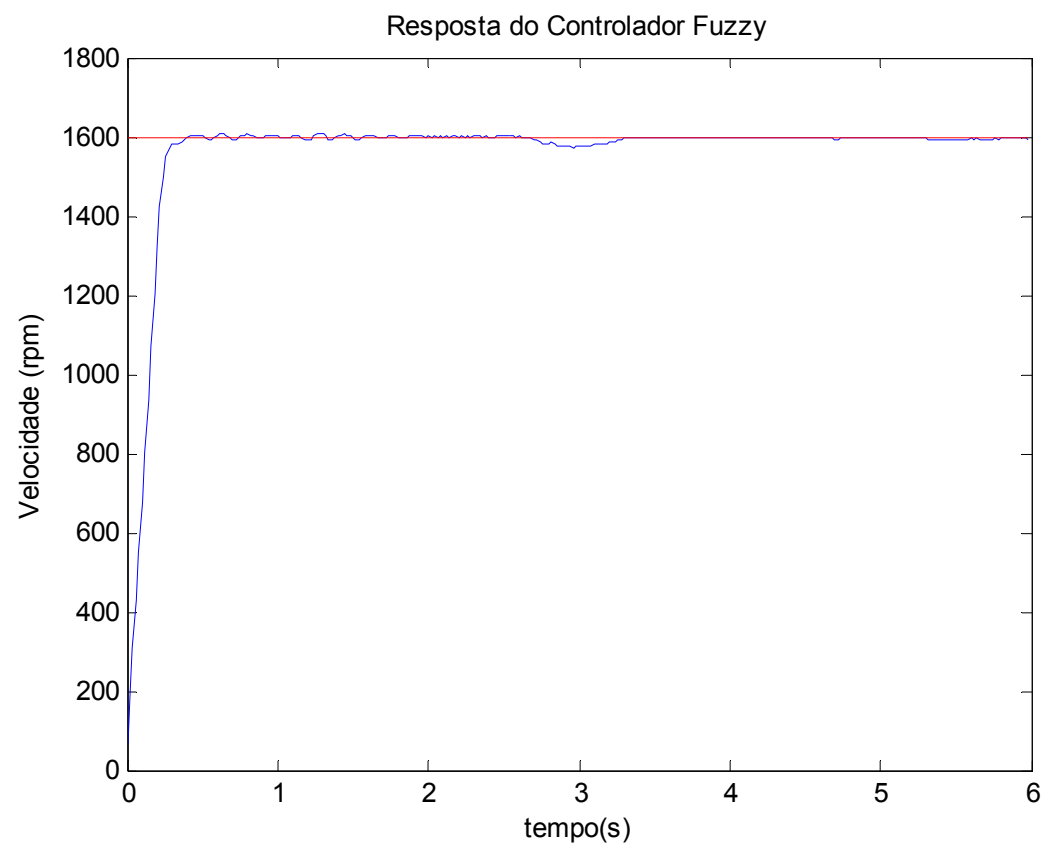

Figura 5.43 - Resposta do controlador fuzzy frente à variação de carga.

O gráfico ilustrado na Figura 5.44 representa o erro de velocidade do controlador fuzzy ao longo do ensaio experimental. Observa-se que a queda de velocidade no degrau de torque aplicado apresentou uma amplitude próxima de $20 \mathrm{rpm}$. 


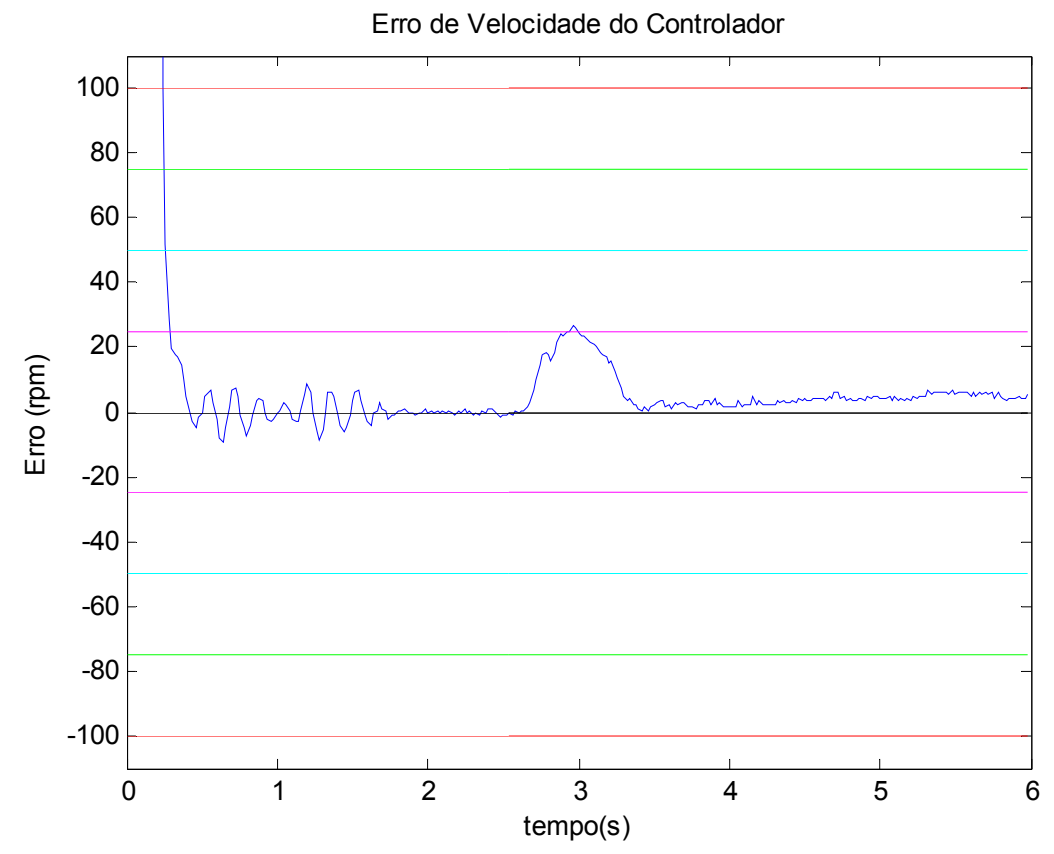

Figura 5.44 - Erro de velocidade do controlador fuzzy.

O gráfico representativo do torque de carga aplicado ao eixo do MIT é ilustrado na Figura 5.45.

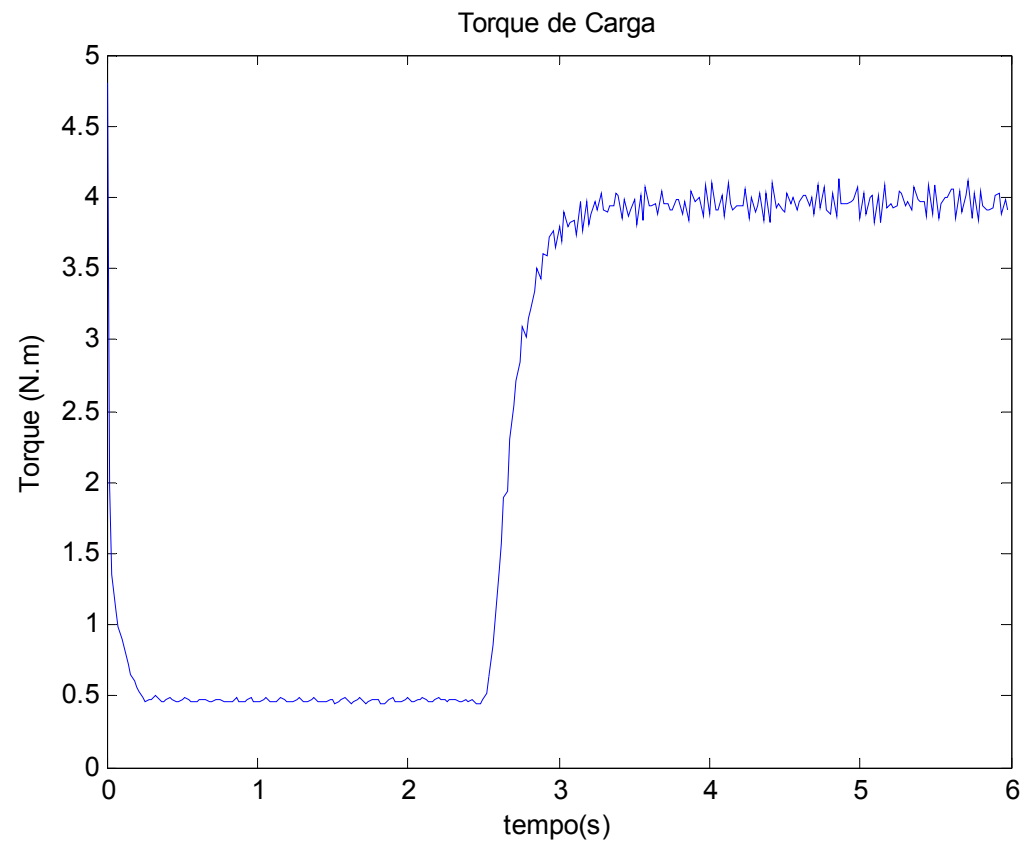

Figura 5.45 - Torque de carga. 


\subsubsection{Análise Comparativa com o Controlador PI}

Na prática, em se tratando da estratégia de controle escalar V/f de motores de indução trifásicos, é freqüentemente empregada o controlador proporcional e integral $(\mathrm{PI})$. Desta forma, desenvolveu-se um controlador PI digital em DSP para fins de análise comparativa com o sistema de controle fuzzy proposto.

Os ganhos do controlador PI foram ajustados exaustivamente mediante sucessivos ensaios experimentais. Sob as mesmas condições de carga de aproximadamente $1,5 \mathrm{Nm}$, o desempenho comparativo de ambos os controladores, PI e fuzzy, são representados em um único gráfico, conforme a Figura 5.46.

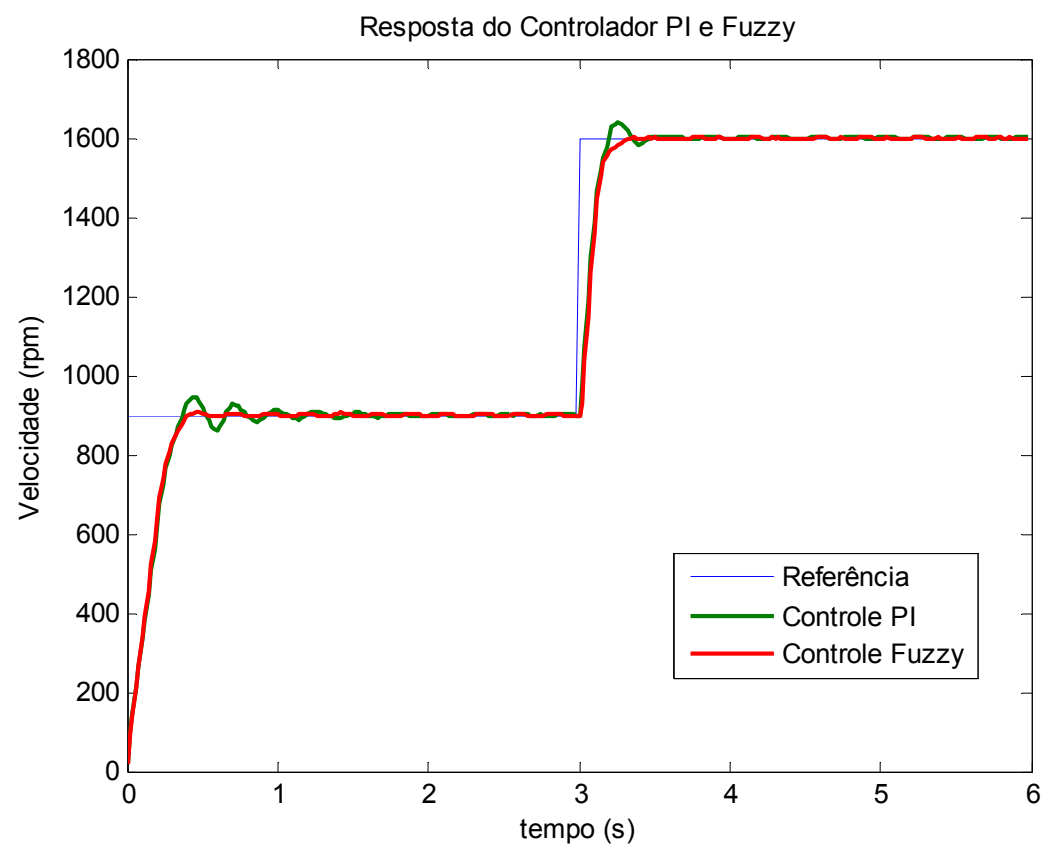

Figura 5.46 - Análise comparativa com o controlador PI (ensaio: degrau de referência).

Observa-se que o sistema de controle fuzzy apresentou resultados relativos ao tempo de subida semelhante ao controle PI. Entretanto, deste controlador apresenta sobre-sinais nos degraus de referência. No primeiro degrau, o sobre-sinal foi de aproximadamente 50 rpm, conforme os detalhes ilustrados na Figura 5.47. 


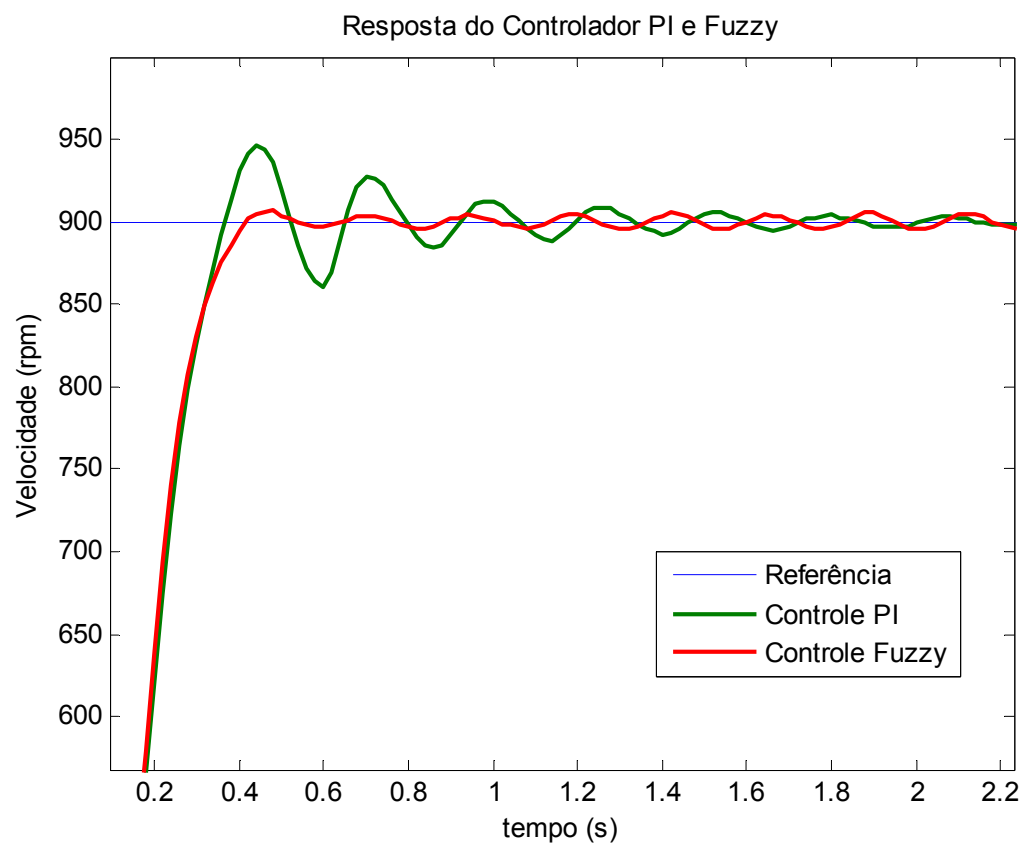

Figura 5.47 - Detalhes do primeiro degrau da Figura 5.46.

As oscilações permanentes da velocidade de ambos os controladores apresentam resultados também semelhantes. Desta forma, a melhoria da técnica fuzzy desenvolvida em comparação com as técnicas convencionais consiste na eliminação dos sobre-sinais iniciais.

Cabe ressaltar que durante a determinação dos ganhos ótimos do controlado PI foi possível encontrar uma configuração com resultados muito semelhantes aos obtidos pelo controlador fuzzy. Entretanto, quando se aplicou a mesma configuração para o ensaio em rampa, os resultados foram significativamente inferiores. Neste contexto, os ajustes foram realizados de forma a encontrar os melhores resultados de resposta tanto para ensaio em degrau quanto para ensaio em rampa de referência de velocidade.

A análise comparativa entre o controle $\mathrm{PI}$ e fuzzy relativos ao ensaio de rampa de referência de velocidade é ilustrada na Figura 5.48. Tanto o controlador PI 
quanto o controlador fuzzy apresentaram resultados semelhantes, com exceção ao momento da partida, em que o controle PI ainda apresenta um sobre-sinal.

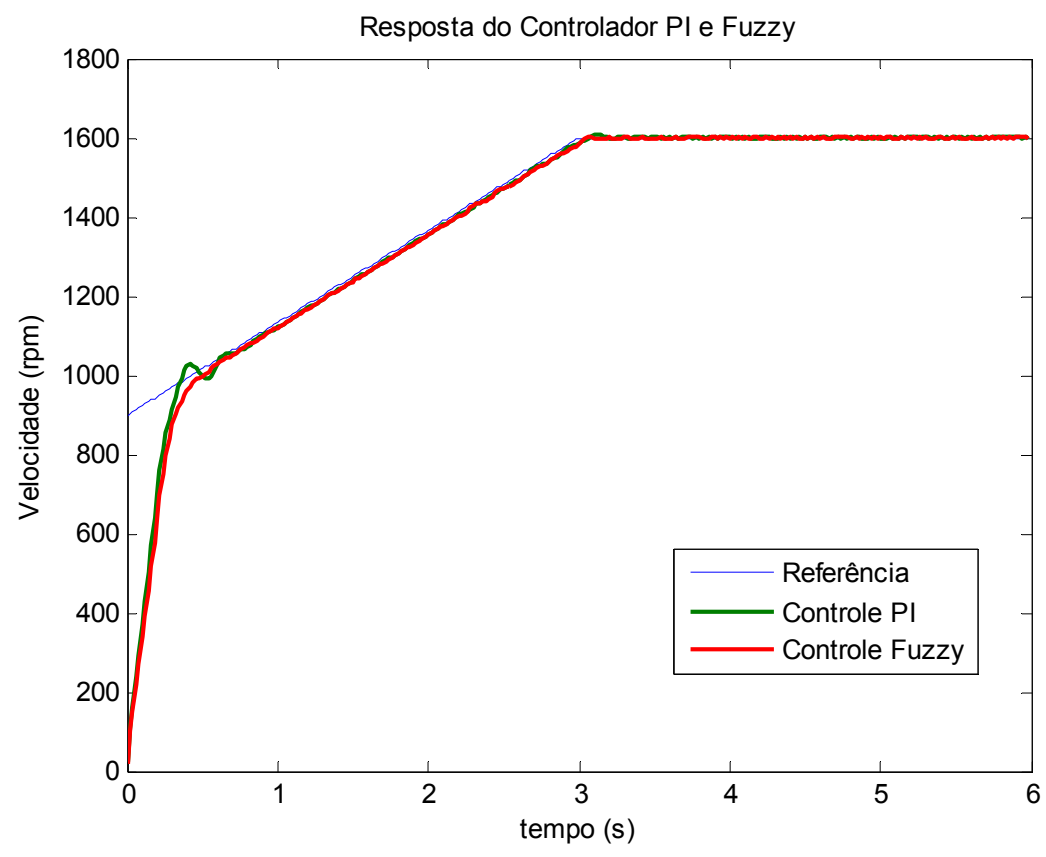

Figura 5.48 - Análise comparativa com o controlador PI (ensaio: rampa de referência).

A Figura 5.49 apresenta a resposta de ambos os controladores relativa ao ensaio de degrau de torque de carga aplicado ao eixo do MIT.

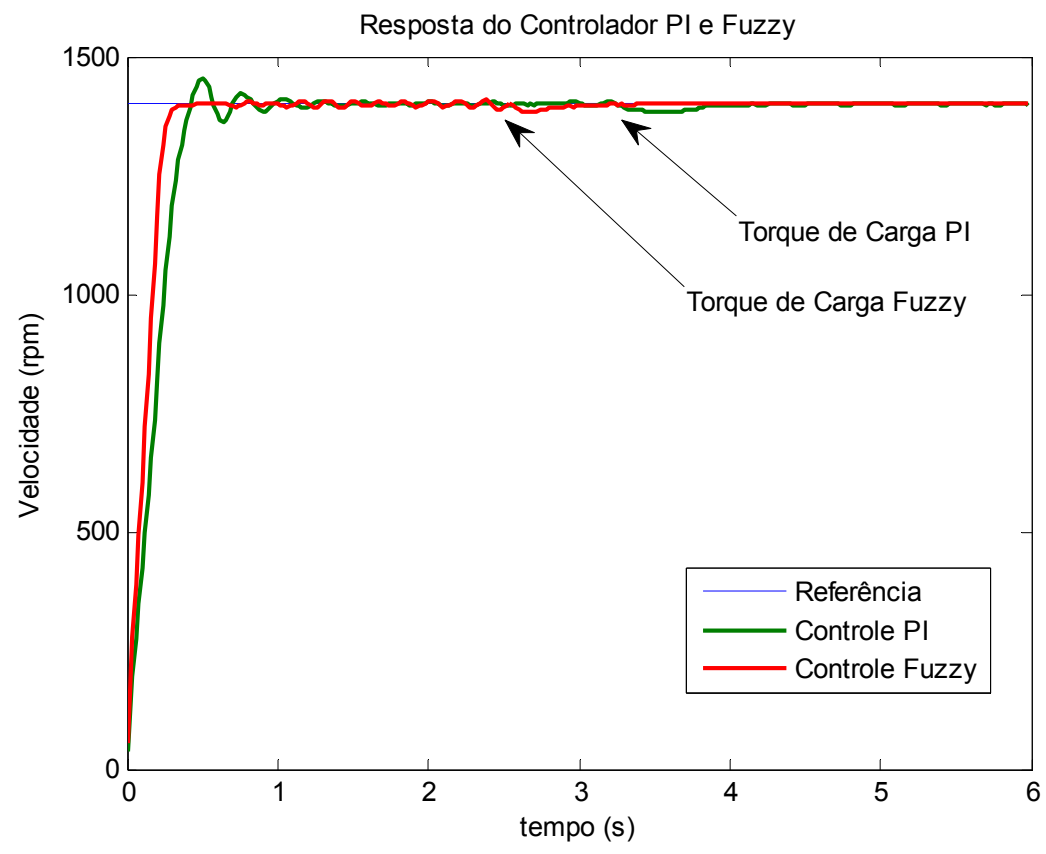

Figura 5.49 - Análise comparativa com o controlador PI (ensaio: variação de carga). 
Neste ensaio, partiu-se o MIT com velocidade de referência de 1400 rpm. Após um intervalo de tempo, aplicou-se manualmente um torque de carga que varia de $0,5 \mathrm{Nm}$ a 4,0 Nm. Como a bancada experimental é única, inicialmente efetuou-se o ensaio do sistema fuzzy e, em seguida, o controle PI. A diferença no tempo de aplicação de carga é inevitável em virtude da aplicação manual. Embora em ambos os ensaios procuraram-se variar de $0,5 \mathrm{Nm}$ a $4,0 \mathrm{Nm}$, tais valores não são exatos para os dois ensaios, visto que o variador de tensão fora ajustado de forma manual. Neste ensaio, conclui-se que ambos os controladores apresentaram resultados semelhantes quanto à correção de velocidade com a aplicação de carga.

Ainda em relação a este ensaio, o sistema fuzzy apresentou uma partida mais rápida que o controle $\mathrm{PI}$, o que contradiz com os resultados de ensaio a degrau de referência em que os mesmos foram semelhantes. Isso se deve ao fato de que na partida, o erro entre a velocidade e a referência foi mais alto (de 1400 rpm para 900 rpm) para este ensaio. Nestas condições, o sistema fuzzy foi capaz de partir a máquina de forma que a mesma produz respostas mais rápidas. 



\section{Conclusões Gerais e Trabalhos Futuros}

\subsection{Conclusões Gerais}

Neste trabalho, realizou-se um estudo com resultados do comportamento dinâmico do controlador V/f fuzzy do motor de indução sob influências de diversos tipos de cargas mais comumente encontrados em plantas industriais.

Com base nos resultados obtidos por simulações computacionais realizadas no ambiente Matlab ${ }^{T M} /$ Simulink $^{T M}$, o sistema de controle fuzzy desenvolvido obteve erros de velocidade relativamente reduzidos, podendo ser aplicados plenamente em bombas, ventiladores e máquinas inseridas em processos industriais mais simples. Além disso, o sistema de controle fuzzy se mostrou robusto, sendo capaz de atender diversos tipos de cargas comumente encontradas em ambientes industriais tais como lineares, quadrática, constantes e inversas.

A partir dos resultados obtidos em simulações computacionais, permitiu-se o desenvolvimento da metodologia de implementação em hardware visando à validação experimental. Embora a máquina de indução em estudo que foi utilizada no ambiente de simulação computacional apresente características diferentes daquela empregada na bancada de ensaio, os aspectos de modelagem do sistema fuzzy foram preservados.

O DSP TMS320F2812 apresenta um elevado poder computacional e constitui de periféricos dedicados ao acionamento e controle de máquinas elétricas. Entretanto, a metodologia empregada para o desenvolvimento do sistema de 
controle fuzzy focou-se na minimização da exigência de memória e na redução dos números de instruções visando uma possível aplicação em microcontroladores de baixo custo.

Considerando-se os resultados obtidos pelos ensaios experimentais, a metodologia é plenamente empregável nas aplicações voltadas à utilização de técnicas de controle escalar $V / f$, cujas exigências se constituem de apenas de variação de velocidade e respostas dinâmicas mais suaves.

Os resultados experimentais também mostraram que a modelagem do sistema de controle fuzzy independe da modelagem matemática precisa do problema. Além disso, as incertezas paramétricas decorrentes das não linearidades e assimetria do motor de indução real foram incorporadas ao modelo de inferência fuzzy, sem a necessidade do seu conhecimento específico.

Em comparação com a técnica de controle PI convencionalmente empregada em ambientes industriais, o sistema de controle fuzzy apresentou melhorias no que diz respeito à redução do sobre-sinal e oscilações iniciais para um mesmo tempo de resposta.

O sistema de inferência fuzzy embarcado constitui-se de uma arquitetura simplificada que exige um espaço de aproximadamente $6 \mathrm{~kb} \times 16$ de memória sem que o custo computacional interfira nos desempenhos práticos. Entretanto, comparativamente à técnica de controle $\mathrm{PI}$, o sistema fuzzy embarcado apresentou uma requisição de memória e tempo de processamento superior.

\subsection{Trabalhos Futuros}

Uma das diretivas dos próximos passos a ser realizada consiste na investigação de métodos de simplificação do sistema fuzzy proposto para efetuar o 
processo de inferência em menos ciclos de instruções, de forma que o desempenho não seja significativamente afetado, e possa ser viável a implementação em microcontroladores de baixo custo.

A análise criteriosa que assegura a estabilidade do sistema de controle fuzzy para qualquer condição de operação é de suma importância, sendo também alvo de investigação de projetos futuros.

A faixa de operação do acionamento e controle fuzzy desenvolvido nesta dissertação está limitada entre $20 \%$ a $90 \%$ da velocidade nominal. Portanto, modificações na relação da curva $V / f$ para velocidades inferiores, bem como a aplicação de técnicas de injeção de sinais de terceira harmônica na senóide de referência que permite elevar os valores RMS de tensão, e conseqüentemente, aumentar a faixa de velocidade de operação também são tópicos de investigação em pesquisas futuras.

O desenvolvimento de placas de circuitos de controle do GCC, bem como a modelagem do algoritmo de geração de sinais PWM de tensão de campo, visando fornecer perfis de cargas industriais no eixo do MIT, é também uma frente de pesquisa a ser explorada.

No acionamento da máquina proposto até o momento, desconsiderou-se o controle de corrente de partida do MIT. Este ponto se torna relevante para investigação no que diz respeito às cargas inversas e às cargas constantes, na qual a partida da máquina naturalmente é lenta. Conseqüentemente, o controle fuzzy procurará alimentar o MIT com a tensão máxima até que a velocidade atinja valor próximo ao de referência. Caso o tempo de resposta seja suficientemente elevado, há a possibilidade de ocorrência de desgastes ou danos ao MIT. 



\section{Referências Bibliográficas}

BARBI, I. (1985). Teoria Fundamental do Motor de Indução, Editora UFSC, Florianópolis - SC.

BATURONE, I., BARRIGA, Á., SÁNCHEZ-SOLANO, S., et al. (2000). Microelectronic Design of Fuzzy Logic-Based System, CRC Press.

BIM, E. (2001). Fuzzy optimization for rotor constant identification of an indirect FOC induction motor drive. IEEE Transactions on Industrial Electronics, vol. 48, pp. 1293-1295.

BORMANN, F. (2005). Digital Signal Controller TMS320F2812. Texas Instruments Incorporated, European Customer Training Center. University of Applied Sciences Zwickau (FH).

BRAGA, A. D. P., LUDERMIR, T. B. e CARVALHO, A. C. P. D. L. F. (2000). Redes Neurais Artificiais - Teoria e Aplicações, LTC.

BRITO, A. U. (2006). Otimização do Acoplamento de Geradores Fotovoltaicos a Motores de Corrente Alternada Através de Conversores de Freqüência Comerciais para Acionar Bombas Centrifugas, Tese de Doutorado, Universidade de São Paulo (USP), São Paulo.

BROWN, M. e HARRIS, C. (1994). Neurofuzzy Adaptive Modelling and Control, Prentice Hall.

BUJA, G. S. e KAZMIERKOWSKI, M. P. (2004). Direct torque control of PWM inverter-fed ac motors - A survey. IEEE Trans. Ind. Electron., vol. 51, pp. 744-757. 
CIRRINCIONE, G., CIRRINCIONE, M., CHUAN, L., et al. (2003). Direct torque control of induction motors by use of the GMR neural network. International Joint Conference on Neural Networks, vol. 3, pp. 2106-2111.

CRUZ, P. P. e PAREDES, J. P. S. (2003a). Artificial intelligence applications in direct torque control. The Fifth International Conference on Power Eletronics and Drive System (PEDS), vol. 2, pp. 1208-1212.

CRUZ, P. P. e PAREDES, J. P. S. (2003b). A novel speed sensorless direct torque controlled induction motor drive. IEEE International Electric Machines and Drives Conference (IEMDC'03), vol. 2, pp. 971-975.

DAZHI, W., RENYUAN, T., HUI, J., et al. (2004). Sensorless-speed control strategy of induction motor based on artificial neural networks. Fifth World Congress on Intelligent Control and Automation (WCICA), vol. 5, pp. 4467-4471.

DENG, J. e TU, L. (2006). Improvement of Direct Torque Control Low-speed Performance by Using Fuzzy Logic Technique. IEEE International Conference on Mechatronics and Automation, pp. 2481-2485.

DIAS, L. P. C. e LOBOSCO, O. S. (1998). Motores Elétricos: Seleção e Aplicação vol. 1, McGraw-Hill.

EL-SAADY, G., SHARAF, A. M., MAKKY, A., et al. (1994). A high performance induction motor drive system using fuzzy logic controller. 7th Mediterranean Electrotechnical Conference, vol. 3, pp. 1058-1061.

ELETROBRÁS (2007). http://www.eletrobras.com/elb/procel/main.asp, Acessado em 25/09/2007.

FITZGERALD, A. E., KINGSLEY, C. e UMANS, S. D. (2006). Electric Machinery, 6th ed., Bookman. 
GOEDTEL, A. (2003). Estimativa de Conjugado de Carga Aplicado em Eixos de Motores de Indução Trifásico Através de Redes Neurais Artificiais, Dissertação de Mestrado, Universidade Estadual Paulista (UNESP/PPGEI), Bauru - SP.

GOEDTEL, A. (2007). Estimador Neural de Velocidade para Motores de Indução Trifásicos, Tese de Doutorado, Universidade de São Paulo (USP/EESC), São Carlos - SP.

GONZAGA, D. P. e JR, Y. B. (2005). Small-variation linear model of the three-phase double-fed induction motor under synchronous operation: Stability. European Transactions on Electrical Power, vol. 15, pp. 325-342.

HAYKIN, S. (1999). Neural Networks - A Comprehensive Foundation, Prentice Hall, Upper Saddle River, NJ.

HUBERT, C. I. (1991). Electric Machines, Macmillan Publishing Company.

ISLAM, N., HAIDER, M. e BASHIR UDDIN, M. (2005). Fuzzy logic enhanced speed control system of a VSI-fed three phase induction motor. 2nd International Conference on Electrical and Electronics Engineering, pp. 296-301.

JUNIOR, G. C. D. N. (2006). Máquinas Elétricas: Teoria e Ensaios, $1^{\text {a }}$ ed., Editora Érica, São Paulo.

KRAUSE, P. C., WASYNCZUK, O. e SUDHOFF, S. D. (1995). Analysis of Electric Machinery, IEEE Press, New York.

KRISHNAN, R. (2001). Electric Motor Drives - Modeling, Analysis, and Control, Prentice Hall, inc., Upper Saddle River, New Jersey.

LIN, C., KANG-LING, F. e ZI-FAN, H. (2005). A scheme of fuzzy direct torque control for induction machine. International Conference on Machine Learning and Cybernetics, vol. 2, pp. 803-807. 
LINS, Z. D. (2001). Controle Direto de Troque para Motores de Indução - Estudo e Implementação, Tese de Doutorado, UNICAMP, Campinas-SP.

MATHWORKS (2007). "Fuzzy Logic Toolbox 2 - User's Guide", http://www.mathworks.com/access/helpdesk/help/toolbox/fuzzy/, Acessado em 27 de Novembro de 2007.

OH, W. S., CHO, K. M., KIM, S., et al. (2006). Optimized neural network speed control of induction motor using genetic algorithm. International Symposium on Power Eletronics, Electrical Drives, Automation and Motion (SPEEDAM), pp. $1377-1380$.

SAKARUNG, P. e CHATRATANA, S. (2004). Neural network mapping of hybrid FOC-DTC induction motor drive. IEEE Region 10 Conference TENCON, vol. 4, pp. $467-470$.

SIEMENS (2006). "Motores de Indução para Baixa Tensão", http://www.siemens.com.br/medias/FILES/2442 20061214081213.pdf, Acessado em 25/09/2007.

SILVA, S. F. D. (2007). Identificação de Torque de Carga em Motores de Indução Usando Abordagem Baseada em Sistemas Fuzzy, Dissertação de Mestrado, Universidade de São Paulo (USP/EESC), São Carlos - SP.

SPRC087 (2003). IQmath Library - Module user's Guide C28x Foundation Software, Texas Instruments.

SPRC097 (2007). C281x C/C++ Headers Files and Peripheral Examples Quick Start, Texas Instruments, Version 1.10.

SPRS174N (2006). TMS320F2812 Digital Signal Processors - Data Manual, Texas Instruments. 
SPRU065 (2006). TMS320x281x DSP Event Manager (EV) Reference Guide, Texas Instruments.

SPRU078 (2006). TMS320x281x DSP System Control and Interrupts Reference Guide, Texas Instruments.

SPRU509C (2001). Code Composer Studio Getting Started Guide, Texas Instruments.

TAE-CHON, A., YANG-WON, K., HYUNG-SOO, H., et al. (2001). Design of neurofuzzy controller on DSP for real-time control of induction motors. IFSA World Congress and 20th NAFIPS International Conference, vol. 5, pp. 3038-3043.

TRENTIN, A., ZANCHETTA, P., WHEELER, P., et al. (2006). A new method for induction motors parameter estimation using genetic algorithms and transient speed measurements. Industry Application Conference. 41st IAS Annual Meeting. Conferece Record of the 2006 IEEE., vol. 5, pp. 2435-2440.

TRZYNADLOWSKI, A. M. (2001). Control of Induction Motors, Academic Press.

TSOUKALAS, L. H. e UHRIG, R. E. (1997). Fuzzy and Neural Approaches in Engineering, John Wiley \& Sons, New York, NY.

VAS, P. (1998). Sensorless Vector and Direct Torque Control, Oxford University Press.

ZIDANI, F., DIALLO, D., BENBOUZID, M. E. H., et al. (2006). Direct torque control of induction motor with fuzzy stator resistance adaptation. IEEE Transactions on Energy Conversion, vol. 21, pp. 619-621. 